Portland State University

PDXScholar

6-11-2009

\title{
Being an "Other": the Significance of Teachers' Lived Experiences in Working with Culturally and Linguistically Diverse Students
}

Yumiko Otsuki

Portland State University

Follow this and additional works at: https://pdxscholar.library.pdx.edu/open_access_etds

Part of the Bilingual, Multilingual, and Multicultural Education Commons, Curriculum and Instruction Commons, and the Educational Leadership Commons Let us know how access to this document benefits you.

\section{Recommended Citation}

Otsuki, Yumiko, "Being an "Other": the Significance of Teachers' Lived Experiences in Working with Culturally and Linguistically Diverse Students" (2009). Dissertations and Theses. Paper 3135. https://doi.org/10.15760/etd.3134

This Dissertation is brought to you for free and open access. It has been accepted for inclusion in Dissertations and Theses by an authorized administrator of PDXScholar. Please contact us if we can make this document more accessible: pdxscholar@pdx.edu. 


\section{DISSERTATION APPROVAL}

The abstract and dissertation of Yumiko Otsuki for the Doctor of Education in

Educational Leadership: Curriculum and Instruction were presented June 11, 2009 and accepted by the dissertation committee and the doctoral program.

\section{COMMITTEE APPROVALS:}

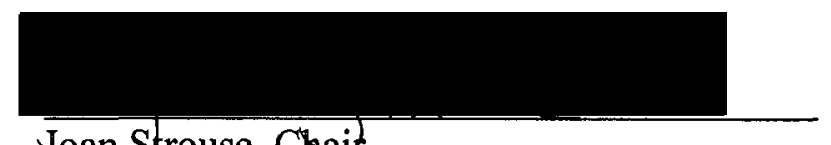

Joan Strouse, Chait

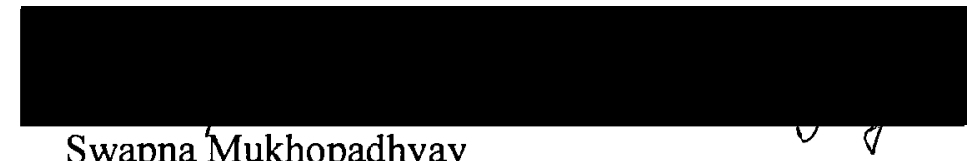

Swapna Mukhopadhyay

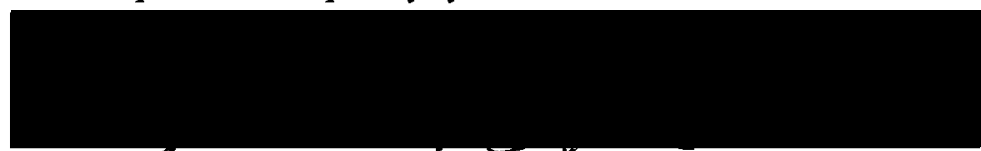

Yer Yhao

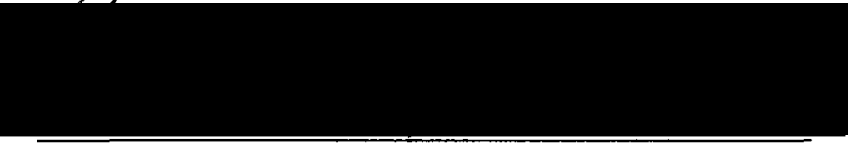

Roberto De Anda

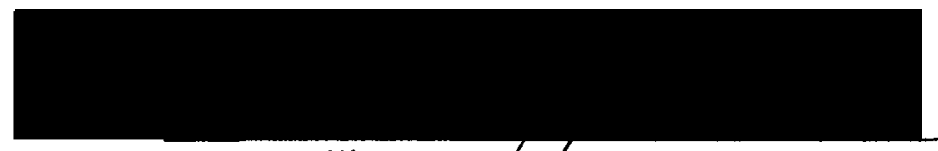

Dalton Miller-Jones

Representative of the Office of Graduate Studies

DOCTORAL PROGRAM APPROVAL:

Randy Hitz, Dean

Graduate School of Education 


\begin{abstract}
An abstract of the dissertation of Yumiko Otsuki for the Doctor of Education in Educational Leadership: Curriculum and Instruction presented June 11, 2009.
\end{abstract}

Title: Being an "Other": The Significance of Teachers' Lived Experiences in Working with Culturally and Linguistically Diverse Students

The study's goal was to understand what contributes to the formation of teachers' perspectives regarding the education of culturally and linguistically diverse students. Its focus was to portray through teachers' stories the experiences in their lives that may have contributed to constructing who they are as people and as educators.

Four teachers from one rural district participated. Using qualitative methods, the study explores and describes incidents in teachers' lives, looking at the way their life experiences are reflected in their relationships with students. In considering ways in which those experiences may have helped shape teaching philosophies and practices, the study also considers the teachers' reported statements about their classroom teaching methods to see how what they may have learned from early life experiences are incorporated. 
Despite each teacher's individual uniqueness, similarities emerged during data analysis. Examining these similarities contributed to an understanding of these teachers and what processes and attitudes made them good teachers of ELLs.

The study reports three broad findings: (a) that the teachers possess a riskand challenge-taking nature; (b) they are life-long learners; and (c) that the teachers had two different kinds of cultural experience during their lives, one that the researcher labeled "Regular" cultural experiences and a second kind which she labeled "Otherness" cultural experiences.

The teachers were judged to share a willingness to make choices involving challenges, many of which proved to be learning opportunities, and they tried to instill in their students the same resiliency and willingness to take risks.

All the teachers personally had both "regular" and "otherness" cultural experiences. "Regular" cultural experiences helped them understand new or unknown cultural values and practices by observation and participation. Through "Otherness" cultural experiences, each experienced the emotion of "being different" and "being marginalized" via the personal, lived experience of being an "Other." This was judged to have contributed to shaping each teacher's ability to better understand the experiences of culturally and linguistically diverse students, enabling greater compassion for them and teaching them more effectively. 


\title{
BEING AN “OTHER”: THE SIGNIFICANCE OF TEACHERS' LIVED EXPERIENCES IN WORKING WITH CULTURALLY AND LINGUISTICALLY DIVERSE STUDENTS
}

\author{
by \\ YUMIKO OTSUKI
} A dissertation submitted in partial fulfillment of the
requirements for the degree of

\author{
DOCTOR OF EDUCATION \\ in \\ EDUCATIONAL LEADERSHIP: \\ CURRICULUM AND INSTRUCTION
}

Portland State University

2009 


\section{DEDICATION}

This dissertation is dedicated to my grandmother and mother, women who paved a path in difficult times for the ones who would follow. That path enabled me to pursue my dreams and goals. It is also dedicated to my daughter and nieces who will come after me, taking their paths toward success as they freshly define it. 


\section{ACKNOWLEDGMENTS}

The completion of my degree would not have been possible if it were not for the people who supported me during this long journey.

I am indebted to my advisor, Joan Strouse, for her time, careful tutelage, unfailing support and guidance through academic and personal storms. Joan, you were always with me, even when we were thousands of miles away, encouraging and leading me along the path. The completion of my degree is in large part due to you. I am so fortunate to have you as my mentor. Thank you.

Gratitude goes to my committee members, Swapna Mukhopadhyay, Yer Thao, Roberto De Anda, and Dalton Miller-Jones for your time, energy, expertise and guidance. I am very grateful.

Thanks also go to four professors in PSU's Graduate School of Education, William Greenfield, Karen Noordhoff, Robert Everhart and Christine Cress, and to former GSE staff member Pat Scott, for providing a rich and supportive learning environment.

Special heartfelt gratitude to the four teachers who participated in my study. You were very generous of your time and personal stories and magnanimous when I suddenly had to put a halt to my project and go back to Japan for personal reasons. Even though you did not know if the time and stories you so generously gave to me would ever come to fruition in the form of my dissertation, you never complained 
and even supported me by sending me forgiving replies to my message of apology. My dissertation would not have happened without your kindness. I am very grateful.

I am thankful to the district ESL Director of my study site. Being so sincere about the education of English language learners, you were very helpful in my access to the district. Without your help, obtaining a study site and recruiting teachers who would agree to participate in my study would have been much more challenging. Your advice and suggestions about identifying teachers also made my study more credible.

I offer my appreciation to my editor, Sam Lowry. Sam, you were careful and precise, and trustful. You always had the magic of knowing what I meant even without detailed explanations, which often eased my mind. You provided me with valuable comments and observations. This offered opportunities to re-think my assumptions and to look at issues from a different viewpoint. I always enjoyed our debate over grammar and your suggestions. Our conversations were some of the few things that were actually entertaining during this lengthy journey, and will remain as enjoyable memories.

I am also grateful to my daughter, Mai Otsuki, for transcribing interviews into 880 pages of data while working full time elsewhere. I also owe her a special debt of gratitude for coming with me to Hong Kong and to the United States. Mai, you had to sit in classrooms at a British private school and then at a U.S. public school as an ELL student: in Hong Kong in a "sink or swim" environment and in 
school as an ELL student: in Hong Kong in a "sink or swim" environment and in the States with once-a-week, 30-minute-pull-out ESL instruction first, then with no ESL instructional help at all. Your experience as a culturally and linguistically diverse student, including a serious identity crisis, was the true reason and motivation for me to start and complete my doctoral degree. Thank you.

I am very thankful for my husband, Victor Walsh, and for his unconditional support. I am finally completing my degree! Thank you for giving me ideas, reading my papers, and most of all countless days of listening to and encouraging me about the challenges I faced in taking on the responsibilities of a daughter in a Japanese family while trying to finish my degree at the same time. Your patience, care for me and faith in me kept me strong. I am not sure I could have sustained the challenges I went through if it were not for you. My success belongs to both of us.

I also wish to express appreciation for my family: my father, mother, and my two nieces. My father and mother, Mamoru and Sachie Otsuki, instilled in me a spirit of expanding my world, which turned into a vision, as I grew up, of pursuing next goals throughout my life. You gave me the foundation of my success. I wish I could share the joy of my accomplishment this day with my father, who doesn't recognize me any more, and with my mother, who passed away last April. My nieces, Mio and Rumiko Otsuki, came to the United States with me and my daughter, and gave me valuable opportunities to learn about American public schools. Your attendance at middle and high school, in addition to Mai's at 
elementary school, gave me a broader and more comprehensive picture of the American educational system and its treatment of the education of English language learners and their families. My heart aches when thinking about how hard it must have been for you to be on your own at school, dealing with the unknown. But I was rewarded when you said, "That was by far the most valuable experience in my life." Thank you.

Lastly, thanks to my fellow students, the 2001 doctoral cohort, for being helpful friends and classmates, especially Tanya Ostrogorsky, my cheer leader. I was also fortunate to have my senior doctoral students, Stephan Gilchrist, Wanna Chongdarakul, and Yuki Monteith, giving me support and ideas from their unique perspectives as diverse students themselves. 


\section{TABLE OF CONTENTS}

Page

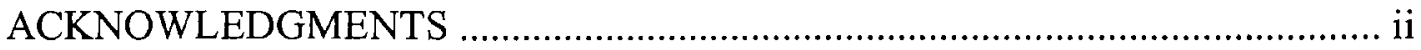

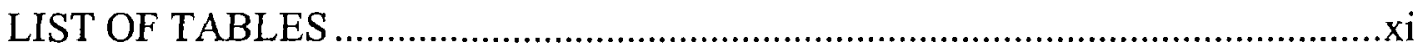

CHAPTER

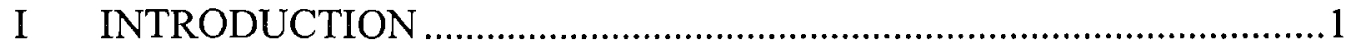

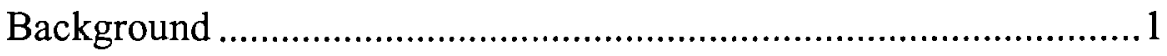

Topic, Purpose, and Research Questions .........................................

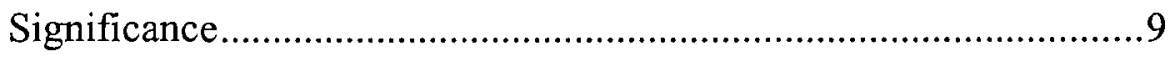

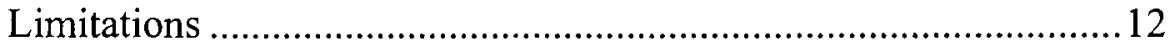

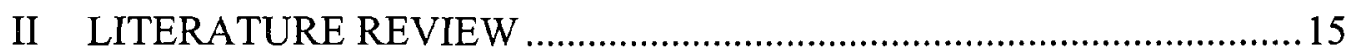

A Historical Overview of Research on Bilingualism and

Language Acquisition ...............................................................16

The "Bilingual Handicap" Era....................................................17

The "Positive Findings" Era ......................................................19

The Newly Evolving Paradigms" Era ......................................20

Sociocultural Learning and its Application to the Learning

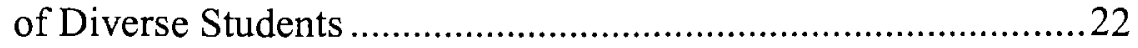

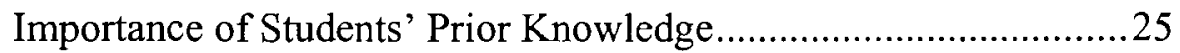

Bringing Students' Life and Culture into the Classroom.................27 


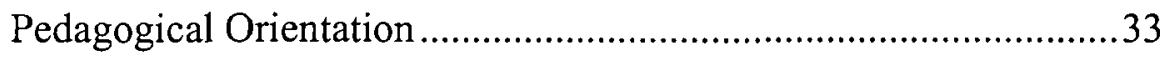

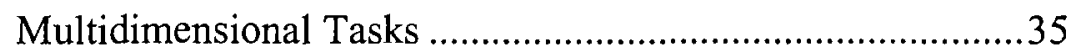

Instructional Assistance or Scaffolding..............................35

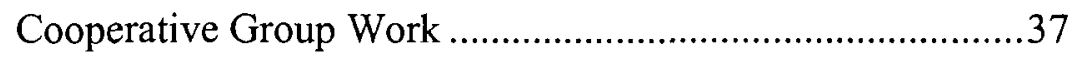

Empowerment Pedagogy .................................................41

Collaborative Creation of Power .....................................4 41

Identity Development of Linguistically and Culturally Diverse Students in the Classroom .................................45

Teachers' Orientation toward Students from Diverse Backgrounds

The Deficit Orientation

The Cultural Difference Orientation

The Importance of Caring .........................................52

Teacher Expectations..................................................59

Culturally Responsive Teaching .............................................63

Relationship between Teachers' Experiences and their

Teaching Practice.

Summary and Research Gap ............................................. 78

III RESEARCH DESIGN AND METHODOLOGY ............................. 82

Problem and Rationale for Qualitative Research ........................83

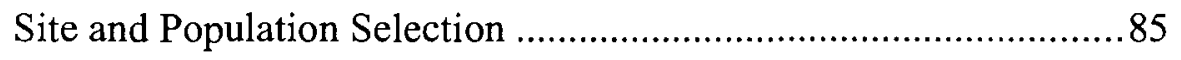

Data-Gathering Methods .....................................................96

Interviews ............................................................ 96 
Strength and Limitation of Interviews.....................................103

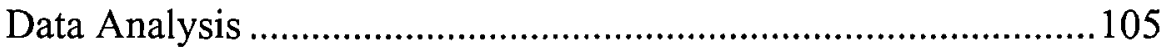

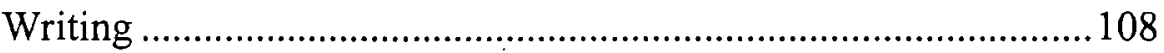

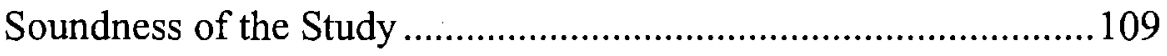

The Researcher's Role ….........................................................111

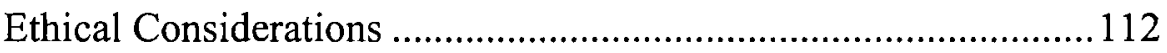

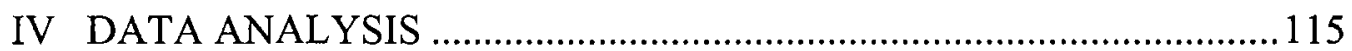

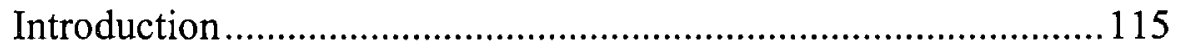

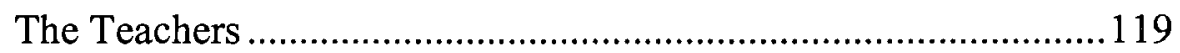

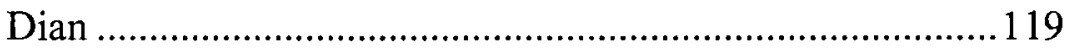

Life History

Dian's Critical Incidents

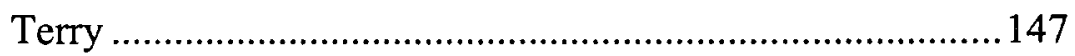

Life History

Terry's Critical Incidents

Sabrina 166

Life History

Sabrina's Critical Incidents

Annette 186

Life History

Annette's Critical Incidents 
Possessing a Challenge-Taking Nature

Being a Life-Long Learner

Experiences in Different Cultures

.232

"Regular" Cultural Experiences

"Otherness" Cultural Experiences

Approach to Teaching

V CONCLUSIONS AND RECOMMENDATIONS 268

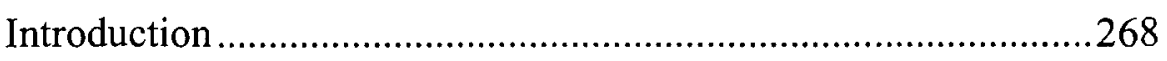

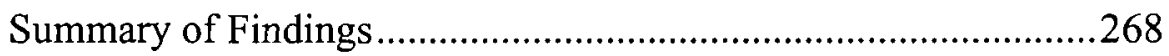

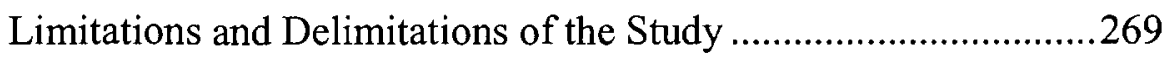

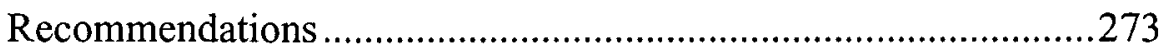

Implications for Small Districts..........................................273

Implications for Teacher Education ....................................276

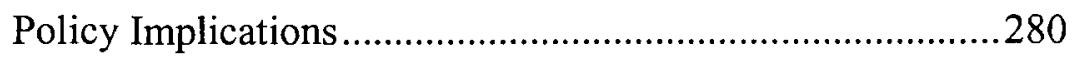

Recommendations for Further Study .........................................225

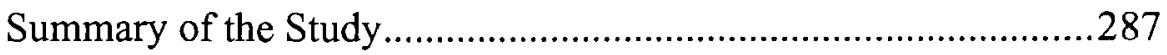

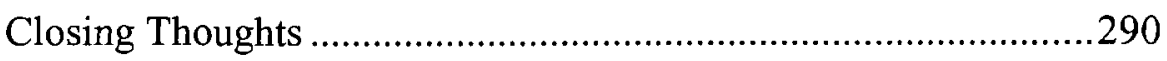

REFERENCES

\section{APPENDICES}

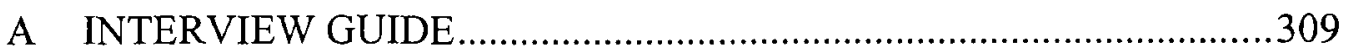


B INTRODUCTORY LETTER FOR NOMINATION AND

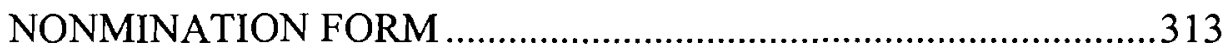

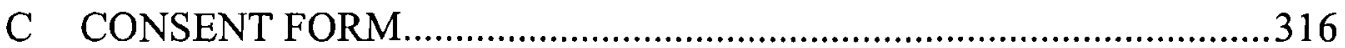




\section{LIST OF TABLES}

Table

Page

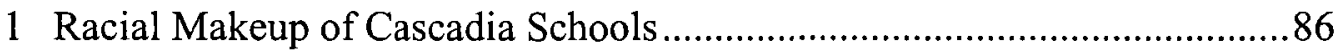




\section{CHAPTER I \\ INTRODUCTION}

\section{Background}

The burgeoning number of students in U.S. public schools whose first languages are other than English has precipitated the need for change in American education. At present, many of these students drop out of school every year. The chances are that they will not become productive citizens who can fully participate in the healthy social, economic, and political life of our society, and that they will eventually become a burden. However, considering that the practice in many schools is devaluation of who these students are (Cummins, 2001; Valenzuela, 1999), it is not surprising that they withdraw from school learning.

Since 1970, immigration, primarily from Latin America and Asia, has contributed to an increase in the foreign-born U.S. population (Ovando, Collier, \& Combs, 2003). In 1970 it was 9.6 million (Ovando et al.. 2003); by 2000 it had risen to 28.4 million or $10.4 \%$ of the U.S. population (National Institute for Literacy, 2003). Of these immigrants, $10.0 \%$ were less than 18 years old and $33 \%$ were not high school graduates. Between 1980 and 1990, the population of Whites increased by $6.0 \%$; African Americans by $13.2 \%$; Native Americans, Eskimos, and Aleuts by $37.9 \%$; Asians and Pacific Islanders by 107.8\%; Hispanic Americans by 
$53.0 \%$ and others by $45.1 \%$ (Ovando et al., 2003). In addition, large numbers of undocumented immigrants settle in the United States every year (J. Banks, 2002). In 2000, nearly one in five Americans spoke a language other than English at home (Crawford, 2002). From 1990 to 2000, the number of English-only speakers increased by $15.1 \%$, while the number of those speaking other languages increased by $103.6 \%$. At these rates, by 2044 the majority of the U.S. population will be speakers of languages other than English (Crawford, 2002).

The changing demographics of the U.S. population have resulted in increasing enrollment of students from diverse backgrounds in U.S. public schools. In $1990,16 \%$ of school-aged children used languages other than English at home (J. Banks, 2002); within a decade, as the 2000 Census showed, the figure had increased by $54.7 \%$ (Crawford, 2003). The total growth in elementary and secondary enrollment nationwide from 1989 through 2000 was less than $20 \%$; for English language learners (ELLs), ${ }^{1}$ the growth was more than $100 \%$ (Kindler, 2002).

These figures are especially important considering that one out of four American high school students will drop out before graduation, and that "the greatest portions of those who are at risk of not graduating are poor, minority, and of limited English proficiency" (Council of Chief State School Officers, 1987, p. 1).

\footnotetext{
'I will use terms such as "ELLs," "language minority students," "students from diverse backgrounds," "bilingual/bicultural students" and "culturally and linguistically diverse students" interchangeably. All these terms indicate the complexity of the education of these students, which goes far beyond language learning per se.
} 
Darling-Hammond and Ancess (1996) assert that in urban areas, the dropout rate for students from non-mainstream backgrounds reaches $50 \%$; among major population groups in the United States, Latino dropout rates remain the highest (Rumberger \& Rodríguez, 2002).

Common consequences of dropping out of school, compared to graduating, include higher unemployment and welfare dependency, lower earnings (Office of U.S. Senator Jeff Bingaman, n.d.), and higher rates of imprisonment (Oregon Department of Education, 2000). In Transforming education for Hispanic youth: Exemplary practice, programs, and schools, Secada and Lockwood (1999) also indicate the burden that future generations may have to bear; for "when students abandon school they foreclose a lifetime of opportunities and place future generations at risk of poverty, low academic achievement, and underemployment"

(p. 1). This has in addition an

implication for the prosperity of the entire state as we enter an era in which knowledge and intellectual resources are key to growth in a highly competitive global economy .... Today the economic performance of a nation depends on its intellectual and informational resources which are directly determined by the success of its schools in educating all its citizens. (Cummins, 2002, p. 3)

It is clear that ELLs' high dropout rates imply a serious problem that affects our society profoundly. Indeed, it would not be too bold to say that the academic underachievement of ELLs is one of the significant educational and social issues in 
today's diverse society, and that advancing the quality of their education should be given primary attention.

Topic, Purpose, and Research Questions

There may be many reasons for ELLs' educational underachievement; one that may seem obvious or may have an intuitive appeal is their level of English proficiency. However, Cummins (2001) asserts that this is not the primary factor:

The fundamental causal factors of both success and failure lie in what is communicated to children in their interactions with educators .... Underachievement is the result of particular kinds of interactions in school that lead culturally diverse students to mentally withdraw from academic effort .... One of the major reasons why students withdraw from academic effort is that the instructional environment frequently does not facilitate or encourage active participation on their part. The message students get is that academic success is unlikely and thus academic effort is not worthwhile. Their identities disengage from the academic life of the school. (pp. 77-78)

As Phuntsog (1995) points out, "historically, the failure of ethnic minorities in school learning has been attributed to their cultural or linguistic deficit" (p. 10), and there is much to show that this has shaped the negative messages Cummins (2001) identifies (see also Rumberger \& Rodríguez, 2002). Specifically, ELLs' "backgrounds are considered deficits to be corrected" (Phuntsog, 1995, p. 10).

Two common components of this prejudice are the "genetic deficit" view and the "cultural deficit" view, assumptions blamed for diverse students" school failure (Bennett, 2003; Gay, 2000; Hollins, 1996; Noel, 2000; Ovando et al., 2003). The genetic deficit view claims that individuals' capacity to learn is determined by inherited genes, that some races are biologically inferior to others, and that this is 
irreversible. The cultural deficit orientation blames cultural factors for students' school failure. Deficiencies reside within the students, their families and their community. Because it holds that "the values and practices children from some ethnic groups learn at home are deficient" (Hollins, 1996, p. 104), this is a "blaming-the victim"" view. If teachers believe that culturally and linguistically diverse students are genetically or culturally deficient, it is most likely that teachers exhibit these convictions in their attitudes when interacting with students, and thus send the sort of messages to which Cummins (2001) refers.

A passage by Rosenthal and Jacobson (1968), quoted below from their seminal work on the influence of teachers' expectations on students' learning, shows the way the deficit perspective can affect teachers' view of students:

The teacher smiles at the children, looking at them to see what the year will bring. The well-groomed white boys and girls will probably do well, the black- and brown-skinned ones are lower-class and will have learning problems .... If the teacher sees a preponderance of lower-class children ... she knows her work will be difficult and unsatisfying .... She knows that lower-class children do not do well in school, just as she knows that middleclass children do do well. All this she knows ... measuring them for success or failure against the yardstick of middle-classness .... The yardstick will be used again when they speak to her, as she hears words spoken clearly or snuffled or stammered or spoken with an accent .... Usually, the teacher is right when she predicts that ... lower-class children generally lag behind and eventually fail. (pp. 47-48)

Deficit theories had strong influence especially in the 1960s and 1970s, and although they

may seem less relevant today, in post-civil rights America, there is considerable evidence that [their] legacy and concomitant presumption of 
non-White inferiority are still very much a part of the present .... More significantly, such theories occupy a dominant position among researchers and practitioners. (Noguera, 2003, pp. 43-44)

For example, Noguera (2003) cites a comment made by a veteran high school teacher when he was provided with research results about students' academic performance: "I expected kids from poorer sections of the city to do less well" (p. 69).

The following statement, made by a White middle-school woman teacher in her 40s who took my own course on the cultural and linguistic impact of students' learning, indicates that these deficit theories are still strongly alive in teacher's belief system:

I must admit that in the past I have had expectations which were influenced by [students'] socioeconomic and ethnic backgrounds. Having taught in my current school for 7 years, I am familiar with many students of similar backgrounds. I often have categorized new students in my mind by their similarities to former children I have had in my classroom. My expectations have probably been lower due to this.

The deficit views represented in the above quotes show the mentality that may cause racism or other "isms" seen in the larger society in areas such as racial police profiling or medical treatment and access. They indicate that these "isms" show up in education, the last place that should happen. Teachers bring these biases to the classroom, as other people bring them to other places.

Regarding the importance of the classroom context in which such assumptions are brought to bear, it is clear from the literature that the most 
significant part of education occurs in the interactions between the teacher and students (Cummins, 2001; Darling-Hammond, French, \& García-Lopez, 2002; Gay, 2000; Kohl, 1998; Minami \& Ovando, 2004; Nieto, 1999; Wink \& Wink, 2004).

"These interactions are major determinants of the quality of education children receive" (Gay, 2000, p. 46). This view, which is central to this work, will be addressed in greater detail below. Here it is sufficient to quote Darling-Hammond (2002b), who writes:

Perhaps the most important differences in what happens to children at school depend on who their teachers are: what they understand about children and about learning, what they are able to do to respond to the very different approaches and experiences children bring with them to the learning setting, what they care about and are committed to as teachers. (p. 150)

Given the high societal stakes for ELLs' success or failure in school, and the critical role of the teacher and his/her cultural assumptions in successful education of students from diverse backgrounds, what I perceived to be necessary was a study asking the following question:

What can be learned about the life experiences and perspectives of mainstream elementary school teachers that has enabled them to be successful teachers of ELLs?

As is clear from this formulation, the focus of the study that resulted, presented in this dissertation, is on what makes successful teachers of ELL students. Since the 1960s, studies have been conducted focusing on language minority students' academic underachievement (Gándara, 1995). The motivation for these 
studies was that "by understanding why students fail, changes can be made in the system, or the students, that will result in improved educational outcomes" (Gándara, 1995, p. 3). Clearly, these studies have not brought expected results as indicated in the dropout rates of ELL students today. ${ }^{2}$ Recently some researchers "turned away from attempting to explain ... student failure and ... focused instead on explaining success" (Lucas, Henze, \& Donato, 1991, p. 458) of linguistically and culturally diverse students. However, there is not sufficient research that focuses on elements that lead to such students' educational success. As Gándara (1995) points out: “An important element missing from most of research [on linguistically diverse students] has been the insights which can be gained from an understanding of how students who don't fail ..." (p. 9) manage this result.

I believe in the positive impact of teachers on diverse students, which may become one of the determining elements of such students' education and later lives. Because of this, following some researchers, I chose to look at good teachers of such students rather than at aspects of teachers that cause their failure.

Irvine (2003) made it clear that "there is a compelling need for research that investigates how teachers' personal characteristics and cultural experiences affect the manner in which teaching is enacted" (p. 57). This call for research is also supported by Knowles (1992), who writes, referring to Woods in 1986:

Understanding the origins of ... teacher perspectives is largely a product of understanding the impact of biography - those experiences that have

\footnotetext{
${ }^{2}$ See page 2.
} 
directly influenced an individual's thinking about teaching and schools. Woods maintained that research on "teacher identities, their interests and biographies", is urgently needed because "we have little knowledge of how teachers' early experiences affect their careers and strategies". He believed that [qualitative] research efforts can uncover the meanings behind the actions of teachers. (p. 102)

In the context of bilingual/bicultural students' learning, this call reflects an even more significant gap in knowledge.

\section{Significance}

There is little doubt that enhancing cultural identity and self-esteem of

ELLs is one of the imperative elements of successfully educating these students (Cummins, 1979, 2001; Hakuta, 1986; Ladson-Billings, 1994; Nieto, 2000; Soto, 1997). Soto (1997) states, referring to Cummins' study from 1979, that "native language instruction develops pride in one's identity, which in turn has been shown by research to be linked to school achievement" (p. 9). Nieto (2000) states that underacheivement ... is ... the result of the interactions between teachers, students, and their families. When teachers respect and affirm the identities and experiences of students and their families, they ... change the nature of interactions they have with them, and this can help promote student achievement. (p. 244)

However, it seems that there is a further lack of scholarly work on the ways teachers can learn to do this.

Grant and Secada (1990) conducted an extensive literature search on the demographic discontinuity between student populations and the teaching force; they anticipated finding research on such discontinuities in three areas of the 
teacher education process: the recruitment of teachers; the pre-certification of teachers; and inservice staff development. The authors investigated three content areas in which teachers receive education: multicultural education; sex equity; and second-language concerns.

Grant and Secada (1990) originally found over 500 journals and 700 ERIC citations from 1964 to June 1988. However, after eliminating documents based on empirical validity of claims about the effectiveness of specific efforts, they had reduced the number of documents to 23 . They concluded, regarding this paucity of research, that "it suggests the marginal status and low importance that has been given to research on the preparation of teachers to work with diverse student populations .... Research in teacher education has been slow to address those challenges" (p. 404).

The present study is designed to contribute to filling the gap in this area of knowledge, specifically regarding teachers' competence working with linguistically and culturally diverse students. Even though literature shows that teachers have the central role in all children's education, teacher education programs have not been very successful and "continue to be criticized for their ineffectiveness to prepare teachers for the nation's multicultural schools" (Phuntsog, 1995, p. 10). In order to know better ways to prepare preservice teachers for working with diverse student populations, "rather than starting with the question of what teacher education looks like, we should start with the question of what good teachers look like and then 
work backward"' (Sleeter, 2001, p. 242). By understanding who quality teachers of culturally linguistically diverse students are, teacher educators may be able to better prepare their students, future teachers, for classrooms with such students.

The study may also be beneficial to practicing teachers. I have met and taught inservice teachers who are stressed out by their own ineffectiveness in teaching culturally and linguistically diverse students. When they say, "Give me some tips on how I can help the students who are sitting right in front of me and who I know I'm not helping at all," I realize the struggle that they face every day. Their voices echo Gay's (2003) statement that there is a "need for teacher efficacy and empowerment in multicultural education-that is, to be competent in and confident about one's ability to do multicultural teaching" (p. 2).

Assuming continued growth of the minority population, it will be increasingly the case that teachers will have students from diverse backgrounds in their classrooms. If teachers do not have cultural sensitivity, and awareness that students from different backgrounds have different perspectives and knowledge, teachers and students alike may have difficulty in the processes of teaching and learning. This study could give teachers who are struggling to become more effective in the education of diverse students an insight into what they can do to help their diverse students achieve educational goals. Following Irvine (2003), the study explores successful teachers of linguistically and culturally diverse students 
in terms of who they are, what their life experiences have been, and how these experiences shaped their frames of reference.

\section{Limitations}

Three limitations that were of concern and that color the results bear mentioning here: sample size, alternative interpretations, and participant willingness. These will be discussed later in more detail.

Regarding sample size, in a statistical sense, findings from the personal accounts of a small number of people, which I have employed, may not be applicable to the larger population of teachers in other situations; however, it may have a value in that such a study can be a facilitating opportunity for other teachers to reflect on their own beliefs and practices. Additionally, as McMillan and Schumacher (1997) contend:

Qualitative studies aim at extension of findings rather than generalization of results. Generalizability is usually not the intent of the study. Design components that enhance the extension of findings are specification of the researcher role, informant selection, the social context, data collection and analysis strategies, authentic narrative, typicality, analytical premises, and alternative explanations. (p. 423)

Regarding alternative interpretations, it is to be expected that data, depending on perspective, can be interpreted in different ways in relation to the

\footnotetext{
${ }^{3}$ I will address most of these components later in the Design and Methods section in relation to the soundness of the study.
} 
literature. A commonly accepted practice, which I have employed, is to actively record and analyze negative instances that contradict patterns of meaning.

Regarding teachers' willingness to participate in the study, this could have been a major challenge, and was a challenge to some degree. Not only was participation time-consuming for them, but also, the study, due to its characteristics, required participants to disclose personal experiences and life history. The necessity of exploring their assumptions, values, and beliefs about people and cultures usually described as "marginalized" sometimes may have risked making them feel vulnerable and even defensive. I tried to have participants understand that my intention was not to evaluate them, and I made explicit that I was truly interested in how we might make education for language minority students more meaningful and equitable, which, I believe, is the common goal for everybody who takes a serious part in their education.

As a person who was born and raised in a different country, which has a very homogeneous population, and who learned and taught in a different educational system prior to coming to the United States, I had not directly shared my participants' experiences. However, my own and my family's experiences, which I will also mention below, and my commitment to advancing the quality of education for linguistically and culturally diverse students, created trusting relationships with my study participants as it became clear that I desired to learn 
what they face in their day-to-day classroom life, with its increasing challenges as the student population changes. 


\section{CHAPTER II}

\section{LITERATURE REVIEW}

In this chapter, I will provide a theoretical framework for my study through investigation of relevant literature. Since an understanding of the factors that cause bilingual/bicultural students to succeed in school directly informs an understanding of their successful teachers, I will present the literature in this order. I will first offer an historical overview of research on bilingualism that provides an understanding of the ways ELLs' education has been shaped over time in this country, and shows how past research influences teaching practices, significantly affecting the education of students from diverse backgrounds. I will then summarize relevant theories on the relationship among language, culture, and learning. These issues are so pertinent to diverse students' educational achievement that without understanding them, consideration of successful teachers may not be complete.

My research is informed by social constructivist theories of teaching and learning, which provide its conceptual key. I will discuss these theories in some detail, presenting research on the sociocultural concept of language acquisition and showing how culture and language interplay in human cognitive development. I will then present literature that relates social constructivism to the bilingual classroom. Specific sub-themes I will present include: (a) impact of past research 
and theories, (b) importance of students' prior knowledge, (c) bringing students' life and culture into the classroom, (d) pedagogical orientation and teaching strategy, and (e) empowerment pedagogy. The concept of empowerment pedagogy, which I will explore at some length, illuminates the teacher's role in diverse students' educational success.

I will then present, as a synthesis of the literature explored to that point, empirical and conceptual literature concerning elements of effective instruction of linguistically and culturally diverse students. These in a sense "define" successful teachers of bilingual/bicultural students, and thus lead to my central questions concerning the relationship between teachers' experience and their practice. I will present the literature on this topic, which finally will lead to a more detailed description of the gap I have identified in the literature: lack of research that relates the practice of teachers of ELL students to their life experiences and frames of reference. As has been mentioned, identification of this gap was the impetus for this study; in the literature review, I will suggest possible further directions for research on successful teachers distinctively of ELL students.

A Historical Overview of Research on Bilingualism and Language Acquisition

Educational research can either benefit or harm students' lives. It can influence educational policies, pedagogical practices and organization of educational systems, which in turn determine priorities in the school system, and 
these priorities have consequences that are critical to students. Products of this whole process, students deal for life with consequences of research. Thus, it is important to understand that the theories that were advanced by past research have had a significant effect on bilingualism and the education of bilingual/bicultural students, and that they constitute the basis of the field in this country (Moran \& Hakuta, 1995). Soto (1997) categorized the modern history of research on bilingualism into three eras, each with consequences still visible today. She calls these eras (a) the "bilingual-handicap" era, (b) the "positive findings" era, and (c) the "newly evolving paradigms" era (p. 2).

\section{The "Bilingual Handicap" Era}

The social beliefs that were generated by results of intelligence tests administered to immigrants in the first part of the $20^{\text {th }}$ century, with no consideration of English language proficiency, supported biased research and had a great impact on subsequent research findings. According to Soto (1997), in this "bilingual-handicap" era, "a biased philosophy permeated the literature by pointing to bilingual learners' inherent deficiencies and pathologies" (p. 2). Studies that assumed immigrants have inferior IQ led researchers to conclude either that bilinguals are hereditarily inferior or that bilingualism handicapped people, causing retardation in their language development.

For instance, as referred to in Moran and Hakuta (1995), researchers such as Yoshioka in 1929, Smith in 1939 and Saer in 1942 compared Japanese-American, 
Hawaiian, and English-Welsh bilinguals, respectively, with monolinguals, and concluded that bilinguals are inferior. It is important to note that in these early studies, research designs and methodologies were flawed (Hakuta, 1986; Moran \& Hakuta, 1995; Snow, 1994), yet "neither school of researchers considered the inadequacy of the instrument used to measure intelligence" (Moran \& Hakuta, 1995, p. 447).

A. J. Banks (1998) argues that social science and educational researchers "have often harmed low-income students and students of color...[and]... reinforced inequality" (p. 5). Nowhere is this truer than with research findings and theories derived from false assumptions in the bilingual-handicap era, which have perpetuated perceptions of bilingualism and affected the structures and the quality of ELLs' education, and the perceptions of larger society about such students in very detrimental ways that they still deal with today.

Even though the "bilingual-handicap" research era (Soto, 1997) has passed, the notion of immigrants' deficiency, which is the era's legacy, has been institutionalized in many ways in the school culture and in society (Moran \& Hakuta, 1995; Nieto, 1999; Soto, 1997). As Soto (1997) argues, "the problem with the research era of the 1920s through the early 1960 s is that in spite of additional contemporary research, it continues to drive existing programs employing subtractive practices" (p. 3). In subtractive practices, students' home languages and home cultures are to be subtracted and replaced with a target language and culture. 
Moran and Hakuta (1995) address this point. They contend that modern concepts and practices rooted in the era include: (a) the widely used term "Limited English Proficient" (LEP), (b) that having a different language background while learning in a U.S. school is a factor that contributes to academic failure, (c) that students learn best in English and (d) therefore, that the sooner the students are out of the bilingual classroom into the regular classroom, the better.

These concepts manifest in teachers' attitudes in their interaction with ELLs, causing failure to understand the importance of students' native language and culture in their learning, and affecting students' identity development. Such attitudes may lead students to withdraw from academic engagement. Cummins' (2001) concept of "identity negotiation" speaks to this important area, which I will examine in a later section of this literature review.

\section{The "Positive Findings" Era}

Starting in the early 1960 s, studies started to show positive findings regarding bilingualism. The study that set the new methodological standard was by Peal and Lambert in 1962 (cited in Moran \& Hakuta, 1995; Soto, 1997). They recognized the importance of demographic variables and controlled for socioeconomic status and language proficiency of bilinguals, comparing their performance with monolinguals of similar socioeconomic status from the same school on tasks that required cognitive flexibility. The study was a turnaround in that "a brighter, more positive view of bilingualism began to emerge" (Soto, 1997, 
p. 3). The study's findings indicated that "bilinguals significantly outperformed their monolingual counterparts on verbal and nonverbal intelligence tests" (Crawford, 1999, p. 135). Peal and Lambert's 1962 study was followed by a number of others, such as Bain and Yu in 1974, Ben-Zeev in 1977 and Cummins in 1977, that supported the argument that bilingualism was an advantage (Moran \& Hakuta, 1995). These studies showed this advantage in cognitive flexibility, linguistic and metalinguistic skills, concept formation, and divergent and creative thinking.

\section{The "Newly Evolving Paradigms" Era}

In the 1970s, growing awareness of sociolinguistics resulted in the emergence of studies that had greater focus on the sociocultural aspects of language acquisition, notably the relationship between socialization and language acquisition. One concept introduced by Hymes in 1974 was "communicative competence" (Bialystok \& Hakuta, 1994; Minami \& Ovando, 2004), which concerned the ability for correct language use depending on a given sociocultural condition. This concept became the foundation for studies in the 1980 s, especially in the field of education as seen in the following quote in Minami and Ovando (2004) from Cook-Gumperz and Gumperz in 1982:

The task of exploring the cultural transmission of knowledge as communicative competence requires us to see the interactional face-to-face relationship of teacher to student as embedded interactively within a context of the procedures of classroom practices within schools, which themselves 
are part of an institutional system of education policies and ideology. (p. 571)

As a result, since the latter half of the 1970 s, research studies have increasingly shifted to explore issues related to the newly-emerging concept that language is a socially and culturally mediated product (Minami \& Ovando, 1995). The central assumption of this concept comes from a theory by Vygotsky in 1978 (Minami \& Ovando, 1995). According to Vygotsky's theory, human thought development is determined by language; social interaction is the key to a human's higher mental functions and is mediated by cultural tools, the foremost of which is the language the child was born into; therefore, "children's communicative competence, reflecting a certain cultural identity, develops in accordance with socially accepted rules" (Minami \& Ovando, 1995, p. 430). In other words, children's language ability develops through social interactions within the framework of their own culture.

Along with Vygotsky (1978), Bruner (1977) also contributed to the new social interaction paradigm. Inspired by Vygotsky's concept of the "zone of proximal development"- the distance between a child's ability to solve a problem on her own and the ability to do so with help from and interaction with an adult or a more capable peer-Bruner argued that children's learning takes place through verbal and nonverbal interaction with adults. 
Thus, starting in the 1970s and increasingly in the 1980s and 1990s, growing focus on social and practical aspects of language acquisition gave rise to recognition of its sociocultural nature. This provided broader conceptual frameworks for researchers, allowing them to look at language acquisition, bilingualism and academic achievement of linguistically and culturally diverse students in a new light where language, culture, learning and educational success are considered to be strongly related (Cummins, 1979, 2001; Gay, 2000; LadsonBillings, 2001; Lopez, 1999; Minami \& Ovando, 1995; Nieto, 1999, 2000; Ochs \& Schieffelin, 1984; Ovando et al., 2003; Wink \& Wink, 2004).

Sociocultural Learning and its Application to the Learning of Diverse Students

The social constructivist theory that learning is socially, historically, and culturally constructed has its foundations in Vygotsky's (1978) work (Bruner, 1997; Minami \& Ovando, 1995; Moran \& Hakuta, 1995), as has been noted. Given the deeply interrelated nature of language, social interaction and learning upon which humans' higher mental function develops, one can assume that children from diverse cultural backgrounds have different ways of thinking, knowing and communicating, and that knowledge is constructed and new understanding emerges when new input is put together with existing cognitive structures. From this prospect, further exploration of the sociocultural perspective and details of Vygotsky's theories offers significant insights into quality education for culturally 
and linguistically diverse students, and implies that pedagogy for these students must be deliberated within a sociocultural framework.

Bruner, who introduced Vygotsky to American educators, attests to this view of learning (Lambert et al., 2002). In his book The Culture of Education, Bruner (1996) makes a case that culture shapes our minds, our worldview, and "our very conceptions of our selves" (p. x), by saying that

you cannot understand mental activity unless you take into account the cultural setting and its resources, the very things that give mind its shape and scope. Learning, talking, imagining: all of them are made possible by participating in a culture ... (p. xi)

"So, in the end, while mind creates culture, culture also creates mind" (Bruner, 1996, p. 166). Darling-Hammond (2002a) further notes that "in one sense culture is the foundation of all learning" (p. 206).

Vygotsky (1978) "persuaded us that learning could not be viewed without context, as if independent of cultural or historical influences of significance. Learning is a cumulative experience derived and informed by an individual's and group's cultural and historical experience" (Lambert et al., 2002, p. 30). He argued that social transactions are mediated by cultural tools including language, systems of counting, mnemonic techniques, algebraic symbol systems, works of art, writing, schemes, diagrams, maps, mechanical drawings, and all sorts of conventional signs. These are the symbols that cultures have created over time to help people communicate, think, form concepts, and develop human cognition in an evolving manner. Among all tools, the language a child is born into is paramount. Indeed, 
Vygotsky writes: "the most significant moment in the course of intellectual development, which gives birth to the purely human forms of practical and abstract intelligence, occurs when speech and practical activity, two previously completely independent lines of development, converge" (p. 24).

Vygotsky's (1978) zone of proximal development (ZPD) represents the amount of learning possible by a learner given the proper instructional conditions; through the ZPD, what can be known becomes what is known.

Vygotsky's (1978) theories have since been supported by other scholars. Minami and Ovando (2004) state that "through different processes, from a very early age children are socialized into culturally specific modes of organizing knowledge, thought and communicative style. Language acquisition and socialization are, therefore, two sides of the same coin" (p. 573). Ochs and Schieffelin's (cited in Minami and Ovando, 2004) assert that:

1. The process of acquiring language is deeply affected by the process of becoming a competent member of society;

2. The process of becoming a competent member of society is realized to a large extent through language, by acquiring knowledge of its functions, social distribution, and interpretations in and across socially defined situations, i.e., through exchanges of language in particular social situations. (p. 573)

If there were a universal way of thinking and knowing, all cultures in the world would teach the same knowledge in the same way. If learning and knowledge are "independent of culture, we could conclude that all knowledge is equally accessible to everyone, and a single standard for learning [and] ability ... 
would be warranted" (Oakes \& Lipton, 2003, p. 84). In this sense, if the role of culture is viewed as critical in students' learning process, and "schools allow [culturally and linguistically diverse students] to use all the knowledge (from all cultures) they have experienced and when standards are not so narrow as to exclude the value of that knowledge and experience" (Oakes \& Lipton, 2003, p. 84), those students would have more opportunities to access quality learning, and thereby higher educational performance.

\section{Importance of Students' Prior Knowledge}

When students from diverse backgrounds come into the classroom, they bring their experiences and prior knowledge with them. As the previous section makes clear, their cultures and individuality become the basis of their learning, which is built upon their experiences and prior knowledge (Cummins, 2001; Wink \& Wink, 2004). Students use their cultural frames of reference to make learning more meaningful and easier to comprehend, and to internalize what they have learned. In other words, "what goes on in the learner's head is dramatically influenced by what is already there" (Wink \& Wink, 2004, p. 36). Some experts argue for the major role that students' prior knowledge and experience can play in the successful education of linguistically and culturally diverse students (AshtonWarner, 1963; August \& Hakuta, 1997; Bennett, 2003; Crawford, 1999; Cummins, 2001; Gay, 2000; Kohl, 1998; Oakes \& Lipton, 2003; Wink \& Wink, 2004). Cummings (2001) cites Chamot to make this point clear: 
Nowhere is the role of prior knowledge more important than in second language educational contexts. Students who can access their prior knowledge through the language and culture most familiar to them can call on a rich array of schemata, whereas students who believe they can only use that knowledge they have explicitly learned in the second language are limited in their access. (p. 127)

However, Kohl (1998) claims that educators often do not know how to

make the most of students' prior knowledge and experience. He writes:

Students bring ... complex skills ... to school with them .... Yet usually no one at the school bothers to ask what students already know, and all the knowledge residing in the student community is wasted as a potential resource for learning. Often students have the solution to problems they are blamed for, and the skills to help redeem a failing educational program from disaster. It's just that teachers are not experienced in the craft of involving students in their own learning and helping them take responsibility for the quality of life during their time in school. (p. 194)

Teachers must develop ways to recognize the experience and knowledge

that students bring to the classroom and allow them to build their learning upon these resources through their own cultural experience and orientation. One way to do this is to "reach ... children by learning about central concepts and themes in their lives" (Kohl, 1998, p. 53). Ashton-Warner (1963) illustrates this process eloquently in the context of teaching young Maori children:

It's not beauty to abruptly halt the growth of a young mind and to overlay it with the frame of an imposed culture .... The true conception of beauty is the shape of organic life and that is the very thing at stake in the transition from one culture to another .... Back to these first words. To these first books. They must be made out of the stuff of the child itself. I reach a hand into the mind of the child, bring out a handful of the stuff I find there, and use that as our first working material .... And in this dynamic material, within the familiarity and security of it, the Maori finds that words have 
intense meaning to him, from which cannot help but arise a love of reading. (p. 32)

Through this kind of teaching, teachers can validate diverse students' prior knowledge and experience, learning style, and worldview. By bringing these aspects of students' identity in their teaching processes, teachers can make teaching and learning more relevant to diverse students' lives; i.e., teach "to and through the strength of these students" (Gay, 2000, p. 29).

\section{Bringing Students' Life and Culture into the Classroom}

We often hear a claim that "good teaching is good teaching. It doesn't matter who the student is." However, teachers who resonate with this idea do miss the critical influence cultures have on students' educational success. As Gay (2000) asserts, "decontextualizing teaching and learning from the ethnicities and cultures of students minimizes the chances that their achievement potential will ever be fully realized" (p. 23). This view of teaching also ignores students' individuality. As discussed above, culture is so integrated into our very existence that our individuality cannot be separated from it. If teachers do not realize this, and operate from a view such as, "All I see is a child; it doesn't matter what color s/he is, or what language s/he speaks"-which, ironically, often comes with a declaration of recognition of individuality - this is a denial of the student's identity and individuality, upon which her learning should be built. 
Gay (2000) notes that research shows there is a strong relationship between culture (ethnic identity, cultural background) and cognition (leading to student achievement). That is, when teachers use socioculturally relevant pedagogy, recognizing and honoring prior experiences, this promotes diverse students' educational attainment. It does so because the teacher accepts and values students for "who they are," ultimately assuring students that they do not have to compromise their identity. It is educators' responsibility to "deliberately create cultural continuity" (p. 25) in the education of diverse students. In order to do so, Pang (2001) suggests an approach that fleshes out socioculturally relevant pedagogy, which she calls "culturally relevant teaching":

Culturally relevant teaching is an approach to instruction that responds to the sociocultural context and seeks to integrate cultural content of the learner in shaping an effective learning environment. Cultural content includes aspects like experiences, knowledge, events, values, role models, perspectives, and issues that arise from the community. Cultural context refers to the behaviors, interactional patterns, and underlying expectations and values of students. Culturally literate teachers develop an inside perspective of a cultural community. They understand that cultural elements operate simultaneously and respond in congruence with their students. Culturally knowledgeable teachers are keen observers, understand the importance of context, and can read nonverbal communication cues like facial expressions or hand gestures of students. (p. 192)

Pang (2001) makes clear that culturally relevant teaching is not mere integration of ethnic food and holidays into the curriculum a few times a year. It is connecting curriculum content and the sociocultural environments in which students' lives are rooted. "When the curriculum and context of learning arise from 
the lives of students, not only are the knowledge and culture of students seen as valuable school resources, but also students can build on what they know" (p. 195).

Teachers who are successful in relating to diverse students and helping them have a more positive and constructive educational experience, through such teaching, can be seen in works of scholars and teachers such as Gruwell (1999), Igowa (1995), Kohl (1998), and Ladson-Billings (1994).

As an example, to highlight what culturally relevant pedagogy looks like, I cite Kohl's (1998) anecdote from the time when he was a beginning teacher at P. S. 103 in Harlem, New York, in the 1960s. I do so at length because it demonstrates so vividly what the teacher and students can accomplish together when the teacher knows how to connect learning with students' lives and culture. It also shows how much teachers can learn from students about how and what to teach.

In his classroom, Kohl (1998) had 36 students, none white, from various linguistic and/or cultural backgrounds. Many were below grade level in reading and way behind in math. "None of them wrote well" (p. 30). Before he came to P. S. 103, Kohl taught at another school, and while teaching there, he had come to believe strongly that rote memorization and workbooks did not do much for his students other than giving them "disconnected information" (p. 27). One day at P. S. 103 , two of his students gave him a written short story about a murder that happened in their neighborhood the previous evening. He shared it with the class and it prompted a class conversation about their neighborhood, from which he 
found that the reality was much worse. After the discussion, he gave them a

homework assignment to write about their block.

Over 30 papers were turned in, the most ever for a homework assignment. Perhaps this was because I had asked them to write about something they knew and wanted to talk about .... My response to children's responses was to ask them to write about what they would do if they could change their block. I wanted to tap into their dreams as well as their immediate reality .... The students' responses to these two assignments entirely changed my plans for that school year .... My impulse was ... to transform [the curriculum] ... into an interesting series of projects based o $\mathrm{n}$ inquiry and experience .... Students' voices spoke to me so strongly that the authority of my supervisors, the instructions in teachers' manuals, and the practices of my colleagues weren't collectively strong enough to keep me from listening to those voices, learning from them, and then teaching to my conscience. (pp. 28-30)

From these assignments, Kohl (1998) developed a project called "What I

Would Do If I Could Change My Block," for which he first integrated curriculum

on ancient cultures including Egypt and Mesopotamia, then moved to Greece,

which would be the center of the curriculum. He wrote:

My idea was to rethink, with my students, the creation of society and the potential for people to live in groups governed by compassion and mutual aid .... Everyone's effort was required to make the world better; I wanted my students to feel that their voices counted and that their intelligence and ingenuity were important .... I did not teach Greece in order to produce experts on Greek culture. My goal was to draw my students into the creation of new myths and the development of their own social visions. I encouraged them to rewrite old tales and change them. The goal was to have them draw upon their own experience and, through the structures of Greek mythology, classical fables, and other traditional genres, develop larger conceptions of the world. (pp. 33-34)

Through this writing project, the students built vocabulary and developed complexity and depth in their thoughts, imagination, and responses. In this learning 
community, Kohl (1998) and his students were engaged in activities that expanded their learning from their immediate environment to a conceptual world that required higher levels of thinking by tying what they already knew and understood from their own life experience to the classroom. Kohl's teaching to culturally and linguistically diverse students' cultural backgrounds helped them develop cognitive ability with which they could perform at higher levels.

Gay (2000) and Pang (2001) list reasons "why culture should be considered in the classroom" (Pang, 2001, p. 203), some of which may have been factors in Kohl's (1998) and his students' accomplishment. The authors cite: teachers' acknowledgement that students' life and cultures have to be valued; the building of bridges between home and school, which allows rooting learning in students' real life situations, making it more relevant; further bridges of meaning "between academic abstractions and lived sociocultural realities" (Gay, 2000, p. 28); use of students' own cultural reference, allowing them to use their prior knowledge; and use of instructional approaches that teach to students' learning styles and elicit students' strength.

Kohl's (1998) story is an indication that teachers' recognition of students' culture is strongly related to students' academic achievement (Gay, 2000). It shows how students learn in their cultural context; how, with the collaboration of the teacher and students, meaningful and relevant knowledge is constructed, not transmitted in a disconnected way; and how ownership of learning is affirmed. 
Also critical is teachers' understanding that cultural knowledge affects students' familiarity or unfamiliarity with topics, and the possibility that they can make intelligible input in the target language. Meyer (2000) highlights the importance of teachers' role in lowering “four significant barriers to meaningful instruction: cognitive load, culture load, language load, and learning load" (p. 229). All four barriers are worth describing in detail, however, I will use as an example part of Meyer's description of "Cognitive Load," which makes very evident (a) how lack of familiarity with concepts in a new sociocultural environment makes making connections problematic, and (b) how prior experience and knowledge can help ELLs learn in a more graspable and comprehensible way:

The number of new concepts embedded in a lesson or text is its cognitive load. Whether or not a learning activity is "cognitively loaded" is not so much a factor of the specific content of the lesson but rather depends on the students' initial familiarity with that content. If the English learner has little entry knowledge about the subject matter, the cognitive load of the lesson will be heavy, for many concepts will be new and unfamiliar. The student will have little basis from which to generate hypotheses regarding the meanings the teacher is conveying through English .... If the student's entry knowledge of the topic is considerable, this will lighten the cognitive load. Learners can draw on their knowledge to interpret linguistic and nonlinguistic clues in the lesson in order to make educated guesses about the meanings of the teacher's English talk and text. Instruction through the student's primary language contributes in important ways to lowering the cognitive barrier, for content knowledge acquired through the first language aids the English learner to interpret the meanings of lessons received through English. (p. 229) 
Similarly, culture load, language load and learning load refer respectively to the amount of new cultural knowledge, new vocabulary and grammar, and learning expectations embedded in a lesson.

My personal experience as an international student substantiates Meyer's (2000) contention. A course on U.S. higher education completely lost me. In this instance, unfamiliarity with the U.S. educational system and the classroom language were at work. Even though I spoke and understood English, technical knowledge of the language did not help me overcome practical unfamiliarity with context, nuance and jargon shared by the instructor and other students.

\section{Pedagogical Orientation}

The next task for teachers is to recognize that students vary in their prior knowledge, and that some may not realize that they have prior knowledge in their $\mathrm{L} 1$ and therefore may fail to acknowledge the connection between their knowledge in L1 and what they are learning in L2 (Cummins, 2001). Hence, a key aspect of the teaching and learning process is to construct knowledge with students according to and upon their level of prior knowledge, thus "activat [ing] students' prior knowledge" (p. 127).

The traditional "banking" (Freire, 1999) concept of education, whereby the teacher simply transmits knowledge to students, controlling the interaction with them in an effort to guide them toward an instructional goal, does not promote connections to ELLs' prior knowledge and experience with the topic. In this model 
of pedagogy, "the scope of action allowed to the students extends only as far as receiving, filing, and storing the deposit" (Freire, 1999, p. 53). "As a result, the input will be much less comprehensible for those students" (Cummins, 2001, p. 128). By contrast, Vygotsky's (1978) social constructivist theory says that an essential feature of learning is that it creates the zone of proximal development; that is, learning awakens a variety of internal developmental processes that are able to operate only when the child is interacting with people in his environment and in cooperation with his peers .... Once these processes are internalized, they become part of the child's independent developmental achievement. (p. 90)

Minami and Ovando (2004) argue that interaction between the teacher and students should be conceptualized and put into practice under the framework of Vygotsky's (1978) theory. Vygotsky's ZPD provides a space where interaction of the teacher and students occur, via which knowledge is constructed. As Meyer (2000) puts it,

collaboration with adults who explain, supply information, question, correct, and make children explain provides the structures of adult language and rational thought that children will finally internalize. Adult collaboration ... enables children eventually to solve problems verbally and cognitively on their own. (p. 228)

What is clear in the above quote is the fact that teachers' role is not that of merely transmitting knowledge to their students. Sociocultural theories of teaching and learning "lead teachers to structure classroom lessons that are active and social" (Oakes \& Lipton, 2003, p. 229). In order to activate students' prior knowledge for the purpose of constructing new understandings, the teacher and students engage in 
inquiry-based activities, exploring and learning together in collaboration (Wink \& Putney, 2002). Oakes and Lipton (2003) explicate three particularly important elements that make the classroom reverberate with sociocultural learning theories: (a) multidimensional tasks, (b) instructional assistance or scaffolding, and (c) cooperative group work.

\section{Multidimensional Tasks}

Multidimensional tasks are those that provide students with duties that come in various shapes and at various levels, giving them opportunities to contribute to class projects by succeeding with what they know. Since there are choices of tasks, this approach allows students to stretch to the level of the task they can reach with the help of the teacher or a more capable peer. Some of the characteristics of multidimensional tasks are: (a) they include more than one answer or multiple ways to solve the problem; (b) they are interesting and rewarding; (c) they allow students to contribute in different ways; (d) they call on an array of media to approach a problem, such as sound and touch; (e) they involve reading and writing as well as other skills; and (f) they are challenging.

\section{Instructional Assistance or Scaffolding}

In social-constructivist classrooms, all interaction among the teacher and students considers all pertinent educational dimensions such as academics, behavior, and social concerns. Interactions are designed and conducted "in ways that lead students to develop new insights, deeper understandings and greater 
thinking skills ... through questioning and sharing of ideas to go beyond current thinking" (Oakes \& Lipton, 2003, p. 232). Oakes and Lipton provide three research-based "scaffolding" strategies.

The first is "substantive conversation," as coined by Newmann and his colleagues in 1992 (Oakes \& Lipton, 2003). In extensive conversation, students are involved with the teacher and/or peers in a way that leads them to develop shared or improved understanding of the topics. For this understanding, conversation must go far beyond talking about facts, procedures, or definitions. It requires critical thinking skills with which students can

“[make] distinctions, [apply] ideas, [form] generalizations, and [raise] questions ... The teacher's skill, art, and knowledge both of the students and the subject guide the conversation and return it to the teaching goals and extend important themes and principles. (Oakes \& Lipton, 2003, p. 234)

The second approach is "reciprocal teaching," described by Brown, Campione, and Palinscar in 1996 (Oakes \& Lipton, 2003). Students form groups of six or so where they take turns leading discussion. They discuss the material一such as a video or an article-that they are using as a source of certain information. The leader asks questions about the content, ask peers to predict what comes next, or to summarize. The activity helps students clarify ideas which in turn contribute to their better comprehension of the subject. The researchers contend that in ZPDs generated in such interaction, students at different levels can find support, and group collaboration helps them reach consensus and understanding of meaning and importance. 
The third principle is "cognitively guided instruction," developed by Carpenter, Fennema and Franke ${ }^{4}$ (Oakes \& Lipton, 2003). This approach focuses on "how students are thinking... (rather than simply assessing 'what they know')" (Oakes \& Lipton, 2003, p. 235). It asks students to explain how they come up with an answer rather than just asking them the answer. In this way, teachers can insinuate alternative ways to solve the problem. Because of this shift from "what" to "how," teachers' focus is "less on what they are transmitting to students and more on how the students are thinking, [and] instruction becomes more closely aligned with the help that students need" (p. 235). This environment also allows students to learn interactively through talk and activities about the subject, with "relational" (p. 235) learning taking the place of doing drills individually.

\section{Cooperative Group Work}

In cooperative group work, students are in charge of their assignment, and together they decide who is responsible for what part of the assignment, what method they will use to complete it, and when they will do it. Because of the way the group work is structured, all members can contribute.

Even though a number of different approaches to cooperative learning have been put forth by various scholars, Oakes and Lipton (2003) argue that they all include common assumptions:

${ }^{4}$ According to Oakes and Lipton (2003), the Cognitively Guided Instruction team consisted of Carpenter, Fennema, and Franke. The team produced a number of research-based articles to inform teachers about children's mathematical thinking and help them develop teaching strategies. 
- Positive interdependence among group members: this leads them, individually and collaboratively, to success.

- Talking together about what is being learned: asking questions and providing explanations are critical to mutual learning.

- Individual accountability: everybody is in charge of their own learning and contribution to the group.

- Group social skills: by participating in the group work, students learn how to work together.

- Debriefing the group process: conversation about group cooperation and how well the group learned is important to reinforce the learning. There are numerous other practical strategies that can be used to promote linguistically and culturally diverse students' learning - preview, view, review; peer tutoring; thematic teaching; modeling learning strategies; connecting with students' cultures; vocabulary building; using graphic organizers; promoting oral language. Cummins (2001) also lists use of approaches such as "total physical response, developing learning strategies, dialogue journals, [and] authentic assessment" (p. 132). Darling-Hammond (2002a) writes that

effective teachers ... are passionate about content and use an active, direct approach to teaching: demonstrating, modeling, explaining, writing, giving feedback, reviewing, and emphasizing higher-order thinking skills with avoiding excessive reliance on rote learning drill and practice, or punishment. (p. 211) 
These strategies and techniques are all useful to make content more understandable. However, if they do not involve teachers' authentic compassion for students, they can be futile. To illustrate, a veteran teacher who once took my course on the role of culture and language in ELLs' learning stated at the beginning of the course, "The district should spend money to send me to Mexico so that I can learn Spanish rather than providing us with these courses. Then I would know what they are saying and I could tell them in Spanish what they need to learn." What she intended was later made clear when the same teacher wrote in one of her papers, "I don't understand (maybe deep down inside where I don't want to admit it, I don't want to understand) ELL students or their culture."

I have already discussed the effectiveness of $\mathrm{L} 1$ instruction, and quoting her statement is not to indicate that learning Spanish is not important. Teachers' speaking students' L1 has great value in the education of linguistically and culturally diverse students. However, if the teacher's desire for communication skills only came from desire to handle students with ease, i.e., seeking a quick fix, then it is totally different from a genuine desire to connect with students to understand their life, experience, needs, interests, emotions, strengths, weaknesses, and so forth. In other words, the teacher did not really want to understand her students as persons who have lives in and outside of the classroom, and she was only seeking some kind of skills to deal with the ELLs in her classroom so that she could have better handle of the situations with the ELLs. Fortunately, toward the 
end of the course, the teacher stated, "Throughout the course, the literature has been hammering at us to take an interest in our culturally diverse students' personal and cultural backgrounds. I'm finally convinced, if a bit intimidated at the prospect." Without a teacher-student relationship that is based on trust and caring, practical skills and strategies will not work as effectively as they could. As Cummins (2001) puts it, "much more crucial is the recognition that human relationships are fundamental to students' academic engagement" (p. 132). If teachers are only playing the "role" of a teacher and form relationships with students only from that perspective, the relationships will remain within that domain.

I believe that teaching is not just about skills and methods. I believe teaching is about teachers' core values and the ways and reasons humans interact with one another. In other words, teaching is about who the teacher is, and about the depth of her understanding of who her students are. To truly connect with students from diverse backgrounds, the teacher's outer life and actions will always have to come from her inner life so that her actions will never be shallow and will always be genuine. As Palmer (1998) writes, good teaching cannot be reduced to technique: good teaching comes from the identity and integrity of the teacher ..... The courage to teach is the courage to keep one's heart open in those very moments when the heart is asked to hold more than it is able so that teacher and students and subject can be woven into the fabric of community that learning, and living, require. (pp. 10-11) 


\section{Empowerment Pedagogy}

Cummins (2001) contends that relationships between teachers and students that "affirm [students'] identity can result in empowerment of... students" (p. 4). He argues that the empowering teacher-student relationship is the key to educational success of linguistically and culturally diverse students.

In this section, I will explore the ways that teachers can either nurture or obstruct bilingual/bicultural students' academic engagement and thereby their higher cognitive development. Cummins (2001) offers valuable insights about teacher-student relationships, the quality of which may determine students' success or failure. This part of the literature review considers various aspects of the teacherstudent relationship, under the overarching framework proposed by Cummins: empowerment. Sub-themes of this subject include: (a) collaborative creation of power, (b) identity development of linguistically and culturally diverse students in the classroom, (c) teachers' orientation toward students from diverse backgrounds, (d) the importance of caring, and (e) teacher expectations.

\section{Collaborative Creation of Power}

In order to promote ELLs' academic success, teacher-student interaction has the foremost importance (Cummins, 2001; Darling-Hammond 2002a, 2002b; Gay, 2000; Kohl, 1998; Minami \& Ovando, 2004; Nieto, 1999; Wink \& Wink, 2004). Indeed, "the connections that [teachers] establish with students are central to their 
development" (Wink \& Wink, 2004, p. 21). Nieto (1999) explicates this idea by stating that

anybody who has spent any time in a classroom knows that teaching and learning are primarily about relationships. What happens in classrooms is first and foremost about the personal and collective connections that exist among the individuals who inhabit those spaces. (p. 130)

A teacher who was taking my class in the ESL Endorsement Program had

observed other teachers who were teaching ELLs, and stated:

From the limited ELL students I have observed or heard about in other classes, I can see a dreadful pattern: The ELL student working individually on a separate assignment ... To learn, one must be actively involved. Having the ELL student not interacting with the other students while working on their often meaningless desk work is not going to help them achieve academic success. By involving them in the class activities they are challenged to interact with other students and progress will be made at the very least in his/her verbal abilities.

By being made to work alone on an assignment different from those that other students are working on, the ELL student may feel lonely, sad, angry, ignored, disrespected, dishonored, or devalued, and may say to himself, "I'm not good enough for the work other students are doing," "I'm stupid," or even "I'm not worthy of anything." Even though the teacher does not intend to do so, these may be the messages $\mathrm{s} / \mathrm{he}$ is sending to students by using this type of teaching strategy. This kind of treatment may be one of the most effective ways to push bilingual/bicultural students toward disengagement from academic learning and eventually to dropping out of school. When an instructional method is perceived or used "as a form of punishment" (Ladson-Billings, 1994, p. 125), even if the teacher 
does not recognize it, it is not difficult for culturally and linguistically diverse students to experience self-doubt as a result.

In Bilingual and ESL Classrooms: Teaching in Multicultural Contexts, the joint work of Ovando et al. (2003), Ovando, who is one of the prominent scholars in the area, tells his story as an immigrant student:

Troublesome initial contact with the U.S. cultural experience in the school made me question who I was and why we had left the cultural and linguistic safety of Nicaragua and Latin America for a strange and at times cold and hostile society .... Was I stupid for not appropriating the English language quickly enough to keep up with my classmates? .... Oh how I longed to show my teachers and classmates what I knew in Spanish in those days! I wish I could have been able to answer my teacher's questions in class to let my classmates know that I was intelligent and liked class discussions and ideas. Feeling alone in a strange world, having flunked sixth grade, I withdrew into a shell and began to entertain self-doubt about my intellectual abilities and my Latin American heritage. (p. 4)

The statements from Ovando (Ovando et al., 2003) and my teacher-student are vivid and graphic descriptions of what devaluation of linguistically and culturally diverse students look like, and how powerful this kind of negative relationship can be in communicating disempowering messages to students.

Cummins (2001), who is "one of only a handful of academics whose work consistently determines the direction of the literature" (Ruíz, 1991, p. 222) in the area of linguistically and culturally diverse students' education, originally advanced the concept of "empowerment" in his 1986 article titled Empowering Minority Students: A Framework for Intervention, which "has become one of the most influential works in the literature on the education of minority students" (Ruíz, 
1991, p. 220). Cummins argued that when instruction that is in accordance with sociocultural learning theories and that values students' language and culture is combined with an empowering teacher-student relationship, its effect in ELLs' educational success is greatly reinforced.

Cummins (2001) claims that schools' and educators' reflection of U.S. societal values and power relations is a fundamental factor in failure of students from diverse backgrounds. According to Cummins, current school cultures often mirror the coercive power relationships between the dominant and the dominated, and so have become the breeding ground of ELLs' failure. He writes:

Inter-group power relations in the broader society are reflected in the organization of schooling (curriculum, language of instruction, assessment practices, tracking, degree of parental participation, etc.) and in the mindset that educators bring to the teaching of culturally diverse students. These educational structures and the role definitions that educators adopt directly affect the interactions that culturally diverse students experience in schools .... I argue ... that one of the major reasons why previous reform efforts have had only limited success is that the relationships between teachers and students ... have remained largely unchanged ... leaving the deep structure of relationships between educators and culturally diverse students untouched. (pp. 197-198)

Building upon this reasoning, Cummins (2001) suggests the concept of empowerment as a framework for reversing ELLs' pattern of school failure: "Educator-student interactions [must] be oriented towards empowerment, defined as the collaborative creation of power" (p. 199). According to Cummins, collaborative creation of power assumes that power can be created and shared 
within the interaction with others. The power is not "imposed on or exercised over others" (p. 16), by a dominant group, but rather

generated in interpersonal and intergroup relations. In other words, participants in the relationship are empowered through their collaboration such that each is more affirmed in her or his identity and has a greater sense of efficacy to create change in his or her life or social situation. (p. 16)

In a learner-centered learning community that is rooted in such a teacherstudent relationship, "the learning process is negotiated, requiring leadership by teacher and mutual teacher-student authority" (Shor, 1992, p. 16). It is in such a context where creation and sharing of power happens. It requires "implementation of change [that] is dependent on the extent to which educators, both collectively and individually, redefine their roles with respect to culturally diverse students" (Cummins, 2001, p. 199). Regarding redefinition of educators' roles, Cummins' (2001) recommendations that are especially relevant to teacher-student interaction have already been discussed: incorporation of bilingual students' language and culture, and orientation to pedagogy. It is this pedagogical shift that creates an environment where ELLs feel strongly that they are valued, and where there are increased opportunities for them to participate in the learning process more competently because of their enhanced sense of identity and power.

\section{Identity Development of Linguistically and Culturally Diverse Students in the Classroom}

In this section, I will look further at empowering teacher-student relationships, drawing on four areas of literature: (a) diverse students' identity 
development, (b) teachers' orientation toward students from diverse backgrounds, (c) caring, and (d) teacher expectation.

Identity, like empowerment, comes from human relationship (L. Ramírez \& Gallardo, 2001, p. 3). Cummins (2001) advances the idea of "identity negotiation" in his book entitled Negotiating Identities: Education for Empowerment in a Diverse Society; its pivotal argument is that "devaluation of identity play[s] out in the interactions between educators and students [and] convinces many students that academic effort is futile" (p. 3). Cummins writes:

The interactions between educators and students always entail a process of negotiating identities. The concept of negotiating identities recognizes the agency of culturally diverse students ... in resisting devaluation and in affirming their basic human rights .... The ways in which student-teacher identities are negotiated in classroom and school interactions play a major role in determining students' orientation to self and their orientation to academic effort. (p. viii)

If, in interactions with teachers, students sense that their identity is respected and affirmed, they are more likely to engage in academic endeavor. On the other hand, when students sense that their culture, language, and past experiences are being excluded from and devalued in the classroom, their silence and non-participation are inevitable. Cummins (2001) contends that such devaluation manifested in the teacher-student relationship sends students the message that academic success is not realistic for them. Cummins' argument is supported by other scholars such as Gay (2000), who argues that messages from the teacher, invalidating who they are, work as a powerful demotivator for culturally 
diverse students. These teachers "don't care to value, demean, and even fear [culturally diverse] students in the classrooms" (p. 46), which results in low expectations about their intellectual ability. In such cases, "the message students get is that [their] academic success is unlikely and thus academic effort is not worthwhile" (Cummins, 2001, p. 77). Such devaluation may result in students, in some cases, dropping out of school to regain their sense of who they are as a result of feeling their identities being endangered (Cummins, 2001). In other words, dropping out of school will protect them from further devaluation of themselves. According to Sleeter (1991), "empowering [teachers] work with students ... to build on what they bring; disabling [teachers] ignore and attempt to eradicate knowledge and strengths students bring, and replace them with those of the dominant society" (p. 5). Empowerment of ELLs in part occurs in the process of identity negotiation during positive and affirmative interaction with teachers, where students can establish a sense of self and feel their voice is respected in the classroom. They gain confidence and motivation to participate, which in turn contributes to their academic success.

\section{Teachers' Orientation toward Students from Diverse Backgrounds}

Messages of affirmation or devaluation of student identity are communicated to students in various ways during teacher-student interactions. Teachers' orientation toward students from diverse backgrounds can be a 
determining factor in the kind of messages they communicate. There are two main orientations in the ways teachers view their students: (a) the "deficit orientation" and (b) the "cultural difference" orientation (Bennett, 2003; Hollins, 1996; Noel, 2000; Ovando et al., 2003). The deficit orientation has already been described in the Introduction; ${ }^{5}$ here I will show how it can hurt the teacher-student relationship and thereby students' achievement. Then I will present "cultural difference orientation," which ultimately treats cultural difference as strength.

\section{The Deficit Orientation}

Aside from unconscious assumptions about linguistically and culturally diverse students and unconscious like or dislike of their cultures, most teachers, I believe, try not to judge students based on their race. However, "teachers tend to regard individual differences based on cultural differences as deficits or disadvantages" (Bennett, 2003, p. 241). In ELLs' case, their native languages are regarded as an obstacle to academic achievement as a result of "the prevailing view that bilingualism is a deficit for language minority students .... [and] that language diversity is an illness that needs to be cured" (Nieto, 2002, p. 87). This, of course, is the legacy of the Bilingual Handicap era, as has been discussed.

Valenzuela's (1999) ethnographical study of Mexican students in Seguín High School in Texas shows the way that U.S. education has treated ELLs' native

\footnotetext{
${ }^{5}$ See pages $4-5$.
} 
language and culture. The quote clearly refers to perpetuation within school culture of the "culture and language as problem" view. The author writes:

Mexican youth continue to be subjected on a daily basis to subtle, negative messages that undermine the worth of their unique culture and history. In sum, the structure of Seguín's curriculum is designed to divest youth of their Mexican identities and to impede the prospects for fully vested bilingualism and biculturalism .... Students' cultural identities are systematically derogated and diminished .... ESL youth, for example, are regarded as "limited English proficient" rather than as "Spanish dominant" or as potentially bilingual ... The belief in English as the ultimate panacea is so strong that it outweighs the hard evidence confronting classroom teachers every day. (pp. 172-173)

The deficit orientation implies that teachers expect students to be molded to fit "the school program rather than altering the school program to make better linkages between the home-culture and school practice" (Hollins, 1996, p. 105).

The deficit perspectives, whether genetic or cultural, assume the existence of "normalcy" with language majority students serving as the intellectual and sociocultural norm (Noel, 2000; Ovando et al., 2003). Normalcy is speaking Standard English and teachers who hold the deficit orientation use that as "the yardstick" (Rosenthal \& Jacobson, 1968). "The yardstick will be used... when [students] speak to her, as she hears words spoken clearly or snuffled or stammered or spoken with an accent" (p. 48). Since "mother tongue [is] the key to [human's] identity" (Cummins, 2001, p. 9), "if language is denied, thought is denied; culture is diminished; identity is endangered" (Wink \& Putney, 2002, p. 39). The deficit 
orientation says that denial of self, family and community is required for academic success (Bennett, 2003).

\section{The Cultural Difference Orientation}

The cultural difference orientation views students from diverse backgrounds as those who have different values, knowledge and practice from those of the mainstream society. Ovando et al. (2003) cite Jacob and Jordan to explain the underlying assumption of the cultural difference orientation:

minority students and their families and communities are no less endowed, in basic intelligence, talents, language, culture, or life experience, than members of the majority population. Therefore, clashes with majority culture schools, when they occur, are matters of not of deficit, but of difference. (p. 214)

This orientation claims that U.S. education is based on mainstream, Euro-American culture; that traditional schooling requires children from diverse backgrounds to learn through its perspective and practices, not their own; and that this disparity is the main reason for diverse students' underachievement (Hollins, 1996).

For example, Mong ${ }^{6}$ students who fled to the U.S. during the Vietnam War did not have formal educational experience and they did not have "implicit and explicit knowledge about how to be a student" (Lucas, Henze, \& Donato, 1990, p. 457). Mong parents were unforthcoming not because they were unconcerned about their children's education, but because they did not understand the school system. They also thought that they were not trained enough to help their children's

\footnotetext{
${ }^{6}$ In literature, "Hmong" is usually used instead of "Mong." However, I use Mong following Thao's suggestion, who himself is a Mong and a scholar in the field.
} 
education and trusted the school and teachers for it. This, by any means, does not indicate that Mong culture is inferior to the American mainstream culture. It shows the difference in its cultural values. For example, Mong maintain a very strong sense of community, collective responsibility, and respect for the elderly. These values are different from the American mainstream values that appreciate individual merit and needs more than collective ones.

Teachers who operate from the cultural difference orientation do not blame students or their families for educational underachievement, nor ask them to alter their way of life and practices. They see cultural differences not as "deficit," but as differences and potential strengths, and they try to build students' learning upon this strength (Noel, 2000). Ayers (1995) writes that

teaching at its best requires knowledge of ... the hopes, dreams, aspirations, skills, challenges, interests, preferences, intelligence, and values [students] bring with them to the classroom. Teaching at its best is first an act of inquiry, investigation, and research into the lives of children. (p. 6)

Thus, teachers who view students as individuals with different strengths are mindful of their own practices and always examine their pedagogy to determine if it includes the experiences and prior knowledge of their students.

In short, the key difference between the two orientations is that the cultural difference orientation, rather than finding something that students do not have or cannot do, and blaming it for students" "abnormal identity," instead endeavors "to find out what students can do, what they enjoy, what engages their imagination or 
energies" (Ayers, 1995, p. 7). Naturally, instructional practices that originate from this orientation "make accommodations according to cultural backgrounds [that] enhance minority [students'] achievement" (Ovando et al., 2003, p. 214). This is a fundamental component of socioculturally relevant teaching.

\section{The Importance of Caring}

Extensive literature attests to the central role that authentically caring teachers play in the achievement of linguistically and culturally diverse students (see Cummins, 2001; Darling-Hammond et al., 2002; Gay, 2000; Ladson-Billings, 1994; Nieto, 2002; Noddings, 2003; Pang, 2001; Valenzuela, 1999; Wink \& Wink, 2004). Scholars such as Ayers (2001), Cummins (2001), and Nieto (2003) talk about how much students want to be cared for by their teachers. Ayers writes that "students who drop out say that the main reason they left school is that no adult cared if they stayed" (p. xiv). "Students need and want teachers to care for them as persons and to convey this care through listening and responding to their expressions of concern" (Noddings, 2003, p. 244). If "personal manifestations of care are... more important in children's lives than any particular curriculum or pattern of pedagogy" (Noddings, 1995, Choosing and Organizing Themes of Care section, $\uparrow 1$ ), it is natural that "students view caring, or reciprocal relations, as the basis for all learning, [i.e., being] engaged in a caring relationship with an adult at school" (Valenzuela, 1999, p. 79). 
In defining "caring," Noddings (1995) writes that "caring is not just a fuzzy feeling that makes people kind and likable. Caring implies continuous search for competence" (Why Teach Caring section, \ 7). Gay (2000) agrees, stating that is not "merely exhibiting feelings of kindness, gentleness, and benevolence toward students, or expressing some generalized sentiments of concern" (p. 48). She also agrees with Nodding's "continuous search for competence" (Why Teach Caring section, \ 7); citing Webb, Wilson, Corbett, and Mordecai, Gay writes:

Caring is a value and a moral imperative that moves self-determination into social responsibility and uses knowledge and strategic thinking to decide how to act in the best interests of others. Caring binds individuals to their society, to their communities, and to each other. (p. 45)

Applied to students from diverse backgrounds, caring means that self-determined teachers act to help them realize their higher performance, using their best of knowledge, thinking, and skills. In the process, caring binds "underachieving students of colors and their teachers" (Gay, 2000, p. 45).

Kohl (1998) describes caring in an even more personal way:

[The] question go to the heart of the relationship between teacher and student. For me there are some central obligations of teaching that go beyond concern for the mastery of content, beyond the academic support of students. These obligations have to do with the personal quality of life in the classroom and involve giving yourself as fully as possible to every student, playing no favorites, and being as supportive and ingenious as you can in the quest to bring out what is strong and special about each youngster. (p. 58)

Furthermore, teachers who care "generate higher levels of all kinds of success than those who do not. They have high performance expectations and will 
settle for nothing less than high achievement. Failure is simply unacceptable to them" (Gay, 2000, p. 47), and they have "interest seeing all of [their] students succeed and [are] focused on doing whatever [is] necessary to make that happen" (Kohl, 1998, p. 203).

In contrast, Valenzuela (1999) gives examples of what uncaring teachers look like in her ethnographic study entitled Subtractive Schooling: U.S. Mexican Youth and the Politics of Caring, which explores what it means to care about students from linguistically and culturally diverse backgrounds. One example is a statement made by an English teacher who, ironically, regards himself as a student advocate; its first half is addressed to the author, the latter to a Mexican student, as an aside, while the teacher was talking to the author:

They are immature and they challenge authority. Look at them, they are not going anywhere. I can tell you right now a full quarter of these students will drop out of school come May .... Joel, stop thinking, you know it might hurt you, cause you some damage upstairs $[$ sic $]$. (p. 64)

Although one would hope that this is an extreme and rare example, which the author happened to hear in that one specific occasion, she confirms that she frequently encountered such "verbal abuse" by teachers during her research at the high school. To most teachers' eyes, these students are not going anywhere because they do not even care to try.

Pang (2001), who posits that caring must form the basis of the education of linguistically and culturally diverse students, lists elements of this philosophy: 
- Relationships are reciprocal and built on trust.

- Trusting relationships form the basis and context for teaching and learning.

- Teachers and students feel an interconnection with each other. Each is concerned with the well-being of the other and within this context a community of learners is created

- Intellectual development is seen through diverse lenses and stimulated through diverse methods.

- Culture is an intimate aspect of how many students identify themselves, define themselves, value, behave, and are motivated; their sense of being may be culturally rooted.

- Caring students develop a capacity to feel, see, or view the world from someone else's perspective, which promotes problem-solving and academic skill development from a community orientation.

- The teacher along with students create [sic] a democratic classroom. (pp. 64-65)

Pang (2001) underscores the importance of caring in the education of diverse students and goes onto say that even though social justice is a critical factor in the education of diverse students, a "paradigm shift from a political focus to a caring one" (p. 80) is called for crucial; caring must "always be a critical component for good teaching" and "[act] as a compass that guides our way" (p. 65).

In her book Culturally Responsive Teaching: Theory, Research, and Practice, Gay (2000) similarly argues that caring is one of the most indispensable aspects of quality education for culturally and linguistically diverse students. She devotes an entire chapter to caring, delineating clearly and efficiently what it means to be a caring teacher and presenting four dimensions of caring, different from those described by Pang (2001): (a) it is concern for persons and performance, (b) it 
is action-provoking, (c) it prompts effort and achievement, and (d) it is multidimensional responsiveness.

Gay's (2000) first dimension, "concern for persons and performance" speaks to teachers' confidence in diverse students' capability and aspiration. It demands teachers' persistence in supporting and encouraging students to reach the highest possible level of performance, and concern for other aspects of students' life such as physical, emotional, and economic well-being. It considers development of students' dispositions such as "patience, persistence, and responsibility to self and others," and skills and qualities such as "interests, aspirations, self-confidence, and leadership" (Gay, 2000, p. 48). This dimension of caring calls on teachers to help students develop full humanity, not just learn a body of knowledge. It is championed by scholars such as Noddings (2003) and Ayers (2001), who believe that to accomplish this immensely hefty job, teachers "must ... be committed to establishing and maintaining relations of care and trust" (Noddings, 2003, p. 250).

Gay's (2000) second dimension, "caring is action-provoking," insists on teachers' accountability for diverse students' higher levels of performance. According to her, teachers who act as if they are protecting and saving these students from potentially embarrassing situations, and who keep them from working hard in case they don't know how to engage academically, are in fact relinquishing their pedagogical responsibilities. The author contends that this is "a 
most effective way to be uncaring and ... facilitate academic apathy, disengagement, and failure" (p. 48). She also argues that skirting such responsibilities with diverse students happens when teachers do not "thoroughly understand their own and their students' perspectives and experiences" (p. 48). This kind of attitude undermines and disempowers diverse students' ability and aspiration.

Gay's (2000) third dimension, "caring prompts effort and achievement," describes teachers who are "supportive and accessible both personally and professionally" (p. 50). These teachers are very firm in their expectations for students, but not totalitarian. They balance tough academic demands with emotional warmth and positive nonverbal communication. Their relationship with students goes beyond the classroom. Their affectionate, supportive and facilitative attitudes inspire, on students' part, not only higher grades, but also other higher performance including "good manners, being respectful, having high positive selfconcepts, persisting in their academic efforts, and ... [improved] school attendance" (p. 52).

Finally, the fourth dimension of caring, involving "multidimensional responsiveness," asserts that teachers must be able to understand each student in a "situated, cultural context" (Bruner, 1996, p. x), and relate to them accordingly. It means that teachers, in order to be culturally responsive, "must be competent in cultural diversity and committed to its inclusion in the educational process" (p. 52). 
Gay (2000) regards this responsiveness as the essence of caring for culturally and linguistically diverse students.

Returning to social constructivism, Vygotsky (1978) and Bruner (1996) remind us that "people are cultural beings" (Pang, 2001, p. 4). Through childhood interactions within their specific culture, they become competent members of the cultural society. This means that teachers must understand that each diverse student has different experiences prior to coming to their classroom, and therefore,

there can be no formulas, no "best" cultural curriculum [for all]. The curriculum of culture is within the students themselves, and all other learning (such as literacy, science, etc.) will take place in the context of this culture. If students' bicultural identities are not valued, then all other curriculum will be fragmented and resisted. (Oakes \& Lipton, 2003, p. 295)

For instance, a teacher who has Mong children in her classroom must know the fact that they "move[ed] not only physically but also across time" (D. E.

Freeman \& Freeman, 1994, p. 75) when they came to the United States. As Y. Thao (personal communication, November 20,2004) puts it:

In our home land on the mountains of Laos, we didn't have electricity or running water. We got water from the stream. Our houses had bamboo walls and dirt floors. We were agricultural people, but it was very different agriculture than you could think of in the United States. We had to rely on the sun and rain to grow vegetables, but nothing else. When we moved to the States, we found that our time also has moved to two centuries ahead.

Consequently, Mong children and American children in the same classroom know different things in different ways, and the teacher must recognize this fact. For teachers, "understanding the cultural contexts in which they teach [is] as crucial to 
instructional effectiveness with diverse students as the mastery of content knowledge and pedagogical techniques" (Gay \& Kirkland, 2003, p. 184).

\section{Teacher Expectations}

Assuming that teachers are informed and committed, the fundamental question they must ask themselves is, "Given what I now know (about the world, about the class, about this student before me), what should I do[?]" (Ayers, 2001, p. 23). According to Gay (2000), when teachers perform in accordance with the aspects of caring discussed above, they produce:

... an ethical, emotional, and academic partnership with ethnically diverse students, a partnership anchored in respect, honor, integrity, resource sharing, and a deep belief in the possibility of transcendence; that is, an unshakable belief that marginalized students not only can but will improve their school achievement under the tutelage of competent and committed teachers who act to ensure that this happen. (p. 52)

Research strongly testifies that if the teacher holds high expectations, students will live up to them, but if expectations are low, students will perform down to those expectations (Fueyo \& Bechtol, 1999; Gay, 2000; Graybill, 1997; Haberman, 1995; Nieto, 1999, 2000, 2002; Oakes \& Lipton, 2003; Olneck, 1995;

Ovando et al., 2003; Plata \& Robertson, 1998; Pransky \& Bailey, 2003; Rosenthal \& Jacobson, 1968).

Paccione (2000) argues that teachers are not usually aware that they have lower expectations for students of color, but differences in teachers' perceptions about students' race, class, and other social and cultural factors still govern their 
expectations for students' academic performance and behavior. Our values and assumptions are so deeply rooted in our minds that we can easily act upon them without critical reflection. "Consequently, teachers' beliefs and values, how these are communicated to students through teaching practices and behaviors, and their impact on the lives of students - these are the factors that make teaching so consequential" (Nieto, 1999, p. 130).

Tatum (1997) presents cases in which teachers exhibit stereotyping and low expectations for students of color that reflect Nieto's (1999) statement quoted above. For example, she cites Malcolm X's withdrawal from school in response to his English teacher's suggestion that Malcolm consider carpentry, since his career goal of becoming a lawyer is "[not] a realistic goal for a nigger" (p. 58). Tatum (1997) contends that although language use has changed to create more appropriate formulations today, similar examples are still seen in contemporary educational settings. Her example of a high school student illustrates that this is the case.

Because the majority of students from this school go on to college, [the teacher] used the free time to ask the students about their college plans .... [and] she offered some suggestions. When she turned to this young man, one of few Black males in the class, she suggested that he consider a community college. She had recommended four-year colleges to the other students .... This student got the message. (pp. 58-59)

Rosenthal and Jacobson (1968) argue that our expectations of other people may become a factor in determining their behavior, as in the example of Malcolm X. In their classic on the subject, Pygmalion in the Classroom, they found that 
"when teachers expected that certain children would show greater intellectual development, those children did show greater intellectual development" (pp. 82-83). In the same vein, teachers' low expectations have the effect of a self-fulfilling prophecy. As Oakes and Lipton (2003) argue, lower teacher expectations lower student self-confidence, which results in lower achievement. "'Poor performance,' then, begins the cycle anew, giving additional justification to the [teachers] to lower expectations and reduce opportunities" (p. 331). Olneck (1995), referring to an unpublished dissertation by Becker, states:

Teachers' perception and interpretations of immigrant youth guide their practices with them. Expectations of poor performance, early school departure, and resistance to assimilation, as held by New England teachers of Portuguese immigrants, result in neglect and indifference to poor academic performance, while high expectations, like those held with respect to Asians, result in encouragement and individualized attention. (pp. 316317)

Nieto (2000) suggests that "when teachers and schools believe their students are capable learners and they create [an] appropriate learning environment for them, young people are given a clear and positive message about their worth and abilities" (pp. 244-245). Citing a 1990 study by Lucas et al. on high schools that were successful with education of Latino students, she considers the most significant factor for students' success to have been belief that students were all capable of learning. In another review of relevant literature, Nieto (2004) cites Zeichner's 1995 study of urban teachers showing that the main factor in students' success is teachers' belief in students' capability and teachers' ability to 
communicate this belief. Nieto also refers to Steele's study in 1992, for which he reviewed programs that were successful in promoting academic achievement of African American students. Steele found that students' performance got better when they were treated as talented and capable. Graybill (1997) cites Kunjufu to point out that the most critical factor in student success is teacher and parent expectation, more so than home circumstance, socioeconomic status, or school funding.

A final example of student success as a result of a teacher's high expectations comes from Ovando et al. (2003); the example also shows the way expectations can germinate from societal assumptions (in this case, Japanese students' being the model minority), which shape teachers' beliefs. The description comes from an experience of one of the authors who was supervising student teachers:

I noticed an unusual joy on the part of my student teacher's third-grade cooperating teacher. She told me that she was eagerly anticipating today's arrival in her classroom of twin brothers who had just recently come from Japan. I asked her whether she was worried about possible linguistic, cultural, or academic difficulties. "Oh, no!" she replied. "On the contrary, I know that they will do very well in all those areas and our students will enjoy having them around ...." True to the cooperating teacher's predication, the twin Japanese third graders adjusted well socially, [and] did well academically .... Embedded in the teacher's sense of positive anticipation for her Japanese students was a set of notions related to the Japanese students' prior knowledge, schooling experiences, ability to acquire a second language, motivation, and family support that somehow corresponded to an ideal that would produce success. (p. 27) 
The above quote illustrates the way that teachers can already have set assumptions about students before they come into the classroom, often based in beliefs about a particular cultural group. I agree with Pang (2001) when she states that like our students, "the teacher [is] also a cultural being. [Teachers'] worldview and perspectives shape the way [they] teach, what [they] teach, how [they] interact, and what [they] value and expect in the classroom" (p. 9). This statement reminds us that teaching and learning cannot be examined without the cultural and social effect of teachers' and students' own pasts, and the way these play out in the current classroom. That is, teachers' assumptions about certain students that shape their low (or high) expectations may be products of their earlier cultural and societal interactions, and these assumptions are a determining factor in diverse students' school success or failure.

\section{Culturally Responsive Teaching}

In recent years, considerable literature has emerged addressing features that effective teaching exhibits in successfully educating culturally and linguistically diverse students (see Armendariz \& Armendariz, 2002; Gay, 2000; Ladson-Billings, 1994; Lucas et al., 1990; Moran, \& Hakuta, 1995; Nieto, 2000; Pang, 2001; Villegas \& Lucas, 2002). This type of pedagogy is called by many names, including: culturally compatible, congruent, appropriate, responsive, sensitive, centered, reflective, mediated, contextualized and synchronized. However, according to Ovando et al. (2003), the pedagogy described by each term originates 
in the cultural difference perspective, ${ }^{7}$ and Gay (2000) notes that the ideas behind the different terms are almost identical: why it is important to make instruction relevant to students' cultural orientation, and how it can be done.

I have already touched on some aspects of "culturally responsive teaching" (Gay, 2000), the term I will use from here on; specifically, those that concern what teachers must know and do in order to effectively promote educational success of students from linguistically and culturally diverse backgrounds. I have also looked at features of teachers who have detrimental influence on such students' achievement. Here, I will summarize empirical and conceptual literature on culturally responsive teaching; this will also provide a synthesis of what we know about effectively educating such students. The summary includes studies of teachers and schools as well as reviews of literature.

Lucas et al. (1991) studied six high schools (five in California and one in Arizona) that were successful in promoting Latino students' academic attainment, and identified eight factors that they concluded were critical for effective education of linguistically diverse students:

- Value is placed on the students' language and cultures.

- High expectations of language-minority students are made concrete.

- School leaders make the education of language-minority students a priority.

- Staff development is explicitly designed to help teachers and other staff serve language-minority students more effectively.

\footnotetext{
${ }^{7}$ See pages $44-45$.
} 
- A variety of courses and programs for language-minority students is offered.

- A counseling program gives special attention to language-minority students.

- Parents of language-minority students are encouraged to become involved in their children's education.

- School staff members share a strong commitment to empowering language-minority students through education. (pp. 464-465)

Studies of teachers offer suggest significant information about what they do and know and what their individual dispositions are toward effectively promoting academic success of diverse students. Ladson-Billings (1994) presents "the stories of the pedagogical practice of eight exemplary teachers" (p. xi) of students from diverse backgrounds. The author summarizes important characteristics that all share of them and that she thinks make them successful in educating such students (she calls this kind of teaching "culturally relevant practice"). She explains some of the characteristics by comparing them with characteristics of teachers (and pedagogies) that do not employ culturally relevant teaching (she calls this type of teaching “assimilationist").

According to Ladson-Billings (1994), teachers with culturally relevant practice:

- Have high self-esteem and high regard for others (frequently, teachers do not have high regard for themselves and others, but those who practice culturally relevant teaching tend to have these). 
- See themselves as part of the community, see teaching as giving back to the community, and encourage their students to do the same (on the contrary, assimilationist teachers tend to identify themselves as individuals; for them, moving out of the community implies success).

- Identify themselves as artists, and see teaching as an art (rather than considering it a technical job).

- Believe that all students can succeed (as opposed to assimilationist teachers' belief that some students will fail).

- Help students make connections between their community, national, and global identities (by contrast with assimilationist teachers, who can prefer to homogenize students into one "American" identity).

- See teaching as "digging knowledge out" of students instead of putting knowledge into students' heads (as assimilationist teachers often do. (pp. 30-53)

A study of urban "star" teachers identifies " 14 functions" of effective teaching "by comparing the behaviors and undergirding ideologies of star urban teachers with those of quitters and failures" (Haberman, 1995, Functions of "Star" Urban Teachers section, $\uparrow 1$ ). Seven of the 14 are more extensively explored and clearly stated than the others; according to Haberman (1995), star teachers:

- Have a conviction that engaging all students in learning activities is teachers' responsibility. They work hard trying to meet students' particular needs. They never give up looking for what works better for each individual student.

- Find ways to continue maintaining a genuine learning environment where students can thrive and where learning goes beyond curriculum, textbooks, and achievement tests. 
- Are capable of translating theories and philosophies into practice.

Because of this ability, they can see the important relationships between significant ideas and day-to-day classroom practice.

- Do not blame students for their school failure. They believe that it is teachers that should take responsibility for inspiring students to learn.

- Expect themselves to be able to teach all students regardless of their like or dislike for students and students' like or dislike for them. They have genuine respect, care and concern for their students.

- Learn how to cope with interfering bureaucracy. They do minimum things so that they can function in and not get punished by the system. They also have a network of fellow teachers on whom they can rely emotionally.

- Accept their own and students' mistakes. Those they recognize as mistakes are the ones that have a serious nature (such as something to do with human relations), not merely a simple nature (e.g., grammatical or arithmetic).

Mehan, Lintz, Okamoto, and Wills (1995), from a review of literature made up of ethnographic studies on "the various strategies that educators have employed to incorporate diversity into the curriculum and the school" (p. 140), came up with five recommendations regarding teaching practice that are beneficial to diverse students from various ethnic backgrounds: 
- Academic rigor with social support: expectations are kept high; curriculum is academically rigorous and is accompanied by a social support system. If curriculum is not rigorous, even with cultural sensitivity, students do not seem to thrive academically.

- Student-centered classroom and discourse organization: cooperative and small group work and student-centered, participative instruction engage students more in learning than teacher-mandated participation. Studentcentered classrooms also promote students' higher cognitive performance.

- Teacher as ethnographer: teachers should learn about students' individual lives and discover their particular experiences and knowledge. In this sense, teachers become ethnographers who explore students' lives and culture.

- Students' knowledge as resource: students' prior knowledge and experiences must be used as resources for teaching and learning. Through this practice, students become more engaged and more productive. Linguistic and cultural exclusion invites resistance on students' part.

- General principles adapted to local circumstances: general recommendations must be tailored to fit the needs of local schools and classrooms. 
In the area of teacher education, two sets of literature together offer an important synthesis of aspects of successful teaching for linguistically and culturally diverse students. Villegas and Lucas (2002) reviewed a large body of literature in search of "central themes ... that give conceptual coherence to the teacher education curriculum [they] envision" (p. 21). They list six traits that define culturally responsive teachers. Such teachers:

- Are aware that there are multiple ways of perceiving reality and that these ways are shaped by social context.

- Have affirming views of diverse students, and see individual differences as resources for learning.

- Consider themselves to be capable agents, responsible for change permitting schools to be more congruent with students' different backgrounds.

- Understand the knowledge construction process and are able to promote this process.

- Know about their students' lives.

- Root instruction in their students' lives and prior knowledge in order to build on them and guide students from the familiar to new domains. Villegas and Lucas (2002) state that the above six characteristics of culturally responsive teachers are constituted of knowledge, skills and dispositions 
that "constantly intertwine and [are] dependent on one another to form a cohesive whole" (p. 21).

Zeichner (2003) uses similar terms for his sets of culturally responsive teacher characteristics: knowledge, performance and dispositions. In reviewing literature on culturally responsive teaching to analyze the strengths and limitations of three approaches to teacher education reform, Zeichner identified, in relation to the third approach (a social justice agenda), "remarkably consistent sets of knowledge, skills, and performances that are related to successful teaching" (p. 507) for diverse students:

- Knowledge. The teacher understands the ways in which life is organized in the communities in which his or her students live, how students use and display knowledge, tell stories, and interact with peers and adults. They know something about the funds of knowledge that exist in these communities.

- Performance. The teacher is able to incorporate aspects of his or her students' abilities, experiences, cultures, participation styles, frames of references, and community resources into the class in ways that enhance student learning.

- Disposition. The teacher sees resources for learning in all students rather than viewing differences as problems to overcome. The teacher believes that he or she is responsible for making a difference in his or her students' learning. (p. 508)

Looking across the summaries of literature on culturally responsive teaching, I believe that Gay's (2000) definition is prominent and extensive in describing features of the pedagogy. Even though her ideas seem somewhat idealized, they embody the goals of the education for culturally and linguistically 
diverse students. Her definition of five significant features of culturally responsive teaching is also a description of rationales for why instruction should be consistent with cultural orientations of diverse students, and an explanation of how it can be done.

- Culturally Responsive Teaching is Validating: this dimension defines such teaching as "using the cultural knowledge, prior experiences, frames of reference, and performance styles of ethnically diverse students to make learning encounters more relevant to and effective for them" (p. 29). The basic assumption of this approach is that positive self-concept and cultural recognition and academic achievement are strongly related.

- Culturally Responsive Teaching is Comprehensive: it creates "intellectual, social, emotional, and political learning" (p. 30). This means that it not only considers academic learning, but also the aspect of the whole child as an individual and social being.

- Culturally Responsive Teaching is Multidimensional: it encompasses all dimensions of school learning-curriculum content, learning context, classroom climate, student-teacher relationships, instructional techniques, and performance assessments. A variety of cultural knowledge, experiences and perspectives is necessary for teachers to teach well. They must also be reflective about their own value systems, 
opinions and emotions along with factual information in order to make curriculum and practice more reflective of and relevant to diverse cultures.

- Culturally Responsive Teaching is Empowering: teachers hold high expectations of all students, show that they believe in their success, and make this happen. They establish an environment that supports students' effort to reach higher levels of academic success through such tools as:

(a) boosting spirits, (b) providing resources and personal assistance, (c) developing ideas and attitudes of achievement, and (d) celebrating students' individual and collective achievements. Through this empowerment, students develop academic competence, confidence, and courage and will to act.

- Culturally Responsive Teaching is Transformative: it honors experiences and cultures of diverse students and uses them as the basis on which their learning is built. It values students' strengths and accomplishment and brings them to higher levels. Educational success comes along with students' cultural consciousness. They learn that they must be proud of their cultural identity and heritage instead of being ashamed of them. It also helps students develop skills for thinking critically on social issues. Students become active in decision making and effectively implementing decisions personally, socially, politically 
and economically. By so doing, they become change agents promoting equity, justice and power balance.

- Culturally Responsive Teaching is Emancipatory: it liberates diverse students by making clear that there is no single "truth" and that they have a different way of knowing than do those from the mainstream. Students learn ways to incorporate new knowledge created by people from diverse cultures into their examination of social issues and their own experiences. This teaching perspective gives students a sense of pride and liberation by validating the authentic knowledge about diverse cultural groups and making it accessible to students. It helps them develop multiple perspectives, find their own voice, and become more active learners. For this kind of learning, cooperation, instead of competitiveness, is essential. In this kind of learning community, all students reach to the best of their ability through mutual aid, interdependence and reciprocity.

\section{Relationship between Teachers' Experiences and their Teaching Practice}

The above-mentioned literature on culturally responsive teaching extensively discusses features of successful teaching for diverse students. However, it does not explore in much depth reasons why teachers use these features. Nieto and Gordon (2002) argue that: 
It is in their classrooms that teachers enact their most deeply held values .... Teachers' beliefs are deeply embedded in their classroom practices.

Teachers do not-indeed, they cannot-leave their values at the door when they enter their classrooms. As much as they might want to hide or avoid them, their values and beliefs slip in the door with them .... "Even in our indifference, we take position." ... Teacher's identities, beliefs, and values influence their work with students. (pp. 67-75)

In What Keeps Teachers Going (Nieto, 2003), which contains teachers' essays, journal excerpts, and other writings that mostly came from an inquiry group of teachers with whom the author engaged, Gordon, one of the teachers, further affirms how personal experience shapes teachers' perspectives, from which their practice arises:

I teach who I am. What I value and believe arises from my personal background and experience- - whom I have loved and who has loved me; what has encouraged and hurt me; and the idealistic quests involving myself, other people, and American society. My identity as a teacher was formed through parents, family, friends, successes, and failures. What I decide is true and necessary for my students and me, in both the anxiety-filled nights and clear daylight, comes from my no-longer-negotiable identity, character, and philosophy. (p. 30)

The contention of Nieto and Gordon is further supported by other researchers and scholars (see Coughlin, 2003; Fickel, 1999; Galindo, 1996;

Gaudelli, 1999; Muchmore, 2001; Paccione, 2000). These researchers study the relationship between teachers' past experiences and their classroom identities, finding that the former shape the latter, and that teachers' belief systems play a vital role in defining the philosophy that guides their actions in the teaching and learning process. 
Muchmore (2001) presents a case study of a high school English teacher's life history and experiences, and their relationship to her literacy beliefs and practice. Using formal interviews and informal conversations with her, classroom observation, interviews with her colleagues and students, and documents such as her teaching evaluations and academic papers she wrote for college courses, the researcher focuses on understanding how a high school English teacher's life experience shaped her beliefs about literacy. The research concludes that the teacher's personal experiences and life-long concern with the ways children learn generated most of her beliefs about literacy, which shaped her classroom practice.

Gaudelli's (1999) study analyzes patterns in social studies pedagogy, ways in which the teacher's self-identity influences course content, and ways that approaches to topics are manifested in global education classroom. The study includes 14 teachers and 27 students from three high schools, and employs an ethnographic approach and the grounded theory method of data analysis. Data from classroom observation, interviews and document analysis were collected on teacher identity; specifically gender, occupation, religious background, family history, athletic background, ethnic identity and travel. The findings of the study suggest that teachers' identity influences their course content selection and topic emphasis, and that teachers may or may not be aware that their identity has an effect on their pedagogy. The study also demonstrates a need to increase teachers' consciousness 
about themselves, their own backgrounds, identities and beliefs, and how these affect teachers' practice.

In his ethnographical study on three Chicana teachers, Galindo (1996) highlights the contribution of biographical identities to the way the teachers define their professional role in light of their cultural minority background. The study presents portraits of these teachers that reveal a sense of who they are as teachers and that identify the critical influences that played a role in shaping their lives, biographies, and teacher role identity. Data on the three teachers, who average 17 years of teaching experience, were obtained from interviews, autobiographies and papers written by the teachers for a graduate program in education. "Family values" and "Identity" were chosen as integrative categories, to summarize the teachers' life histories, because these represented collective effects across situations, history, people and incidents. The study's two foci were to identify which contexts, people and interactions played vital roles in shaping the teachers' lives, and what influence the teachers' family values had on their own identity development. The study shows that the three teachers' present identities are rooted in and constructed by their past experiences as minorities, informing their present and future roles as minority teachers. Their teacher role identity is able to bridge their past and future especially because of the similarity between their students and themselves.

Paccione (2000) explores teachers' life experiences, factors and processes that guide them to become committed to "equitable education of students of color" 
(Teacher Education for Diversity: Becoming a Multicultural Person section, \3). The study involved written survey and open-ended telephone interviews, conducted with 45 educators who were NAME (National Association for Multicultural Education) members and already committed to such education. Phenomenological methodology was employed to analyze data collected by the phone interviews. Through the analysis, significant statements that captured the essence of critical experiences and processes that contributed to developing the teachers' commitment to multicultural education were identified and reexamined. From this process, the researcher identifies four stages of transformation in cultural awareness that ultimately led the teachers to commitment and action to diversity. Findings of the study highlight the fact that there were critical experiences in the educators' lives that significantly influenced their awareness of diversity.

Given that "some of the strongest messages teachers communicate to students are expressed through classroom behavior" (Good, 1996, p. 632) and that this behavior is shaped by their life experiences, exploring teachers' life experiences and understanding how these shape the beliefs and assumptions that manifest in the teachers' classroom practices must be a key consideration in preparing teachers for an increasingly diverse student population. Ultimately, what influences diverse students' learning and educational attainment is what they experience within the given educational setting in the interaction with their educators. 


\section{Summary and Research Gap}

This review of literature helped illuminate the ways that education of linguistically and culturally diverse students has been shaped in the United States. It also elucidated the importance of understanding (a) the sociocultural concepts and theories of teaching and learning, and their application to practice, and (b) the way the teacher-student relationship affects diverse students' educational success. It looked into the features of successful pedagogy for linguistically and culturally diverse students, which ultimately confirmed that successful instructional practices respected and encompassed such students' native languages and cultures and communicated empowering messages to them. The review also investigated the fact that teachers' past experiences shape their beliefs and manifest in their classroom practice.

Thus, existing literature addresses the issues and factors that are vital to ELLs' academic achievement, and the kind of teaching that promotes school success diverse students. However, in many cases, literature on successful teaching of diverse students deals with teachers of African American students (see for example, Irvine, 2003; Ladson-Billing, 1994), or diverse student populations "in general." There is a scarcity of research specifically about successful teachers of ELLs. It is also the case that when ELLs are the focus of a study, most frequently it 
is either about bilingualism, language acquisition, or effectiveness of programs and the language of instruction. ${ }^{8}$

Even though there is literature about the way teachers' orientation toward diverse students' differences influences their perceptions and expectations for the students, and about the way these play out in teachers' practice, not much research on this subject is concerned exclusively with ELLs. Also, from what I have found, there is not much written about how ELLs' teachers' frames of reference were shaped, which has some bearing on teaching such students.

Again, going back to Vygotsky's (1978) social constructivism, human development and learning occur in social and cultural interaction. Gillani (2001) clearly states the way we develop our mind:

Cognitive development is ... socially situated. Because humans are born with an innate genetic predisposition to respond to the environment, the individual mind reaches out into the social and cultural context and derives specific social patterns, or "modal personality," that are unique to a given society. In such a manner, the interactive social experiences become an integral part, during maturation, in shaping the individual mind to reflect the values of the society in which the individual lives, In effect, the society forms the individual mind .... (p. 128)

Based on this theory, my supposition is that teachers' past experiences have direct connection with the formation of their frames of reference. Regarding the

\footnotetext{
${ }^{8}$ In this review, I did not mention literature on language acquisition or effectiveness of programs and the language of instruction. Even though these are very important issues to address in the education of ELL students, they do not have direct relevance to my proposed study. These issues are discussed in works such as August and Hakuta (1997), Baker and de Kanter (1983), Bialystok (1991), Collier (1987), Crawford (1999), Cummins (2001), Hakuta and McLaughlin (1996), Kindler (2002), Moran and Hakuta (1995), D. Ramírez, Yuen, Ramey, and Billings (1991), Snow (1994), and Tikunoff (1985).
} 
relationship between their frames of reference and behaviors that stem from these, Irvine (2003) writes, using the word "positionality,"

teachers ... operate from the concept of positionality, that is, they have frames of reference for viewing the world depending on how the world makes sense to them based on personal history .... It would be ... naïve to assume that their teaching beliefs and behaviors are not influenced by their positionality. (p. 57)

Knowles (1992) further states that a "small but growing body of knowledge about teachers' biographies ... suggests that it is not primarily the pre-service teacher education programmes that establish teacher role identity but, rather, previous life experiences" (p. 147). Given these contentions, knowledge about the kinds of experience that shaped teachers' worldview in a way that permits them to embrace diverse students' points of view in their classroom practice will add to the existing literature.

Reviewing the literature, I encountered only a few studies (see Muchmore, 2001; Paccione, 2000) that described what kinds of life experiences shaped teachers' frames of reference. Even though these studies deal with the relationship between the two elements, the student population of the teachers studied is not exclusively ELLs. I concluded that it is important to study the kinds of experiences that lead teachers to beliefs that cause them to incorporate ELLs' native language and home culture as a genuine endeavor, and form a caring and trusting relationship with their students. Mine aims to be such a study, and my dissertation aims to contribute to filling the gap in knowledge. 
Going forward, I would argue that additional research on ELLs' education must include such students' teachers' life histories, values and beliefs, and the relationship of these to the teachers' practice. If studies can identify the reasons behind, or underlying philosophy for, this kind of practice, and how these were shaped, it may contribute to teacher education programs, including endorsement programs, specifically to help in deciding what kind of experiences programs should include to prepare pre- and in-service teachers to work with bilingual/bicultural students. It may also help in "recruiting and selecting for certification ... those who bring experiences, knowledge, and dispositions that will enable them to teach in culturally diverse ... schools" (Sleeter, 2001, p. 215). 


\section{CHAPTER III}

\section{RESEARCH DESIGN AND METHODOLOGY}

As has been stated, the central question that guided this study is:

What can be learned about the life experiences and perspectives of mainstream elementary school teachers that has enabled them to be successful teachers of ELLs?

In Ladson-Billings' (2001) terms, I am interested in looking at the way "their ... background [influenced] and [shaped] the way they understand and act'" (p. 83).

Considering Bruner's (1996) claim about "the cultural 'situatedness' of all mental activity," i.e., that we "cannot understand mental activity unless [we] take into account the cultural setting and its resources, the very things that give mind its shape and scope" (p. x), exploring teachers' past experiences will reveal social and cultural factors that have played a part in shaping their value systems, and will allow for the connection between their past and present values and beliefs.

As Nieto (2000) has specifically argued, "because we are all products of a society that is racist and stratified by gender, class, and language, among other differences, we have all internalized some of these messages in one way or another" (p. 339). Some teachers seem to have done so in a way that enhances their ability to teach ELLs; how is this so? 


\section{Problem and Rationale for Qualitative Research}

Two of the most important conceptual frameworks of this study are (a) that learning fundamentally happens through social and cultural experiential processes (Bruner, 1977; Minami \& Ovando, 1995; Moran \& Hakuta, 1995; Nieto, 2002; Oakes \& Lipton, 2003; Ovando et al., 2003; Vygotsky, 1978; Wink \& Putney, 2002), and (b) that the teacher plays a critical role in the educational experience of culturally and linguistically diverse students (Cummins, 2001; Darling-Hammond, 2002a, 2002b; Feuerverger, 2005; Gay, 2000; Kohl, 1998; Minami \& Ovando, 2004; Nieto, 1999; Rosenthal \& Jacobson, 1968; Wink \& Wink, 2004). Using these frameworks, the study explores and describes the participating teachers' life histories to look at the influence of their life experiences on their beliefs and assumptions about culturally and linguistically diverse students, and the way the experiences are reflected in their relationships with such students. In considering the ways their life experiences have helped shape their philosophy and practice of teaching, the study also considers the teachers' reported statements and stories about their classroom practices to see how the experiences are incorporated into them.

Such exploration requires the researcher to see teaching, learning, and the teacher-student relationship together, as a holistic entity. This entity involves multiple levels of human action, the history of teachers' and students' life contexts, 
and ideologies held by the individuals and the larger society. To comprehend the complex web of all these elements, I, as a researcher, have to interpret how they are related in the big picture. In the interpretation, I cannot separate myself as an interpreter and completely objectify the participants and the data gathered. The data should be gathered in natural settings in order to maintain authenticity regarding changing human cognition and behavior.

All of these characteristics place the current research into categories for which Creswell (2003) prescribes qualitative study:

- Qualitative research takes place in the natural setting.

- Qualitative research is fundamentally interpretive.

- The qualitative researcher views social phenomena holistically.

- The qualitative researcher systematically reflects on who he or she is in the inquiry... and is sensitive to how it shapes the study. (pp. 181-182)

Marshall and Rossman (1999) argue that "the unique strengths" of qualitative research are that it is "exploratory or descriptive, that [it] assumes the value of context and setting, and that [it] searches for a deeper understanding of the participants' lived experiences of the phenomenon. One assumption ... is a focus on the meaning that people express about some aspects of their lives" (p. 60). Since my study is an exploration of teachers' life experiences and their interpretation of these experiences, it squarely fits in the qualitative research genre.

The study, which examines issues relevant to culturally and linguistically diverse students' educational experience with their teachers, may contribute to a better understanding of quality education, in the larger picture, for all such students 
who share a similar background. By using a qualitative study method, "the particulars of the study [can] serve to illuminate larger issues and, therefore, hold potential significance for [the] field" (Marshall \& Rossman, 1999, p. 11).

Site and Population Selection

Qualitative researchers purposely choose sites and individuals that will best help them learn and understand the research problem (Creswell, 2002, 2003; Marshall \& Rossman, 1999). For this study, my population of interest is mainstream elementary-school classroom teachers whose students include linguistically and culturally diverse students. I have decided to focus on elementary teachers in the Cascadia ${ }^{9}$ School District.

The Cascadia School District is one of the major employers in the town of Cascadia, a small rural community that became a thriving agricultural center in the mid- $19^{\text {th }}$ century. Even though the town is not very far from a large metropolitan center, it is surrounded by farms and its adjoining area offers outdoor activities such as fishing, hunting, boating and hiking. The community and its Chamber of Commerce take pride in preserving a small-town atmosphere and wholesome rural values. Although residential development is present, the costs of land and housing are still moderate. The town's rural character is evident from the fact that major employers include a lumber company and a forest products company, and every

\footnotetext{
${ }^{9}$ Pseudonym. For reasons of confidentiality, the district's name and sources used for the summary of the city and the district will not be published.
} 
year the town hosts a very long standing rodeo festival and a fruit festival. Timber and lumber have been among the community's biggest products. The town's population was 5,647 in the year 2000 , of which $10.6 \%$ (596) was Hispanic. Of the remaining $89.4 \%(5,051), 85.7 \%(4,840)$ was White and the rest consists of Native American and Alaskan Native, Asian and other Pacific Islander, African American and other races. Hispanic population is significantly above state average. ${ }^{10}$

The Cascadia School District includes one high school, one middle school and six elementary schools. In 2000, there were 869 students in grades 1-8 and 323 in grades 9-12. The racial makeup of each school is indicated in Table 1.

The ESL program director for the district inherited the Lau Plan, which was adopted in May 2002. He revised it for the 2004-2005 school year and it was revised again for 2008-2009.

Table 1

Racial Makeup of Cascadia Schools

\begin{tabular}{|lcc|}
\hline & Hispanic & Asian \\
\hline Elementary School A & $5 \%$ & $4 \%$ \\
\hline Elementary School B & $7 \%$ & $0 \%$ \\
\hline Elementary School C & $7 \%$ & $2 \%$ \\
\hline Elementary School D & $0 \%$ & $0 \%$ \\
\hline Elementary School E & $19 \%$ & $<1 \%$ \\
\hline Elementary School F & $10 \%$ & $2 \%$ \\
\hline Middle School & $8 \%$ & $<1 \%$ \\
\hline High School & $7 \%$ & $1 \%$ \\
\hline
\end{tabular}

${ }^{10} \mathrm{I}$ intended to present the demographic data of 1900 in order to show the rate of increase for the Hispanic/Latino population in Cascadia, but I could not locate any data. I also looked up other sources and communicated with organizations such as the city itself and the PSU Population Research Center. However, I could not get any helpful information. 
The reasons for which I decided to focus on the Cascadia School District are as follows:

1. The district is located in a rural area of the state and had a very homogeneously White population until recently.

2. The area now has a rapidly growing immigrant population (mainly Hispanic/Latino), so that district schools have new non-English speaking families joining their learning communities.

3. As a result, educators in the district face the new challenge of dealing with this new population.

4. The fact that the district recently participated in the ESL Endorsement Program run by a public university indicates the district's intention to meet this challenge.

5. Although some educational studies focus on explaining success of ELL students, most were "conducted in urban elementary schools" (Lucas et al., 1991, p. 458), so there is a paucity of research dealing in any depth with ELL populations and their teachers in small rural districts such as Cascadia.

6. Similar small districts across the nation will be dealing, if they are not already, with the same situation, so the study will be a contribution to a needed body of literature.

It has been suggested that "site selection and sampling begins with accessible sites" (Marshall \& Rossman, 1999, p. 77). This idea is further supported 
by Rossman and Rallis (1998), who suggest conditions that an ideal site should meet, again including accessibility. I have taught a course about cultural and linguistic influences on students' learning, to Cascadia public school teachers, in an ESL Endorsement Program. One of my students in that class was the director of the Cascadia district's ESL program as well as the principal of one of its elementary schools. In addition, he was very enthusiastic about the education of ELL students in the district. As a person who held an official role in the district, he was able to make my access to the site easier and helped me with various procedural aspects of the study.

For selecting participants, I adopted the process that Ladson-Billings (1994) employed in her study of effective teachers of African American students. She took two steps to identify teachers: (a) community nomination and (b) cross-check by school principals. Community nomination is an approach in which "researchers rely upon community members ... in order to judge people, places, and things within their own settings" (p. 147). For her study, Ladson-Billings asked African American parents to nominate teachers and then consulted principals to ensure accuracy of the nominations. For my study, I replaced "parents" with "educators" and "principals" with "the director of the ESL Program" of the district. However, later I decided, at his suggestion, to use opinions of principals of nominated teachers for accuracy of the nominations. I decided to use educators, not parents, for the following two reasons: (a) It would be more difficult to distribute the 
nomination letter to parents than to educators. Later, when I was trying to distribute the letter to educators, I was told by the district that they could not give me the educators' personal addresses. This indicated that I would not have been able to obtain the parents' addresses even if I had tried to. (b) Even if it were possible, there would be the issue of the language in which the letter was written. I could not assume Spanish language would do for all parents. Even with families from Mexico, some might use native dialects other than Spanish. Also, there were Asian families even though the ratio was small. I also had to think about the possibility of some parents not being able to read and write. I had another concern that ELLs' parents might not feel adequate to "be a part of" something unknown that was related to their children's education, and therefore they might not be willing to respond to my request. This concern came from my own personal experience when my daughters were going to American public schools. I was never made to feel "accepted" or "adequate" in their schools as a parent of "students of color" and never felt "appropriate" attending school-related events. If I felt accepted I also felt patronized. It was not difficult to imagine that migrant parents would not think that they were suited to join something that did not look familiar nor perhaps even relevant to their day-to-day lives. Even though I made my decision on the basis of the above two reasons, the sentiment about ELLs' parents crossed my mind as a strong concern. 
Below, I delineate the two challenging steps I took to identify teachers whom I would ask to engage in conversations with me and who agreed to do so.

Step One: I sought nominations, based on reputation, from all administrators and teachers in the district. I started communicating with the abovementioned district ESL program director, Aron Lowry, ${ }^{11}$ in July of 2005. We initially had some disagreement over how to distribute the nomination form to district educators. After this was resolved, I obtained a list of educators' names from him in November 2005. We decided that it would be better for me to send a packet to the principal of each school in the district so that they could distribute the nomination forms to each of their teachers.

In the middle of November 2005, I mailed packets to the principals of eight district schools. The packets contained my letter to the administrators and envelopes addressed to each of the principal's teachers and to the principal himself. ${ }^{12}$ Enclosed in each envelope were: my letter asking for nomination of mainstream elementary classroom teachers they consider successful at teaching ELLs, a nomination form, and a self-addressed, stamped return envelope. I assigned numbers to returned forms in order to protect anonymity. At about the same time I mailed the packets to principals, I e-mailed each of them to inform them that a packet would be arriving, who the sender was, why they were receiving

\footnotetext{
"Pseudonym.

${ }^{12}$ There was no female principal at the time this survey was conducted.
} 
the packet and what was in the packet. I also asked them for support for my study. The total number of envelopes in the packets was 159 .

I only received 12 nomination forms back by early December 2005, of which 3 did not nominate any teachers for the reason that the senders, being high school teachers, did not have any contact with elementary school teachers. Following this scarcity of response, I again contacted all principals, via e-mail, asking them to encourage their teachers to respond to me. I attached to this message my letter soliciting nominations, for principals to forward to their teachers, if they should choose to. At the same time, I asked Aron to remind the administrators to encourage their teachers.

By the middle of December, I received five more responses. Again, I communicated with all the administrators and asked them to push their teachers to respond to my request. After their encouragement, three more educators returned nomination forms to me.

To summarize Step One, I sent out one 159 nomination forms, of which 73 went to the six elementary schools, 39 to the middle school and 47 to the high school. Altogether I received 20 forms back: of these, three did not nominate any teachers, three nominated middle school teachers and 14 nominated elementary school teachers. Those that nominated elementary school teachers were all from elementary school educators except for one, which was from a high school educator. The fact that high school educators who returned nomination forms responded with 
no names and that the three middle school educators nominated middle school teachers may imply that teachers at the 6-12 level indeed do not have close connection to those at the K-5 level. As one of the three high school teachers stated in the returned form: "As a high school teacher I have very little interaction with or knowledge of the competency of elementary school teachers in the district." Another of the three expressed almost the same sentiment. The high school educator who nominated elementary school teachers seemed to be an administrator of the school who is also a district administrator. I inferred so because the five teachers she/he nominated are from five different elementary schools, which is a pattern that I did not see in any other nomination forms.

The overall return rate was thus $12.6 \%$ (20 out of 159 ), although I consider the practical returning rate to be $27.4 \%$ ( 20 out of 73 ). Excluding blank forms and those that nominated middle school teachers, the rate drops to $19.2 \%$ (14 out of 73 ). I will leave discussion and implications of the low return rate for a later chapter.

The number of returned forms was very low and I hoped to have more; however, considering that I had already done what I could do, including communicating with the principals three times for support and asking Aron, the ESL director, several times to remind the principals, I considered that it would not have produced any greater result if I had asked district educators to cooperate with 
me. ${ }^{13}$ In addition, the holiday season was approaching, which would certainly not be a favorable factor for my solicitation. I thought it was time to wrap up Step One.

As the last stage of Step One, I ranked teachers according to the number of nominations they received on returned surveys. A qualitative study typically involves a small number of participants (Creswell, 2002; McMillan \& Schumacher, 1997) because "the overall ability of [the] researcher to provide an in-depth picture diminishes with the addition of each new individual" (Creswell, 2002, p. 197). From the outset I considered that more than 10 participants would not contribute to my intended exploration. Based on this idea, I decided that if fewer than 10 teachers were identified as successful by at least one administrator or fellowteacher, I would identify all of them as candidates for the next step. If the number should be more than 10 , I would take the 10 top-ranking teachers as candidates for the next step. It turned out that six teachers were nominated by more than one colleague and 12 others were nominated by one. I decided to name the six teachers as my candidates to be study participants.

Step Two: The second step was to cross-check the nominations by conferring with the director of the Cascadia district's ESL program, Aron Lowry. As mentioned earlier, he was also the principal at one of the district's elementary

\footnotetext{
${ }^{13}$ Since I was unable to obtain educators' home addresses or individual e-mail addresses, the only way I could disseminate my letter of solicitation was through the schools and their administrators.
} 
schools. My plan was to ask teachers, who were confirmed as effective by him, to participate in my study.

Immediately following identification of the six teachers, I contacted Aron and asked him to confirm the accuracy of the six nominations. He suggested confirmation/feedback from the principals of the teachers as well as his own. I thought principals' professional opinions would strengthen the soundness of the nominations. Upon my agreement, he offered to communicate with them for feedback.

When I did not hear from one of the principals about his teacher, despite Aron's second prompt and a request from myself, I decided to send the invitation letter to the other five teachers at their schools at the very end of 2005 . This time, I sent to individual teachers, at their school addresses, an invitation to participate in my study; included were two copies of the consent form and a self-addressed, stamped envelope for them to return a signed copy of the consent form.

I received a positive response from one of the five teachers at the beginning of the following year. In the middle of January 2006, I again sent out my invitation to the remaining four teachers, one more of whom agreed to participate. This effort was followed by a message from Aron, at my request, encouraging other teachers to join. Responding to his encouragement, one more sent back a signed consent form. I had obtained a total of three research participants since starting the long process of subject recruitment. I thought about re-inviting the teachers who had 
already been invited and had not responded, but the idea seemed futile after Aron's message to them.

As mentioned earlier, I also had a list of teachers, each of whom was nominated for the study by a single person. Even though I was not so convinced about the idea of inviting teachers who were nominated by only one person, I decided to ask Aron about this group. I gave him the 12 names, out of which he confirmed five as being effective teachers. He also gave me names of two others who were not nominated, but whom he considered good teachers of ELLs based on his observation of their teaching. After consulting with my advisor, I decided to add these two teachers to the mailing list.

In February 2006, I mailed out invitation letters to the seven teachers. Only one more agreed to participate. Again, at my request, Aron communicated with the remaining six teachers in support of my invitation, but I heard from nobody. I felt that I had exhausted what I could do to recruit my research participants. I also had to be realistic about resources, especially in terms of time.

To summarize Step Two, I invited two groups of teachers, those nominated by more than one educator, and those nominated by a single person, together with two more at Aron's recommendation. The two groups were invited at different times, the first at the end of December 2005, and the second in February 2006. These invitations were followed by Aron's message of encouragement. As a result, I identified a total of four mainstream elementary classroom teachers to be my 
research participants. The significance of such an admittedly small number is addressed in chapter 5 .

\section{Data-Gathering Methods \\ Interviews}

Marshall and Rossman (1999) recommend in-depth interviews as a datacollection method for studies that focus on individual lived experience. In their view, qualitative studies can be grouped into three categories: "(a) those focusing on individual lived experience, (b) those focusing on society and culture, and (c) those with an interest in language and communication" (p. 60). According to them, each category is typically associated with three distinctive overall design strategies: category (a) with an in-depth interview strategy, category (b) with a case study strategy, and category (c) with a micro-analysis strategy. Each strategy requires a different approach to data collection; "in-depth interview strateg[y] ... rel[ies] on a single primary method for gathering data" (Marshall \& Rossman, 1999, p. 61), i.e., the interviews themselves. In order to get a reliable look at what, specifically, teachers' lived experiences have contributed in forming who they are today, this study relied on in-depth interviews concerned with participants' life stories and narratives.

Interviews in a qualitative study are frequently unstructured, using openended questions (Creswell, 2002); this study used such questions. This type of interview "serves to elicit depth, range, specificity and personal context of 
responses" (Merton, Fiske \& Kendall, 1990, p. 15). It allows interviewees to "voice their experiences unconstrained by any perspectives of the researcher or past research findings" (Creswell, 2002, p. 204), and allows interviewers to "capture the deep meaning of experience in [participants'] own words" (Marshall \& Rossman, 1999 , p. 61). In other words, it has the strength of allowing the researcher access to a significant depth of information and understanding of participants' experiences at a profound level. Significant aspects of qualitative study, these features allow the researcher to understand participants' thinking from the perspective of an insider looking out, not that of an outsider looking in (Muchmore, 2001). The method also helps participants express their experiences by prompting their reflections. It also allows probing and follow-up questions over time. By employing in-depth interviews, the connection between participants' past and present lives may reveal the significance of their past experiences as contributing factors in their core values.

Since I hoped to learn how teachers' life experiences have shaped their identity, interviews inevitably involved their life histories. Goodson and Sikes (2001) write about the significance of life history:

When the focus of enquiry is something ... far-reaching and significant ... [and] when it is something like why someone becomes a teacher, how they cope with imposed change, or why they adopt a particular pedagogical style ... or what it means to be ... a teacher from an ethnic minority group, the potential of life history is enormous. There are likely to be many influences, experiences and relationships within any teacher's life which have led to their developing a particular philosophy of education and taking on a specific professional identity which informs their work .... As Robert Bullough (1998: 24) has written: "to understand educational events, one 
must confront biography". If the researcher wants to know "why", "how", "what's it like" and "what does it mean to you", then they may be well advised to include life history methods among their modes of enquiry. (pp. 21-22)

Goodson and Sikes (2001) recommend the time-line as a useful way to start a life history study. It can be developed before the project starts or developed and expanded during the project. They suggest developing a time-line of key events in each participant's life that had a significant effect relevant to the purpose of the study.

Using in-depth interviews, life histories, and time-lines, I addressed the topics related to formation of teachers' values and beliefs that are presented below. These topics are adopted from Paccione (2000), which is one of the only two studies I encountered in reviewing literature that deal with the relationship between teachers' real life experiences and their beliefs. The goals of Paccione's study were to uncover "the relationships between individual life experiences and a commitment to multicultural education" (Summary of the Study section, ๆ 1). Even though my study does not mention "a commitment to multicultural education," considering the relevance of this specific subject, I believed that application of the life themes that Paccione identified through her data analysis would serve the purpose of the proposed study. These themes, with some revised and one added to better fit my purpose, include:

- Influence of school and teacher 
- Influence of friendship, role model and /or mentor

- Influence of training, educational course, books

- Influence of immersion experiences in other cultures

- Influence of critical incident(s)/significant events

- Significant social or political [temporal] event (such as the Civil Rights Movement)

- Motivation from empathy, moral disposition, religious/spiritual convictions

- Discrimination/racism due to minority status

- Influence of job situations

I also adopted and revised, and incorporated into the interviews, themes mentioned in Muchmore (2002) including:

- Theoretical orientations that guide teachers' instructional practice

- Strategies teachers employ for this instructional practice

- Approach to students

I started conducting interviews during January 2006, while I continued recruiting research participants. Prior to the first interviews, I asked each participant to select a place and time with which she or he would feel most comfortable in order to create as relaxed an environment as possible. All chose their own classrooms after school. 
In our first meetings, prior to interviews, I explained to each participant about confidentiality, the purpose and nature of the study, the role they would play in it, and approximate length of interviews. I said I would ask for their feedback about my interpretation of what they would tell me, ${ }^{14}$ that the study would be available for them when it is done, and gave other details. I also asked them if they wanted to pick a pseudonym. Some of them did and some did not, in which case, I picked one for them.

Even though I had a pre-prepared, written list of question probes and started an interview with a set of questions, I did "not necessarily follow the questions in any set order. This [was] because the answers that the interviewee provide[d] continually inform[e]d our evolving conversation" (R. D. Freeman, 1998, p. 90). Topics and information emerged as our conversation progressed, since "the participant's perspective on the phenomenon of interest ... unfold[ed] as the participant view[ed] it, not as the researcher view[ed] it" (Marshall \& Rossman, 1999, p. 108).

Considering the nature of the interview content, it was hard to predict accurately, before I actually started interviews, the number and length of the interviews it would take to obtain the necessary data. Goodson and Sikes' (2001) description of some studies suggests that this depends greatly on informants' willingness and the relationship between the researcher and the informant; however,

\footnotetext{
${ }^{14}$ Due to unforeseen and uncontrollable personal situations, I was not able to do member checking.
} 
as it turned out, in our case, these factors were not so relevant. As I mention later in the "Strength and Limitation of Interviews" section, my informants were all very willing to share their stories, which I took as an indication of our trusting relationship. The number and length of interviews varied from teacher to teacher because some had a lot to say and some were very concise and to the point even about the same questions: for instance, when asked if they had any cultural immersion experience, one teacher simply said, "No," whereas another needed quite some time to talk about the experiences.

In this initial "round," I had 14 interviews. The number of interviews for individual teachers ranged from three to seven. The length of an interview ranged from about 45 minutes to 1 hour and 40 minutes.

Since interviews for my study could be intensely personal and emotional I made it a priority to construct trusting relationships with the teachers. We were able to do this relatively easily, even though it was not at a very intimate level: two of the teachers were accidentally my former students, from the class I had taught the previous fall, and we already had a foundation to build upon; another one ended up calling me "my counselor" after our first interview; and the fourth would have invited me home for interviews during the break, if there had not been the distraction of children. I also continued assessing, during interviews, their emotional state and willingness to continue engaging in our conversation in order to keep the level of intensity appropriate and to be responsive to their needs. 
Several times in every interview, I asked the interviewee whether or not she or he wanted to continue.

One procedural challenge was scheduling. Given the commitment and workload the teachers had, canceling and rescheduling were not rare events. The fact that all teachers worked in the same district made scheduling even more difficult in that all elementary schools had the exact same district-wide event schedule, including such things as the deadline for report cards and conferences.

All interviews were tape-recorded and as I was collecting data, I was also having the data transcribed and reading and analyzing the transcribed data during the same period of time. I felt the need for clarification about some of the things the teachers talked about in interviews, and asked for follow-up interviews. Since it was already toward the end of the school year and the teachers were extremely busy, I could only have one follow-up interview with one of the teachers before summer vacation began. In fall 2006, I again started scheduling interviews after things settled down in the new school year.

In the follow-up interviews, I was able to ask questions for elaboration and clarification that had occurred to me while I was reading the transcriptions. The interviews also allowed me to concentrate on areas that I wanted to explore more extensively and to probe more deeply into what the teachers' life experiences meant in terms of the formation of their value systems and how this was relevant to the education of culturally and linguistically diverse students. I had eight interviews in 
this round, their lengths varying from 50 minutes to 1 hour and 15 minutes, and they were all transcribed verbatim as the previous interviews had been. In total over the course of the study, I had 22 interviews.

\section{Strength and Limitation of Interviews}

By utilizing interviews, I was able to obtain participants' historical information, which is vital data for my study. It also "allowed 'control' over the line of questioning" (Creswell, 2003, p. 187) and was effective for gathering a large amount of data in a short time.

However, a limitation of interviews is that the researcher is dependent on the informants. As Marshall and Rossman (1999) maintain, some informants may not be comfortable revealing personal information; it may be possible that "interviewees may have good reason not to be truthful" (p. 110). Nonetheless, I was able to reduce interviewees' anxiety by offering privacy to them: I made every attempt to assure anonymity, confidentiality and changing of names to protect their identity. I also informed them that collected information would "not be shared with other participants or individuals outside of the project" (Creswell, 2002, p. 188). These measures were all explained to them beforehand. I also selected a nonthreatening location to create as comfortable an environment as possible, as already mentioned. Aside from these research protocols, the participants were all so open and forthcoming from the beginning, I did not perceive they were holding back. All participants expressed, in different ways, appreciation for having the opportunity to 
engage in these conversations; all were thankful for having the rare chance to reflect on and talk about things they had almost never thought or talked about. Some comments that indicated this were: "I have never thought about my dad in this way," "It was really good for me to think through the things I rarely think about," "Why have I never thought about it?" and "You really got me to work hard." One teacher showed appreciation by saying, "More people [researchers and teachers as participants] should do this kind of thing. Then they will know the importance of this kind of work." An unexpected remark came from another teacher with heartfelt thanks to me: "You pushed them [long held and deeply buried emotions] out. You really did. It has really brought many things ... to light. It was like [your saying to me], 'You bury those things for a reason; may I help you?"' These comments indicated the quality of the in-depth interviews; they truly prompted teachers' reflections on their lives and shed light on the meanings of their past experiences. Interviewees' views may "filter" the information and some may not be as articulate and perceptive as others (Creswell, 2003, p. 187); I attempted to resolve this issue by trying to maximize my skills at listening, personal interaction, framing questions, and prompting elaboration. Recording interviews also helped solve multiple problems. Follow-up interviews also turned out to be very valuable as well, as has already been mentioned. 
Data Analysis

I employed the constant comparison method (Creswell, 2002) of concurrent data collection and analysis. Even though the proposed study is not a grounded theory study (see Strauss \& Corbin, 1998), I found this method to be useful. Goetz and LeCompte (1981) state that constant comparison "combines inductive category coding with a simultaneous comparison of all social incidents observed" (p. 58). I analyzed collected data by using inductive methods that are suggested by Creswell (2003) and that include six steps for analysis:

1. Prepare the data for analysis including transcribing interviews, typing up field notes and arranging the data into different types according to the data source.

2. Read through the data in order to grasp their general sense and reflect on them. Start recording general thoughts or write notes in margins.

3. Divide the data into smaller parts that contain "chunks" of meaning (topics). Label these chunks/topics with codes.

4. Group codes to generate a small number of themes/categories (5-7). These themes are major findings in the study.

5. Construct a narrative description from the coding and the themes to convey the findings of analysis. Develop further analysis, going beyond mere "description and theme identification and into complex theme connections" (p. 194). 
6. Make an interpretation of the meaning of the data. The main idea in doing this is to describe the lessons learned.

For a simultaneous comparison of data, I followed Creswell's (2002) suggestion, and:

1. Conducted the first couple of interviews and analyzed the data collected.

2. Sorted it into categories.

3. Developed tentative conclusions.

4. Collected and analyzed data from additional interviews and compared it with the categories and initial conclusions that emerged from the first set of data.

5. Reassessed and sought new themes.

6. Repeated the process.

This method contributed to comparing and contrasting themes in order to see similarities among and distinctive characteristics of teachers' experiences, and to seeking new themes and categories. It was also helpful in deciding what was important to include in the final account of the large picture of teachers' life experiences, beliefs they developed through these experiences, and their practices. McMillan and Schumacher (1997) write that, in order to organize data, researchers can use preliminary classification ideas such as: themes or categories found in the literature; the research questions and foreshadowed problems; the interview guide; and prior knowledge of the researcher. However, the authors 
continue, preliminary categories are only tentative and they must be refined. Other categories should emerge as more information is collected and the researcher's analysis and reflections on the data progress. As new understandings emerge, category changing will become necessary. As I analyzed the data, I continually altered and adjusted categories until I subjectively determined that they completely explained all the information I had.

Marshall and Rossman (1999) cite Schatzman and Strauss: "Probably the most fundamental operation in the analysis of qualitative data is that of discovering significant classes of things, persons, and events and the properties which characterize them" (p. 152). In conjunction with using preliminary and changing categories, I kept asking questions, for the purpose of coding, as data were added, “clean[ed] up" (Marshall and Rossman, 1999, p. 153), and refined:

- What is this about?

- What were these people doing?

- What were these people talking about?

- What was important in this setting at this time? (McMillan \& Schumacher, 1997, p. 510)

As described in Creswell (2002) and McMillan and Schumacher (1997), inductive analysis is "the process [of] both simultaneous and iterative phases" (Creswell, 2002, p. 257). Although the general process of analysis starts from the particulars and detailed data, then advances to the production of a synthesized larger descriptive picture, still, "as the researcher moves to more abstract levels of data analysis, she or he is constantly returning to the prior level of abstraction, 
always double-checking and refining her or his own analysis and interpretation" (McMillan \& Schumacher, 1997, p. 502).

\section{Writing}

A qualitative study report has a flexible form (Creswell, 2002). Glatthorn (1998) states that, although there is a widely used structure for a dissertation, "techniques of organization have no intrinsic value; they operate only to facilitate communication - to help you achieve your goal of informing the reader. Obviously, the particular organizational strategy you choose will be affected by such considerations as the nature of your study ...” (p. 123). Adopting the structural suggestions of Creswell (2002) and Glatthorn, I developed an outline of the study. Following the introduction, the literature review and the procedure, in the next chapter, I will present my findings and understandings in the following fashion:

1. For each participant, in turn:

a. Specific descriptions of the participant.

b. Specific incidents that may have shaped her/his frame of reference.

c. Interpretation of the meaning of the incidents.

2. A narrative that presents a larger understanding connecting the interpretations (1c) for all participants.

Specific incidents for each individual (1b) will be described in chronological order, when it is possible. Descriptions (1a through 1c) will be presented for each 
participant before I proceed to (2). Also, as a scholarly paper, interpretations must be accompanied by enough evidence that supports the interpretations.

McMillan and Schumacher (1997) argue that "the result of the analysis is some type of higher-level synthesis. While much of the analysis consists of analyzing smaller parts of the data, the final goal is the emergence of a larger, comprehensive picture" (p. 505). The final report will display such a comprehensive picture as a holistic entity employing a "thick description [as] the vehicle for communicating a holistic picture of the experiences" (Creswell, 2003, p. 205) of participating teachers.

\section{Soundness of the Study}

Creswell (2003) claims that "reliability and generalizability play a minor role in qualitative inquiry" (p. 195). Marshall and Rossman (1999) articulate more clearly that the "concept of replication is itself problematic" (p. 194) for qualitative research. They assert that reliability, in a traditional sense, presumes that an inquiry could be replicated because of unchanging conditions and that "this assumption of an unchanging social world is in direct contrast to the qualitative/interpretive assumption that the social world is always being constructed ..." (p. 194).

As has been noted, transferability, or generalizability in the traditional sense, is not the purpose of qualitative studies. ${ }^{15}$ Donmoyer (1990) maintains that the concept of generalizability should be extended to the learning that may happen to

\footnotetext{
${ }^{15}$ See page 11.
} 
readers of the study. One example of such learning is knowing what other teachers do in struggle-filled situations in the classroom. In the same vein, qualitative studies may serve as a trigger for self-reflection. Muchmore (2002) advances this idea about "generalizability" in his life-history study of one teacher:

Narrative accounts of teachers' lives and careers can also serve as tools for self-reflection. Anna's story provides readers with a tool for reflecting upon their own beliefs and practices. By actively weighing Anna's experiences against their own evolving life stories, readers may gain deeper insights into the underlying beliefs, assumptions, and experiences that shape their own teaching and research practices. Engaging in this kind of self-reflection has been shown to be an essential part of teachers' professional growth and development. (Learning from Anna’s Story section, \2)

As opposed to reliability and generalizability, Creswell (2003) states that validity is one of the strengths of qualitative inquiry. However, according to him, validity of qualitative research does not have the same denotation as it does in quantitative studies. He states: "it is used to suggest determining whether the findings are accurate from the standpoint of the researcher, the participant, or the readers of an account" (pp. 195-196). In this sense, terms such as "trustworthiness" or "authenticity" represent the idea of validity more appropriately in qualitative research. Creswell suggests eight primary strategies to check the accuracy of findings. Relying on his recommendation for using one or more of these strategies, I used the following:

- Use rich, thick description to convey the findings. This may transport readers to the setting and give the discussion an element of shared experiences. 
- Clarify the bias the researcher brings to the study. This self-reflection creates an open and honest narrative that will resonate well with readers.

- Also present negative or discrepant information that runs counter to the themes. Because real life is composed of different perspectives that do not always coalesce, discussing contrary information adds to the credibility of an account. (p. 196)

I actively looked for and analyzed negative instances that ran counter to the emerging themes and patterns. The researcher's self-reflection will be clarified in the next section.

\section{The Researcher's Role}

Since the researcher is the primary tool in a qualitative study (R. D. Freeman, 1998; Marshall \& Rossman, 1999), it is essential for me to articulate my personal values, assumptions and biases at the outset of the study. Due to my experiences as a second language learner myself, and the mother of three ELL students who went to American public schools with little or no knowledge of the English language and American culture, I brought certain biases into this study. However, the study is a result of reflections on those experiences; they have been the force driving my doctoral study. In other words, without my beliefs and biases, shaped by my personal experiences, this study would not have been undertaken. Although I made every effort to proceed with careful awareness of my perspectives, it is possible that collection of data and the way I viewed and interpreted them may have been shaped by my personal experiences and biases. Therefore, "rather than seeking to pretend that any aspect of research can ever be bias free" (Goodson \& 
Sikes, 2001, p. 25) I acknowledge my bias. I believe, nonetheless, that my longtime experience as a teacher of diverse students in diverse settings, ${ }^{16}$ along with my awareness of cultural diversity, enhances my sensitivity to and understanding of challenges and issues that the participating teachers' confront in the classroom.

It is my hope that my research has enabled me to have a deeper understanding of ELLs' real educational situation. I should also keep in mind that the study may be beneficial to the ELLs and their teachers. That is, it is my aspiration to reveal what ELLs need in their education. As a result of my study, I desire to promote understanding about the education of language minority students. Finally, I desire to elevate society's awareness about the importance of making education for these students meaningful. For this purpose, in the big picture, I hope to create a connection between the researcher, the participants, and the reader of my study to "link the vastly different worlds of [the researcher] and [the] readers and those who are written about in a compassionate drama of empathy, understanding, mutuality, caring, responsiveness and sometimes, outrage" (Lincoln, 1996, p. 23).

\section{Ethical Considerations}

Creswell (2003) argues that "first and foremost, the researcher has an obligation to respect the rights, needs, values, and desires of the informant(s)" (p. 201). My study required me to "enter into the lives of the participants" (Marshall \& Rossman 1999, p. 79) and stay in their lives for some time. Our

\footnotetext{
${ }^{16}$ Since I left Japan, I have taught diverse students in diverse situations in different countries.
} 
relationship was personal and therefore had to be highly trusting. Personal relationship was fundamental and critical to my study, for the study required disclosure of the participants' personal experiences and life histories. This characteristic could have caused the most frequent ethical dilemma (Goodson \& Sikes, 2001); i.e., when "research intrudes into the private sphere of some deeply personal experience" (p. 96). Ultimately, consideration of the participants' privacy must be one of the priorities in a qualitative study: it must be participants' decision whether or not to tell a story about a deeply personal issue (Goodson \& Sikes, 2001). No matter how much the researcher believes the issue to be relevant to the research purpose, "it is wholly unethical to pursue a topic when an informant does not wish to talk about it" (p. 98). Fortunately, my participants were all very forthcoming; even when our conversations became intensely personal, my participants were incredibly generous in sharing their experiences and their honest feelings about them with me, as was made clear in their comments cited previously.

Another ethical dimension that concerns the qualitative researcher is accuracy: I must be accurate in presenting participants' stories. It is particularly important to do so when participants' perspectives are in conflict with my own; this requires that I not be judgmental, based on my own values and beliefs.

These ethical considerations represent some of the seven safeguards that Creswell (2003) proposes for researchers. I also closely followed five other Creswell safeguards to protect my study participants. These are: (a) articulating the 
research objectives verbally and in writing so that they were clearly understood by the informant; (b) receiving written permission to proceed with the study (informed consent); (c) filing a research exemption form with the institutional Review Board $;^{17}$ (d) informing the participants of all data collection devices and activities; and (e) considering the informant's rights, interests and wishes first when choices were made regarding reporting the data.

Creswell (2003) also suggests that the final decision regarding participants' anonymity should rest with them. Although I assured the participants that I would use pseudonyms to keep their identities private, some even said that using their real names would not be a problem, an offer I declined. However, I confirmed to the participants that any information that was obtained in connection with them, could be linked to them, or could otherwise identify them would be kept confidential. I made my awareness of the importance of this evident to them. I always conveyed my sense of gratefulness to them for sharing with me the essential and vulnerable parts of their very existence.

One other safeguard of Creswell's (2003) that I intended to follow, but was unable to, due to unanticipated and uncontrollable circumstances, was making transcripts and written interpretations available to the participants for verification. However, I promised and plan to give them copies of my dissertation.

\footnotetext{
${ }^{17}$ Human Subject Research Review Committee.
} 


\section{CHAPTER IV}

\section{DATA ANALYSIS}

\section{Introduction}

Henry Adams said that "a teacher affects eternity" (Shribman, 2001). Cummins (2001) strongly agreed: "Many of us can vividly remember inspiring teachers who, because they believed in us, generated far greater academic effort on our part than did teachers who just taught their subject" (p. 2; see also Rosenthal \& Jacobson, 1968).

Some who participated in my study said their influence on students' lives will not be measurable because it will only become visible after students have left their classrooms. The research reported here embodies their comments and the observations of Adams (cited in Shribman, 2001) and Cummins (2001). A related story, which inspired the work along the way, does also, and vividly. I met a woman by chance, at a conference, during the time when I was doing interviews with my study participants. Hers was an every-day-story, not in a book by a prominent scholar or a famous teacher. As we discussed our lives and careers, she mentioned a teacher of hers. "Without that teacher, I wouldn't have made it," she said. ${ }^{18}$ During our short stroll on the university campus, I found out she did not speak fluent Korean, her native language, even though she had some understanding

\footnotetext{
${ }^{18}$ I did not know I would encounter a story like hers in a place that has no relevance to my dissertation research. I am grateful for her letting me use her story in this section.
} 
of it. Later that evening, I discovered that she came to the United States when she was 10 years old. She described how devastating it was not to have understood a word spoken in the classroom. And then she told me how deeply indebted she felt to her first teacher in America, Mrs. A, for being who she is today, a scholar with a Ph.D. in Education and a medical school administrator. She wrote a letter to Mrs. A when she received her master's degree. Mrs. A sent back a letter, and with it a class picture and a poem that her Korean student - this woman - had written when she was in Mrs. A's class 37 years before.

Although my new friend did not detail exactly what Mrs. A did to help her, the story tells that in those "sink or swim" days, Mrs. A reached out to her "lost" Korean student in some way that ultimately led to her educational and life success.

Her story was also personal to me, because it made me think about my daughter, who was placed in an American elementary school classroom at a similar age, and who perhaps had gone through comparable experiences as a child with no English. However, my daughter's experience was the opposite, which brought a lesson home in a jarring way.

My daughter had a teacher who said to me, in no particular context, "Let me tell you, your daughter is just ordinary, nothing special." I was confused and did not understand her intention. I felt her statement was pitiable, reflecting some lack on her part as a teacher and person. I could not help thinking about my daughter's misfortune to have been taught by someone who did not believe in her. 
I never told my daughter what her teacher said, but I can't imagine that the lack of belief did not manifest in their relationship. I still sometimes have to wonder, especially after I have learned about the education of culturally and linguistically diverse students, how my daughter's classroom experience might have been different, as an ELL student herself, if she had had a teacher like Mrs. A.

In this chapter, I am going to tell stories of present-day Mrs. A's, teachers who are trying to do the best they can to help culturally and linguistically diverse students be successful in school and in their later lives. The narratives of the teachers' lives will show the different places where they started as children and the similar places they arrived as adults who care for their ELL students' education and well-being. In between, the narratives will show something about the routes that these four distinctively different individuals took to become teachers whose colleagues believe them to be particularly effective teachers of culturally and linguistically diverse students.

This chapter illustrates life events of four teachers, Dian, Terry, Sabrina, and Annette, ${ }^{19}$ and the events' possible meanings in formation of the teachers' worldviews. It consists of two sections. In the first section, I introduce each teacher's profile, life history and critical life incidents, which I gathered from what they told me. In the second section I discuss the study's findings, in the way I understand them, which came to light through reading the data repeatedly,

\footnotetext{
${ }^{19}$ All names are pseudonyms.
} 
developing codes, and comparing and contrasting the life stories and events. I attempted to capture similarities among the participants' life events as well as their meanings, in an effort to reach an understanding that connects themes into a broader conceptual framework.

Relying on Creswell's (2002) claim that "description needs to be detailed so that the reader is transported to a research site or can visualize a person" (p. 269), I first introduce each teacher by portraying his or her profile. I depict what I observed in our meetings, mostly from my first few meetings with each teacher. I introduce life history: family backgrounds, childhoods, and salient life events that punctuated the teachers' lives. The main purpose of these descriptions is to give readers pictures of the teachers so that they can "see" the teachers as though they are in front of them. Next I portray specific critical incidents in each teacher's life in an attempt to identify the elements that apparently had a strong impact on shaping their frame of reference. Most of the life events that were identified in the teachers' profiles and life histories are further explored in this section. Since my desire is to discuss the teachers as thoroughly as possible, there may be some redundancies in descriptions, but $I$ intend this to serve the purpose of reminding readers who the teachers are and giving a clearer idea about meanings that the teachers bestow on their own experiences. In describing the teachers' profiles and life histories, I try just to present information, whereas with critical incidents, I begin to be more analytical, trying to interpret meanings of the incidents. 
Finally, in the "Findings" section, I discuss my understanding of the themes that I found to be shared among all four teachers' experiences, and the characteristics the teachers share in their approaches to teaching. This discussion considers the ways their experiences are reflected in their relationships with students and incorporated into the way they teach. Discussing the teachers' classroom practice, I will refer back to literature that I reviewed in chapter 2 as well as new literature that I explored after I began my study. I will compare teachers' stories with existing studies in an effort to bring all the stories together into one larger, cohesive picture of the reasons why these teachers are called quality teachers of culturally and linguistically diverse students.

The Teachers

\section{Dian}

I arrived at Dian's school a little earlier than the appointment time. A woman in the office called Dian and told me that if I waited right outside of the office, she would come out with her students. A few minutes later, I saw her coming. She smiled and waved at me from a distance. As she walked by me, she said that she would come back in a minute and walked outside with the kids.

As she walked toward the school buses, I got close to the window, and took advantage of this little window of time to watch her interacting with children and their parents. Outside it was sunny and clear, the sky was blue and the temperature was pleasant although it was only the beginning of February. Her outfit reflected 
the day: a short-sleeved grey t-shirt, short-sleeved blue cardigan with flower prints, and dark blue pants. A girl ran toward Dian and wrapped her arms around her as she bumped into her. They chatted a little while and the girl got onto the bus. After that, Dian talked to two mothers, one after the other, amid the cheerful "chaos," with students running around in the waiting area. Later when I asked her about the bus routine, she said, "Yeah, [I take the opportunity] to talk to kids that we taught and saw in the past and hope I can still remember their names."

When most of the children were gone, Dian came back into the building. We commented on the weather and she told me how she opened the back door of her classroom and how nice it was to feel the air. "But," she said, "of course I couldn't continue my lesson because kids found this spider that came from outside through the door and that was it!" She then talked to herself, "Oh yeah, I'm going to open that door again. It's such a nice day." Her tone was congenially upbeat, showing her positive attitude, which I had known about since she was in my own class.

When we reached her classroom, I instantly noticed that the paper snowflakes that were hanging down from the ceiling last time I was there were gone. Instead, there were red and pink paper hearts on the windows and springy colored paper birds, animals and butterflies on the walls. Hanging down from the ceiling were numerous "Mother Earths" (that's what she called them instead of just "globes"), painted blue and green—calming and peaceful small spheres that 
reminded me of the first moment when humans looked at the Earth from the moon. Clearly, art projects with seasonal themes were one of the things she enjoyed with her students.

When Dian was ready, having finished her left-over chores and I my quick notes on the classroom's physical setting, she invited me to sit at a little desk by the window that was opposite the classroom entrance. We lowered into tiny $3^{\text {rd }}$ graders' chairs. As I took my tape recorder from my backpack, she asked me if I needed a plug for recording, which I took as her permission to record our conversation. I said, "Technology is advanced, so I don't need any plugs." That remark made her laugh and made us relax.

\section{Life History}

Dian was born to a school teacher and a logger. Her father also worked on construction jobs a lot of times. Her mother liked reading, but her father did not. $\mathrm{He}$ was born in the Midwest and dropped out of school at a very young age because he was needed on his family's farm. She describes their difference as follows:

It was kind of strange; my mother who had education, my father [who] did not. And you can see as I was getting older that the interests kind of clashed because she was very happy reading a book and he thought she should be a little more traditional.

Because of her father's occupation, her family moved many times when she was small. They finally settled down on 40 acres of land in an adjacent state when she was 7 years old. She said, "The place was so remote and way out-way out in 
nowhere that we could not even get television reception." Because of the remoteness of her home and the absence of TV entertainment, in addition to her mother's influence, her childhood was spent on a lot of reading. Her father often went away from home because of his construction jobs. She and her mother and three sisters, especially when the father was away, would get together around an old kitchen stove, "the old farm kind of stove that you see pictures of," and the daughters helped their mother make teaching materials with paper, pens and scissors.

The environment with no TV contributed to another wonderful childhood memory:

We had the stove in the kitchen and when we would build a fire, we would all kind of huddle around. Sounds like pioneer days, but it really was very nice to sit around and listen to people talking .... My mother had a very vivid imagination and she would tell lots of stories, true and otherwise, and she would say things like, "Creatures from outer space could be looking in this window right now." And we wouldn't even be able to see them because it's dark outside and light inside. Then she would say, "Well, time for bed!"

When Dian was a teenager, the family moved back to the city where she was born. Growing up in a small logging community and going to an "all-white" school, it was "kind of a shock to have a big [italics added] class of kids," where there was more diversity. However, she "thrived at it ... [and] found that it was great." She was also happy because she was able to do all the things that teenagers wanted to do in the city. She lived in a working class neighborhood, where people knew all the neighbors and all the kids: "All of us went to berry picking and bean 
picking together so it was all kind of out [in the] street." Even with the great things that she experienced in her teenage years, looking back, she still recalls that the place she spent her childhood was a great place to have grown up.

She went to college on a scholarship, but came home after a year. Then she worked and took night classes at a big suburban university, where she met her husband. When they got married in the late $60 \mathrm{~s}$ she left school. She and her husband had six children and when she was working a night shift at a nursing home, she made an important decision: "I really decided that I would have to go back to school because [it was] not really what I want[ed]." Her youngest child was in kindergarten and she thought "it was time." She went back to a community college in the late 90 s and after 2 years, she transferred to a small four-year state university. After she graduated, she was unable to get a job and decided to go back to school again for a master's degree and reading endorsement. With a graduate degree and an endorsement she was still working as a substitute teacher for a while, until she finally got hired by her current school a couple of years before our conversations.

Dian is a Caucasian woman with short brown hair. She is lively with a quick laugh and facial expressions, and animated, pleasant gestures. She is always dressed casually and nicely and every time I saw her for an interview her attire amiably reflected the season and the weather of the day. She is in her late 50s and, as she would describe herself in an interview later, she is a "grandma." 
She thinks this "grandma-ness" works very well for her as well as for her 24 third grade students, who include five ELL students—one Russian- and four Spanish-speaking:

My granddaughter's in the third grade and is in my reading group. So they know that I'm the grandma and I say that to them. One little girl had an accident and wet her pants and I said, "You don't have to be embarrassed: I'm a grandma!" and she was like, "Uh, yeah." So that works to your advantage to say I'm a grandma. Moms get uptight about things like that, but grandmas don't. "Okay, that's okay ...."

Dian enjoys that her students see her as their "grandma type" person; she thinks it makes them see her "as a real person." She says: "A lot of my students feel close to me because of this and they still come back and visit, wave and say 'Hi."'

Being asked to describe herself as a person, she said that she would like to think of herself as caring, encouraging, outgoing, independent, and tenacious. The caring part of her personality seemed especially important to her:

I'd like to think that I am a caring person. I used to ... used to have a thing where, if I was feeling down or something, I think that I'm not doing enough for other people, so I challenged myself one year that every day I had to do something nice; every day, for somebody. And other women that are here [at the school] going ... "Dian, have you ever done anything just for yourself?" and I'm like "No ...."

Religion is also important to Dian. She joined a church of a religion different from her family's when she was 14 . Religion plays a big part in her life and many of her friends are from the church. She says that church had a big impact on her and it plays a part in who she is. However, she says that the members of the 
church are "very conservative people" and that she does not agree with them about many things. She jokingly states:

... like same-sex marriage, I'm like, "Hey, they can have a right to be just as miserable as we are." So I don't think a lot of things along the same lines and I don't feel any pressure to do that.

Dian is also a very critical-minded person: reflective, deep thinking, able to look at things from different angles. During our conversation, she often asked herself questions such as "Would I have been the same if I hadn't gone back to school?" which indicates that she is very inquisitive and has a tendency to probe her own thinking.

\section{Dian's Critical Incidents}

Family. Dian grew up seeing her mother spend a great deal of time and energy at home preparing either for teaching or for special school events. She also remembers that her mother came home from school exhausted all the time, but Dian could tell that her mother really loved her students. Her mother would tell funny stories about her students and what they would do in school. She thinks that her mother influenced her in deciding what she wanted to do. She states: "I am sure I went into teaching because my mother was a teacher." Her respect for her mother as a teacher is present in the following comments:

I was close to my mother ... so I probably got a lot of my ideas from her .... There were many things I admired in her, so I did try to follow what she did: she was very patient ... she had more of a - because she was from New York City - I think she had more awareness of things that was going on and she was sensitive to need of people. 
Even though teaching has changed since Dian's mother was a teacher, she is still a mentor to Dian, and still has a lot of ideas about how to reach a child. They often have conversations about teaching and her mother asks her questions such as "How is that idea going?" or "Have you tried this?"

Dian's mother nurtured love of reading in her. She would read books with her children and ask them questions about the books. Dian recalls how fun it was to talk to her mother about the books that she read in her high school literature class:

[This class] was wonderful because we got to read those racy Chaucer tales, not just the one in the book, [but] [the teacher] photocopied [other tales] and brought those in .... And it was so fun to talk to my mom about them. I think I probably did it a little more because she liked it and it would give us something to talk about. And we did; a lot. I remember her giving me Catcher in the Rye, and she wanted me to read it so we could talk about it.

One incident that shocked her happened at the dinner table when she was in high school. Dian's father said that he spit at a mixed-race couple. He said, "Well, you don't see cows and pigs marrying." Dian confronted him:

I can remember, and I got in a whole lot of trouble for this so I remember it very clearly. He said it was a black man and a white woman on the street and he said he was going to spit at them. I remember that ... spit at them? And he said, "Well you don't see cows and horses ...." I said, "Oh yeah, but you see black cows and brown cows ...." To me, "What are you talking about?" and he was so mad. He was so [italics added] angry. [He] slammed his hand down at the dinner table, went out the door and slammed the door after that, you know, but his logic was faulty in my book, that he would ... but just the fact that he would spit at somebody was just ... you know ... I just didn't like the way he was saying it. 
She thinks that a person's environment contributes to developing such attitudes: she points out the fact that when she was growing up, the family lived in a small logging community where they did not have any friends who were different from them and the children went to all-white schools. She also believes that education and fear can play a role in shaping a person's way of thinking:

... My father had a great deal of ... and I look at that lack of education and also when he was competing - then he was working for construction-I think he was competing for jobs, and I think lots of prejudice comes from fear; and I think he was afraid of losing his job to someone ....

Even with this reasoning, however, the outcome of the event was crucial to her development:

I made a conscious decision back in the Kennedy time that I'm not going to be like my dad. I think I honestly said that I don't like it. I think it's mean and I think it's cruel and I'm not going to be like him. And I don't know if it's just a rejection of my dad; I hope it wasn't that, but I just wanted to be smarter than that.

The fact that Dian was becoming a young adult in the midst of the Kennedy era may have some bearing on her way of thinking, manifested in the above quote. The impact of the time was conspicuous.

High school. Going to high school during the Kennedy years afforded Dian many encounters that influenced her in various ways. Among all of these, the most 
powerful encounter was the one with Tom Dooley, ${ }^{20}$ who "was a doctor in Laos

[and her] hero." Coming across his life story made her decide, when she was a

senior, that she would become a nurse "to save the world." The profession, she did

not pursue after all, but his spirit she clearly embraced.

Stumbling on the short version of Dooley's book in her grandmother's

Reader's Digest led Dian to search for his books. Reading three of them, she was

extremely influenced by his way of life:

In high school, what influenced me probably the most was Thomas Dooley. He was a doctor in Laos and that shaped me, just because he really talked

${ }^{20}$ Tom Dooley enlisted in the U.S. Navy as a Medical Corpsman in 1944 while he was still doing his undergraduate work at Notre Dame. After he received his D. M. from St. Louis University in 1953, he became a medical intern as a lieutenant in the Navy. In 1954, he was involved in the evacuation of more than 600,000 North Vietnamese as a French interpreter and medical officer for a Preventive Medicine Unit in Haiphong. Dooley ended up overseeing the building and maintenance of refugee camps until May 1955, tending thousands of North Vietnamese fleeing for the south, when the Viet Minh took over the city. He returned to the U.S. later that year and wrote his first book, a best seller, a Vietnam memoir entitled Deliver Us from Evil, a condensed version of which was also published in Reader's Digest.

In 1956, Dooley, with three other former Navy corpsmen, established St. Patrick's hospital with support from the International Rescue Committee and the royalties from his best seller. They founded the hospital at Nam Tha, a village in Laos five miles south of the Chinese border. Dooley said he chose Laos because there was only one doctor for 3,000,000 people. The hospital did not have crucial things such as electricity, $x$-ray equipment and plumbing; under these conditions, Dooley treated about one hundred patients a day. During this period, he also trained Laotians in medicine.

In 1957, after handing over St. Patrick's hospital to the Laotian government, Dooley started the Medical International Cooperation Organization (MEDICO) to assemble stocks and supplies, and train staff for hospitals. He convinced American pharmaceutical companies to donate thousand of dollars in medicine and supplies. In the following year, he created his second hospital in Laos, again near the Chinese border. Despite developing melanoma and undergoing surgery in August, 1959 , he raised one million dollars for MEDICO by returning to the lecture circuit in October of that year.

Dooley died in January 1961 at the age of 34. His cancer had already spread to his lungs, liver, spleen, heart and brain. He was awarded the Navy's Legion of Merit as the youngest U.S. Navy Medical Corps officer in history. Congress honored him with a posthumous medal. He made the Gallup's list of the 10 most admired men in America. He was also honored by the South Vietnamese government with the highest national decoration that it can confer to a foreigner. 
about a life of ... he would've preferred a life ... he was a doctor, so he could've had a life in America with ease, you know, but he often quoted the Robert Frost poem ... "the woods are lovely dark and deep, but I have promises to keep and miles to go before I sleep." I was really influenced by that in thinking "if this was a person who chose, because he saw the need, and he gave up [an easier life in America] ...." That really influenced me that you would sacrifice something good for something better, that he was doing that for the people, and talking about how the war was affecting villages. I mean, how the big thing affected really the small, the unimportant really, this little village, I mean, what could you really do in the scope of things, but that it made a differences to the people who lived there [although] maybe it didn't make any difference to anything except for the people there .... The story of the little boy: [he] comes across all of these starfish that had washed up from the storm and he starts throwing them in. And somebody comes by and [says], "There are thousands of them here. Why are you ... you can't do anything!" and he says, "Well, it makes a difference to the ones I'm [throwing back to the ocean]." That kind of stuff really affects me, and I think it did when I was in high school, in the Vietnam era, [when I did] a lot thinking about what you can do.

Dian also spoke of the book Catcher in the Rye, which her mother

recommended to her to read when she was in high school. She briefly explained to me, since I had not grown up in the U.S. and had not had a chance to read the book, that it was about a teenage boy who was quite disenchanted with the world and wondered if there was a purpose to life. At the end, there is nothing solved, but "he decides that, in essence, he would not do anything huge, but he is going to be the person that catches children before they fall off the cliff." Dian found the book's theme, in her interpretation, parallel to the philosophy that she found in Dooley's deeds: "I can only influence a very small puddle, but I can do what I can do." One of her history classes also contributed to cultivating her mind. Dian was involved in the school newspaper and those were the days when articles in the 
newspaper were screened by the principal before publication. The teacher of her class, without indication of his political ideology, provided his students with opportunities to discuss controversial issues. She recalls some of her teachers, including the history teacher and the journalism teacher, as follows:

Those were the times of Vietnam to start thinking about things and wondering about our country and they posed a lot of questions that I still think about. So I know that they influenced, if nothing else, for me to start thinking about things and how you think.

Her high school days, the time of the controversial war and social movements, played a crucial role in her personal growth by prompting her to think in intellectual terms about what she had been feeling at the emotional level and cultivated her sociopolitical consciousness—even though she denies that tendency of hers - which manifested many times in our conversation.

Teachers. Throughout grade school, she had a lot of great teachers: one that "pulled strings" so she could get into a different math class; one that took extra time to give her a different project; and one that made memorable comments on her journal-teachers "that went above and beyond to do things to encourage me":

I always had teachers that were very, reaching-reaching out ... encouraging. A math teacher, he went on to become someone at a different high school, and I saw him years later in a furniture store or something, and I was so impressed 'cause he remembered my name. I have a hard time doing that and I was so impressed and he was like, "Oh, I still remember you!" which made me feel really good. In high school, there were just a lot of ... I had some really good teachers, some really fun things that did a lot of ... I got to be in some honors classes and then they were real small so the teachers took some real personal interests in projects. And I remember in one year, my senior year we had to keep a diary like Samuel Peets did, and I 
remember the teacher had such wonderful little comments in it. I still have it because I just thought they were so sweet to put things in there-like I was worried about how I looked and he wrote in this whole little thing about, you know, beauty and stuff in there. It was such a nice thing to do for a .... You know, when you're a teenager and ... and you know, I certainly was not into any make-up things or any of that stuff so ....

Those teachers played a critical role in her teenage years in that they gave her confidence. As for everybody, for Dian teenage years were difficult times. She started to wonder if she was focused enough to realize her dreams: "They helped me to think that I was capable."

Dian also talked about teachers who had great influence on her as a teacher, and whose practice served as a model for her teaching:

One of them was a senior English teacher. He influenced me a lot, just in my writing. We would write a lot and he would put lots of comments on it. So I know he influenced me about how I write and what kind of things to write. And I tried to make those kinds of comments on my kids' papers: more than just "'Oh, good job," but "Well what did you think about this part?" or "Why did you think this person did that?" So I know that was a strong influence on me. I had another teacher that ... I thought her class was boring and so she gave me a special assignment to do and - uh, I knew I had to do a recitation of a poem and I still remember that-she saw that I was not involved, and you know, to take the time not only to find the project for me, but to carve a little spot, probably on her break somewhere to work with me, I'm thinking, she had to-knowing now-she had to give up her prep time or something to do that. And knowing how valuable time is, I think, you know, somebody, somebody made some extra effort. Now I keep thinking, when I see a child not involved, I think of that teacher, because of that teacher, I think of ways, you know "How can I get this child pulled into this either by something I know they like or just by giving them a special assignment to do?"

Dian said, "I grew up seeing how much time my mom was doing [the same] at home." Now she follows what her mother did, at home, for her own students in 
the classroom. She described her family's fond "criticism" - that she sacrifices her time for her students. But she seems to enjoy doing so just like she enjoys "sacrifice" for her own children: "It's just kind of an extension almost of the things I like to do with my kids at home; you know, let's have a tea party, or ...."

Dian still retains innocent and ingenuous views of the excitement of childhood. Even though she partially ascribes this attitude to the fact that she has not yet burned out in teaching, her use of her fun-loving nature, including planning fun activities as a teacher, is indisputable. She is able to recall how little, simple things can bring happiness to children:

I love planning all the little valentine things, I just think it's ... I don't know! All those fun little things! I like to do it; it's rewarding. It's just fun. Just fun. I mean, not every ... not every minute is fun, you know? But for the most part, probably, I think $80 \%$ of it is still .... Of course, I'm new; I don't feel like I have been beaten down by anything, you know; it's only my second year, and still it's like fresh and new, but I like talking to the adults about what we're doing and planning with our other third grade teachers about what we should do, and it's just [fun]. I don't know .... This teacher came in today, and she said, "Wouldn't it be fun to do bubbles out side?" And I was like, "Oh my god! We're having bubbles!" So, you know, throw that out; we're gonna do bubbles, you know, so ... "Ooh! Oh! Yeah."

Teacher education/training. "When my kids go to school, I'm going back to school." This is what Dian thought for a long time. When her youngest child went to kindergarten, Dian, then in her 50s, did go back to college, after more than 30 years away. She was fine at a community college, where she went first, but at a small state college in a rural community, to which she transferred, she found herself "scared": 
I was really scared "cause I ... I was thinking, "Oh my gosh," and I still remember taking this class ... uh, and going in and the teacher, you know, gives you ... and they give you all the stuff you're gonna do in the class. And I remember crying all the way home and saying, "I don't think I can do this!" I mean, we had to do a website, and we had to teach science to a class somewhere and videotape it and put it on ... and I was like "God, I can't do it; I can't do it ... Why am I doing this?" And my friends were all saying, "Oh, we're going to [do this and that] ...." And I'm like, "Am I doing this?" And it was a lot. I [also] had to drive an hour each way, you know, it was a long commute ....

Dian did not mention whether she was scared because she found herself among traditional, straight-out-of-high school students who were used to dealing with classroom projects, while she was returning to academic rigor after so many years; or because she had other responsibilities and commitments that could intervene with her academic responsibilities; or from a combination of both. It is possible that, finding herself inept in a foreign environment, where she couldn't relate to anybody or anything around her, was intimidating. With the more-than-30year space between, going back to undergraduate study could have made her feel isolated and helpless- she might have been made to feel that she was an "other."

One time when she was talking about how she thought the American educational system was not fair to everybody, Dian said, "When I was young, I did think [that the playground was flat], I honestly did. I did believe in the American Dream; I did. Anybody could be anything if you worked hard enough; you could do it." Being asked what changed her mind, she spoke about one of the classes she took after she transferred to the state college. It was a class in Diversity that she 
took just by coincidence, which she lists as one of the earlier incidents that contributed to raising her social awareness. She remembered how she initially felt offended in the class, as many people do when they first encounter multicultural issues that they have not thought about:

I went down to [the state college], and I registered late and so there were very few classes; and then I took a class on um ... Diversity, and I remember being irritated in the class, because I'm like, "Oh I always have to feel like I have to apologize for being white, and this is what [we]'re doing and it's so awful." And so I'd sit in this class, and I was kind of irritated a lot, because you know, it was always, "Oh, this is what you're doing, this is what you're doing" so I'm kind of like "Okay, this is what we're doing, this is what we're doing. Fine, okay, fine!'

However, the class gave her an opportunity to examine her beliefs. She went on to talking about her memory:

But then, I lived in a very white little town, and I remember um ... I remember seeing a black person in the store, and I remember thinking, "Oh I wonder if they're ... if they live here, if they're moving here, or if they're just visiting." And I remember watching out of the corner of my eye, I watched a clerk [and] watched that person. And I realized what they were talking [in the class] about how White people have ... and it just kind of clicked that very same thing that the speaker [italics added] had been talking about, you know, out of the corner of my eye, saying, "Oh my gosh! You're watching that person just 'cause they're Black".... So I still remember sittin' there [in the class], thinking, you know, "Yeah, it's my fault, everything's my fault." But the more you sat there you just kinda go .... And then you did ... you look around and it's true, those things are true. It's true .... We do .... That poor person, you know, oh he knew he was being stared at at that store watching what he was doing, for the simple fact that he was Black. There was no other reason for that person [store clerk] to stare at him .... 
The "speaker" in the above quotation was Jonathan Kozol, ${ }^{21}$ who came to present at her university, coincidentally, when she was in the Diversity class. His talk gave her an unexpected, memorable moment in her life. When first asked, in our earlier interview, about times that made her think about equity and fairness, she did not recall this incident, but in the following interview, she indicated it was clearly an important event in her life by saying, "I'm surprised I had forgotten this [incident]":

So the first year I was down at [the state college], they had Jonathan Kozol come down to speak! And I had no idea who he was; now I would be really excited to go, but they were giving like, you know, "[If] you go and do a little paper [on Kozol's lecture], you don't have to do some other assignment." So I thought, "Well I'll go hear him speak." And I read one of ... I think I read "Savage Inequities" before [the class], or I read it after ... or one of those, but I really started to be ... uh ... a little more involved in looking at education and fairness of education.

Dian went on to reflect on the combined effect of Kozol's talk and the

Diversity class, especially one of the projects she did in the class-writing a paper on "My Philosophy of Education":

So I really think that ... taking that class on Diversity and going to ... hear him speak - and he was a really good speaker, besides ... and he was very passionate about it - and of course we had to write philosophies, and what's my philosophy of education made you think a little more. So I think that ... those two combinations of how I feel about education, and listen to the man, and doing all this research [for the philosophy paper], and talking about what it's really like in different schools made me really start thinking about [inequality in education].

\footnotetext{
${ }^{21}$ Examples of his work are the books Savage Inequalities: Children in American Schools (1991), Amazing Grace: The Lives of Children and the Conscience of a Nation (1995), Ordinary Resurrections: Children in the Years of Hope (2000), and Letters to a Young Teacher (2007).
} 
After this Diversity class, which was a general education course, she took another in the same subject in her teacher education program. Among readings they did, she mentioned one particular article:

You know, the backpack story, $\left[{ }^{22}\right]$ that were ... and it was the first time that I'd ever really thought about advantages ... not really advantages, but you had to see it written about that. We really had some heated discussions about [it] .... But in the Ed. program, we had other ones where we talked about the needs of educating [teachers].

Taking these classes, reading and discussing issues that related to diversity and inequity, and attending Kozol's talk, brought back the socio-political consciousness that she had started to develop in high school, and that might have been buried somewhere in her mind for those 30 years. The incidents "rekindled some feelings" that she had in her high school days about how unjust lives are:

I think I had that from high school days thinking that life wasn't fair. I was really big about it. I think that all high school kids think that things aren't fair. But I was really into ... ah ... the Vietnam War, but I was looking at it from the people point of view .... Especially from the Laotian point of view .... I thought that ... that Tom Dooly, that doctor serving in Laos, and that he wrote a lot of stories about the children there, and I remember thinking, "Boy that's so isn't fair, that war goes and that children don't get the same opportunities." And I still feel that.

The awareness Dian cultivated as a result of these events was further

developed in an ESL endorsement program. She talked about how people could learn to question their own thinking and embrace views different from their own:

Since I started taking these classes, I think I ... at least I can examine myself a little more closely about how I feel about ... you know, and my kid of course call me on it because I know I say things like "There's a

${ }^{22}$ See McIntosh (1988), Unpacking the Knapsack of White Privilege. 
driver and he's Hispanic and he's going really slow ...." I say things like that ... "I wonder if they really have a license." And my daughter will say, "Mom, do you think that's what's really happening?" So you cringe, and say "No, that's not what I'm thinking." We've had lots of discussions [in classes] about undocumented people, and expectations, and .... [You asked me] how we change because of courses we've taken. I think it makes a dialogue happen. Maybe it doesn't change anybody's feelings, but at least you have a ... protocol, or a way that you can say, "Well let's just look at it." And so ... with education, it doesn't ... maybe it doesn't change you, but it makes you think differently, so you say, "Well, let's not get excited about this, and let's just look at both sides of this and entertain some ideas." And uh ... I think from those classes you can start to say that you might feel that way ... that that's happening, but is that really happening? So it makes it when you have that discussion with people, then they can ... they stop ... they kind of calm down, and it's not an emotional issue that can come down. It's more an intellectual issue ... you know, instead of just being ready to argue, instead you can be like, "Why do you think ...." Anyway, you know, just having that kind of class ... it makes you think about things differently.

She brought such erudition to her classroom, where it helped her relate to her culturally and linguistically diverse students in a different way. She even took her

learning into her home, even though it created controversy in her family:

... Then usually they filter ... they come home with you, and you're talking with your family, or you're talking to ... like my sister about hot topics with her and immigration, and it turns out to be some kind of a yelling match ... "Well I read this great little article that talked about ...." I [also] think the things that I learn in class I think does come into the classroom, and ... to be thinking about them [ELLs] as individuals and what their lives might be, and so you would maybe ... ask an open question of how you feel about that, so they learn a process or two about thinking about other people, really do try to ... how do you think it makes the other person feel when you do that?

The ESL endorsement program helped further her attentiveness to diversity.

Unsurprisingly, as with most of the teachers I have taught, there were times when

Dian wanted to become skilled at practical approaches to teaching ELLs as quickly 
as possible. Nevertheless, in retrospect she believes that there is a reason to learn

the foundations or philosophy first, then the technical parts:

I understand, in looking back on it [the ESL endorsement program], that they're trying to lay the foundation on cultural things and I was thinking, "Don't tell me that! ... Just give me things that I can do in my class. I've got kids I don't know what to do with, and don't do that. Just tell me the strategies." But looking back, I can say that they were laying the foundation for all these things and I was impatient because I didn't wanna know how we learn a second language and I just wanted to know how I could reach those kids. But in looking at what they want to do I could see that there's value in what we did. They were laughing at me when I got my reading endorsement because I took Foundations of Literacy last, and you know, I think you're suppose to take that first, you know, and I just wanted to get into the practical part. But things are always a building, really should be ... here's the foundation and we're gonna lay this on top of it ... I realized there were a lot of things I didn't know so I'd be like, "Oh, that would've been helpful to know that when I was doing the next level." You need to take the Foundations class [first], you know, eat the cake, bake the cake and save the frosting for last because ... uh ... yeah, I can see why they do that.

Dian found that building on sound theoretical and philosophical foundations for working with ELLs, and incorporating methodological parts of the programs as well as SIOP $^{23}$ training (another learning opportunity that the district provided at about the same time as the ESL endorsement program), brought the best result into her classroom:

... In the ESL endorsement, I learned [specific strategies] for ELL students. And we have had in-services where they've just stressed that what's good for ELL students is best practice, and that it's really good for all students to do the same strategies. I did think ... um ... to use ... actually it becomes the best teaching practices.

\footnotetext{
${ }^{23}$ The Sheltered Instruction Observation Protocol.
} 
Apparently, Dian thinks of education as a change agent: "I think [with]

education ... hopefully, the scales fall from your eyes so that you can see even your own self better." The effect of education on Dian, from high school to graduate school to teacher training, is clearly discernible in her descriptions of her life incidents.

Role models. Asked about teachers who had an influence on her personal and professional development, Dian told me about a woman professor at her state college. At the end of her master's program, the professor encouraged Dian to write a thesis rather than choosing a final project as many other students did. Responding to her encouragement, Dian wrote a thesis that she dedicated to the professor. Dian said that she admires this professor for her strength and "still look[s] at her as the kind of woman that [she]'d like to be," i.e., a strong woman. Dian told about her and another strong woman she knew while at the community college:

Well you know, she had a very, a traditional ... she married ... she got married and her husband was working on his doctorate, and he left her so she was a mom with three kids and I just see that ... see that strength and I like to be around women who are .... I think when I went to the community college I was working in the tutoring office and there was a woman there who had gotten her doctorate when she was still teaching high school and she would drive down to [a university that took 2 hours by car] to take [courses]. And I just liked to be around those kinds of women and I liked to be around strong women that ... you know, that do that. And I'm just thinking, "I'd like to be around these women, who think' and yet, have gone through those struggles like [the professor]. [She] talks about ... falling asleep one day at her class because going through all these things and her husband had left and she had little kids at home and she didn't sleep very well and they showed a movie in class one day, and it was dark and she fell asleep. You know I just thought ... she would tell us these vulnerable parts 
and yet she persevered and she became a Fulbright scholar to Australia. I mean, you know, you just look at that and go, "Wow," you know, I can't say I wanna be like that when I grow up 'cause I'm all grown up, but I still like that.

Dian indicated her desire to see women be powerful and successful, saying that women should pursue the goals they can and want to reach, regardless of obstacles:

I like ... I really like to see ... I really like to see women who do these things that ... that ... I just am so grateful that I was born now, because a 100 years ago, some of these choices won't be ours to do. But although my family ... when ... the women in my family have been ... I mean, when my great-grandmother was married five times ... I think that would've been scandalous in those days and yet she was a very strong woman and ... and I guess I just like that. I like to see women that-I don't want to see them struggle but-I'd like to see them rise above that to say to me ... I'd like to be around those kind of women.

Even though Dian admires strong women, she appeared never to consider herself one of them; she talked as though this had never even occurred to her. In her own words, not intending to describe herself but citing characteristics she herself possesses, Dian described strong women as follows:

I like to be around strong women. I admire that they're strong to know what they would like to do, and they do it. And it doesn't necessarily mean that they're more educated to something than ... just that they're strong and they ... they don't give up easily. They persevere and I like being around women like that. Women are nurturing, so even if they're strong, they still will mentor in a way; they still will take time enough [to mentor others]. I see real strong women that are ... they kinda wanna bring you along with them.

Dian considered the strength of the professor to be not only her resilience, but also the source of her openness - strength to show her vulnerability to her 
students: "you open up your life enough for your students to see who you really, really are. I like that." Dian considers this trait to be one that good teachers should have; she wants to share who she is with her students, hoping that they can relate to and feel closer to her:

I think I should tell them [my students] stories about me and the silly things, and ... oh yeah, "I got in trouble all the time for talking [when I was in school]." You know, and they ... and I don't' mind if they laugh, and I'd like them to see that I'm making mistakes [and] to say, you know ... "Yeah, I'm still taking classes." I think it makes them like that [and] I think it makes the connection between me and my students stronger ....

Car accident. Dian had a life-threatening car accident in the late 90 s and still has a scar from smacking her head. She said, "I'm not a person who wore my seatbelt a lot back then, but I just felt I needed to put my seatbelt on [that time]." If she had not worn a seatbelt, she would have been dead. "That has changed my views in that I think that I do have a purpose--that I'm here for a reason." This made her believe that we all have purpose to our life and a role to play:

And so, we really are ... all of us here ... and I do ... I feel like there's this master plan and you have some kind of role to play and that really-before then I probably ... I didn't ... I mean I think of myself as a religious person anyway - but that really cemented it in me that something told me to put my seatbelt on. And so uh, you know, makes you think whole lot on fate or something. It's cemented in me this grand design or uh ... that we're here ... we're all here and have a purpose and a plan.

The incident reminded her of the importance of her motherhood. Compared to her influence as a mother on her children, as a teacher, Dian said, "I might have a small influence on these kids [her students] 'cause I still remember my teachers." 
However, as humble as she was about the influence she has as a teacher, asked about how her role as a teacher fits into the "grand design," Dian moved on to talking earnestly about where her desire as a teacher lies:

I do feel that if you're a teacher, you're certainly not doing that for the pay that you get. There is prestige in that though. There is prestige in ... even when people say that it's not respected, I don't think that's true. I feel very respected to be a teacher. The kids - maybe the kids don't have a perfect home life. Even if they do, to know that everybody cares about them ... that I could say, "Listen, you don't have to worry "cause everyone in this whole community would care about you." You know. "If this building collapsed, the first thing they would go to is a school," you know. For kids to know that people care about them, I think, is important "cause I see kids that ... they ... they don't always get that same thing that I had. But I still feel that everybody is ... loves their kids and they're doing the best they can with what they have available to them, too. It's easy to judge but ... no, I see lots of parents that care about their kids, but they don't quite know how to ... how to do it. So, if I can fill in any gaps, that's where I would like to do that.

Dian used the phrase "the purpose of life" in our conversation about the car

accident. Hers seems to be a desire to make the world a better place by playing a

small part in "helping each other." This is inseparable from her being a teacher:

I just really believe that ... that we need to, you know, invest in [teaching and in students]. Because each of them have the plans for them too, and ... I like being part of that and I feel that that's what makes this world better, if we ... you know, if we pay into that, that's what makes this world a better place. And so looking at my life and yeah, we didn't have very much money and we probably wouldn't have any in retirement either because I got my social security letter yesterday and you know, and my [retirement] you know .... I hear people talking about how much they're gonna have in [their retirement], that isn't going to be me, because if I can work 10 years, you know, because I am ... how old am I? I always forget. This year I'm going to be 59. So my [retirement] will never .... if I can work 10 years, I'm gonna be pushing it, really. And that's my goal. To work 10 years. Then after that, I want to ... um ... kind of go somewhere in [an economically and educationally challenged part of the city nearby and teach reading. I 
think I will be prepared to do that and so, that the kind of ... thinking that we're all here to help each other. Sounds kinda corny, but that's me. And would I have lived my life any differently? Uh, I hope not.

It was evident that one of Dian's goals as a teacher is to be a change agent, to better the world. This inspiration of hers started when she was in high school and was strongly opposed to her father's myopic viewpoint. The fact that the nation was in an era of sweeping political and social change contributed to her rising consciousness. It is apparent in her talk about what she learned from Tom Dooley's life that her family's restricted views were giving way to a much more comprehensive way of thinking. This consciousness was reawakened when she saw in college how unequal opportunities were for non-mainstream people. It developed further, in the ESL Endorsement program, into her awareness that people need to rethink their own tenets for living. All these experiences helped her realize that she could be a pebble that makes ripples in the pond-and this realization has become her strongest principle as she experiences and learns more. The ripples may affect her students, who eventually may affect society. Her attitude, "I will do a small thing I can do, no matter how small it is," makes clear her belief that teachers can be change agents from within their classrooms.

Husband's mother. Dian is married to a man whose mother is a daughter of Italian immigrants. Even though she was born in the States, "they spoke Italian and [did] Italian things in the home, so they were Italian. [Also], she didn't speak 
English until she went to school at about six." Dian explained her mother-in law's

family circumstance and how much she wanted an "American" identity:

My husband's grandmother never really spoke English. She spoke Italian because she was still in the home. so she learned a little ... she had enough to communicate in English, but the grandfather-his grandfather - they opened up a little grocery store and so of course, he learned English so he could talk to the customers, and so um ... now, it's just so sad 'cause it's all lost 'cause his mother then changed her Italian name because she wanted to break. [She changed] from a [Italian name] to [American name]. She had it legally changed and I always thought, "Well that's a great name!" But no ... no, she needed an American name and I just think that's too bad. That whole things of breaking away from it. And she didn't' even wanna date Italian boys, which drove her parents crazy, She married a German who wasn't even Catholic, so that was just like "Oh!" And the family ... caused a big rift. And I think she wanted to break away completely from ... the old [world]. She still has friends that ... but most of her friends are not Italian.

It is not difficult to imagine that her husband's mother wanted her children to grow up speaking only English: “My husband doesn't speak Italian because she didn't ... she didn't want that." Although her husband is very American and they do not experience any cultural conflict based on ethnic heritage, in our conversations Dian said more than a few times, "My husband is Italian."

Dian might have reflected back on her husband's and his mother's experiences to better understand her ELL students' struggles with cultural and linguistic issues, as when they show reluctance to stay in the ESL program, which I will look into later in this chapter.

Dian and her children regret that they did not have a chance to carry on their father's cultural heritage. In fact her children look forward to taking Italian classes 
in college and want to "reach back and claim some of the culture." In Dian's words, "They've kind of all embraced that Italian side."

Sons. Because of their ethnic heritage from the father's side, Dian's two sons are often mistaken as Mexican. They have had people come and speak to them in Spanish. Even though they laugh about the experience instead of being negative about it, saying that they should learn Spanish, a story about one of her sons was very distressing:

One of them [sons], when he doesn't shave-and he's young - and drives, especially a really good car, he gets stopped a lot by the D. [the name of the city they live in] Police Department. So when he doesn't shave and his hair's skuzzy, so he pulls a stocking cap on, just gonna run into town to, you know, get a movie or something .... He knows full well why he gets pulled over. He says "I got pulled over again today. They said they were looking for someone, but I know they pulled me over to check for my insurance ... to see if the car was stolen." One time, he had ... he had two radios in the car, because he had taken out this radio, and he was gonna put the other radio in, but then he was having such difficulties with it, and he said he was going over to his friend's house [for the friend] to help [him] do it. When he got pulled over, the police went ... asked to search his car, and he said "No"; and so the policeman goes around and asks why he has radios. Just, you know? "Did you steal that radio?" And he's like, "I took the radio out; this is the broken one, and I have this other radio that I'm putting in, but I'm half way through, I couldn't figure out how to do it, so I'm taking both radios to my friend's house and he's gonna help me put it in there."

Dian's sons' experiences may have helped her better understand and connect emotionally with what it is like to be treated as a second class citizen, although she is very thoughtful in not claiming that she fully understands the challenges that people from non-mainstream backgrounds face in their day-to-day lives: 
I'm not racially profiled when I'm driving in a car, I can go faster than someone else, and I know I'm not gonna be stopped just because of my skin color. So I don't think we know it completely because we don't have any fear because we don't have the right documentation. So they might be annoying, but it isn't fearful, like I would imagine that they [undocumented immigrants] would be fearful, to have that on top of that, annoying and then fearful, so I don't know that ... I don't know that feeling.

This statement is also an indication of her awareness about what differences race and ethnicity bring to people's lives.

Discrimination. As she indicated above, Dian realizes that it would not be possible for people from a mainstream background to have a full understanding of the experiences of those from marginalized populations. However, she has had her own share of discrimination because of her age and religion. After she graduated with a teaching license, she could not find a job. She says, "I figured [it was] probably my age. It was against me":

I've had age discrimination against me, and I know I've ... I've had people make comments because of my religion. So I know I have-I've gotten just small, just minority compared to lots of things- I know I have been ... when I interviewed for jobs, I know that age has played into it, and I ... and if ... if there wasn't a principal here a couple of years ago who was a women at very much an age like me, and I came in and subbed for a teacher for like 3 months, and she would just come in and say, "I'm gonna hire you. If there's an opening, I'm gonna hire you." And I think that's the only reason that I got a job because this woman and I ... she realized that ... because otherwise, I would come in for interview against young ... and I could see why people would just think, "Well, you know, we're gonna hire this young ...."

She also experienced religious discrimination:

And the other one was from religion. I was in a PTA something, and uh, and I know they were um ... it was a group who was doing Anti-Mormon 
showings, you know, calling us the God Makers or something. And so they were showing a video about, you know, we have a temple there and they were saying, revealing everything that goes on in the temple and what kind of people Mormons are and stuff. And it was very uncomfortable, and I remember thinking, "Hello, I'm here!" And I think they were thinking, "You will come and we'll save you." And I remember watching some ... it was some ... evangelical and the man was speaking ... and he goes around and ministries all over the world and I was watching him on TV one night, and he was saving someone, saving these people who were crippled, and he said, "Save this one. He's Mormon." And I remember thinking, "What?" you know, "Aren't we all just trying to be good? What? If they say one thing one more time about church, I'm outta here!"

Despite these experiences, being keenly conscious that race and ethnicity

speak much louder when it comes to discrimination, Dian unassumingly maintains

that her experiences are not even close to those that people from ethnically and culturally diverse different backgrounds face:

And I felt a form of discrimination, but I don't think it's anywhere near that ... if I had black skin, you know, I don't think ... but I've had a taste of it. And I know that it's uncomfortable, and I don't like it. And I thought, "You're judging me and you don't even know me." This is what it feels like ... but I don't mean it to say it's the same because I don't think it's nearly as intense as what those people feel. But I've had like a little taste of it, and I don't like this. I don't like how this feels and you are judging me and you don't know anything about me. Yeah. So yeah, I've had .... so like I said, I'm almost embarrassed to say that because I think it pales in comparison to other kinds of discrimination that other people ... feel. So I don't mean to make light, because they probably look at me and go, "Psst! That's nothing!" And they're right, it's nothing, but I think it has been good for me to ....

\section{Terry}

In the front office, I was waiting for one of Terry's students to come pick me up. In a second, a little girl in a pink sweater popped in and asked me if I was 
there to see her teacher. I told her I was and we walked out of the office. In front of Terry's classroom, the girl very politely showed me the entrance to the classroom and walked in behind me.

As I was stepping into the classroom, Terry came out from behind his desk with a genuinely warm smile and attitude, extending his hand to me. We shook hands. His firm grip conveyed a welcoming message to me. I had been a little nervous because he only responded to my second invitation, with which I sent a solicitation memo, knowing he happened to be one of my past students. I thought he might have decided to join the study because he felt obligated when he read the memo.

My anxiety disappeared, however, as soon as I saw him coming toward me with a big smile and his extended hand. I felt like I saw some kind of aura surrounding him at that moment: I imagined an orange, warm power that made people feel very accepted.

The students were still sitting at their desks. Terry introduced me to the class as one of his PSU professors who was there to see his students and interview him. Then he went back to talking to the students, trying to finish up the day. He asked a few questions about homework and some kind of videos. Some students answered the questions and then it was time for them to leave.

Terry opened the classroom's back door to the outside, stepped out, and saw students off as they walked out one by one. Two Spanish-speaking children came 
in with videos in their hands. Terry smiled at them; they smiled at him and handed the videos to him. Terry then said to one of the children, as they were about to leave, "Good job on your test!" Another student, a girl, who seemed to be from a different class, popped her head in to say "Bye" to Terry. Then yet another girl came in and said "I found one [a video]."

It was a busy, lively end of a school day. The interaction between Terry and his students suggested that he is one of those teachers who is very much liked by students for his warm, positive and accepting attitude toward everybody. This observation turned out to be true as I later listened to him in the interview.

Terry is a Caucasian man in his early forties. On this day, he was dressed nicely in a pale blue-and-white-striped, button-down shirt and dark blue dress pants. Over time, I saw him wearing jeans, t-shirt, shorts, and casual pants, but one common thing, whatever his outfit, was that he gave a very clean impression. He is not very tall, but well built, which as it turned out in the interview is the result of his love of sports. He has 11 years of teaching experience in elementary and middle schools. Currently, he teachers 27 fifth graders, among whom are five Spanishspeaking students.

\section{Life History}

Terry was born in one of the big cities in the state and as a child lived in a town near the Cascadia district. His mother was alcoholic and she left her husband when Terry was $2 \frac{1}{2}$ years old and his sister was an infant. His father got custody of 
the children and raised them. His father went to one year of college on a football scholarship, but injured his leg and as a result, left school. The family has always loved outdoor activities such as camping, fishing, digging clams and crabbing. His father also loved sports and was a professional bowler for a while and coached many sports.

Terry grew up in the town until he was a first grader. He describes his vivid memory from those days:

We grew up with some different Russian families around the area, which was kind of rare back then, but they just happened to be living where we were at, so we were friends. I remember playing with the kids and going into their home and eating different foods and stuff. Um, and everyone would sit out in the summers on the porches and watch the drive-in movie theater, because, there were no trees in the way and you could see the movie perfectly. The local community was mostly guys that were farmers, and farming type families, and so that's how we ended up all being so close all the time, because the kids would go with the mothers and pick berries in the summers and you know, do things like that, and they'd have a crawdad feed, crawfish, stuff like that...

Before Terry was in second grade, his father got a new position as a manager in the company he had been working for and the family moved to the southern part of the state, about 4 hours' drive from where they had been living. They lived in that part of the state until Terry was a sophomore in high school. There, the family lived in two different homes, one after another: one on a big piece of land with a horse and the other on a farm with animals. He recalls the enjoyment of his boyhood: 
All the kids got together and played baseball all the time, kind of like the Brady Bunch type family thing, and we had kids over playing, and we had a horse to ride .... And I had best friends. But they lived a half a mile away or so, and you'd have to hike to their house through the bushes and through the fields and whatever, and if we ever wanted to go into town, um-we lived in the country-we'd have to ride our bikes, like five miles,

When Terry was 8 years old, his father got remarried to a woman with three children. He remembers the fact that he and his sister were "very confused and did not really know what was going on for sure." The family relationship was difficult because his father and step-mother each put their own children first. Although there were good times going camping and taking trips as a family, he says, there was not "that true love feeling" and he "never really enjoyed living with [the stepmother] ever"; he "never felt enough trust with her."

He went to a big state university to play baseball; however, after tearing his rotator cuff, he experienced many things that he thought detrimental to his well being, and could not find any reason to stay in college. He wanted to change his life because he thought he would probably ruin it if he had continued living as he was. He joined the military on condition that he be sent to Germany because he "wanted to be clear out of the United States, and start over." After basic training, at the age of 22 , he lived in Germany for 3 years. When he came back to Oregon on leave, he and his girlfriend, whom he had liked since she was an eighth grader, decided to get married; they came back to Germany together for his last half year in the military. 
Coming back to Oregon after military duty, Terry went to a small private Christian college in a small town in a rural area.

Then a tragedy happened. His father, whom he describes as "by far [the] most influential" and the "only, real parent that really truly loved me," died in a plane wreck. Terry was already a teacher, but during the summer he was salmon fishing in Alaska and "when it happened, [he] was in Alaska up in the bush and [he] couldn't go home for a while." When the devastating news arrived, "[he] would be crying at one moment, laughing the next moment and the next minute, [he] would just not know what to think." The ordeal caused him to leave his teaching position: "I knew I wouldn't be able to treat kids how I wanted to." As opposed to the loving and caring memories of his father, Terry's memories of his mother, he says, are "mostly negative for my whole life." Despite this, he kept seeing his mother every summer for a while after she left. She has been married five times, has been married to a son of the last chief of a Native American tribe for about 20 years, and lives on the tribe's reservation. He says that he "sees them twice a year at least." As this remark indicates, his relationship with his mother and her family now seems to be closer than it used to be when he was a child. In fact, he has in his classroom Native American artworks that were made by his stepbrothers, and as he told me, he even tries to invite them to his classroom to speak about their lives.

Terry described "goodness" as the most important piece of his identity: 
If I see someone that needs help or someone that ... I usually try to help anyone. It doesn't matter who they are or why. I don't ask them what's their problem always. I just try to help if I can. And that's probably the thing I like to do most out of anything that I do.

He mentioned that he occasionally has a short temper that he attributes to the trauma that his father's death triggered. Nonetheless, he has other positive characteristics, such as being creative and fun. He loves anything that comes as a challenge; likes to explore and go to places to meet people; likes to learn about places and things; and likes to make people happy. He said, "The older I've gotten, the more I like to do [these things]."

Terry's Critical Incidents

Family. Terry's father's remarriage gave him and his sister a difficult time in their childhood. Describing his stepmother, Terry said, "She was fake."

What I [mean] by fake was ... she acted like she was someone who she wasn't. When she was around family, when she was around people that knew our family, but didn't really know her very well, she acted like she was very loving, and [a] very nice person, and in fact, she was not.

She was also "very physical and beat and did rotten things to me and my sister," he said, for petty offenses such as accidentally throwing a sock behind the laundry hamper. Terry recalled how hateful she was: "she would hold us in one arm and just beat us and beat us with belts and things."

When Terry's father died, he was very wealthy and had a will made out. Terry was supposed to receive the house in which he and his family are currently living, but his stepmother did not let it go so easily. In spite of the fact that his 
father left her millions of dollars and another house in a different state, and something else for her children, she fought for Terry's current house and he ended up with having to buy it, which was "very hurtful." He said of his stepmother, "she was loving to her own children, but not to us." She made him and his sister feel that they did not belong. To her, they were "others."

Terry's father was an athlete and encouraged Terry to excel in sports. He always rewarded Terry for being good at sports, but never for school work. He never helped him with homework either:

I remember one time, the whole time I was going through school, my stepmom helped me once with my homework, and my father never helped. And so pretty soon after knowing that I was being rewarded for sports and my parents didn't care how my grades were really, as long as I was able to play sports and have good enough grades, then that's all that really mattered.

Terry said he thinks about this situation once in a while: "Why didn't my parents help me? Why was my education not important to them?" He considers that it was because they themselves grew up in a family situation where for various reasons other things had more importance than children's education, for example, his father's responsibility for looking after his brothers and sisters in their father's absence. Many of Terry's students are from homes that, in terms of parents' educational expectations for their children, are similar to his own home or much worse. His family environment, which did not value education so much, influenced him in a reverse way and he tries to help his students understand the importance of education. 
Teachers. When Terry was in 4th and 5th grade, his teacher said that he was very slow in reading and in math, and he was put in some remedial classes. As a defenseless child, the words from the authority made him think that he was slow:

That teacher said, "He's not going to be able to learn his multiplication tables," I remember, "even the reading part." I thought, "This is my fault, I'm now slow."

This experience helped Terry understand what ELL students may feel about going to ESL classes: "It makes me relate to them a lot more ... because in a way, by putting them in these classes, that's what we are telling them." He is aware that with the help of ESL-trained teachers, such students will have a better learning environment and get up to speed more quickly. However, he is also aware that by being sent to ESL classes, ELLs may feel they are not smart enough to stay with their mainstream counterparts, even if they know that such classes are set up to help them:

We take these classes [in the ESL endorsement program], and we know that we are learning all different types of ... varieties of teaching techniques to help them [ELLs], and that they have lots of different learning abilities or learning techniques, or styles of learning, and that we can recognize those things, but ... we just tell them you need to go to the special class, to learn how to speak better English. You know what I mean?

Special classes are not regular classes, whatever the system's intentions, and students will not feel the same when they have to be pulled out of the regular classes when everybody else gets to stay. 
In his teacher education program, Terry had a glimpse of what

discrimination is like. He was very different from all other students, being the only male elementary education student; he had a lot of experience that other students did not have, and he did not act the same as a lot of them. As a result he "almost felt excluded" and "[was] made to feel bad." These feelings came from disagreement with a few of the faculty members, especially those who had difficulty dealing with his creativity and open thinking:

She said I would never be able to be a teacher because I couldn't do math the way she wanted it done. I had many ways that I could solve a problem, but she would only accept it the way she knew, and so she always counted it wrong.

With another professor he had a similar experience:

She wanted you to stay on the trail of what she thought was right, and I would question some of those things, and I would come up with different reasons for doing something different, and I would put proof behind it, and she didn't like that.

His learning from these experiences was reflected in his statement: "Now I know that's one of the worst things you can do to a kid."

Mother's marriage. Terry's mother was friends with and worked with Native American people prior to living on a tribal reservation when he was in high school. She got married to a Native American man when Terry was in college. This allowed him the opportunity to be accepted by the tribal people as part of their family. He has experienced many things that he could not have experienced without his mother's family: 
The Indian culture, compared to ours, is totally different. Their rules and what they do [are very different] and if you break a law it's different there than it is when you're not on the reservation and a lot of things like that.

He has attended school events and interacted with children there because his step-brother, who is much younger than he is, was going to school. He has been to many Indian story-telling and dance events where they do traditional tribal dancing. He has also taken a high school youth group and their parents to the reservation to work in the community to help clean houses, cut grass, fix broken things, paint, and work on the church. He even experienced, while trying to help a mother and her children, a domestic situation where violence, weapons and the police were involved and where he learned that "no matter how badly you want to [help], you do not ever get involved in anyone's family business [on the reservation] because they have lots of family members and they settle things their own ways." The incident taught him the lesson that on the reservation one must observe the tribe's way first:

Being in that type of situation and not knowing how the reservation social standings, and how dealing with problems work and stuff ... it was ... it was .... I would go in, and sometimes I would find myself in situations where, if I would have just been quiet and learned and watched, I would have ... um ... maybe had fewer problems.

His reflection connects with his culturally and linguistically diverse students' experience, in and outside the classroom. He stated his understanding about such students' experiences in an unfamiliar environment: 
When you're with your own people, there's no pressure, you know, I mean there's social pressure, there's status pressure, you know, but ... when you're ... when you're forced into a new area, or a new life, you have to change your complete lifestyle, um ... and so some of the foods may not be available, some of the um ... places ... the same types of things you would do for fun, or um ... family ... there's not much of your family there and friend, so it's very uncomfortable. And um ... it's just ... from my experience of having to do that when I was in the military, or when I first started going to the Indian reservation .... you have to be careful, because you don't want to get hurt, or you also ... you don't want to make a bad first representation, and so people are most of the time more quiet, and a lot of the time ... I would think they would be terrified, almost ....

Terry knows that the length of time spent in the new environment of a classroom makes a difference in how safe ELLs feel there. Although he is not sure if his ELL students feel comfortable when they first come into his classroom, he tries to make a difference with the knowledge he gained from the ESL Endorsement program. I asked him if he thinks his ELLs are nervous at the beginning of a school year:

Well, depending on how long they've been here. But I think they understand that there's gonna be a teacher they don't know for sure .... Maybe they got a teacher that was not trained for ELL before, and so um ... I think they have understood a lot of ... a lot of stuff passed over their head because of the teacher, and um ... I think that when they come to my room they are scared at first, but I think once they know that I ... I don't know for sure though, you know, "cause I was thinking today, I was thinking ... "I know I'm teaching different, but are the things I'm doing making a better impact on these kids?" I mean "Do they notice more from the other classes?" and I think the answer is "Yes." But I don't know for $100 \%$ because there's no way for me to gage that except for ... with their test scores. But I think if they are enjoying being in my class--and they arethen - and they tell me its one of their favorite classes-that shows me that they're not like that [scared] anymore.

Although his interactions with the tribal people taught Terry that "they are really a lot different than we are in some ways," the same experiences also gave 
him the realization that "they are not really that different than we are in some ways." His statements indicate the way he forms relationships with all his students as individuals.

Military service. Terry lived in Germany for his military service. He describes it as: "one of the best times of my life." His experience included homestays, meeting "tons of German friends and family, [helping] teach some German kids English," and traveling all over Europe with his friends and later with his wife. With these fun memories, he also recalled that he was a little lonely. When asked if there was any prominent incident that was influential in the development of his personality, he stated that "being alone itself" in a strange land was prominent because he had to learn a new way of life and since he did not want help from anybody, he learned a lot: "It made me have to learn more about the people and the customs."

Terry ascribes the development of one of his very positive characteristics to the decision that took him to Germany. He stated that, most of all, accepting that he was leading his life in the wrong direction took tremendous courage. Then making a choice to get to a place far enough away that he could not be influenced by the same factors that had been affecting his life was equally significant. To change his life, he wanted to make his circumstances more difficult, and so he chose to go to a place where he would not be able to speak the language: 
I wanted to be able to start all over and I felt like it would be [too] easy for me in the United States, because I could speak the language. I didn't want that. I wanted it to be hard. And it was hard, and I made lots of German friends and I learned the language really well, and it was excellent. And that changed my life more than anything changed my life because it gave me the confidence and the courage to know that I could do it on my own, and I could, from that point on, I've never ever been scared to try anything else again.

One of the lessons he learned from this experience is that life is about making choices. He teaches his students to make good choices. He stresses how important it is. He even places making good choices above academics on the importance scale. He tries ...

... to make these kids realize that the social part of it is the most important part of school and so [he] would really like to be in [the classroom] and to be able to guide them and to let them know they can act silly and have fun and then to let them know that [if] there [are] wrong things that they do, they need to be told when they are doing wrong.

This directly connects to one of the primary goals of his teaching: helping his students grow as people. In order to do so, he thinks that instilling confidence in his students can play a significant role:

Academics are very important, but anyone can learn academics if they have faith in themselves, and have some courage. If they have confidence, if I can build enough confidence in them, they should be completely different student when they leave my classroom.

Father's death. His father's death in a plane crash almost destroyed Terry emotionally to the extent that he actually had to leave his job as a teacher because he did not think he could interact with students in the way he would want. His father was such a powerful, influential, loving and caring figure in Terry's life that 
the incident almost shattered him; he still sometimes suffers from mild depression even today. However, he also picked up positive lessons from this catastrophic incident. He asserts that everybody should make every minute count while they have the chance.

Try it if you want to try something. Don't sit back and wait, because there may be no tomorrow, you know? Just do what you can when you can do it, and realize that you are not always going to be good at everything you do, but that when you try other things, you are going to find other things that you really do like to do.

His ability to reflect in this way on such a devastating event also indicates his capability of adopting the idea that things are not "one-sided," that there are always different ways of looking at things. This is an idea he tries to get across to his students; asked about how this lesson from the death of his father is reflected in his teaching, he said:

Losing my father is that ... I try to get the kids to there's always a negative side of everything and a positive side of everything. And I always get them to look ... try to look at the positive side of everything. Even though they may have a parent at home who treats them bad, they have food, they have a bed, you know .... Look at these in Iraq, right? And we're at ... or Africa, wherever, that don't even have food, that don't have medicine, who don't have a building to learn in. And when they start seeing all the positives, then they start thinking, "Yeah, there are some good things too ...."

Teacher education/training. In his student teaching, Terry had a student body and a principal who provided him with unusual and valuable experiences. He did his student teaching at a small school in an area where there was a "huge old Russian believer community." Most of the students at the school were Russians, 
along with five or six Mexicans and a few Caucasian students. His own students were all Russian. He recalls that he was given an opportunity by the principal to teach full time right away, as opposed to opportunities that most student teachers get, where they have to observe first, then start teaching a few lessons and gradually increase the amount of teaching until they get to teach full time:

He [the principal] said, "You have all this new knowledge, and we need these kids to learn. I'm going to put you downstairs with your own classroom with teaching the third and fourth graders fulltime from the first day." So I said "That's fine" and I wrote all my own lesson plans and everything, and every single day, I would teach, and he would come in maybe once a day and see how things were going, and they were always fine, and [it gave me] confidence to be able to do that on my own during my [student teaching]. I knew that none of the other 60 people in my program were doing the same thing, and plus I ended up coaching at the school, and doing that a lot, so [I] was kind of part of the school. I wasn't a visitor; I was actually an important part of the school, and he made me feel like that.

Being placed with his Russian students in his own classroom from day one, with his supervising teacher coming around only once in a while, made it hard for Terry to teach them at first. He told me an anecdote about how he had to be very innovative to teach multiplication tables: he tried to teach with flashcards, which he found would not work. He would come home and think: "What can I do, what can I do?" One night, he came up with teaching materials using a beach ball on which he wrote different math problems using different shapes, numbers and sentences. With this ball, he created a game in which everybody could participate:

I told them we had this game, and what we were going to do is [this]: we are going to throw this ball around, and wherever it lands, you have to stand up and read the problem out loud. And while you are trying to get it in your 
own head, the rest of the people can get it in their head because that's why you say it out loud. And if you need some help, you can pick someone else to help you. And if they help you, and you get the answer, then you throw the ball to them, and if you don't get the answer right, that's okay, too. You just throw the ball to someone else and pick someone else to answer it. So anyway, within two weeks, every student in my class knew all their multiplication tables. It was amazing.

This teaching tool impressed the principal so much that when he was invited to give a speech to Terry's entire teacher education program, he brought the ball, which Terry left behind at the school, to show the game as an excellent example for teaching. Terry ended up selling the idea to an education company with the encouragement of one of his teacher education professors, whom he describes as an influential teacher. Terry said that she had a lot of patience and was very calm. "She always had good things to say and had good ideas for me to try. She was the one that pushed me to do something else with the game."

With his student teaching came another valuable experience: home visits with every one of his Russian students. Because their parents would not come to school for student conferences, he decided to do in-home visits with the parents. He went to each student's house with an interpreter and asked questions and told them how their children were doing at school. The parents first thought it was strange because they had never had a home visit by a teacher before. However:

They were very receptive and satisfied with how everything went. They told the interpreter that they were glad that I came and that they learned a lot about my teaching, [what] the kids [are like] at school and relationships between me and the kids and stuff like that. They were happy after it all 
happened because prior to this, I think they knew nothing about their kids' education.

Not only did the families learn about their children's schooling, but Terry also learned about the families' life practices, for example that they were very private people; that each home had a shrine; that they had different Holy Days, each with its particular reason; that the youngest of the family's children is the one to get the house and take care of the parents, while the rest of them get gifts of money, and so forth. In other words, he became aware of families' traditional knowledge and practices, essential for them to function in culturally healthy ways.

The result of the home visits was significant:

It was the first time [the students] ever had it happen to them, so I think that they thought that I cared about them more, and that some of them that were harder to communicate with, it became easier to communicate with after that because they knew that I could go to their parents if I needed to, and they just accepted me more as a whole overall as someone who was a part of their life, I guess.

As such, the home visits clearly brought about students' deeper trust in Terry. It is natural for students to feel a stronger connection with teachers who show interest in their lives than those who do not.

Terry has taken an ESL Endorsement program and pursued other learning opportunities, such as Math Leadership. Any time he has a chance, he is always enthusiastic about learning new things in order to pass them on to his students.

Through these programs, Terry said, he has grown immensely as a teacher. He mentioned, for instance, that his view of ELLs' second language acquisition 
problems has changed. He thought that children from the same language group had the same issues in learning English, but through the endorsement program courses, he came to realize that it was not the case:

Well, the top thing is that ... I always had a stereotype of ... that all ELLs from one um ... that spoke one language, like for instance all Mexican or all Japanese or whatever, had the same problems, and they all have different problems just like anyone does. Anyone has ... when we did case studies, I knew that we used the Mexican kids here, but I thought that the findings would all be the same for each kids, and they're so different, and so ....

He learned ways to help these students, not only with their language

acquisition, but also with their content learning. The programs gave him opportunities to learn that there are different approaches to teaching and helping diverse students with comprehension and internalization of the content:

[There are] many protocols to approach different problems that kids have, to be ... able to help them in different ways ... there's such ... there's just a big variety of ways to be able to um ... help the kids with their language acquisition, and their vocabulary ... um ... retention, and um ... it's just ways of building up to um ... the concepts that you want them to learn, and I think that there are ways that come more easily for the kids, and they can comprehend something easier, and then you can keep building from that comprehension until you get it to the point where it needs to be.

He described the effectiveness of the programs in broader terms such as these:

It completely changed how I do teaching: my whole outlook on teaching. When I'm thinking about teaching something, lesson plans [and so forth] [what I have learned in the programs] is just always there in the back of my mind: all those different strategies and everything and issues that come up with the families, and with history and with everything. There are so many things that I have answers to, just ready to jump out all the time, that I know what I need to do to get this across. 
The ESL endorsement program not only helped Terry as a teacher, but also provided him with opportunities to become more conscious of and responsive to social issues surrounding culturally and linguistically diverse students and multiculturalism:

People ... don't understand these kids .... a lot of the things people say are ... "If they come to our land then they should speak our language," and they don't understand that um ... yeah, we want them to speak our language, but they have to learn their own language before they can be a good learner in our language. And people just have been raised ... it's evolving slowly, but people don't know a lot about that. I didn't even know a lot about that a long time ago and now I know a lot more and so I try to educate my friends and people ... and some people are racists-I don't run into as many people any more though, like I use to. Like in high school, we used to call

Mexicans Wetbacks or Beaners, some people called them Spicks-and actually I had a friend who the other day ... the other day, one of my friends called a Mexican a Spick, and I just ... I just looked at him and I said, "Why would you say that?" you know, "Why would you ...?" He's a teacher, and I said, "Why would you say that?' And he goes, "I don't know. I haven't heard it or said it for years and I just guess it came to mind real quick [sic]."And I said that I just don't like to ... don't like to talk like that, you know ....

He once mentioned that he was amazed how much he learned in the space of 3 months during an ESL endorsement course, and said he passed the knowledge he gained in the class on to others.

\section{Sabrina}

I was standing facing Rm. 15, trying to figure out where Rm. 12 was. I looked around to my left, right, front and back and saw a smiling face looking back at me: a girl in a pink cardigan, in what turned out to be Rm. 12. I smiled back and spotted the teacher, who was busy talking in the room where the girl was. I stared 
at the teacher for maybe one minute, hoping she would notice me. No signal. So I looked at the "pink-cardigan" again. She invited me in with a hand gesture. I knocked on the door very lightly and opened it very slightly. I peeked in; the class was still going on, and the teacher, who now recognized me, gestured to me to come in. I slid my body through the small opening of the doorway. A few of the little heads turned around, then went back to what they were doing. The pinkcardigan kept looking and smiling at me.

I found a small chair in the back of the room, sat down, and started to observe and take notes on what was going on in the room. Sabrina, a Caucasian woman about 5'2" tall, who seemed to be in her late 30s, was standing in front of the classroom. Dressed in a brown suede jacket matching her hair color, a pink sweater, and blue jeans, she looked very stylish, with the finishing touch of a green, red, and white mixed-colored, fluffy long scarf. She wore modest makeup, earrings, and glasses. Asking the class questions, she was very vibrant and it almost made me draw in my imagination a picture of her jumping up and down: of course she was not, but I enjoyed her spirit as her students must have.

The class was now into one of the day's final activities, which everybody seemed to love: students passed a soft, red, apple-shaped ball around by throwing it to each other. Sabrina waited until everybody had a chance to throw it. "Twinkle your fingers if you haven't gotten it even once," she said, expecting that half of them would not raise their hands or twinkle their fingers. 
Of course, everybody did. "Oh, that can't be true," she said. The ballthrowing continued and she repeated the question, to which more than half of students again twinkled their fingers. "Oh, that can't be true," she said again. The game was too fun for the students to stop.

After the game, she gathered all her students around a round table in the back of the room to talk about the following school day, a sign that she was dismissing them. Sabrina asked the children to line up and stepped out to stand by the classroom door to say goodbye to each of them. When she had said goodbye to the last student, she quickly came back and told me that she would be back in 10 minutes. She was going to see her students off by the school buses.

\section{Life History}

Sabrina was born in a big city on the East Coast in the mid 1960s. She was adopted as a baby by a couple that had no children and she became their only child. Sabrina's father, an insurance adjuster with a college education, and her mother, who had training as a dental hygienist after her high school graduation, "had a very bad, bad marriage," she said. Her mother was from Oregon and her father "had really ethnic parents that came right from the boat in Italy." The neighborhood she grew up in was "predominantly first very Italian, then Irish and Polish." In this neighborhood, the family first lived in one of many row houses and then she and her mother moved to an apartment about five miles away after her parents' divorce when she was 13 . By this time, she had developed a love of music and started to 
play the drums. Hers was "a very strict Catholic upbringing" and she went to very

big Catholic schools all way through to high school:

It was really pretty important that you went to the private schools because given the neighborhood we lived in and the belief system, that was a really important thing that you did that for your kids, that you sent them to Catholic school if they were Catholic. So it was big. I mean that was like the thing you do.

In spite of her upbringing, "I turned away from [Catholicism]" because "it is not just something that I completely buy into even though I still respect it," she said.

Sabrina has always been fond of her grandparents on her mother's side.

When her mother decided to come back to Oregon, she chose to come to Oregon, too, to attend a small urban private college. She said, "I blindly made the decision because my grandparents lived [in Oregon]." They had 10 grandchildren and she was always their favorite. When they came to visit her family on the East Coast, "that was the most glorious thing" for her. They would come in the summers and they drove across the country a couple of times together.

Although she feels much more warmth toward her mother's family than her father's, she still identified herself as Italian:

Simply because um ... that's the family I lived closest to, because [mother's] family lived out west, and I lived back east, so when I see the family from [Oregon], I felt like a hard closeness, much more love and affection, and comfort level with them than with my other family that I lived closest to. But on the other hand, when you're eating these meals, and your holiday and things like that, and you're eating those traditional foods and you celebrate it a certain way, I was more Italian than anything else ... if I'm going to cook, or if I'm sort of nervous and need some comfort food, always Italian food for sure. I have to have that house ... and I wouldn't 
really know why because I wouldn't necessarily think it was a comforting place for me to go, but it was just what we did.

Her East Coast and West Coast identities have always co-existed within her; however, she described settling in Oregon as the best thing that ever happened to her:

I feel like, here, in my heart, in my mind, like that's the kind of person I am. I'm not an East Coast person. It's weird. Well, you're born there, you're raised there, you have that mentality, but that wasn't me. It's kind of strange.

Sabrina started college with the intention of going into the advertising business. In her sophomore year, however, she had to change her direction: “something tells me I need to teach, and I don't really understand what pulled me that direction, but I was compelled to do it." In the teacher education program, she felt she found a niche and that she excelled at it.

She got married 2 weeks after graduation and within about 3 weeks, she had a position as a 1-year substitute teacher. She continued substituting for a few years after the contract ended and stayed home with her children until they went to school. She started to volunteer teaching music for her daughter's third grade class, which led her to substituting again, which eventually guided her to a full-time position as a music teacher when music education was reinstated after it had been cut. She taught music for a few years until it got cut again, and then finally went back to the regular classroom. At the time I was interviewing her, it was her third 
year teaching second grade students. She has 27 students including six ELLs who are all from Mexico.

Talking to her, I found her to be very funny and entertaining. She is very animated with a lot of facial expressions and gestures that she used in making timely jokes. In fact, Sabrina describes herself as a person who "like[s] to amuse people, [and] like[s] to be funny," which was evident in some of the stories she told me in our interviews. Her own descriptions of her characteristics as a person very quickly shifted to those of herself as a teacher, which indicated that her professional identity was inseparable from her personal identity: "I'm loving, I'm a good mom, I think I'm a good wife, good friend, I'm a good daughter. Good, good, good. Um, I think I'm a pretty good teacher." Her "goodness" as a teacher is expressed in the following way:

I really love kids. I really, really do. I'm really passionate about it. I just ... you know it's funny because, when I'm not here [at school], it's like, oh I worry about some of these little kids. I'm just like, oh my gosh, you know, and I know I shouldn't be like this but sometimes, I just feel like I'm their second mom, but I'm with them so often during the day. And I'm like, "Oh did they get enough to eat? Did they get a bath last night?" because when they come to school, kids shun them if they don't. So I worry about that.

\section{Sabrina's Critical Incidents}

Neighborhood. The community where Sabrina grew up consisted of diverse cultural groups (Italian, Irish and Polish). One thing they had in common was religion. She told me that in the big city where she was born and grew up there were sections that were just Irish, just Italian, and just Polish, but hers was a more 
mixed one. Asked if there were conflicts in her neighborhood among the different cultural groups, she answered with an unambiguous "No." However, she mentioned that people in the community were prejudiced against Blacks and non-Catholics:

I will say that I ... there were no black people in my neighborhood. But ... I just didn't know why, and many of the people were probably pretty prejudiced. I never was ... I mean .... So I would say probably a lot of people in my neighborhood may very well have been prejudiced because there wasn't very much cultural diversity as far as you know ... um ... a black population. Religiously, I don't think that Catholic people and the Jewish people really melded, but again, I didn't understand that. I was just like, "Wow, what?" you know?

Although there might have been conflicts among the same three cultural groups elsewhere, in her community, they may have developed a sense of unity by defining themselves in contrast to yet other groups that had identities different from their own.

Family. Sabrina's grandparents on her father's side "came straight out of Italy," as she put it. The fact that "they were afraid of anybody who [was] different" puzzles her; she does "not understand that idea because they came to the country where people were different [from them]." Asked to elaborate, she said:

Well I'm just thinking, you know, you come some place, and you're the new kid on the block, so you shouldn't put up this attitude, like ... I don't know, I guess I don't understand that; like "Okay, we're all kind of in the same boat here and we're all new, so let's get along and ... and work together. But it was sort of "me against you" theory. I didn't understand that, and talking about other people behind .... But see, I don't know if it was an Italian thing or it was just them [my father's family], because they were really pretty negative people, and you know, they'd be nice to somebody's face, and then that person would leave, and I thought, they're best friend, 
and then they'd leave, and ... boy, they'd just start ... and I'd think, "That's horrible!" I spent many uncomfortable moments with that family.

The family's negative attitudes toward anything different may have had a connection to Sabrina's emotions about being an adopted child, which I will look into later in this section.

Sabrina spoke about her father's being "quite a prejudiced person." She thinks that it was the result of the way he grew up in the "me against you" mind-set of his family:

I remember my father being quite a prejudiced person. My mother wasn't, but he was. Very. And I was just horrified. I just ... I just didn't understand that. Gosh just, I mean, you know, that black people were inferior, and Jewish people .... I just remember them being the targets, but that's pretty much how he was raised.

Even though she did not give many concrete examples of his remarks about "other" people, her thoughts reflected feelings and attitudes of people in his family and the community. I asked her how she felt when her father made prejudiced remarks about other religions or races:

This is so funny because I was really young, and we were very Catholic, you see ... and so I just remember the first time he would talk about the Jewish people; because in [the city where I was born and grew up] Jewish people and Italian people don't like each other. Why? I didn't understand that, and I was like, "What's that all about?" and he [my father] was talking about the Jewish and I just remember being very young, and going, "Jesus was Jewish. Jesus was a Jew!" and he's just looking at me like, "Okay, whatever," and I didn't understand it because here we are, these Catholic people, and we follow Jesus because Jesus is our Christian leader, but Jesus was Jewish, so what's wrong with Jewish people? I'm not ... I don't understand. And then, he ... well, gosh, I don't think I grew up around very many Black people, and of course, he was terribly prejudiced [against them], 
and I didn't understand that either because all the Black people I ever met ... I really liked them, and they were people, and I just like .... I didn't understand it. I felt highly uncomfortable, you know, just physically uncomfortable-you know, when you get that feeling, like you're gonna be sick-I just thought, "Well I don't understand that; why people would talk about anybody that way?"

Sabrina talked about another aspect of her father's personality. In the very beginning of our first interview session, I asked about her parents' general characteristics and interests. She told me about her mother, instantly and delightedly, but when she got to her father she exhibited hesitation and needed moments of silence. Then she said, "My dad was kinda ... um ... probably ... not a very nice person most of his life, he was ...." After my prompt, she continued: "Not very ... not very warm. Not a real warm person. I mean, nice enough, you know, pleasant enough, [but] not probably real warm." It seems that she has had complex feelings about her father: "I love my dad, and that's fine, it's fine, but we weren't like, really bonded." Later, in a follow-up interview, she said that she had been thinking about her father since our first interview and described their relationship in more detail, and with less hesitation, which I thought showed the process of her reflection on what she may have unconsciously (or otherwise) tried not to deal with.

She spoke about her thoughts about her father's generally "downhearted" personality and conceivable reasons for it as follows:

I would probably think that perhaps, just perhaps, he was a person that came with a personality disorder, or some deep-seated problems, or ... I think he 
was just a very unhappy person .... He would get kinda nasty, and talk nasty, and he was a big drinker, and a lot of prescription medication, and just lot of things like that ....

With this personality as the footing, becoming the father of a child for whom he was not prepared would not have been a joyful undertaking:

Well, I've been doing a lot of thinking about that [why he was not nice to me] lately, to tell you the truth, because as he got older, be became a little bit nice toward me .... And I know he really loved my mother just with everything .... And then when I came along, they adopted me, and he really didn't want to adopt me; he wanted my mother's attention all to himselfthis is just stuff that I kind of come to a surmised ... later in life looked back upon-and later in life as he got older, he realized you know, having a child is very enriching, but I just think that he really didn't want to share my mother ... with anybody. And you know, when you have a deep seeded unhappiness, with yourself, you're just not a nice person to be around, so he had a real skewed view of life. He wasn't inherently kind to others; it wasn't a natural thing for him to show kindness or consideration to somebody else ....

For any child, sensing that her father is distancing himself from her must be a brutal experience. Sabrina later said her father's problem could have been innate, but as a child, there was no way she could tell it was his own problem and was not because of her. Although she never mentioned that she had made a connection between her being adopted and her father's not being warm toward her, she may have suffered as a result of their non-biological relationship. As she says in the above quote, "he really didn't want to adopt me."

Being an adopted child. Sabrina very strongly articulated that being an adopted child has undoubtedly shaped her worldview. When I asked her to list her critical life events, she exclusively talked about it: 
Critical events ... um, I wouldn't call them critical events, but I would say that [being adopted] really, definitely shaped me in my way of thinking. Um ... first of all, I feel like, being an adopted kid ... my parents didn't differentiate between that, but in my mind, I did. And some of my family members did, and really differentiated me ... um ... compared to my other family, and I didn't like that. I would say that would almost be a critical event.

Her description about how she felt about being adopted came after this clear

and definite assertion:

You know, [being adopted is] basically good, because you feel like, you know, these people, they go looking in the little baby department and they're like, "Ooh, I pick you!" and that's cool! And you know, obviously they really want you, because they adopt you. So that's a really good feeling. But then, you always - and I know that every adopted person carries this with them - carry a kind of a feeling of ... rejection or abandonment .... Even though it might be really minute, it's always there. Even though it's ridiculous. Because, okay, you have a 15-year-old mother who gives birth to you, that .... You know, she did the right thing [by giving up her baby], that's great ... I mean like, where would my life be with that? I'm not attached to that, but somehow I can't almost wonder that a childsomebody who's adopted-doesn't have that one sliver of that feeling. I feel like it's pretty common, I would think.

Sabrina said, "I have carried the feeling [of rejection or abandonment] in all my life." Although I was well aware that she was getting emotional, I had to ask her a harsh question, about how it affected her. I added as an aside, "You don't have to answer any of my questions if you don't want to." She jokingly said, "Don't upset me," and continued with a gesture of wiping sweat from her forehead:

No, yeah, okay. Wheewww! Yeah, it's a ... it's okay [to answer the question]. It's weird, because it's like, it's not even ... um ... it's ridiculous. But it is ... it's something ... it's present. Particularly, when you have a family that ... you know ... they differentiate. 
The sense of being abandoned by her birth parent(s) seems to have amplified the sense of being excluded by her adopted family, as Sabrina indicated in speaking about how they treated her:

Well, now, remember, this is East Coast, and it's just, really, really particular, and when you're an ethnic group, it's, you know, "you're my blood." Blood is thicker than water. So I wasn't [their blood]. So, it would be like .... Now, here's a for instance.

To give me an example, she told me to stand up, then she stood up for a comparison and asked me if I thought she was a tall person. I said, "No."

No, I'm maybe like, five foot two. Okay. Well I was enormous. I mean, I was huge, compared to the rest of the family. Like my dad's side of the family ... they were very little, like four foot eleven. And so my cousins were really small too. So they're like, "Well, look at this one over here. She's ... she's huge! And that ... and no, I'm [not], but compared to them, I was. So it would be something like that ... would be a physical difference, or emotional. And like I said, I, for some reason, I really didn't have the same mindset as them, so I don't know if that's a genetic thing or a rebellious kind of a thing or what. So, you know, I'd kinda like, watch and be, "Hmmm ...." I'd wanna be really a part of it, but I wasn't really. So maybe I detached myself just a smidge.

She did not feel she belonged to her adopted family, physically or mentally. It seemed as though in spite of her desire to be part of the family, the family did not let her. Because of her experiences with the family, she took a different path psychologically.

Ever since I was very small, I knew ... I knew I was put where I was for a reason, with my family, but I knew that I wasn't really a part of it, because my mindset was very different, And when you're like, "Boy, I'm really different from those other two people [parents]," it's ... it's weird. It's really weird. 
Sabrina did not feel she was unconditionally accepted. She did not belong. She was an "other" in the family.

Teachers. Sabrina's parents sent her to Catholic schools, as other families in her community did. Schooling was generally not fun for her and it seems that she went to school out of a sense of duty:

When I went to school, I knew that was my job, I knew that my parents were paying a lot of money for it, and I knew that no matter what, you're to be respectful to adults. So I went to school everyday, I did my job and I don't think I loved it. I just don't think that I really loved it.

Discussing her grade school experiences, the first thing Sabrina talked about was about her "unhappy" teachers. That she talked very little about her K-12 experience before talking about her teachers implied that they left a strong impression - unfortunately, as the adjectives she used to portray her teachers indicate, not a good one:

I feel like many of my teachers-and that ... I'm not ... I'm not trying to be disrespectful, I'm just going to be honest-I feel like many of my teachers were personally unhappy people, [and] that maybe they didn't start out to be teachers, but that's where they were placed in the religious community. Um ... so I don't know if they really were teachers, if they wanted to be teachers, or if they were personally unhappy with their location base. Because I had a lot of teachers that were very cold, and very bitter. And I don't ... then really [didn't] get the warm, fuzzy [feelings with them].

Although she would like to think that "not all nuns were cold," her memory was that they really were.

Not-so-nice memories of teachers were not restricted to the nuns. She also spoke of a lay teacher: 
I remember being in the second grade ... um ...very, very, very specifically, and I remember ... I was working on something and I called my teacher Mommy ... instead of whatever her name was, and she was like, "Mommy!? Why would you ....!' and she completely shamed me, and I will never forget that ... and I feel like, you know, I look back on it, and I have kids that called me mom, that called me dad, called me grandpa, they call me ... like, I don't care. And sometimes they have this face, like, "oops!" and then I just say, "I'm somebody's momma, just don't even ..." because why would you ever make a child feel like .... Kids make mistakes all day long, every day, and you expect it ... and that really .... And that woman was somebody's mother; she wasn't a nun or something like that ... she was ... and she coulda just said, "Yeah?" 'cause most mothers .... You think about it ... you think about it, you're in the grocery store, and someone's like, "Mom?" and you turn your head ....

Experiences with her "unhappy, cold and bitter" teachers might have contributed to shaping her teacher identity. Although she had not thought about their influence on her, our conversations seemed to have gotten her thinking that she might have developed, as a teacher, in an opposite direction from her teachers.

She said, "I don't think I was conscious ever, but since we started talking about this, it's like, 'Yeah, I would never be like that ...."' Her positive attitude as a teacher was reflected in the following statement, too:

You know it's funny because even co-workers ... if I'm around negative co-workers, I have to get away from it. It's not that I see life through rose colored glasses, [but] when you're in this kind of job, there are negative things that you see everyday. But there are things that you have to do, and I'm not going to complain about it. There's too much you have to deal with; there's children's problem that you have to deal with; there's testing that you have to deal with. It's part of the job. If I'm gonna sit and complain about it, you become negative, you know, you can get sucked into that, and I won't ... I mean, I can complain just like anyone else. But what's the sense of it ... I don't know. Trust me, I can complain, but I just really ... I just don't like negativity because I think it just sucks a lot of people down, and as far as .... It's just a downward spiral. 
Role models. Asked to talk about K-12 experiences, the subject almost instantly brought bad memories back to Sabrina about some of her teachers, as we have already seen. So when Sabrina very clearly articulated that no teacher of hers positively influenced her as a teacher, it sounded expected. However, her statement about the two teachers whom she liked in high school holds a valuable implication about the key role that a teacher can play for students. Even though she indicated that she did not "love" the teachers, rather that she liked them "at least mildly," the fact that she spoke about them in the context of her philosophy as a teacher shows that, when she relates to her students, she may be, most likely unconsciously, referring back to what the teachers did in her high school days.

Regarding the personalities of the two teachers, Sabrina mentioned their "[being] warm and nice" people and that they "liked kids." Then she stated as follows:

I feel like they took a personal interest [in students]. I felt like there was a lot of smiling, a lot of warmth, and a lot of ... you know, this engaging behavior that I think is really important. I think that kids - well, you know, this is my theory now-I think that kids need that connection with their teachers. You spend a lot of time during the day with your teacher, and if you feel like that person who's teaching you something, is giving you something, you know, doesn't care about you, doesn't like where they're at ... I mean being receptive to something like that .... I mean, every kid wants their teacher to like them or ... or [to] feel like you're welcome there. Or feel like home. And I really didn't feel that except for maybe those couple of times.

Sabrina talked about her teachers' characteristics as her theory of the teacherstudent relationship, but it seems that the two teachers were sensitive and 
responsive enough to students' fundamental and vital needs-e.g., knowing that their teacher cares about and respects them-for her to remember their classrooms as welcoming places where she felt important to and well-liked by her teachers.

Discussing her favorite subjects from high school reminded Sabrina of a couple of other teachers-an English teacher and a creative writing teacher-who were able to relate to students through their subjects:

They had a lot of dynamic qualities, um ... a lot of encouraging behavior, and let kids be individuals, which I really liked a lot, and um ... cherished that kind of feeling, and um ... I think that's good, 'cause when you're writing, you don't wanna be timid about your writing, you want to write as much out as you can, so that was really good. Then I liked that a lot, because when you're going to a Catholic school, you tend to be quite conservative.

As she said above, the teachers let their students be themselves. I asked her if she thinks this has something to do with respecting students for who they are. Sabrina said:

Yeah, it really is, because instead of stunting somebody and saying, "No, don't think that way, or don't act that way, or don't look that way, or don't be interested in that," [they were] saying, "Well let's talk about it, let's think about it."

Even with these teachers, her K-12 memories were not very happy ones: "I mean it [school] was okay. It wasn't like, torturous or anything, but ... I didn't really feel like .... I kept thinking that if it was public school, it might've been fabulous, you never know." She added: "I have some happy memories but mostly of friends." 
Friends. It was not hard to tell that Sabrina's best memories from her grade school days were those involving her friends. As she described herself, she "was a little bit of a practical joker, and had ... a bit of a funny personality." With this characteristic and her love of music, she had the best time playing music and being playful with her friends.

Sabrina was almost expelled from high school for having stood up for one

of her friends. The incident shows her attitude, even as a teenager, toward injustice:

I almost got expelled in high school because one of my nuns yelled at a kid, and it's just like, "What? What?' and it was really ....The story was: Here's this little girl and she plays this trumpet; really, big, loud, instrument, right? [She]'d go up there [to the attic room] everyday, and she'd say, "Sister, where do you want me to practice?" and she'd be like "Go up!" and we were ... down in the basement. But [she]'d go up these two flights of stairs and it was like this little attic room. She'd be like, "Go up to that room up there!" Every, every blessed day, this little girl, "Sister, where should I go?" "Up to the attic room." And one day, little girl goes up to the attic room. Does not ask the sister and we're like, sophomores, juniors in high school, so we're old enough. Clearly, the girl is up there playing the trumpet, "cause you hear, brr-brr-brr you hear; you hear it. And the nun is like, "Where's so and so?" I'm just kinda doing my thing, you know, and "Well, she's up there." "Well she didn't ask me first," and she was in a really bad mood or something because she was like "That's it. I'm gonna ... I'm gonna suspend her because she didn't check in the class." I mean she just went on this big tirade, and I just-I'm a timid kid. Timid - and I just went up to her and said, "Every single day, she says, 'Sister, where do I go?"” so I mean ... I mean I relayed the whole story. "Do you hear her playing the trumpet up there?" And I'm not ... I've never been disrespectful .... And that was it. That was it. I was down there and I was gonna be expelled for my insubordination, but I wasn't. 'Cause I was right.

It was not because the girl was one of her friends that Sabrina defended her. As she spoke, intolerance for unfairness seemed to be a part of her built-in structure: 
Even when I was at school wearing my little uniform, and I'd see kids and I'd see them picking on somebody else, I would just be like the first one up there. I don't know. I just ... I have just ... from the very beginning of my life, and I don't really know why, and I just don't know if it's something within me or something-I'm not trying to say that I'm a really good person--but I just feel like people ... like ... equity to me is super important. What's for one is for everybody. And it's just ... it's just that way. And if I see that that doesn't happen, like I don't understand it .... And so it's just been something very inherent with me.

Sabrina's righteousness prevailed in her stories about her friends, and it was apparently carried over to her classroom when she became a teacher.

Students. Sabrina's experience as an adopted child strongly shaped her way of thinking. She talked about being the only adopted child in her community and the way it affected her:

Really ... I was the only adopted child that I knew of in my community and that really .... I kind of thought that made me quite different. I don't know if they knew that, but they knew it-I didn't think they knew it, but deep down inside, I knew what it was. And, you know ... and I think, when I started school I know that my parents ... they were so into this ... oh, you need to tell somebody that your child is adopted so they're well adjusted. So ... whatever ... I don't understand that whole scene, but it was very important that I was well adjusted. See ... and so they'd say that to my teachers. So I knew that my teachers knew that about me, and that was kind of .... I really didn't want to be any different at all, and then they'd know this ... and once in a while, [I heard] "Well that child's adopted." Great.

She believes in the principle that everyone should be treated justly and fairly, as we have already seen in the previous section: that nobody should be singled out or discriminated against and treated unfairly because of their "differentness," as she experienced as an adopted child; that nobody should be made to feel less of a person than everybody else because $\mathrm{s} / \mathrm{he}$ is different from others in some 
regard; and that everybody should be treated with respect and rightfulness no

matter what. This belief is also reflected in her teacher-student relationships. When

asked about unforgettable students, Sabrina first talked about a student with Down

syndrome, whom she called "the love of my life."

[He was the] love of my life. He was in a regular classroom. He had an aide there all day. He ... this is the funniest thing. This was in fourth grade. So my aid was in there and her name was Ms. K. And he's my little guy and he's, you know, doing stuff, and sometimes he'd listen and sometimes he wouldn't listen. And I always have a hook with my kids, so I said something like, "Oh, um ... Whoopti Doo, Scooby Doo," or something, I don't know. I rhyme things. I said, "Scooby doo, I ... I dated him in high school and Ms. K. dated Sponge Bob," or something like that 'cause they're a little bit older. And my little guy was like, "No, you didn't date Scooby Doo," and he's the only one that ... like ... speaks up, and I was like, "Uh, yeah I did" and he's like, "Mrs. L., Scooby Doo is a dog, you did not [date him]." And this is a Down syndrome child. Every other fourth grader was like, "Did you really date Scooby Doo in high school?" Here's this kid. I'm just like, "You little precious." [To him] it was okay that Ms. K. dated Sponge Bob-and he is a sponge - but I did not date Scooby Doo. So I mean, it's just like, when you ... when you just get, just this .... He was just a doll; he was just a doll. I just ... you know, just the kids that I think just love so much and they might have been the hugest challenges.

Then she spoke about a student with autism:

Last year I had a severely autistic child in my classroom that just ... that just ... was an enormous challenge, and that just didn't relate to anybody around him and didn't understand what was what. And he was very unforgettable because of a lot of the challenges that he posed, and just the love and ... and the relationship that we kind of .... Well, he didn't usually make eye contact with anybody, so we really worked on that, so I could tell him, "Look at me," and it might have been fleeting, but he could, and we got it and we-and I use a lot of figurative language, in my class-and he got it. I mean, he really got it, and he really ... sometimes he'd just pipe up and he ... he'd get something. 
These students are "clearly [different to] the naked eye," but because her conviction is that all people need to be treated with equity and feel they belong, and that students can feel that she genuinely cares for them, she "can break through with a kid, and [the kids] get that."

Although she said that she did not know why she could relate with so-called "challenging" students so well, the following statement clearly indicates what is responsible for her sense of justice:

Being the kind of person who felt ... um ... you know, singled out-whether I really was or not at school-I can't have that here at school, because this is their safe place, this is where it's at for most of these kids, and when you're talking about ... when you're talking about poverty child, when this should be the ... "I'm fed here, I'm loved here, my teacher loves me, and the other kids ..." kind of -I don't care if they love them, whatever, but - they need to respect them and be kind to them, and if you don't, they won't continue through.

Sabrina said that she identified with students who are left out or teased. She even said, "It personally hurts me." For a teacher who has had a personal experience of being treated "differently," the following classroom practice seems a very natural outcome:

If I feel like somebody singles somebody out with ... um ... anything, I don't care what it is ... if it's anything and singled out, um, I just ... I just take it very, very personally. I just don't think it's okay. I don't think it's equitable, so it's really all become part of that kid and it's like, "Okay, let's solve this problem." .... When that happens, um ... it's not like I get in the middle of it, I really have them have a dialogue, sometimes I ... mmm ... facilitate it ... I facilitate it for sure, I'll direct it in the direction that I want it to go, but usually, they can look at each other and really make a good statement. If the kid was called something, I'll have them call the other kid on the carpet and say, "You know, you called me this, and it made me feel 
like this." And the other kid is usually like, "Oh, I am really sorry." .... It's huge in this classroom and how we treat each other ... really, really important.

Sabrina very persuasively and unmistakably affirmed that discrimination is "not gonna happen. It's not gonna happen in this classroom." I pushed her, by specifically asking how her belief applied to culturally and linguistically diverse students. She said: "You know, it's the same thing. We all ...." She stopped talking, obviously emotional. "It's just ... they're children, they're people, they have so much worth, they have so much to offer, it's the same thing. We are ...." She asked me to stop recording; "I'm just having a little moment...," she said. Clearly, just thinking about a child who felt different or left out broke her heart.

\section{Annette}

The building was very quiet and there were no children; nobody to be seen for that matter except for a woman wearing a headset in the tiny front office. A voice that one could assume to be that of a teacher was coming from somewhere in the building; these were the only human activities detectable at that moment.

Then children's' voices started to flow out from everywhere, indicating that school would be out very soon. In a minute, they came out of their classrooms with their teachers, marching toward the front door. There was only one way to get to the door, which also seemed to be the only door to the outside, unlike other elementary schools I had visited, so everybody passed by the office door where I was sitting. 
A boy who seemed to be Mexican, together with a teacher, came in to the office. The teacher asked the boy, "Does she speak English?" He said, "Spanish." I was assuming from the conversation, that the "she" was his mother and the teacher has something that she wanted to communicate to the mother over the phone. A tall man in a fleece vest appeared and said "Hi" to me as he passed by; he later turned out to be the principal of the school. A little Caucasian girl came in and talked to the woman with the headset about the way to go home, using the school bus or by her mom picking her up. The woman and other people who came in then were trying to figure out if they should put the girl on the bus or have her wait. Parents with their kids and teachers came in. Some were using the phone, some were talking to the woman and some teachers were checking their mailboxes.

With all my attention captured by the things chaotically happening in a very short period of time in a tiny space, I did not notice a tall, lean woman, in a black blouse and a jumper of soft material with black and red rose patterns, come into the office. She was standing by my side and at the very second I noticed her, with her hand already extended, she said, "Are you Yumiko?"

Annette is a tall, slender Caucasian woman in her early 40 s, the tallest of all four teachers. Her modern black-framed glasses and medium-length dark-blond hair were well matched with the feeling that comes from her soft-spoken demeanor. This impression did not fit the image of an American "farm girl," the description that she offered as her foremost identity, no matter what her outfit was-even with 
her jeans, cowboy boots or a very outdoor-type jacket. Growing up watching American TV westerns and family dramas in Japan, my stereotypical view of "American farm girls" did not connect with Annette's persona.

Life History

Annette was brought up on a farm just outside of the biggest city in the state. She had three older brothers and a lot of older cousins to grow up with because her uncles farmed with her father. The family was pretty much contained within the farming community and she did not have much interaction with the outside world: "All I knew was farmers from my early years [through high school until college]. I didn't know too many other people because we also socialized with other farmers." To her, it was apparently psychologically a very segregated environment. The family sometimes would take trips in a motor home in the western part of the U.S., but having a farm and their own garden and animals did not allow them to take time for pleasure beyond that. The family environment "negatively influenced" her:

I ... didn't want the same things that a lot of other people in my family did. I didn't want to grow up and marry a farmer and live next door. I wanted to go somewhere when I got older .... I felt a little bored growing up and never getting to go anywhere, never getting to outside of my family.

She helped on the farm from the age of six, harvesting strawberries. When she was eight or nine, she worked full-time in the summer. This brought to her "little isolated" world different experiences:

When we had strawberry harvests, we would have lot of people come in that were very, very different from my family. So we'd have Russian 
families come in and then Hispanic families come in and I was always really intrigued ... there are people so different than I was .... When I was younger, I made friends with kids for a few weeks. That was really the only other people I knew that were not just like my family .... I remember playing with the little girls, who were Russian girls, and they would teach me Russian words and I would teach them English words .... We [also] just played; we'd go and make forts out of the crates and do things that you don't need language for.

This "family" atmosphere of the farm changed after she was older because of the law that prohibited young children from being in the strawberry fields because of the pesticides that were used. Since then, it was mostly migrant Hispanic adult men that came and not so much families with little children.

Annette went to school in the Cascadia district through high school, and to one of the biggest state universities, where all her brothers and cousins also went. Two years later, she decided to transfer to another big state university, "for a big change." After she graduated, she worked as a waitress for quite a while, during which time she had some different cultural experiences: she went to Mexico for a few months; not long after that she lived in Canada for a winter, and she also lived in Hawaii for a year. She regarded the encounters and events during these times as a "huge cultural experience." Annette did not give me the impression that she was the kind of person who is adventurous and willingly and actively travels to unknown places. She thinks of these trips as the result of growing up on a farm: "I so just wanted to go somewhere." 
After a year in Hawaii, she decided that it was time to "get more serious" and she got a job at a private school in California as a counselor. When her mother died, she came home to her family and worked in a residential treatment center with emotionally disturbed children for about 3 years. When she realized it was extremely hard to see children who had gone through treatment and done well, then been without a good support system after they left the center, she decided it was too depressing to work there. However, the fact that she always "felt [she] was meant to work with kids in some way" drew her back to school for teacher education.

Annette went back to school when she was 30 for teaching licensure and a master's degree, attending a suburban private liberal arts college. After graduation she worked as a substitute teacher for a year and coincidentally got a job in a school in the Cascadia district, where she grew up. After teaching second and third grades and fourth and fifth grades at the first school, she was transferred to the current school because of a budget cut.

When she was teaching at her previous school, she met her husband, who was incidentally her brother's long-time friend, and got married to him. This marriage would give her a cultural experience to add to the ones she had already experienced in places she had been: her husband is Korean, and came to the U.S. when he was 13.

One of the other things in her childhood that is worth mentioning is that her mother was alcoholic and ill for a lot of her childhood, from the time she was about 
8 until she was 17 or 18 . Because of this, she had a lot of responsibilities: "I had to cook for my family and help take care of some of the household things when [mom] was too ill to do it." She did not experience much warmth and nurturing from her mother and the family atmosphere was very cold. Due to this experience, she makes it a priority to create an environment where people are happy, warm, and care for each other, whether it is in her family or her classroom. Her fourth and fifth grade class of 27 students, which includes three Spanish speaking students from Guatemala and Mexico, benefits from Annette's unfortunate childhood experience.

\section{Annette's Critical Incidents}

Family. Annette's was one of the typical farming families in her community, where every family mostly associated with other families within the community. The people had a similar lifestyle and way of thinking. Outside of the community, school was just about the only place she could expand her world:

I was the youngest of four children and [the] only girl. And um ... my father farmed with his two brothers, and they grew vegetables and strawberries and marion berries and um ... so I had a lot of older cousins that I lived with too, and when I was younger, um ... didn't have a lot of experiences outside the farm and um ... I stayed here [Cascadia] all through high school until I went to college. And ... um ... I think in my community, really ... I only ... I interacted with people at school, you know, [and] didn't really have very many people over or anything. And then we went to church once a week. Um ... although at our church, it was ... most of the ... not most of the people, but a lot of the people in my church were relatives, so um ... pretty isolated experience.

Although it is not unusual, considering her family business, it is ironic that the people who brought different experiences into her culturally "isolated" world 
were migrant workers and their families, with whom she worked and played on her father's farm:

One thing that intrigued me as a child was ... we ... especially when we had strawberry harvests, we would have um ... just a lot of people came in that were very different from my family. So we'd have Russian family come in and then Hispanic families come in, and I was always really intrigued that um ... there are people so different than I was. And um ... I would makes friends ... when I was younger I made friends with kids for a few weeks.

And as she emphasized: "That was really the only ... um ... other people I

knew that were not just like ... my family."

Mother. The fact that Annette's mother was alcoholic made her childhood difficult. Although she said that she "luckily had brothers, so [they] sort of took care of each other," Annette had to play the role of homemaker, especially when her mother was ill.

Some of the challenges that we had growing up with was that my mom was ... an alcoholic. She's ... she's recovered many, many years ago ... um she went through treatment very well, and recovered, so um ... that was a that was a big part of my child ... difficult part of my childhood.

Annette was very angry at her mother and did not forgive her for a long time for having been "very weak and let her drinking and her drinking was more important to her than her family or her children."

I was very um ... I was very angry until .... I guess after my dad died I finally forgave my mom, but I didn't forgive her for a long time. I was very angry with her, and um ... rude to her, and disrespectful, 'cause um ... I ... I ... um ... didn't have any admiration for her. 
Annette's mother's illness affected Annette in various ways. First of all, she said, "I had to take on a lot of responsibility when I was younger." Secondly, it resulted in Annette's becoming "rebellious" in her teenage days. Even though she was academically solid, many of her friends were not commendable students:

I guess my friends were ... um ... trouble makers. I was ... I hung around with a lot of trouble makers, but I was always pretty careful not to get in trouble myself; and I drank, and smoked, and you know, didn't do like ... criminal activities ... but not a regular good .... Well, I think in those years, those teenager years, I was really angry at my mom still ... yeah ... I think so ....

Annette later became irresponsible as a reaction to her mother: "When I got out of the house, and I went away to college and I was more on my own, I became very irresponsible for a while, and I think that was a reaction to her." Even if it was not a reaction to her mother, still it is not an unexpected response-for which no one can blame her-for a child who had to carry a burden that was unnatural for one so young. Thirdly, the environment did not give her an opportunity to observe what a "mother" is like:

I think that ... too, I just ... I never've had a good model for what a mother is, and I'm a mother now, and sometimes ... I really have to think about things ... it doesn't come naturally to me because um ... I didn't know a lot of warmth and nurturing from her.

Lastly, Annette's mother's alcoholism could have contributed to making her already secluded world even more so. Annette was the only person, among the four teachers I interviewed, who did not mention memories of having fun with her school friends. The virtual "non-existence" of a mother did not allow her to have 
the regular girlhood that she could have had if the situation had been different. For example, she never had her friends over. It seems that most of her grade school memories are associated with her mother's alcoholism. She recalled how lonely she felt at home:

I was the youngest, and the only girl; my brothers had boy cousins to play with; there were not any girl cousins that lived on the farm. And um ... my dad was ... worked a lot, and my mom was drunk most of the time. Yeah, I didn't have friends over 'cause ... um ... for one thing, we were really busy, but also because of my mother's ... my mother's alcoholism, we didn't have any friends over, so ...

Despite this, there were two Hispanic girls with whom she became friends

on her father's farm. Their family came to work on the farm and after the season ended, they, like most other families, stayed in the area. Annette and two of the girls from the family kept up a friendship, and became close friends in high school.

Three of them were in the same class together:

I was pretty close to them for about 2 years because we all played softball together. And then a lot of time before the game I would go to their house and just hang out with them before we went to softball .... And I knew all the kids from their family; they were a really nice family .... [I] stayed for dinner a few times, and their mom was a great cook, so she always made, like home made tortillas, and so ... that was ... that was pretty neat for me to get to be in their house. And they were also just a really warm, close family, and I liked being around that because that's not how my family was....

The Hispanic family's atmosphere must have been the exact opposite from

that of Annette's family. She described her own family atmosphere as follows:

It was very cold ... it was either too quiet, or somebody was yelling. There was no ... nobody spoke nicely to each other in my house. It was ... it was not a very nice place to be. I mean, I have to give my parents credit, I mean, 
they provided for us very well, and there was healthy food to eat, and clothes, and things like that ... had those things for us ... but just emotionally ....

Such a family environment could have developed in her a feeling that her family was different from those of her friends, which could have engendered a feeling of isolation from her school friends. Growing up in the farming community with an alcoholic mother might have meant two-fold isolation for her.

Father. Annette described her father as big and strong, and a typical good, old man: He was liked and looked up to in the community and worked very hard, to the point that she did not see him very much. I detected her affection for her father when she talked about him, not only because she said, "I liked him a lot," but because of the way she illustrated him. However, even with the love of a daughter, she did not fail to see one of his characteristics which she did not enjoy:

He was ... I think he was pretty narrow minded, like a lot of men in his community ... he was ... um ... um ... I didn't like it that he talked about the people that worked for us in um ... in disparaging terms, you know ... he would call Mexicans, call them "Wetbacks," and I always felt really uncomfortable with that part of him. And um ... he and his brothers always told racist jokes, and that was kind of accepted to laugh about that at family parties, and ... um ... I didn't ... I never liked that about him.

Annette offered a rationale for his mind-set: "I just knew that that was his ... he didn't know any better; he just ... he just had stayed in the same place for so long ... that was just part of his culture ... he wasn't even able to see ... see that that was wrong." Nonetheless, it did not change her bearing about his attitude. Later when she got older, she would challenge him about the issue by saying, "That's 
wrong to say that." His reaction to her was: "He didn't like that, he didn't like that at all. He wanted to be the father, you know, he wanted to be the ... in charge." Annette understands the environment in the old days, when people rarely had contact with those from outside and community members were so isolated that they could be racist, but it is beyond her comprehension that her brothers and cousins still think it is okay to have the same kind of attitude.

Teachers/role models. Annette described her schooling experience by saying "there was nothing extraordinary"; however, she liked school and she was a good student. From those ordinary school days, she recalled a couple of teachers who she thought influenced her. The first one she remembered was her first grade teacher:

I loved my first grade teacher. She taught me how to read, so um ... I don't remember her specific techniques ... um, but I do remember getting a lot of positive feedback from her, and being a good reader early, and getting that message from her. And I remember the ... somebody ... when I was in first grade, the little girl next to me wanted to write "fertilizer" in her story, and I spelled it for her, and ... she went up to the teacher to see if it was right, and we were all sitting at the desks and the teacher looked up and said, "Who helped you spell 'fertilizer'??" and it was just like a ... a big moment in first grade that I know how to spell .... You know, I'd seen it on the side of the trucks all the time and so ... (laugh) so yeah, it was Mrs. C.

The other teacher was from her high school:

In high school, my favorite teachers were the ones that um ... challenged me intellectually; there's an English teacher that's still there ... um ... Mr. F. that ... He is just ... made us read some really challenging books, and we got to have ... what I felt like were very adult conversations. 
Talking about the two teachers brought to her mind a professor at her university. "I had a psychology teacher that I liked a lot ... and he inspired me to study psychology as an undergrad; interesting subject that he presented well." I asked her what she thought common characteristics of these teachers were that made her remember them as influential teachers-if there were any:

Well, as I say that to you, I realize that they all were able to um ... inspire me intellectually; they inspired me to ... be a little ... um ... helping me understand that there's more than ... than ... there was just a lot more .... The world was just an interesting place, and it was a lot more ... more to it than I had imagined.

Annette believes that it is difficult to know when you have inspired your students because there is no immediate feedback from them that tells you so. However, she strives to put into practice what she learned from her own teachers, by trying to show her students things they do not even have an idea about in the world. Annette, who grew up and went to school in the same rural community as her students, knows, through her own experience, that this has significant implications for them.

One other teacher who was memorable to Annette was a literacy instructor, who was also an active classroom teacher, and who taught her in her teacher education program. The reason Annette remembered her is different from that for the other three teachers:

Well the first thing I remember about her ... is that um ... she called me at home one day and said, "I noticed that you are really quiet in class, and I 
wondered if everything was okay." And I've never had anybody do that before.

The instructor's caring attitude is something Annette may have unconsciously learned is important for a teacher interacting with students. Annette told me an anecdote about a Mexican student that indicated her caring for students is not confined to the classroom.

The student's mother only went to school through second grade and she was illiterate in her own language. When the family moved to the States, the children's father was still with them. He was very abusive to his wife and also alcoholic. He was also known for carrying a gun. The mom left him and moved to the district with her four boys. For a while, she was very scared because the children's father would come to look for her. It is not difficult to imagine what kind of family life the student, one of the four boys, had under these conditions. As Annette told it: ... I was just so worried about $\mathrm{T}$. $\mathrm{T}$ lives in a house with broken windows and you know ... just ... a mattress on the floor that he shares with his brother for a bed, and they really live in extreme poverty, and so .... He was um ... just the sweetest boy, and he was terribly far behind in school, but he had a really good attitude, he worked really hard, he tried really hard, and I went to their house once, that they ... T told me that he didn't have a table to do homework on, so at the time we had some furniture that we were gonna donate to [a second hand store], but I asked his mom if she wanted this furniture, so she did, so my husband and I took this furniture to their house, and spent a little bit of time there.

Annette was eager to find out her student's family situation, as the story indicates. She remained concerned about how he and his mother were doing even after he left her class: 
So ... last time I heard he was still in school ... his older brother was still in school - trying to think, I think he had one older brother and two little brothers. But um ... his mom was ... had a job that she was working minimum wage finishing doors at a cabinet [or] something .... Um ... the last time I checked this summer ... he was hanging in there, didn't turn in everything, but um ... you know, as he moves up through the system, his teachers won't know him as well, you know. I told his math teacher, you know ... "Do you know what's going on with his family? And he comes to school everyday?" And if he's clean, then that's, he should be ... His whole family should be rewarded for ... because um ... they ... I just think they've had a really hard life and I hope things get better for them ....

It was obvious that she helped the family out of humility and genuine concern about their condition and the student's future. For Annette, caring for her students in and out of the classroom connects with her idea of having students grow to "figure out who they are, and be their best, the best person that they could be." She wanted to help $\mathrm{T}$, whom she describes as having a "good personality [and] really good heart" to achieve his goals and dreams: "He didn't want to drop out, he didn't want to be like his dad, he wanted to take care of his mom [and] he wanted to be somebody; wanted to make something of himself."

Universities. Annette's transfer from S. University to the University of S. seems to be a result of her desire to expand her limited world; and this, according to her, was exactly what she experienced. At the time of the transfer, she thought she was doing so because the University of S. had a bigger department in the subject she was majoring in; however:

Really, I think [I] went there because it was politically liberal; it was further away from home; none of my siblings had gone there; all of my siblings had gone to S. University; all my cousins had gone there. So that was a really big change for me, politically. That's when I ... when I first started to learn 
about what "being liberal" meant because when I was growing up, "being liberal" meant that it was a bad person, you know, you were either with us or against us ....

Having started as an agricultural college, one of S. University's strengths is agriculture, and it was natural for Annette's siblings and cousins to attend as potential successors to their family businesses. On campus, Annette might have felt that she was still in her "farm world," given the university's characteristics and her siblings' and cousins' presence there. One day, her brother "pointed out this coffee shop, B [near campus] and said [to her], 'whatever you do, don't go in the B. because that's where all the hippies go." She once depicted her family as "sort of red-neck, Republican, Christian, limited in their view," and she "never exactly related to that." So going into the coffee shop, as soon as she got a chance, was a natural response to what she was told. It was a fresh surprise for her to see a different kind of people from those she had known from her farm community: "I'm like, 'Oh, what are these people about?'”

Transferring to the University of S. gave her the same kind of blow that Annette had experienced in the coffee shop:

I had never known anybody outside my, you know, farm world, and um ... so when I went to [the] University of S, um ... gosh, there was all these people around me that ... on one hand, seemed exotic to me, but on the other hand, I could relate to how they thought and how they felt, and it wasn't the kind of place where .... I was just really amazed at their free thinking.

The University of S. was the first place where she encountered people and ideas that were new, but ideas she thinks she always carried in her spirit: "I ... 
think I always had that in myself but I didn't really understand what it was ... so... that was very changing":

I remember a ... um ... philosophy class that I went to, and I thought, "Oh my gosh, some of the things that people were saying ...." I thought ... interested in it because I had grown up with [the idea], you know-this is the way we think - that leaves turn color because God wants it to be that way, and um ... I never really liked that, it didn't make any sense to me when I was growing up, but I didn't really know why. So when I went to University of S., I started to understand why that didn't make any sense .... Um ... I very much rejected my family ... um ... inside of myself, like you know, they're just ... they're so limited in what they think and here's this college, that ... people know so much .... So that was the beginning of a free thinking.

The transfer was momentous for her: "It [the culture of the university] was something that I really wanted but didn't know how to find .... [And] I just thought there were a lot of people who thought like I did."

Her yearning for something different seems to have been a driving force directing her life.

Traveling. Annette traveled to a few places that gave her new experiences. As she said, these trips took her to unknown environments and were "a big adventure" for her. Her first trip was to Mexico in and old VW van with a friend of hers. The first thing she mentioned about the trip was a memory of children she met in Mexico; children playing with her, going swimming in the lake, and teaching her Spanish in exchange for her teaching them English. One of the memories she mentioned was a very cute one with a little boy, which led her to a new cultural experience: 
We were setting up camp by this really, in this really beautiful little town by a lake. And ... um ... the kids - I always just loved kids--the kids from the village would all come running out to see ... and we were like these exotic people to them, I think. And this one little boy-we were unpacking things-he stole a box of macaroni and cheese and ran away from us!

The boy came back and returned the food to them because he was yelled at.

So her friend gave the children macaroni and cheese. The next day, the boy came back and said that his parents were inviting her and her friend over to their house:

So we went to his house, and [the boy's mother] thanked us for the macaroni and cheese, 'cause she'd made it for dinner, and then um ... the husband got some coconuts for us, and 1think we had some sodas. And we sat around with the um ... English-Spanish dictionary between us, and spent hours ... gosh, with this family. And um ... they were really different from anybody I knew 'cause they lived in this one, um ... one-bedroom house, and I think they had five kids, dirt floors, the mom sold mangos in the market, and the dad was um ... he would go catch crocodiles for zoo showing? These pictures of ... I think they go to like um ... Central America or something, and he and some of his buddies would capture exotic animals and send them to zoos. So ... that's one, kind of neat memory.

When Annette was younger, she had played with the girls who came to her

father's farm with their family and so learned that even without a common language, people were able to make connections with each other. The exchange with the Mexican family may have let her revive the idea: "they were so warm, and so welcoming, and even though, um ... we couldn't say a lot, 1 think there was a lot expressed between ... between us, you know?" However, not being able to speak the language gave her the biggest learning opportunity:

[The trip] was very humbling for me because when we went ... this friend invited me [to Mexico], and I was you know, "Great, we're going to Mexico! This will be so fun, I'll just get my Spanish book [and] I'll practice 
on the way." And you know, oh no, it was not that easy you know .... The first thing we did when we crossed the border, was we had to find a gas station, and weren't in a big town, and we're like, "Donde esta?" you know, "Excuse me!" And so that was hard and you have to go to a restaurant and get your food and ... okay, so we sort of figured out how to get the hotel, and how to get the food and then um ... I got sick and then ... "Well, what do I do now? I'm sick." Luckily, we met somebody else who knew what to do, so you know, and had a doctor's phone number and so we called the doctor. And then at one point I had to call the airport and change the date of my flight home because we drove down there, but then I flew back by myself. And you know, I tried to call the airport, and of course, I asked them if they spoke English and they didn't, and so um ... I'm trying to carry on a conversation with someone in Spanish, and it took me like 3 minutes to figure out that I had the wrong phone number because my language was so limited .... So ... I think that I just learned how ... how really hard it is just to function in a really basic way somewhere when you don't know the language and you can't read the road signs, and um ... you know, you don't know what the protocol is for finding a doctor, and ... yeah, it's really complicated.

On one hand, she knew that without speaking the same language, people can communicate and enjoy time together; on the other hand, she learned that the same condition can prevent indispensable human activities. In a desperate situation like hers, it is likely that one will feel helpless, vulnerable and scared. She mentioned a few times in our conversation that "it's one thing to be an adult [who] doesn't speak the language, and another thing to be a 10-year-old [who] doesn't speak the language." Those experiences in Mexico may have helped her know what it is like to be in an American classroom as a 10-year-old Spanish-speaking child.

Annette's second trip was to Canada for 4 months in winter. The place was "way out ... just way far from modern civilization." The place was on a lake and did not have regular road access and there was a "little community of people ... [with] 
about 80 full-time residents." Although the people in the community have some resemblance to people she knew when she was growing up in that "they were people that were very connected to the land," they were also very different:

They weren't so much bound by the conventions that we have ... um ... they had to get by in very cold winters, and not a lot of ... they didn't have the kind of materialism that we see now. What people did for fun was people got together, and made their own fun; there weren't movies, and .... And ... you know, we had to get up every morning, and chop wood, and there was a pump in the house, but the pump froze because it got really cold; so we had to melt snow for water. There wasn't any plumbing, to take a bath ... we didn't ... we had to take a bath in a pot that ... you spent all day working on the wood stoves, so ... it made me appreciate how .... And then, um, we fished for ... you know, our fresh food because it wasn't like there was a Fred Meyer or ... down the road or anything ....

The remote place gave her some great memories, among which is a little one-room school with 13 students, who "either walked or skied or rode snowmobiles to school every day." She regrets she did not visit them more often and offer volunteer work to see what their regular classroom activities were like:

We went to a Christmas program at this school and that ... it was just fabulous .... I was just amazed at how ... you know, way out in the middle of nowhere what these kids were doing, and what the teacher was doing with them .... They were singing; I remember they sang in French, and then in English and I remember this school was just so beautiful ... like there was a lot of beautiful art, and ... there were computers there, which I'm still ... I'm not sure how that worked out ... 'cause there weren't phone lines there, or electricity. They had ... people had generators there but I remember seeing computers there, and thinking how that worked. Um ... they must have been able to use them for word-processing or something off the generators. And the kids just seemed really bright and curious, and they didn't seem like backwards kinda kids at all. 
She described this trip as "another huge cultural experience" after Mexico.

In contrast to these two trips, Annette's next trip gave her a different kind of experience. After Canada, she lived in Hawaii for a year, waiting tables. What she experienced there was "so shocking." She was stunned by "really vicious racism in Hawaii." She not only heard or saw it, but also became a target of racism.

My friend and I wanted to go to Saturday Market, and ... we parked on this street in front of this house on a public road, and this old lady came out ... "You haole girl! You can't park here! This is my house!" (shouting) We went ... went to the market, was there for about 10 minutes, and came back to the car. And there's this great big guy with a pick-up truck standing there, and he goes, "You haole girls!" (shouting) - and you know haole's like slang for white, a foreigner-"You haole girls! She told you 'you couldn't park here!"”

Annette and her friend later found that the man was a fire chief in the community and she remembers that at one point, he even yelled at them, calling them "Haole sluts!" Annette talked about how she felt at that time:

I ... I felt like ... I felt like they didn't want us to park there because we were White, and you know, maybe not, but um ... that's how I felt anyway, and he certainly was being degrading to us because we were female and White.

She had another experience that was more personal and therefore even more

disturbing. Her Hawaiian friend invited her to an extended family dinner:

Everywhere, everyone she introduced me to, she introduced me as her "haole friend" .... Not as "This is Annette" [but] "This is my haole friend!" And it was always like "See, she's nice for a white girl, isn't she?" and it was really weird ... to be treated like ... some ... you know ....

Even though the friend was well-meaning, Annette did not perceive the way the friend treated her as nice. She was mostly "[hanging] out with ... White people 
that worked in restaurants" because she "felt pretty uncomfortable in Hawaii." These experiences in Hawaii gave her a chance to think that "racism can take a lot of forms and a lot of colors," i.e., it is not only one-way, from White people to nonWhite people.

Compared to experiences of people who travel extensively to and/or live in very different places, Annette's experiences may not seem significant; nonetheless, for a "farm girl" who was "closed in" in a limited world, the experiences she got from those trips may have opened her eyes to new things. The experience of growing up in the isolated world of a farming community has also influenced her teaching in a positive way. She always tries to teach her students that there is a lot more to this world than what they know within their own world. As a child, she unknowingly longed for something that would show her the world is more than she had imagined. Being raised and going to school in the same school district, she knows what her students' lives are like. She desires to broaden her students' perspectives through her teaching.

Husband. Annette did not mention, until I asked about it, that her biggest cultural experience has been in her daily life--in her marriage: her husband, Daniel, is Korean. His father, Mr. C, was working for the American government in Seoul and Daniel grew up just outside of Seoul. Daniel's father decided to follow one of his brothers who was in the States, when he was close to retirement. The family had three boys and three girls, including one who died when she was younger. Annette's 
husband is the youngest of the three boys. The family was very poor in Korea as most other people there were in those days. Daniel's father was very authoritarian and physically disciplined his children (although it was acceptable and not considered to be abusive in those days in Asia). When the family came to the States about 33 years ago, Daniel was 13 and he went to American middle school, where he did not understand anything because he did not know any English. Consequently, he had to survive the "sink or swim" classroom situation, where "he was just terrified." Her husband's experience makes Annette "think about what it's like not to speak the language, or ... to misunderstand the language." Daniel also never spoke Korean at school. He did not want his difference to stand out. He wanted to be as same as anybody else:

I think it's hard for him to feel, maybe back then, to have felt like he was proud of being Korean because he didn't want to be different; he wanted to be White like everyone else at the school. So I think school was pretty hard for him.

Annette also understands how people from a different culture may feel about their own culture in the States. She told an anecdote about Kimchee, famous Korean pickles. She always wanted to bring some Kimchee to her classroom for her students to try. But her husband said, "No, no! If you're gonna give them something, give them something they'll like the first time!" Annette thought it was a good idea to bring Korean food, especially because she had read her students a 
very old Korean story the previous year. She interpreted Daniel's sentiment as follows:

I think that he is um ... very conscientious of ... his different-ness. And we live in R. City too; we live in a pretty White community. And he wants to present the best of his culture so that people think that it's good to be Korean, you know. He doesn't want them to, you know ... "Ewww! Kimchee! It's stinky!"

Whether it is language or culture that is the issue, Annette's husband's desire is not to be perceived as different from others, and she understands his point of view.

Husband's family. Annette has found many differences between the Korean culture and her own. One example is the way people address their in-laws. She said that Koreans call their relatives by their titles such as "Konabagee (oldest uncle)," "Dolche Konagobee (second oldest uncle)" or "Hyon ${ }^{24}$ (older brother)." Annette likes this cultural practice very much and said that it was nice to be called by a title:

I think that's really neat ... um ... I don't know ... maybe because it's different .... It's neat ... like um ... I can't remember, but like my brother-inlaw told me my Korean name once was for the "youngest son's wife," and then when I had a baby, they added something to it, so my name meant something like "little mother" I thought it was so sweet! .... I think it's so sweet. So my name changed when I had a baby because my status was a little higher ... so ... like that.

As having a baby changed her title and raised Annette's status, so the "title" practice has to do with ranking in the family, about which Annette gives an interview.

${ }^{24}$ All the Korean words were phonetically spelled. They are spelled as I heard them in the 
example. Just after her husband's oldest brother got married by arrangement in Korea and brought his second wife back, Annette had the following experience:

She came over to my house, and she was kind of bossy with me. And I think it was because you know, I'm the wife of the youngest brother, and she felt like it's okay .... Oh, she was um ... this wasn't to me, but to my son, she was kind of um ... chastising him for wearing his shoes in the house, and we ... we wear the shoes in the house, so I thought that was kind of strange ....

As Annette thought, in her husband's culture it may be common for older brothers' wives to hold a higher rank-therefore more power-than younger brothers' wives. Consequently, younger brothers' wives would be expected to obey older brothers' wives. Accordingly, the oldest brother's wife has the highest status among the siblings' wives regardless. The ranking practice would apply to status of men and women as Annette also experienced. Once her husband was pouring tea and it did not flow out from the pot well:

And they said, "Oh, this tea pot's not working right" and I said, just jokingly, "Oh, it's not the tea pot, hand it to me, let me try it! It's probably the way you are pouring it." And I was just joking, but my brother-in-law got serious and said, "You shouldn't speak like that to your husband. You shouldn't shame your husband in public. You should be respectful to him." And um ... that was kind of embarrassing for me.

This was not the only time that her manners were taken as inappropriate. As she said: "I've been [in a situation] more than once where I've been reprimanded by older in-laws ... because I wasn't behaving right ...."

One of another "on-going ... definite cultural differences in his family" is about jokes. One day Annette and her husband were at her husband's brother's 
house. She spilled coffee on her shirt and she did not have another shirt to change

to, so she made a self-deprecating joke:

I made some kind of joke about that, and nobody laughed, and it was kind of uncomfortable ... I said to Daniel, "I'm always trying to make jokes and fit in and nobody ever laughs," and he said, "They don't think it's funny." It's not funny to them to make ... (laugh) and I'm like, "God, that's the only way that I know how to ..." you know? "I can't have a relationship with these people."

Annette always tries to fit into her husband's family. However, it is

undeniable that she often feels inept:

For one thing, people don't speak English when they all get together ... they do when they're talking to me directly, but everybody else speaks Korean .... When it's a big group of people, I'm uncomfortable unless some of the younger nieces and nephews are there-because I feel very comfortable with them-but with his older siblings who, you know, in their 50s-so they've spent a majority of their lives in Korea already - um ... I feel they're very kind to me, but I definitely feel out of place ... and it's not that they're um ... you know, mean or anything, but it's just that I feel ... [I'm] not part of them ....

Annette has felt alienated more directly in some other settings. One of them

- is with wives of her brothers-in-law:

I was at Daniel's brother's house ... and three of the women were all cooking together in the kitchen so I went into the kitchen wanting to be a part of it, and um ... kinda hung out to the side and didn't know what to do, so you know, I asked what I could do, and they brushed me aside, "Oh nothing, nothing, nothing ...." And you know I kind of felt sad because I wanted to be a part of the cooking.

The other case is with Daniel's mother. As Annette put it, "she has had ... out of everyone, the hardest time accepting that Daniel chose to marry somebody 
who wasn't Korean." According to Annette, "Daniel's mom doesn't approve of me because I'm White, and still doesn't'

Annette's memory of the first time she met her prospective mother-in-law was very vivid: "Daniel introduced us, and she didn't say anything to me, and she went like this ... twice, she looked me up and down, really slowly and I thought, 'Oh my gosh!'”

Daniel asked Annette to go help his mother when she went into the kitchen to cook. In the kitchen, her prospective mother-in-law did not answer when Annette asked her if she could help: "she just never acknowledged my presence."

During their 5 years of marriage, Annette and her husband's family members have compromised and tried to understand one another. As a result, they have become more comfortable, but Daniel's mother is still not very happy about her son's decision:

Daniel's mom doesn't approve of me because I'm White, and still doesn't .... She speaks very little English, but even still ... like my attempts to talk to her, she kind of rebuffs me, and she will interact with me if I have one of the kids with me, like if I go sit beside her and you know, kinda get my daughter to play with her or something .... His mom has always been sort of like, "Who are you? And why are you marrying my son?" ... and you know I've tried to speak to her, but she's ... I think maybe she accepts me a little bit now that we've been married-we've been married 5 years now-but I mean, um ... she definitely doesn't approve of me, and she definitely would've liked him to marry a Korean woman. And I'm also the only White person in their family ... so ... I just don't think she knows what to do with me ... (laugh) 
In spite of what Annette has heard from the family about her mother-inlaw--that she is so sweet and loving-her relationship with her mother-in-law makes Annette feel "a little cheated" because she "never got to experience that." It seems that Annette is still in the process of getting to feel "truly" accepted in Daniel's family, especially by his mother, with whom Annette would "like to have a relationship." Although she may have been feeling as though she is an "other" in the family, she does not forget to mention that she is appreciative to the family: "even that being said, for the most part they've always been very gracious and kind to me ... and welcoming to their family."

Teacher education/training. Annette went back to school when she was 30 for her teaching license and a master's degree. The school she attended was a very liberal private college and the teacher education program was designed with multicultural education as one of the main ideas for its curriculum. They did "a lot of philosophical work in graduate school" and had "a lot of discussion and writing and reading about the function of public schools in our society, and the importance of maintaining democracy in a classroom." According to Annette, the multicultural education concept "was just present in every class, and that was part of our discussion." Rather than talking about practical teaching skills, discussions were mostly about race and culture, and these issues in education and students' achievement: 
[We had] little time talking about actual teaching techniques, or how to write a lesson plan, or how to deliver, because their belief was that if you build a strong philosophy, that the details of teaching will come later .... [We talked about] um ... like in different types of instruction, for example, in um ... schools that have a high rate of poverty, there's a lot more phonics instruction and reading, and then in wealthier schools tend to use more whole language approaches. So ... we would spend a lot ... a lot of time talking about those kinds of issues.

Thus, looking back, she recognizes the value of the program in that it made

her aware of the power issue in society:

We talked a lot about the um ... dominancy in white culture, which I probably hadn't really though of that much before the program ... um ... you know, a lot of power issues .... I think we did a lot of work putting ourselves in other people's shoes, and trying to be observers of other people.

However, as Annette remembered, in her program, cultures that were discussed were mainly Black cultures, relative to the mainstream culture. Although she appreciated the way the program was run, she also mentioned that they could have discussed educational issues from a more culturally multifaceted angle rather than just from the usual "Black vs. White" line:

You can ... you can place blame [on], you can raise the awareness [of], you can raise the sensitivity of people .... Um ... you know, I just think that you can have a much richer discussion too, about, you know, why are some immigrant so successful in school, and some aren't? And what kind of role does poverty play? And what kind of [role do] educational cultural values play in the community? And I always hated those discussions in graduate school because I felt like if I piped up some of my ideas then ... people were just very afraid to go there ... so ....

The following anecdote suggests a reason that teacher education programs should be flexible in dealing with important racial issues. As it happened, in 
Annette's cohort, people from non-mainstream cultures "came from very privileged backgrounds." Because of the nature of the school she was attending, it is not difficult to imagine this. One time, one student tried to silence Annette. In a class discussion, she was going to offer the idea that racial issues should be discussed along with other elements such as poverty and class, so that the discussion would not devolve into the concept of racial separatism. After the class, the student, who was African American and from a family with money and political power reacted to her as follows:

He came up to me later ... and um, his-I don't remember exactly what he said, but-his message to me was you know, if you're white, you really can't make that kind of judgment .... And um ... I felt like ... I felt like he was kind of playing a race card on me, because he ... um ... (silence) he was a person from a very privileged background, and um ... I almost feel like he was putting me in my place in saying you know, "Don't speak out." There's ... the message I got ... these weren't his [exact] words, but the message I got was, "If you're white ... (silence) ... racism occurs from white to other colors. Racism cannot occur from other color to white." Because that was the idea that I was trying to express that um ... everybody is somewhat tribal, and wants to be with people that look like each other, and there's always jockeying for power. And um ... he felt like I was stepping out of line to say that. Because I am white, [his message was:] "you need to accept that you are part of the dominant group that is oppressing people, so you shouldn't ... you shouldn't be anything other than very humble to be a part of the dominant group" ... if that makes sense ....

Annette is well aware that "in this country, people that have money are the people that have power, and often, that's white people." However, she tried to look at the issue in multidimensional terms:

It's not that simple, it seems to me that, you know ... because there's so many other factors that .... There's socio-economics, there's where you 
came from, um ... there's your skill-level, there's your reputation in community ... I mean, there's so many things that contribute to your power as an individual ....

Annette's experience in her teacher education program may suggest that teacher education programs should include multiple—-even unexpected or nontraditional- viewpoints in teaching multicultural education.

It is necessary to present the idea of systematic racial oppression, but to note that a given cohort could represent a microcosm of a very different reality, and thus present a very different classroom environment, as Annette experienced:

The people in my group that were not white ... for some reason, came from very privileged backgrounds, and so ... (silence) I ... somehow ... that didn't really contribute to the kind of things we were hearing ....

In such an environment, it might have been profitable for all students to hear ideas that Annette tried to share; a very productive outcome could have been for the class to hear what Annette's colleague had to say about their experience of one another, to understand why he said what he said, and to debate it in an open environment where all students could share their thoughts and ideas without being intimidated.

It almost seems as if Annette experienced being a "silenced other" in the program. She did not mention whether she connected this with her experience in Hawaii, where she was treated not very nicely by some native Hawaiian people, but these two experiences, taken together, could have helped her understand how culturally and linguistically diverse students - "others"-feel in the classroom. 
For Annette, even things that seem to be in disagreement with one another-White power dominance in the society, her being White, her nonprivileged background, her non-White colleagues with money and power, her feeling alienated in the program, her struggle with the idea that she must feel guilty because she is White, etc.- -seem all to be pulled together into one prominent feature of her own practice: empathy for students who feel "different."

\section{Findings}

The main purpose of this study was to answer the following research question:

What can be learned about the life experiences and perspectives of mainstream elementary school teachers that has enabled them to be successful teachers of ELLs?

My method was to describe and try to understand the life experiences of four teachers known to be successful teachers of culturally and linguistically diverse students.

The four teachers share a strong moral grounding, important in enabling them to be genuinely caring teachers, no matter what their students' backgrounds and identities might be. Terry mentioned that he "just want[ed] to help people if someone need[ed] it," first teaching his students how to understand each other by learning about each other, before teaching academics:

You are in it [teaching] because you ... you love the kids, and you love the relationships, and ... and that you can only make it a better place .... I'm not a love, love person all the time. I am ... I can be pretty grouchy 
sometimes and stuff, but that's what drives me .... I do it ... to show them that while we're doing something together, they get to see other people and learn how to be nice to other people and how to show and teach, and understand. And so I think that ... that's where I came from and that's kinda how my kids are getting taught and that's how I teach my kids in the classroom.

Sabrina's empathy and her abhorrence toward any kind of unfairness prevailed in all her stories, no matter the subject:

Every person has value, every person has feelings .... Yes, everybody has feelings .... I think there are so many people that ... who are so selfcentered, that they don't realize that there are people beyond you, and your actions really, really do have an affect all the way out, they just do, and that's a really important issue for me....

Annette sounded very modest when she said, "You can only do as much as you can ... by affecting kids and families as individuals." However, it is clear that she would do whatever she could to help her students both in and out of school, as seen in the anecdote about her work with a struggling ELL family.

Dian, quoting Robert Frost's poem, described what she would like to be and do as a person, and in a way she encapsulated the philanthropic attitude of all four teachers:

I watched that show of, on PBS last night, of traveling to the moon, and ... and uh ... when they were ... those first pictures that they ever took of Earth from the Moon ... and the awe that those people felt when they first looked at ... you know .... Here's this tiny little planet you know, world of blue and white amidst all of this bareness ... and it's ... and it's full of turmoil, and ... what this Earth could be like, if .... So, I really thought about that last night, and I'm thinking ... this world would be a really nice place to live if everyone [is] just even a little bit nicer. So I started talking about that with my [students] about ... "Well, how do we make that change and we really can only ... we can really only change ourselves in a very, 
very small world, but we can do something, rather than just say, 'Well, how do I matter in this whole world?' But if everybody said, "Me!" then we really wouldn't ...." So I guess that's kind of ... that's what it really boils down to ... I can only influence a very small puddle, but I can ... but I can do what I can. So that's kind of sums up.... "The woods are lovely, dark and deep, and I have promises to keep, and miles to go before I sleep." And so that ... I'm kind of a ... I'm kind of a person that thinks that way, you know. It'd be really nice to be nice and fun to just go off and do fun things, but I think - and I'm embarrassed to say this kind of [thing, but] — I'm the person that thinks you need to give back .... you don't always have to be working, you don't always have to be doing that ... but I just think uh ... you know, for the privilege of living here on Earth, you need to be working ... you really should be doing something.

It is beyond the purpose of this study to identify whether this sort of disposition is innate, develops later, or develops because a teacher already has an intrinsic sense of humanity and fairness. Nonetheless, the four teachers' stories show this sense being developed through and strengthened by life experience, whether or not it sprang from an innate sense.

This section will illustrate how specific incidents in the four teachers' lives contributed to the formation of their ways of thinking. In an earlier section describing the incidents and events, whose physical settings and participants were very different for each teacher, we also saw how their life stories including families, teachers, education, travel, marriage and other life factors, were unique. In spite of this, comparing and contrasting the events and incidents uncovered several commonalities, which have become this study's major findings.

Initially I came up with four commonalities, which I thought were discrete and characterized by different themes. These commonalities were that the teachers: 
(a) possessed a challenge-taking nature, (b) were life-long learners, (c) had experienced different cultures, and (d) had experienced being an "other." However, as I read and revised my many drafts, referring back to the data and my notes, I realized that (a) and (b) were related to each other, that (c) and (d) were as well, and that each pair ought to be grouped together. Therefore, in detailing themes drawn from comparison of the four teachers' experiences, under "Experiences in Different Cultures" I will describe two kinds, which I name (a) "Regular" Cultural Experiences and (b) "Otherness" Cultural Experiences; and, as a part of my description of the common characteristic, "Possessing a Challenge-taking Nature," I will include the related common characteristic, "Being a Life-long Learner."

\section{Possessing a Challenge-Taking Nature}

One commonality that the study reveals in all four teachers is a risk-taking or challenge-taking nature, shown by multiple incidents in their lives. As a teenager, Terry, trying to save a mother and her children from domestic violence, got involved in a situation where he exposed his life to danger. The incident involved knives, guns, and police. Even though he was acting spontaneously at first, later he could have left the family behind. Instead he came back, took the assailant down and walked him (while the man was hiding a knife) to the police station, two and half miles away. Without Terry's risk-taking nature, the mother and children could have been injured or killed. 
Terry's strong will in turning his life around, and his choice of being sent for his military service to a country where he did not understand the language, are manifestations of his challenge-taking spirit. Several times he asserted very clearly that this was the event that "changed [his] life more than anything ... probably even more than [his] dad dying ....":

I didn't want anything from my past to ... to have ... any bearing on where I was going and what I was doing, really, I mean, not my past. But my ... I wanted to go to the place because 1 didn't want any help from anyone here. So I wanted to go through a hard situation where 1 knew that I made a substantial growth, and would be able to be proud of myself for making it through something like that and learning a lot about the other countries by doing that. Um ... it was hard, but I started to pick up the language very well and I learned a lot about the countries and history and foods, and you know, even economics and everything.

In the classroom, from the first day of his student teaching he took on the challenge of full responsibility for a class of Russian students-teaching them all day and every day. As he recalls:

When you student teach, you watch for a long time first, and then you teach .... I was thrown into my own classroom downstairs by myself, from the first day, and I taught full-time for the whole time I was there .... Um ... I think it was close to half a year....

Terry, who says, "I'm not afraid to try things" even articulates why he likes to be in a challenging situation: "I like challenges. I ... when I'm challenged, it makes me very effective." 
Terry's challenge-taking, positive soul manifests in the way he understands his father's death. He did not just end up retreating into grief, but turned the experience into something constructive, a reason to aspire:

From losing my dad ... knowing that you need to make every minute count while you have the chance to do it, and to live your life to the fullest .... When my dad died ... that whole thing about [the incident], you know, [taught me] doing the best you can do when you're doing it. I mean, why not do the best you can do if you're gonna do something? Why waste the time doing something that isn't gonna matter when you can really be thinking about something?

This experience was the source for teaching his students to "live life, have fun, fulfill themselves and to think [more] deeply ... than the surface .... scratch a little deeper." These are "the things that I believe," he said. "By the end of the year," he said jokingly, "I see my kids as being 'a little me,"' because "they see me modeling that all the time."

Annette's challenge-taking nature shows when she talks about her desire to get out of the community she grew up in, a place where people have similar life, work, values and practices. Living there did not allow her to see that there were a lot of other different visions and ideas in the world. An idea as simple as going hiking just "to hike" did not exist in her lexicon because in her community, going into the wilderness meant something else directly connected to daily needs:

I didn't realize people went to the wilderness and just walked for recreation. I guess it just never occurred to me that that was just something fun to do, and that's become a big part of my life .... The only time we ever went out in the wilderness was to hunt, or fish, or you know, there was something ... 
there was some kind of a ... some goal ... you know, there wasn't just ... to go out and enjoy nature.

Talking to her, I saw how she longed for the unknown. Three of the four teachers, including Annette, grew up in comparable environments, but Annette was the only one who verbalized "hunger" for the outside world. It seemed as though her longing had been engraved in her mind and soul since she was a child. She could not allow herself to end up marrying a man who lived next door, to spend the rest of her life as a farmer's wife, going to the same church every Sunday.

This "confined" feeling, from living in a small and small-minded, traditional rural community, was a springboard for Annette to make changes. The switch from a university to which traditionally everybody in her family went was one of the first, a change so unconventional that it is not difficult to imagine how it created discontent in her family, as seen in her following remark:

It was a good culture shock, it was something that I really wanted but didn't know how to find, so it was a place where I felt in my element .... I think it was like a starting off place for me, like the beginning. I could've led a life that made my mom and dad happy that would've made me very unhappy, and that was kind of the place where I thought I needed to go my own way no matter ... still don't regret doing that, although I probably caused some people to be unhappy with me, or caused my parents a little bit of grief ....

In spite of the family's disapproval, for Annette it was an event that opened the door to new people and things she never knew she was always intuitively seeking. Maybe because of the craving, Annette is the most "well-traveled" among the four teachers, except for Terry, who has lived in and traveled around Europe for 
his military service. "Well traveled" may not sound descriptive of a person who only took one trip to Mexico, and lived one winter in Canada and a year in Hawaii, compared to people who have expansive experiences in many different countries and cultures. However, coming from a place where most people had the same limited views- - "tree leaves turn red because God wants them that way or liberals are bad people, and if you don't agree, you are not one of us," in Annette's description - these trips probably meant more to her than travel does to a person from a more worldly subculture.

I once mentioned that she surprised me at times when she talked about her trips. I could not really say why because the trips she made were not so unusual. Later I concluded that it was the odd combination of "farm girl" identity"somebody who's practical and down to earth"-which she described as her ultimate identity, with her propensity for "uprootedness," which I intuited in our conversations. These two seemingly opposite characteristics now make sense as front and back of the same coin.

Some views held by Annette's father apparently reflect their community's bias against people from different backgrounds, and seem to have an effect on her. As Annette jokingly said:

One of my first boyfriends ... was um ... part Hispanic, and I don't know if I consciously chose that because I was rebelling ... and I did ... I ended up marrying a Korean man .... So ... I don't know if I consciously chose that but ... it always bothered me that he was like that. 
Whether or not her father's prejudice was responsible for her marriage is not pertinent to this study, but it could have been part of the limited environment she wanted to leave, and it could have helped open her to the challenges that an intercultural marriage would bring to her life.

These challenges range from language, food, music, and daily life to values and beliefs. Being a cultural "outsider" to her husband's family, Annette has been perplexed by her husband's silence when they have a fight; a message she sometimes gets from him that the wife should work harder than the husband; or his family's sudden visits. It is especially difficult when her husband asks her to unconditionally accept whatever the family does: "My husband says, 'That's just Korean,' you know. 'You're gonna have to accept it.'" It makes her feel compromised.

In spite of all difficulties, Annette thinks the fact that her husband is Korean is an added bonus; "I thought that it would be very interesting to be married to someone who's so different, and it has been. (laugh) Challenging, too."

In Sabrina's case, her life itself started as a challenge: being adopted was not a choice she made. She is grateful to her birth mother and adoptive parents for what they did under the circumstances at the time:

You have a 15-year-old mother who gives birth to you, that (pause) you know, she did the right thing, that's great--I mean like, where would my life be, with that? [And] you feel like, you know, these people, they go looking in the little baby department and they're like, "Ooh, I pick you!" 
And that's cool. And you know, obviously, they really want you because they adopt you. So that's a really good feeling.

Nevertheless, the feelings of being "deserted" have always been with her:

“somehow, I can't almost wonder that a child, somebody who's adopted, doesn't have that one sliver of that feeling. I feel like it's pretty common, I would think." Among those involved, she was obviously the only one who did not choose the option, but she has to share the result, probably most directly.

Sabrina knows what it mẹans to adopt, yet despite the complexity and difficulty, she and her husband decided to adopt a child, as she told me at the end of our final interview.

During our conversations she had gone through clear emotional upheavals about her own experience of being adopted; perhaps it was part of a healing process, unloading what she had held close to her chest for a long, long time. It seemed as though this process, in some way and to some degree, triggered her decision, as she implied in our last-moment conversation.

Without a challenge-taking spirit, who would take on this extremely intense responsibility, especially knowing very well what it could bring about? Most people might not even want to face the difficult emotions of being "abandoned" by their own biological mother and not loved by the adoptive father- people from whom unconditional love should have come. However, Sabrina, with her open heart and challenge-taking nature, made the choice to relive her own history in 
order to "correct" it, in the life of her own adoptive child—a tremendously courageous act.

In Sabrina's other courageous story about confronting one of her high school teachers in support of a friend, one finds evidence of her risk-taking nature. She thought the teacher treated her friend unfairly; Sabrina could have been expelled for the belief that nobody should be treated unjustly. It takes a strong mind to actually act upon one's conviction—not just talk about it—when one knows that the action may have consequences. This particular conviction seems to have been rooted in her experience as an adopted child. The realization that her own family regarded her as someone "different" had a profound effect on her personal development. She could not tolerate any kind of mistreatment of anybody by anybody.

Dian mentioned that she liked strong women, and described those who were her role models. The message was loud and clear: "I like women who keep challenging and never give up under any circumstance." And this is also what she has been doing throughout her life.

Getting married as a young person and having six children limited her activities until her youngest child started school. She went back to school and felt intimidated to be in the classroom with traditional, straight-out-of-high-school students. She had a long commute to the university when she still had responsibilities as a mother. She had to regain knowledge of academic rigors after a 
long absence. After finishing her bachelor's and master's degrees, teaching license, and reading endorsement, she did not give up on getting a job, even though she had a very tough time because of her age. Without determination, tenacity and positive sprit, which I consider elements of a challenge-taking nature, she would have given up. She has already set her next goal after retirement: to teach reading in an area in the city she described as "our Appalachia":

There might be kids there that ... um ... don't have anybody to read to. I'm thinking of a child in my class this year that his parents can't read and so just that whole piece becomes missing when you don't have anybody ... someone to be a grandma and snuggle with some little kid and read a book. So they don't associate reading with nice feelings, you know .... So if nothing else, just hold a 4- or 5-year-olds and, you know, read a story to them. I think it is important to do so .... They might know how to read, but they might not love to read. I love to read and I know that comes from my mother holding me and reading stories to me. And I just thought, you know, that ... if you can't read, that ... the whole piece is missing. So that's what I'd like to do.

The way she describes herself is a clear confirmation of her characteristics:

I think if I decide I'm gonna do something, I don't care .... There were times when ... you're just so tired, and you're wondering "Why am I doing this? This is too hard, This is not what I wanted to do," and yet, something in your head said, "come on, you've come this far." "I don't wanna do this, this is too hard ...." Sometimes, I think I didn't have that option because I didn't want my kids to quit because the message you send is, "Well, when things get too hard ... you know, Homer Simpson, if it gets too hard, quit." And I don't ever wanna convey that to kids. You plug it out ....

\section{Being a Life-Long Learner}

The challenge-taking nature of the four teachers shows up in what I finally concluded is a closely related aspect of their personalities: they are life-long 
learners. Learning should be included in teachers' job descriptions, but we often hear that teachers are not willing to spend any more energy and time to learn new things than required. As some of the four teachers pointed out, many of their colleagues do not even take learning opportunities provided by the district. But the four were eager to gain new knowledge. I have already discussed Dian's pursuit of education despite all difficulties. She is still up for opportunities such as ESL endorsement or SIOP training. She says that "[she does] not understand why people don't take advantage of opportunities when they are provided by the district." Terry shares the same observation:

A lot of people like to stay here [at school]; I like to be gone as much as I can. I mean, not be gone as much as I can, but you know what I mean? I like to ... I like to do [as much learning as possible] ... because it makes me be able to add more knowledge to my teaching.

Terry also took ESL endorsement and SIOP training. He utilizes every opportunity to learn new things. He told me he took a Watershed workshop two days before one of our interviews, he is in the process of getting a Math endorsement, and in the summer he takes 9 to 12 graduate credits. Annette is also pursuing a Math endorsement. She was also very interested in my doctoral program and after all of our interviews were finished, we had a long conversation about it. Sabrina appeared enthusiastic when I explained about the ESL endorsement program. Her desire also goes beyond teaching children. She shared her aspiration as though she were telling me her precious secret: she has an ambition to teach adults some day, which made 
me ask if she wanted to go back to school. She said in a definite tone, "Most

likely." Sabrina walked with me to the parking lot and told me she had a friend who was doing her doctorate: "I just talked to this friend of mine and experiencing this [i.e., participating in this study] gave me a much clearer picture and understanding what she is doing." Sabrina did not clearly confirm that she wanted to be on the same track, but she gave me some clues that it would be a possibility. With her positive sprit, I see her taking on the challenge.

Terry explained why learning is so important to him, referring to the two kinds of training in which he has been participating:

Your style comes in from your background and all of that, and I believe that's true ... you're always building that background and no matter what happened to me when I was younger, [I was always learning and] I'm always learning things everyday. I don't always, even in these ESL classes, agree with everything I learn in there, [but] I do take the things that I know is going to help me become a better teacher, and it's going to help my kids more. And even if I don't think it will, I will try it and experiment with it. And whatever I get for the results of that, that tells me if I should use it again or not. And this is the best year ever that I've had teaching, and it's because I've implemented a lot of things from the ESL and the math program actually. They help each other and they work together.

Terry takes learning new things as a challenge that he always likes to tackle.

He brings this viewpoint into his classroom: he wants his students to take chances in their learning:

I tell my [students] that you need to at least give it one chance, and if you don't like it then you don't have to use it again. But if it's something that can help you in life, then you take that and you delete what you were using, or you just add that to it, and make it one more thing that you're doing to make it a more effective or to have more fun while you're doing something. 
For him, teaching is "very exciting and if you want to become a better teacher, then you always have the opportunity to take more college classes, and to deepen your knowledge and your theory as a teacher." He is willing to learn anything that may help students think about or do something meaningful and significant with their lives.

I observe that through their lives, all four teachers have refused to take the easy path, and that rather than sitting and talking about this "ideology," merely telling students to work harder, instead they model what they want them to do and be.

Annette finds students today rather "passive ... they wait for things to come to them." She said, "To me, that's not okay ... that's very frustrating to me, because so many of them are just passing up an opportunity ... a really great opportunity, and I hate to see that. As with Annette, so Dian also sometimes feels pessimistic about current middle or high school students' lack of persistence:

I'm sorry to say that I kinda do it with the kids in there, that they, you know, "I'm tired ... it hurts ...." I think of that, saying, "Half of the work of the world is done by people who don't feel good." I really believe that, so, not that you should, but that we need to have a tougher-and I don't mean that to be mean- but I really mean, you know, we need to have more ... tenacity. Success is getting up one more time than when you fall down.

Echoing Annette's and Dian's spirit is Sabrina's expectation that her students not be afraid to make mistakes in order to open the door for learning: I look at kids and I think, "They're children and they're going to make every single mistake in the book," so I just pretty much tell them that, and 
I'm saying, "You know what? If you make a mistake, I totally expect it!" And their little mouths will drop open, and I say, "Because this is school, and this is where you learn, and if you make a mistake, we talk about your mistake, and we move on- it's to be expected." Now, if there's some-if it happens day, after day, after day, after day, then that's behavioral, then that's a different deal. If it's ... if it's academic mistake, then I just tell the kids, I say — say we're doing something in math - "Please try ... just try. Do I expect you to get the right answer? Or do I care if you get the right answer?" "No," and they're right. I don't even care ... just try, try anything, and see if it works and let's talk about it. Because if they're so timid that they won't even open the door, then they won't learn at all. So ... it's ... it's like .... A few years back, I taught fourth grade and Science, and ... I had a um ... a mentally retarded girl in my room, and I'd set up the science experiment, like the light bulb. She was the first person to light the light bulb because she tried everything. She didn't care that it was supposed to be this way ... she tried everything, until it worked. The two top children, that were the talented and gifted children, were sweating, sweating-I'm not kidding — sweat dripping off these boys ... "I should be able ... it should work," but they couldn't deviate. And gosh, just something else ... don't get so hung up on ... this is the only way to do something .... So I mean, if you can't make a mistake in school, where in the world can you make a mistake? And they need to know that.

The four teachers' challenge-taking minds have not only made them life-

long learners, but compel them to challenge students to be challenge-taking,

lifelong learners as well. They demand of themselves in order to better themselves, and they ask their students to do the same. Gay's (2000) following statement epitomizes the way the four teachers approach to this practice:

Teachers who really care about students honor their humanity, hold them in high esteem, expect high performance from them, and use strategies to fulfill their expectations. They also model academic, social, personal, and moral behaviors and values for students to emulate. (p. 46) 
As caring teachers, they are committed to seeing their students succeed.

Terry's passionate tone when talking about "challenging his students," which he often mentioned in interviews, captures this well:

[I challenge] them to ... to try to learn to their fullest ability, and to let them know that they don't ... that they have an opportunity that most people in this world never will have, to be able to get a good education and become whatever they want, and that if they're lazy now, they're gonna be lazy later. And I try to show them different job of people that have our ... that have not studied or people that have not worked hard and the type of life they have, and the things that go along with it ... and living conditions, and ... and I try to ... I try to challenge them by giving them a picture of what they can have and what they will have if they don't make good choices ....

\section{Experiences in Different Cultures}

The term "experiences in (or with) different cultures" suggests traveling or living abroad and learning new languages and customs, or else participating in a similar fashion with local ethnic or subcultural groups. I speculate that there is a subset that essentially constitutes a different type of cultural experience. If the first is a "regular" cultural experience, the second type that I identify and that is especially pertinent to this study is one in which the subject experiences "otherness." In "regular" cultural experiences, the subject learns new cultural traditions, values, and social customs, with opportunities to observe, take part in and understand what it is like to be a member of different cultures—but in a "virtual" way, without having her or his identity challenged.

"Otherness" cultural experiences put the subject on experientially unfamiliar social and cultural terrain, where she or he can feel an outsider. The 
experiences may or may not be negative; a person may be made to feel other, but not necessarily given a bad feeling. However, when "otherness" cultural experiences are negative, they put the subject in a situation in which she or he may feel neither accepted nor respected, and may receive the message "you do not belong" or "you are an other." The subject may experience feelings of having her or his power taken away, or of being subjugated, resulting in feelings of alienation, marginalization and threat to identity.

I observe that all four teachers had both "regular" and "otherness" cultural experiences, and from the teachers' descriptions of them, I conclude that something about the combination of the two types of experiences was significant in the development of their characters. Specifically, what I saw in my participants was the negative kind of otherness experience. In the next section, I will discuss the effect that these cultural experiences had on the four teachers.

\section{"Regular" Cultural Experiences}

Sabrina has not experienced different cultures as an international traveler, but has had other "regular" cultural experiences. In a way, her parents' divorce brought the first. "When I grew up ... we were upper middle class, and when my parents divorced, we were pretty poor. And I worked for everything I had from that point on." She learned the "culture" of life without luxury:

I know what it's like to work for what I have. I bought all my own clothes, I bought my shoes, I did stuff like that. I ate dinners that was just like, "Well, 
it's food, and okay" .... I [had] to be myself [when] I was like, you know, 13 ish.

This experience gave her an important lesson as she described:

I think it was really good, because I mean, I think it was valuable, feeling like whatever I accomplished wasn't just handed to me ... that I worked for it, and I earned it, 'cause I think if my parents would have stayed married, and it was just handed to me, I don't know if it would have meant as much.

Moving to Oregon gave Sabrina her next cultural experience. Adopted by the son of an Italian immigrant family, she grew up in an Italian, Polish and Irish community on the East Coast, and went to Catholic schools through high school. But for higher education, she chose to move to Oregon. Conditioned into a kind of secluded East coast ethnic community, living in Oregon has to have been very different. As she described her upbringing:

Well, now, remember, this is East Coast, and it's just, really, really particular, and when you're an ethnic group, it's, you know, you're my blood. Blood is thicker than water.

Since college, Sabrina has had a very close friend who is from a different cultural background, and has had "many friends who [have] been handicapped; had a very, very good relationship [with them]." She also has "some family members that are part of [the] gay community"; Sabrina, her husband, and his sister "stood up for them at their wedding":

They mean, very much to my husband and I, and it wasn't really our philosophy that they should probably marry, deep down ... but it was so important to them that they received the support, and when they asked us, we were-we didn't even think twice-we were like, "Well, of course we'll support you, and we'll be there." And that's their life, and that's their view, 
and that's what's important to them, and when you have somebody, "Will you support me?" I mean ... well, it wasn't hurting anybody, it wasn't like they said, "Would you take this gun and go rob the mini mart with us?" It wasn't like that, and so we love them, and we support their happiness, so ... so we did .... We felt like, you know, hey that's pretty cool! Very cool, actually, so ....

Sabrina's perspective that "everybody should be loved and respected for who they are" is clearly evident in the above statement.

Terry as a serviceman, and Annette as a traveler, experienced different environments and had wonderful opportunities to learn new languages and different customs and practices. They made friends with people through means other than language; some of the friendships have lasted to the present. They experienced situations in which they had only themselves to rely on. They learned how tough it was not to be able to speak the local language, especially when trouble occurred and they did not know how to navigate toward solutions. These experiences gave them opportunities to better understand their diverse students. Terry addressed this point, although he pointed out that students' experiences could be much more intense:

[Having these experiences] makes me ... it makes ... it puts me in their situation in a different country where I didn't know the language or anything and I had to learn from scratch, you know, to do everything. And um ... but I had a lot of fun doing it - I didn't have to go direct to a school or anything, so-but yeah, it did, it gave me a very good idea of what my kids are going through now and how I can make it more fun for them.

Dian and Annette experienced cultural difference through marriage. Even though Dian's husband is a grandson of Italian immigrants, was born in America 
and is American rather than Italian - unlike Annette's husband, who himself came straight from Korea as a boy-his mother grew up in Italian culture. She wanted to break away and legally changed her Italian name to an American name, suggesting how strong her cultural environment was and how its influence may have carried over to her son, even if unconsciously.

When asked about her identity, Dian's immediate answer was "I do identify with my mother's family." Her mother's family has been in the United States since 1640:

My mother's family ... her father ... they were Dutch, and they went to ... they settled in New York City, and they were ... they belonged to the Dutch Reformed Church, and they were still ... have various privileges in Sleepy Hollow, and they lived in ... they were wealthy in New York City. They were up and coming and that her mom ... her mom's family was Quakers, and they came from England, and uh they settled in Upper New York, and they were poor farmers.

She is very proud of the fact that her ancestors fought in the Revolutionary War and that "[her] family were founding people of America." Growing up, feeling close to such a cultural and religious heritage, Dian felt her husband's cultural difference. It was the first thing she mentioned in the context of culture: "Well, of course I think that of my husband's Italian family, you know, yeah. That was kind of a ... that was kind of a shock because uh ... well it was um, they're a very Catholic family so that kind of ... I was not raised Catholic ...."

Terry's connection to a Native American tribe is through his mother's second marriage. Even though he never lived on the reservation with his mother's 
family, he is treated as a tribal member when he visits. He has attended many tribal events and has experienced the tribe's ways of handling and solving issues:

All the people there are very intelligent, they just have a different way of life and ... so you can't force your ways on them. You have to learn their ways and then see how to get in.

For Annette, daily life itself, with her Korean husband and in-laws, is a cultural immersion experience: the food, the jokes, the music, the daily practices, and of course the language. She told me many, many interesting, funny, and sometimes sad stories about differences, misunderstandings, clashes, and finding middle ground and solutions:

He is very um ... very much hangs onto his culture, and you know, I ... I hang on to mine too, so you have to negotiate that all the time. Probably the hardest thing is the food (laugh), which sounds kind of funny, but um ... and the holidays work out okay, because Christmas, it's my family, and New Years, it's his family .... We kinda eat ... half time Korean and half time the kind of food that I grew up with, which is ... you know, fried chicken, and you know ... very different kind of food, but um ... I get really offended when he ... like I made a pork roast this weekend - and he doesn't like to eat a lot of meat, but sometimes-it's comfort food for me, so .... He didn't wanna eat it, and he wanted to have rice and soup ... and I was really offended that he didn't want to eat my pork roast, because to me this is kind of like, the special ... a special Sunday dish that I made .... We don't fight about it. I understand, but um ... it's an issue, a lot.

As the only person in her Korean family who does not speak the language or fully understand the cultural practices, Annette thinks “culture's a lot harder to get than language." Faced with incompatibilities, she still struggles to identify whether an issue is cultural or familial: 
I'm still learning what culture is and what it isn't, because like I mentioned, when I yelled at my husband and he wouldn't speak to me, I would've never thought that that was cultural, so .... And then sometimes I do get ... I feel really confused because um ... I think, "If it's cultural, does that make it right when we have a conflict?" .... I get confused whether something is just familial ... I always [have] questions in my mind like where do you need to be respectful of the culture, and where do you need to challenge the behaviors that are offensive to you? So I guess there's ... I guess I'm learning.

For Annette, cultural difference is not something she has to deal with only once a year. It is a practical daily matter and can considerably disturb her life.

Nevertheless, although her experiences are sometimes unpleasant—or maybe because of it - they have contributed to her insight that every culture "needs to be respected for what it is." As she said, "I would hope that kids would learn that their view of the world is not the only view of the world ..." and said she would continue, as one of her very important jobs as a teacher, "with [her] students ... talking about what culture is and what cultural differences exist, and raising awareness in them."

\section{"Otherness" Cultural Experiences}

The four teachers have also had the personal, lived experience of being an "other," which I strongly suspect contributed to shaping who they are and what they believe. In previous sections, I described relevant incidents; here I will review and summarize them.

The way Terry's step mother treated him and his sister was not only nonloving, but sometimes even hateful. He had a teacher who called him "slow" and 
made him feel diminished. Growing up with an alcoholic mother, Annette had to carry responsibilities that a little girl would not usually have. Her family atmosphere was cold and she did not experience much warmth at home. She experienced racial discrimination in Hawaii. Her intercultural marriage to a Korean man came with in-laws, who have not been very flexible about her way of adopting their culture and who are not so tolerant toward her own cultural practices. Some of them may have been unhappy about Annette's being Caucasian, a fact over which she has no control. Dian experienced cultural difference when she went back to school; as a person who might have been older than her classmates' parents, she must have felt isolated. It is not surprising that she felt fear and did not know where it came from. Dian's age and religion also seem to have given her difficulties. Her sons, who looked Mexican, experienced upsetting treatment by the police. As the mother of these young men, it was natural for her to feel hurt hearing what happened to them. The fact that Sabrina was an adopted child left her with a feeling of abandonment, which she could never forget. Growing up, she was very sad and often felt sick inside because she was always reminded by other family members that she was different.

I consider these to be "otherness cultural experiences" in that they do not seem to have happened under "normal" circumstances. One of the differences I have identified between "regular" cultural experiences and "otherness" cultural experiences is that with the former, one maintains who one is and this identity is 
validated, whereas with the latter, one's identity is not accepted, self-esteem is compromised, and one feels a threat to one's identity. The teachers' experiences, as I see it, contributed to characteristics that are similar in all four. All were more disposed to identify with and provide support to students who were in the circumstance of being an "other," including culturally and linguistically diverse students.

Reflecting on her negative experience as an adopted child, Sabrina referred directly to the point: "How I teach children and how ... the ... the warmth and the love and acceptance and our sense of community ... yes ... those past experiences did shape that." Her description of how she felt when treated differently is very powerful: "I was deeply sad ... and a lot of times, I felt ill inside ... very, very ill." Those feelings of alienation and marginalization had to have contributed to compassion for people who see and feel themselves as "others." As she said:

And it just ... so, equity is really, really important to me, and belonging, and things like that. Really, really important. I think that would shape ... um ... me as a person, and me as a teacher for sure. Definitely. That ... that's just ... it is not okay to differentiate. Period.

Sabrina mentioned that treating people respectfully and justly is "one of the major things [she teach] ... above and beyond academics even" and that "it's important for [her] to instill [that value] in [her] students." Her experience helped shape her view that she "just would never treat somebody that way .... I always try to be equitable to my friend-I'm not perfect, mind you but- - that is one thing that 
I am very conscious of." She knows too well what it is like to be regarded as an "other: "when you don't feel like you're valued, or you feel like you're so different because of a reason that ... you know ... it's just ... that's so not okay."

Like Sabrina, Annette's desire to establish a learning community where all students feel welcomed and important may have come from her childhood experience with her alcoholic mother. Her childhood was lonely and difficult, and her non-loving home environment might have made her feel that her home was different from her friends'. The impact of this experience shows in her telling of her students with disabilities and how her class "[grew] and learn[ed] ... and [came] together as a class" because these students were brave about others learning about them:

To me, that was ... that's what it's all about, because that group of kids have bonded and they're gonna take care of each other, um ... they're gonna feel safe and they're gonna learn better um ... nobody can learn when they think they might be teased or they can't expose their differences, so ... that's like a great moment. And I was the facilitator of that, but it just all came from the good hearts of that kids. All I did was giving them an opportunity to do that.

It is clear from the description already given how the experience of being an "other," in Hawaii and in her in-laws' family, also contributed to Annette's way of understanding how "different-ness" should be regarded in her classroom.

Terry explained how "that experience [with his step mother] ... has given [him] an insight that a lot of teachers don't have." In his school, a lot of students "come from split homes, and [he knows] they're not being treated nicely at home": 
I give them hugs, you know, and they should know that they can come in here and ... and trust me, and I can trust them, and that this is a safe place for them and that they can have fun here and be themselves, and they don't have to worry about anyone coming in here and hurting them or doing anything else ....

Another comment of Terry's affirmed how "otherness" cultural experiences help teachers become capable of viewing things from students' perspectives: "when it happens to you, it makes it more realistic, you know; makes it so you can identify with other people [about] what's happened."

\section{Approach to Teaching}

The negative messages, intentional or unintentional, that the teachers received in these experiences communicated to them that they were devalued or disrespected. As Kohl (1994) puts it, "What seemed to be at stake for them was nothing less than their pride and integrity" (p. 7). Cummins (2001), in "Identity Development of Linguistically and Culturally Diverse Student in the Classroom," asserts that in the relationship between the teacher and students, there is always negotiation of identities. When one feels one's identity threatened, there are not many ways to deal with it, except to act out or withdraw (especially when the relationship involves issues of power, as between majority and minority, or teacher and student):

Not-learning tends to take place when someone has to deal with unavoidable challenges to her or his ... integrity and identity. In such situations, there are forced choices and no apparent middle ground. To agree to learn from a stranger who does not respect your integrity causes a 
major loss of self. The only alternative is to not-learn and reject the stranger's world. (Kohl, 1994, p. 6)

What happens in "these ways of negotiating identities [is] fundamental to the academic success of culturally diverse students" (Cummins, 2001, p. 2). The extreme case of "not-learning" is when they drop out of school to protect themselves from "further devaluation of their identities" (p. 3). However, "when students' developing sense of self is affirmed, and extended through their interactions with teachers, they are more likely to apply themselves to academic effort and participate actively in instruction" (Cummins, 2001, p. 2).

The four teachers were probably not conscious of theory (such as Cummins and Kohl), nor of the political implications of "identity negotiation" (Cummins, $2001)$, but what they made clear they were doing in their classrooms was establishing an environment where students could feel safe and be confident of who they are. Consider some examples of what the teachers did in their classrooms: Dian stressed to ELLs the importance of preserving their first language even though this was against the ESL department's policy. Terry had ELLs teach Spanish once weeks, as well as having them translate texts such as posters so that they could feel proud. Sabrina gave ELLs opportunities to talk about experiences that no other students in the class had had. Annette used a book about a Chinese girl, to which a Guatemalan girl in her class could relate, enabling her to share her feelings with the class. This kind of environment can lead diverse students to 
realize that their cultures and languages are not something they should be ashamed of, but rather something they ought to be proud of and share with other students. Such practices contribute to ultimately providing the foundation for culturally and linguistically diverse students to grow confident with who they are.

I believe the experience of "being an other" could have evolved into such practices. Somewhere in their lives, all four teachers had more or less experienced the powerlessness and devaluation of their identity that came with "being an other." Avoiding creating situations in which diverse students could feel excluded and undermined might have been the natural, unconscious-or conscious-response to their own experience.

Terry taught his students to be proud of themselves: "If they do this, academic success will follow," he said. Annette wanted to be very sensitive about placing any student in the position of representing her/his cultural group. She stated that drawing attention to differences is not always good for all students and that you have to first understand the individual student's needs. Sabrina demanded very strongly that there should be no exclusion of any kind in the classroom. And finally, an expression of Dian's may sum up what all teachers have been doing in the classroom: "I want to be with Citizens of the Earth." The message is one of fairness and acceptance no matter what the similarities and differences might be; everybody should be proud of who they are. 
How teachers define their roles affects how they relate to culturally and linguistically diverse students. Being socially open systems (Hoy \& Miskel, 1996), schools are influenced by and dependent on their environments. They are "affected by outside forces" (Hoy \& Miskel, 1996, p. 34), that is, "everything that is outside the organization" (Hoy \& Miskel, 1996, p. 40) including the values of the community and other social, legal, economical, political, demographic, cultural and historical factors. It is not unforeseen that "schools reflect the values and attitudes of the broader society that supports them and so it is hardly surprising that in the United States, students from [marginalized] communities have experienced extensive devaluation of their cultures and languages" [i.e., their identities] "within the school context" (Cummins, 2001, p. 3).

In this circumstance, there are many factors that can restrain and shape the way teachers build their relationship with their diverse students; however, it is, ultimately, largely in the teachers' power to define what kinds of relationships they form with these students and what messages they communicate to them. If they allow themselves to have a power relationship that reflects those in the wider society, this attitude is manifested in their interaction with students. The result will likely be reflected in students' identity formation. When you do not like who your are, the detrimental effect of this is obvious: you lose confidence, and you dislike, disrespect, and are ashamed of yourself. 
The four teachers in the study do not let the "socially-powerful vs. sociallydevalued" relationship invade their classrooms. They position themselves in such a way that they encourage their students to be who they are. In such a classroom, bicultural/bilingual students construct their self images in a positive way. They get the message that they can "bring [everything] with [them] to school. All that [they] had accumulated from birth to [the present] (language, culture, personality, talent, interests)" (Kazoullis, 2001, p. iii), and that what they bring to school will be treated with respect as a source of their learning. The four teachers are sending their students self-affirming messages:

... we should [not] stress similarities - or differences .... It is a question of acceptance and individuality. Each person is an individual and each person brings something with him or her to school. The teacher's position should be to accept and refine, first of all, accepting that she/he is not dealing with a class of 25 but with 25 individuals. She/he should be the coordinator who organizes methods so that each individual can teach the other. The students should not compete with each other but begin at their own level and enrich their knowledge. If the relationships in the classroom are like this, perhaps relationships in society will one day change .... In society, we are constantly accepting and rejecting. We are constantly fighting for a position or power that must be acquired at the expense of someone else, whether this means position in the job market, economic success of a business or military expansionism of aggressive countries. Power should in fact be collaborative, not coercive. As a pebble drops in a pond and sets off ripples, the point where the rock breaks the surface of the water-the nucleus-is the individual. The ripples are first the home, then the classroom, the school and ultimately the society. What ripples the classroom sends off to some extent define our small scale society, the classroom, in such a way that the relationships of power are generously divided for the benefit of all. (Kazoullis, 2001, p. iv) 
Teachers' messages affirming students' identity may be perceived by students as "caring":

Students, over and over again, raised the issue of care. What they liked best about school was when people, particularly teachers, cared about them or did special things for them. Dominating their complaints were being ignored, not being cared for and receiving negative treatment. (Poplin \& Weeres, 1992, p. 19)

As seen in the quote above and in other literature (e.g., Noddings, 1995, 2003;

Valenzuela, 1999) teachers' caring attitude, manifested in their interactions with

their students, is of the foremost importance. When trust and respect are established and students feel affirmed, it gives rise to success both in teaching and in subject learning. Terry described how care, trust and learning work in the classroom, using a very familiar, easy to understand example:

If they ... if they trust you and they count on you, and they can count on you, they believe in you, then it's pretty much ... it's like having a baby rabbit in your hands and you have to take care of it, you know ... the rabbit will pretty soon ... I mean, at first it's gonna run from you, but after you feed it and you water it, and you take care of it ... pretty soon it's gonna jump on your lap all the time. And um ... same thing with the kids, after a while, you become so ... you become so close that you let down all your guards, like ... this cat that I had at my house, it doesn't really like anyone at our house, it was kind of a wild cat that we got, but now it's so close that it sleeps beside me every night, and it comes up on my chest every night and I rub it's ears or whatever, but um ... it will let me walk up it outside and everything ... it trusts me $100 \%$ and ... and when the kids can be like that, then I know I've reached a point where my teaching is gonna be the most effective.

Terry gave another example involving Native American children on the reservation where his mother lives. Even though he has not taught in their classroom, he gained 
important insights about the children and their education through the close

relationships he maintains on the reservation:

A lot of people think that the kids don't want to learn and can't learn, but ... there's some teachers, I've heard, you know, that think that it's worthless to go to places like that, and [that] it's hard to crack the shell and get inside to. those kids. But if you can get them to trust you and count on you, then you can teach them, probably more than at a normal school because once they decide to do that, they have to break away from their friends ... kind of - I don't know if you know what I mean - but they have to ... um-to me-to like a teacher and to like to work in class, there is ... is um ... [an idea] like it's cool not to do it ... like, in school in New York, um, they beat kids up if they get good grades. And so the kids don't wanna get good grades and pretty soon, they're tellin' everyone else how cool it is not to get good grades. And kinda like that .... And so the kids don't wanna get ... but if you can get to know them and their families and what they want and their interests and all of that, then um, then you can do it. And ... and it's fun and the kids are very intelligent.

There are commonalities between what Terry said in the quote above and

what is stereotypically said about ELLs-that they are not smart, do not want to

learn, and think learning is not cool. I asked Terry to give me more details:

If you got with these kids and you ... you could build their trust and get them to listen to you - and the way you would do that is by spending time with them and doing fun things and being a good ... uh ... role model for them-and pretty soon they'll start following you around and wanna do good things, make good choices, and ... and ... 'cause they've never had that opportunity before .... So I guess that's mainly the things that I'm saying .... If you can crack that shell- they're hard to get into-but I've been there for so long and I know so many people that a lot of these kids are adults now, but they always trusted me and would always let me in, and ... and ... it gave me a chance for me to be able to see their culture and their lives in a totally different way. They are more eager too ... once they realize that they actually ... someone's complimenting them and they have ... someone is affirming that they are smart, then they - and they know that they can do something - then they really want to attack it, I mean they really want to .... It gives them confidence, and they wanna grow fast ... 
they wanna try to learn, I mean it's exciting ... it's something new .... It's like giving someone that's never had a chocolate candy bar, you know, and if they really like it, it's just a way for them to really want to ... they want to learn, and once they have something positive happen, and they know that you're there to help them along with it and stuff, they wanna just keep doing more and more and better.

This quote points to the impact of caring teachers on culturally and linguistically diverse students' educational success, mentioned with great frequency in the literature (see Ayers, 2001; Cummins, 2001; Darling-Hammond et al., 2002; Gay, 2000; Ladson-Billings,1994; Nieto, 2002, 2003; Noddings, 2003; Pang, 2001; Valenzuela, 1999; Wink \& Wink, 2004). As Gay (2000) points out:

This kind of caring is one of the major pillars of culturally responsive pedagogy for ethnically diverse students. It is manifested in the form of teacher attitudes, expectations, and behaviors about students' human value, intellectual capability, and performance responsibilities. Teachers demonstrate caring for children as students and as people. (p. 45)

The literature suggests that caring means diverse students "matter" to the teacher; that teachers have "a belief in the worth and potential of the children, all children ...." (Rose, 1995, p. 423) and the desire and ability to find strengths that are unique to each student. In his eloquent depiction of teachers and students who are finding their "possible lives" in their classrooms, Rose writes:

At heart, the teachers in Possible Lives were able to affirm in a deep and comprehensive way the capability of the students in their classrooms .... Such affirmation of intellectual and civic potential, particularly within populations that have been historically devalued in our society, gives to these teachers' work a dimension of advocacy, a moral and a political purpose. "Teaching children to read is, after all, an egalitarian business," writes Michael Walzer in Spheres of Justice "Like the democratic theorist," he continues, the reading teacher "assumes that all her students have an 
interest and are able to learn." We tend to forget what a radical idea this is in the history of Western political thought - this belief that all members of the state have an intellectual and civic contribution to make, have the potential for full participation in society. The shame of our school is that, over time, we have denied such merit to so many. "I do think it is revolutionary, said New York principal Mary Stevens, "to get kids to believe they are worthy ... to understand themselves as learning, growing beings." Given the populations with whom many of our teachers choose to work, the enactment of egalitarian beliefs in their classrooms becomes a vehicle for social change, a realization of the democratic idea in real time. (pp. 422-423)

All four teachers showed how they are eager to bring out each student's individual strength as much as possible. Dian and Terry are very aware that students' native language (L1) is a significant source of their learning (Collier, 1987/1988; Crawford, 1999; Cummins, 1979, 2000, 2001). They understand that ELLs' LI and second language (L2) are interdependent, that is, when they are reading and writing in their $\mathrm{Ll}$, they are not only developing skills in their own language, but they are "developing a deeper conceptual and linguistic proficiency that is strongly related to the development of literacy in the majority language (English)" (Cummins, 2001, p. 174). They believe in the importance of investing in ELLs' linguistic and cultural capital-a vital priority to keep in mind if the teacher is to nurture and cultivate these students' potential capability. Dian is remorseful about the fact that some bilingual/bicultural students are losing their LI very quickly. Even though she did not articulate that the way students' LI s are treated at school may be partially causing ELLs to lose their languages, Dian described how she feels about the way the school and some educators deal with ELLs' L1: 
In kindergarten [and] first grade, they teach them to read in Spanish, and then by, I think, second grade, they start doing it in English. So by my grade, they're expecting these kids to do everything in English unless they're recent arrivals. Our ELL department does not encourage it [preservation of students' LI], but I do like to [do so] .... I really think that you could do both [keeping ELLs' LI at the same time improving their English]. I really do think you could keep their language, and allow them to ... in writing and things allow them to [use it] if they've done their other [assignments in English]; let them write in Spanish. I don't have a problem with that.

Terry had his ELL students teach his class Spanish:

I let the Mexican kids help teach in here, help teach Spanish. We haven't done it as much this year, but last year ... every Thursday, for a half an hour we would have Spanish class, in here. And ELL ... the ELL kids would be teaching. Up on the board, would be teaching. And they would be teaching the rest of the kids and then they would practice in their groups. And we play the Spanish on ... tape and they try and kids have to enunciate it, certain amount of times, and then they have to practice.

He also utilized their language resource for other things. It was his way of

affirming ELL students' cultural pride:

They feel important by giving them things like, translating a poster into um ... Spanish when there's something going on in the community, and school's have fund raisers or something, so they can feel important, and we put it up around the city, or we ... urn ... around the class, or have them help teach Spanish to the rest of the class in here. Um ... there's just a lot of different things like that [that teachers can do].

Dian gave an expressive description of her related approach

Especially when they can have a chance to shine like they can read in Spanish to me. In fact, today ... it was a book give-a-way, and uh ... it was three little pigs. One side in English, and the other side in ... you flip it over and it's another language. So today, I got the book, and I showed several of the kids and I asked the kids to read it; to read it to me, you know. And ... and they were all laughing, and saying [to me], "Are you trying to learn Spanish?" and so I said, "I don't think 1 could do nearly a good job as you do ...." So ... I was not trying to even bother pronouncing it right, so they 
could [help me]. [I said], "Help me, Help me ...." It gives them 2 minutes to shine.

Sabrina spoke at length of including multicultural resources in her practice:

"I don't have a lot of materials that ... you know ... [because multicultural education] isn't a part of the curriculum" other than books that are available at the school library. However, she indicated that she does not have to rely on the "official" materials because "resources [are] available at their [ELLs'] fingertips":

I really like to talk about ... we write a lot about what happens at home and what we do and how to celebrate things and so when something comes up, and it seems like, a little bit different than what others are experiencing, it doesn't matter, so it could be, again, that Italian family that, "Oh we do this" and so then we incorporate it .... I'll have the Hispanic kid be like, "Well in Mexico, we celebrate such and such this way, or "In Mexico, we call that animal blah, blah, blah." So we really discuss that. We incorporate.

Sabrina seemed intuitively to know that by capitalizing on their life experiences, bilingual/bicultural students can connect more easily with subject learning. When she talked about what she does, it sounded as though she had already done some ESL training. She illustrated how the entire class can be livened up by bringing ELLs' prior experiences into subject learning so that everybody can benefit from it. She gave examples from a math class:

Today we're doing stuff with measurement and um ... a speedometer is one of the things you measure - how fast you're going in a car. And so-this is a really poor example so it's just something off the top of my head-so it's sort of like, "Okay, how many of you have a car; how many of you have seen that?" Oh they've all seen it. And um ... "How do you measure how many miles you've gone?" and these kids ... some of these kids are veryparticularly the Hispanic kids go to Mexico once a year. Okay, so they spent--they don't fly there; they drive, so there's a lot of car time - so 
"How do you measure, you know, how fast you're going to go?" "How do you measure how many miles you went?" "How do you ... do you have to put gas in your car?" You know, make it ... make math real life, but try and get ... 'cause a lot of the Caucasian kids have never gone anywhere. So, usually the Hispanic children are much more well traveled, and diverse as far as, like, "I've been to this country, I've been to this country, I've been to these states in between."

Another example came from Social Studies:

The other thing is, when we're looking at a map-we'll do more mapping later, but - we'll ... we'll think up something, and someone will be like "Well I was born in Texas" you know, it'll be a Hispanic child. "Well, let's look at that. Let's look at the map" and "How did you come here? Did you know...??" "No, I don't really know." But sometimes they do. So we'll bring it in and the other kids'll be like, "Gee, I didn't know that about you!" Yeah, pretty cool. They're like, "That's pretty cool." "What's it like in Mexico?" or "What do you do?" And the Hispanic children, very often, if they've been to Mexico, they'll bring back the candy or some treats or, they'll really get to share quite a bit about it so, that's kinda nice.

These are also examples of moments that Sabrina used to make her ELL

students proud. She pointed to the importance of this, saying

A prior experience that might be like, that's something that they're really successful about, or can pipe up about, then it's part of [class] conversation, and they can stand up and be like, "Oh, I know all about that. Let me tell you something about it ....

Annette's way of incorporating diversity in her practice is a little different

from the other three teachers. Here, Annette, the teacher, brings her own

multicultural experience to the classroom. Because her husband is Korean, she experiences cultural differences on a daily basis: "I bring in my personal experiences. I talk about things my husband teaches me a lot." She also combines her personal experiences with books, for example, from different cultures. At the 
time when our interviews were taking place, her class was reading a book about a Chinese girl who came to the United States with no English. The book looked at traditions, customs, family relationships, values and so forth in the girl's native culture as well as her adopted one. Annette's sharing of her own experience about what she knows outside of the classroom heightened students' curiosity:

I don't know very much about being Chinese, but I can ... relate some of the things that [the author] talks about in the book to what I know from my husband and his family. And so ... one thing I thought that the kids were really interested in ... is that you wouldn't call somebody older than you by their name, and so I told them like in my family, we have ... my husband doesn't even know the names of his ... some of his in-laws; so [kids] wanna know um ... how that works, and I told them what they call me, and um ... kids are very interested in that. And that discussion has come up a few times. And you know, even though I'm not quite sure about um ... some thingslike I don't know if it's the same in China as it is in Korea-but I try to ....

A main theme of the book involved changes that the Chinese girl showed in the process of adapting to her new way of life, while preserving ties to the past.

This gave Annette an opportunity to involve the class in a discussion about "identity shifts," as she called it. It also gave one of her ELL students, Graciela, a chance to validate her own experience. Graciela, who is from Guatemala, lived the experience of the character in the book:

When we had gotten to this part of the book, I stopped and talked to my kids about identity shifts, so um ... we had a very good conversation, because a lot of the kids in here have already experienced big changes .... Graciela was one when she started school here, she didn't speak any English ... [and] when we have these discussions and when we talk about the book, she's ... just has brilliant things to say, 'cause she's been there and she can totally relate to this character .... And she has something really important to say, and ... we're lucky that she has this experience. She says, 
"I know exactly how she felt, because when I came here, I didn't know what any of you guys were saying ...." and she just has ... she moved here from Guatemala, and she was five, so she has a lot of memories about making that shift, so ....

Reading the book was not only a learning opportunity for her students, but an occasion for Annette to learn more about Graciela. She acknowledged that before reading the book, she "didn't know all the details of what Graciela went through ... I've learned a lot about her just from reading this book." After the class read the book, Annette noticed Graciela's positive change: "I think she has a little more presence in the classroom since she's been able to speak to things directly that we've only been able to talk 'about' in ... in third person ...."

What the four teachers do in the classroom is to bridge their ELLs' lives to their learning, which the literature claims is one of the core concepts of multicultural teaching (Ashton-Warner, 1963; August \& Hakuta, 1997; Bennett, 2003, Crawford, 1999; Cummins, 2001; Gay, 2000; Kohl, 1998; Oakes \& Lipton, 2003; Wink \& Wink, 2004). As Annette put it:

When I'm teaching a lesson or starting a new unit, I, first of all, want to know what they know about it, and um ... we do that a lot of different ways. Sometimes it's just a discussion, it depends on how much time we have .... sometimes we'll do like a quick writing about something ... and um we do ... you know, like with this age of kids, I like just doing a lot of kind of group story telling, so I might say um, you know, "What do you know about .... whatever subject?" you know, and then maybe take 5 or 10 minutes for a discussion, and um ... that's probably the most common way that I start off a lesson, and it gives me a sense of what they know about a subject and also helps them to make connections to their own lives. Um ... well, always try to relate things to their lives ... their real lives. 
Annette's statement, about the way she has her ELL students perform the best they can, summarizes what all four teachers do in their classrooms:

Recognize what they can do, and acknowledge what they do know and validate that, help them feel like they have a safe environment, and give them um ... enough challenge and enough struggle to let them move a little bit beyond where they're already at ....

Kohl (1984) affirms this as an example of good teaching:

Taking with students and discovering their current level of sophistication and interests are basic diagnostic tools of good teaching. Being able to set challenges that are appropriate to these levels and then provide students with resources, hints on occasion, and personal support are what make it possible to turn this diagnostic information into rich learning experiences. (p. 150)

The four teachers' classroom practices validate the literature that in turn asserts the significance of validating students' knowledge acquired from their lives and brought into the classroom (Cummins, 1979; Hakuta, 1986; Nieto, 2000; Wong Fillmore, 1991).

The four teachers' dispositions and actions display aspects of the practice identified in the literature as culturally responsive teaching (see Armendariz, \& Armendariz, 2002; Gay, 2000; Ladson-Billings, 1994; Lucas et al., 1990; Moran \& Hakuta, 1995; Nieto, 2000; Pang, 2001; Villegas \& Lucas, 2002). According to Zeichner (2003), culturally responsive teaching strongly concerns social justice. He states: "Often referring to the cultural gap between teachers and their pupils, advocates of the social justice agenda ... see both schooling and teacher education as crucial elements in the making of a more just society" (p. 507). The four teachers 
did not mention "social justice" per se, but many of their statements clearly showed their concern for it in their practices. By employing aspects of culturally responsive teaching, they are, consciously or unconsciously, being agents of social change toward a more just society.

Although they all know the importance of capitalizing on diverse students' cultural and linguistic resources, teachers expressed some concerns related to diversity, especially in language. Annette is mindful that not all bilingual/bicultural students necessarily want to share their diverse resources with classmates, and is careful to note for each student whether they mind talking about their language and/or culture in class, and whether they do not want to be made to feel that they are different from other students. She gave an example of each side:

The other day, I said, "Does anybody speak Spanish who knows what this word means?" and then um ... someone ... um ... I mean, there's one boy in here and they speak Spanish at home, but I don't think he wants to ... he wants to ever exhibit that and that's cool, but 1have another girl who, "Oh, I know what that means, I know what that means!" [At that time] we were sorting - for our spelling - we were sorting out the list of words by the country of origin. So there were some words that were from French, some from Italian, some from Spanish, and there were several other categories that were several other things. So um ... you know, there were some of them I wasn't sure of, and so we were all kind of doing it together. So I said, like ... um ... oh, "guitar!" [note: here, Annette recalled the word that they were dealing with at that time] I said, "Is the Spanish word for guitar the same or similar to this word?" and the ... the two girls in here were very eager to help - and I asked one of them before hand, you know, "You think you could help me?"- -but the little boy in here, he's very silent. I think um (pause) he doesn't wanna appear different than the other boys. I know that.... 
Annette's sensitivity may have derived from awareness of her husband's experience of not having wanted to be seen as "different" from other students.

The desire of some ELLs not to be "visible," or to be "the same" as other students, also concerns Dian and Terry. They were troubled at the thought of how their bilingual/bicultural students felt about being in the ESL program. Terry thought that although the purpose of the ESL program was to give students extra help from specialized ESL teachers, being pulled out during regular instruction times to go to a place where "regular" students do not go would have given them the feeling that they were "different." Dian's anecdote about one of her ELL students told more clearly what "feeling different" means:

He's been doing all this extra pull-out for math to pass bench mark, and so uh ... they were tested again just a couple days ago, and uh ... he passed both math and reading bench mark and .... "High five!" And the first thing he said was "Can I go to a regular reading group now?" So-I hadn't brought it up to him but—apparently they had told him that ... "You're in here until you pass bench mark." So ... he's ready! "I'm moving to a real [italics added] reading group, instead of this ELL stuff [italics added] anymore!" I thought that was kind of interesting that he was so eager to move out of it .... I think it says to them that ... you know, "I'm not high enough to move into regular ...." I hadn't thought about it until he said that to me ....

She acknowledged that her other three ELL students were also eager to move out of the ESL program. This issue was "one of [her] biggest concerns about education of ELL students":

They feel like they don't belong. They feel like they're not [regular kids], you know .... They feel ... that ... they feel different .... Although it probably is better for them to be in sheltered instruction separately - that they really 
learn more-but um ... they feel like they're not part of the group until they're in a regular class.

This observation of Dian's addresses a critical concern about diverse students' own perceptions of their identities, i.e., that they are different, not normal, and do not belong. The issue of belonging becomes more and more important for diverse students as they gain more understanding about social status as it relates to their culture, language, and identity. Dian's comment is evidence from the front lines supporting the following theory, from Thomas and Schwarzbaum (2006):

It is important to understand the development of the self and the intersection of cultural factors with self-concept .... By the time they reach school age and develop the ability to classify on multiple dimensions, children begin to understand that others have perceptions of them ... and they begin to incorporate others' perceptions into their perceptions of themselves. They become hypersensitive to others' perceptions and will often elicit feedback from others on their personality traits, abilities, and characteristics. The knowledge that others have perceptions that may differ from one's own underscores the need for acceptance by peers and the desire to fit in, to be "normal," and to feel validated .... School-age children begin to have solid understanding of group membership, and they become aware that group membership includes social status. (pp. 3-4)

The perception of society and school that "subtractive" practices are better for the education of culturally and linguistically diverse students has propagated to such an extent that even students themselves think it is better to replace their own languages with the majority language.

National mood and public sentiment affect education, especially for diverse students. As Ruiz (1988) declares, many problems of the education of bilingual/bicultural students are caused by "hostility and divisiveness" (p. 3) 
inherent in the societal view toward languages. Even though this view is not directly related to classroom instruction, conflict over it has shaped the education of ELLs. The "three language orientations" developed by Ruiz provide insights into the ways that education of such students has been influenced. Ruiz created a typology that describes three concepts of language, two of which have special relevance:

- "Language as problem" treats limited English proficiency as a handicap for children and a liability in academic achievement. Bilingual education is viewed as a remedial program for the poor and disadvantaged.

- "Language as resource" underscores the social value of cultural capital, especially bilingualism. From this perspective, bilingual education promotes fluency in two languages and cultures.

There is little doubt that students of Annette, Dian and Terry, who did not want to feel different, knew the status of English and viewed their L1 as "a social stigma" (Bialystok \& Hakuta, 1994 p. 192), considering the message they got is that the sooner they are out of the ESL program into the regular classroom, the better, and that learning in a U.S. school with a different language background is a factor that contributes to academic failure. To their eye, their language is a problem and lack of English skills is a handicap to overcome. These students may even 
instinctively associate it with poverty and little social success. A statement of

Annette's illustrates many ELL students' emotions about their L1 and English:

I think I can understand why kids sort of wanna hide and not be noticed and just observe, um ... I know that you're afraid to look stupid and I know that ... you know, you don't want to say anything because you may be speaking at the level of a 2 year old and if you're just learning a language that's hard to do that, especially when you're fluent in your own language.

In order to avoid a situation in which ELL students feel embarrassed because "answering is going to be a language issue," what Dian does is this:

I've been trying to do the one where, if he has to share, he does it within his small group so he doesn't feel threatened and always ... it's an option whether they want to share their answer or not, or if they want to read, or do that so that they don't have to feel as ... on the spot to have to answer. I also .... I try not to have him be the first one I call on. If we're doing something, I want him to be able to see how others are responding before I call on him.

The teachers are aware, if not of the theory, then of how the "language as problem" perspective at large in society is harming ELL students' self-esteem. Dian talked about this issue as her other biggest concern about the education of ELLs:

Well, my biggest concern ... that they lost their native language because I think it's important for them to keep their native language. I don't think that's emphasized enough in America. I really hope that they don't lose their native language. I keep saying to the kids, keep them both ....

The four teachers try even harder to encourage their students to preserve their L1 by practicing from the "language as resource" perspective. Sabrina told me how she thought it meaningful to be able to speak one's own first language, citing one of her close friends and her family on the East Coast: 
I just think it's huge. I think it's really, really important, but my fear and worry is that many of them [ELLs] will not be able to write it, or read it later on, they'll be able to speak it, I think, if they speak it at home ... but .... One of my very best friends from college is Hispanic, and I just remember going some place with her, and we went and stayed in a motel some place 'cause we took a beach trip, and waking up in the morning, and I had never, ever heard her speak Spanish, and she was on the phone, and just ... speaking Spanish to ... of course I knew she spoke Spanish, but she was talking to her mother on the phone, and I thought, "Well I've never heard that" because she's so Americanized, and she's so grown up in America. I was like ... that was so ... I felt like ... I was like, 'That was so cool!" She's looking at me like, "Well of course I speak Spanish, hello? What are you talking about?" And also my family from back east, when they used to fight with each other, when they had an argument, it was in Italian. I was like, “Awesome!" You should be able to do that ....

Sabrina uses direct and creative ways to help her ELL students keep their L1:

For instance, today ... was speech giving, and one child wrote her speech on her poster in Spanish, because her parents were able to help her that direction, though she gave her speech in English, and I said, "Can you read some of that Spanish for us, that's really cool!" And she said, "Of course I can." And she got up and read in Spanish. And they were like, "Cool! Cool!" 'Cause they can't do that. So that would be an example. Or at the beginning of the year, we have a weekend news ... you report on your weekend, and they sit there like this, and I say, "Is it easier for you to write in Spanish?" "Yeah, it is." "Good, do it" because I can't get enough from that, that I sort of know and then I'll ... I can't even really say it out loud though, and I say, "Oh, you went to a party" and "Oh your sister was there" and they're like, "Yeah!"

Dian also told me an anecdote that was very indicative:

My one experience last year ... I had a little girl ... she had finished her story, and she asked if she could write ... another story in Spanish, and I said, "Sure." But ... our ELL department was not happy with me because I wanted them .... I took it to them and said, "Can I have ... [a teacher] correct this to see .... I could just give her some help in Spanish then?" [They said,] "Your job is to teach them English." So I was like, "I thought my job was to teach them how to write!" But um ... I haven't had that... now [because] what I would do is not to take it to them, and have them 
correct it, and say, "Yeah, you can write it, you can write any of your journal stuff in your native language." Because I think that part is sad; we do early exit model, so that the kids are taught to read in Spanish until second grade, and then they exit out, and then ... it's in English, and if you're gonna be teaching them, you need to be teaching them English. And I think that's too bad 'cause I think they lose their native skills. And ... and she ... but our ELL [teacher in charge] ... she is very adamant about it, because she believes that the place to do that [keep up their L1] is at home. And she makes ... she says that your job is to these kids up and running to be competing with their classmates. Okay! So the advice I got is; close your door. Basically, close you door. My mistake was to ask someone to correct it. 'Cause I was ... wanted to make sure that she was doing it. And I still feel ... especially since she had her ... her assignment done for me. She had fulfilled to me, her obligation to me ... but maybe she could've written another ... well then, she should've written you another story, but I'm thinking ... "Well, to be a good writer in Spanish, wouldn't it ... wouldn't it just transfer to be a better writer in English? Does to me, if you become a better reader in Spanish, you're gonna be a better reader in English." That's what I'm thinking. But that's not the school's policy, so ... so I do what I need: to close my door.

For all four teachers, teaching is about relating to their students as individuals. Dian showed why she likes teaching so much: "The teaching part? I think it's the interaction with the kids and [being] close with them and finding out what's going on in their lives." Or in Annette's words: "As a teacher, I think probably my biggest strength is my ability to form individual relationships with kids and families in my class, and you know, I know when I'm teaching 27 kids, I'm not teaching a class of 27, I'm teaching 27 individuals."

Developing individual relationships with students and finding out about their lives helps teachers relate to and better teach culturally and linguistically diverse students. When the teachers would say "my students," this included all of 
their students, regardless of their cultural, ethnic, and linguistic backgrounds. They know their students all come from different environments: even within the same cultural group, there are loving homes and broken homes, homes with furniture and homes without, homes with one parent and with two. There are parents who do and do not have time to sit with children and do homework, and parents who encourage and who discourage children speak their native languages, whether or not their reasons are clear. All homes have their own cultural differences, with "haves" and "have nots" exhibiting cultural variation beyond ethnic cultural differences. All teachers know that different cultures have different perspectives and ways of life, having learned this through their life and academic experiences. Through these experiences, they developed empathy for people made to feel they are "others," and learned to understand that fairness is something everybody should strive for. Palmer (1998) describes "identity" as follows:

By identity I mean an evolving nexus where all the forces that constitute my life converge in the mystery of self: my genetic makeup, the nature of the man and woman who gave me life, the culture in which I was raised, people who have sustained me and people who have done me harm, the good and ill I have done to others and to myself, the experience of love and suffering-and much, much more. In the midst of that complex field, identity is a moving intersection of the inner and outer forces that make me who I am .... (p. 13)

Who we are is a sum of what has happened to us in the course of our lifetimes: encounters with people and things, places we have been, experiences that those encounters brought to us, emotions, reflections and thoughts about the experiences, 
meanings we assigned to those experiences, and the learning that resulted from them. It is not likely that we can just turn off our personal identity in order to switch to a professional identity when we walk into the place where we live out our careers. Likewise, teachers carry their "selves" into the classroom. Their histories and biographies, each unique to the individual, shape their attitudes toward their classroom practice (Agee, 2004; Auerbach, 2002).

Michie (2007), in his study of teachers of color, describes his study participants' suggestions about how to become quality teachers of diverse students. They are very clear, and the author strongly agrees, that teaching such students well is not about strategies:

So what do White teachers need to learn, do, and commit themselves to in order to be effective with students who are racially and culturally different from themselves? The teachers of color I interviewed had number of suggestions, but they would all agree that there is no simple set of rules to heed, no easy five-or-ten-step plan. In fact, none of the lessons that follow are in any sense quick fixes for White teachers: It's not a matter of putting up a few posters that represent the cultural heritage of your studentsthough that couldn't hurt. Rather, the teachers I interviewed suggest changes to White teachers' belief systems, thought processes, self-concepts, interaction patterns, and classroom practices that are deeper and in many ways more personal, and thus requires a greater commitment, longer view. (pp. 3-4)

The stories of the four participating teachers resonate with Michie's description. Their accounts of their lives and classroom practices illustrate how their experiences contributed to developing "belief systems, thought processes, self-concepts, interaction patterns, and classroom practices that are deeper and in 
many ways more personal" (Michie, 2007, p. 4). It was a long and at times painful process they had to go through, as children or as adults, resulting in their reputations as quality teachers of diverse students. It was unquestionably not the overnight transformation that many teachers hope for, to be achieved perhaps by learning more methodological tips. As we have seen in previous sections in this chapter, the cradles of experience that contributed to these teachers' values and beliefs were vast. Rose (1995) states

[They] emerged from and [were] shaped by one's family or church or from the early experience of being valued and affirmed by a teacher; from the experience of race or class or gender or sexual orientation, from spiritual sources or an intellectual popularism. It came from love or anger, from a sense of injustice or sense of abundance and hope. In any one teacher's history there was usually a complex intersection of such sources. (pp. 422423)

Although I am not attempting to make generalizations from the stories of the four teachers-I even state that one limitation of the study is that it is difficult to make broad claims, especially because the sample size was small—-the stories of Dian, Terry, Sabrina and Annette that I have presented are evidence for Rose's claim. Thomas and Schwarzbaum (2006), scholars in the field of psychology and counseling, stress that psychology alone cannot explain why people act the way they do:

These individual dimensions are not enough to understand human behavior, motivation and change. People do not wake up one day and decide to act in a certain way. Historical, sociological, anthropological, political, and geographical explanations are needed to make sense of a person's life 
choices, life cycle events, and patterns of individual and relational behavior. (p. 4)

Who quality teachers of ELLs are "lies in the intersection of the diverse forces that make up [their lives]" (Palmer, 1998, p. 13). In other words, their identities are shaped by social, historical and cultural context (Bruner, 1996; Darling-Hammond, 2002a; Vygotsky, 1978), both at the individual and group levels. Identities of the four study participants as people and as teachers are constructed by countless experiences in their lives. This chapter explored and described these experiences, identified important elements shared in all four teachers' lives, and argued that these experiences contributed significantly to shaping the teachers' worldviews. Their classroom practices were presented to show ways in which these practices are strongly influenced by the teachers' worldviews, making clear this study's central theme: that a teacher's entire biography is one of the most important authentications for knowing what led to their philosophy and approach to teaching (see Coughlin, 2003; Galindo, 1996; Gaudelli, 1999; Irvine, 2003; Knowles, 1992; Muchmore, 2001; Nieto, 2003; Paccione, 2000). 


\section{CHAPTER V}

\section{CONCLUSIONS AND RECOMMENDATIONS}

Introduction

This final chapter presents summaries of key findings and of the study's "limitations and delimitations," then offers recommendations, including implications for small school districts, teacher education programs, and policy development, followed by recommendations for further study. The chapter closes with a summary of the study and some concluding thoughts and images.

\section{Summary of Findings}

Detailed presentation of the study's findings is contained in the previous chapter. To summarize, four principal "themes" were placed into two groups. In the first group, the finding that teachers' "Possess a Risk- and Challenge-taking Nature" also incorporated the finding that they are "Life-Long Learners." In the second group, the finding that the teachers had "Experiences in Different Cultures" comprised two different kinds of cultural experience: "Regular" Cultural Experiences and "Otherness" Cultural Experiences.

The participating teachers were judged to share a willingness to make choices involving a challenge. Some of the challenges they took up could have had serious consequences. However, the teachers never stopped taking them on. Many of these challenges were, or proved to be, learning opportunities, and it was judged 
that seeking life-long learning opportunities was a demonstration of the challengetaking spirit, being additional taxing work when the teachers' commitments in their professional and personal lives were already arduous. Some already have their next demanding project in mind. And all four teachers, try to instill in their students, by modeling, the same resiliency and willingness to take on risk and challenge.

All four teachers have had both "regular" and "otherness" cultural experiences. "Regular" cultural experiences helped them understand other cultural values and practices in a "virtual" way, by observing and participating in different cultures. And through "otherness" cultural experiences, they came to know what it is like not to be accepted for who they are, and this was judged to have nurtured in them deep empathy and compassion for people who are considered to be "others" by society, and to have shaped their way of thinking about power, fairness, acceptance, and belonging. They bring into their classrooms their othernesssensitivity, and it is represented in their caring, helping and humanistic attitude in their relationship with their students.

\section{Limitations and Delimitations of the Study}

Several limitations have been identified, one of which was detailed in chapter 1-teachers' willingness to participate - and another of which was the difficulty of getting nomination forms back from district educators. I will discuss these in reverse order. 
Recruitment of participants took an unexpectedly long time, which resulted in numbers that were much lower than desired. Soliciting nominations turned out not to be the absolutely perfect way of recruiting participants for this study. I adopted the two-step method from Ladson-Billings (1994), who used it in her study of effective teachers for African American students. For her Step One, she asked African American students' parents to nominate teachers they considered to be quality teachers for their children. I replaced "parents" with "all educators" in the Cascadia district. I assumed that since it was a small district, most teachers would know about other teachers regardless of the grade level at which they were teaching; this turned out to be an incorrect assumption. Evidently, as one of the high school teachers who returned the nomination form commented, teachers are not associated with those at different levels, so that those who do not teach at elementary schools had no basis for making nominations. This pattern was repeated in the nomination forms returned by middle school teachers.

Another oversight was that people who were asked to nominate teachers in Ladson-Billings' (1994) study were parents of students, whereas those in my study were educators. This is not to say that parents care more about their children's education than teachers; on the contrary, teachers may be more aware of the importance of education. However, the level of investment in and concern about children may be higher on the parents' part and hence the willingness to participate 
in nomination may have been lower in my study. In short, the stakes may not have been as high for teachers as for parents.

As to the reluctance of nominated teachers to join my study, there may be several reasons. The most understandable one would be the heavy work load and commitment they may already have had at the time of the invitation. Another, anticipated in chapter 3 , is that the nature of the study may have discouraged teachers from participating (i.e., because telling about their own lives would inevitably require self-disclosure and breach of privacy). Still another reason could have been teachers' level of awareness about the importance of educating culturally and linguistically diverse students, and the role they could play in such students' educational attainment. Even though schools have been experiencing increasing numbers of diverse students, and teachers have thereby experienced growing difficulty in teaching them, many teachers may still think that it is ESL teachers' job to teach such students, while their own job would come after students had already become fluent in English. Or teachers just might not be very interested in diverse students' education, as one of the invited teachers' comments indicated, who simply wrote: "Not interested." The awareness issue may be also a thread that helps explain the low return rate in Step One (nomination of teachers): why would it be important for educators to participate in nomination if education of ELLs is not significant to them? This reminds me of district ESL director Aron Lowry's experience of recruiting teachers to enroll them in the ESL Endorsement Program, 
for which I taught, and for which the district would pay the tuition: He had a very hard time doing so and asked me to loosen the attendance policy for my class. ${ }^{25} \mathrm{He}$ indicated that, otherwise, the teachers whom he recruited might drop out. To many teachers, the need to educate culturally and linguistically diverse students well may not be as important.

The lower participation rate of educators in nomination and in the study itself resulted in a smaller sample size than expected. This makes generalization of the study results difficult. The study would need a larger return to be more generalizable. However, because the number was small, I was able to spend more time with the study participants, which led to constructing more reflective and trusting relationships with them. The result was much more in-depth conversation with and deeper understanding of them. Going far beyond what I expected, they powerfully came forward with their personal life stories, telling me without any hesitation, "You can write whatever you want." Much of the "whatever" consist of pieces of their identities that I suspect were never exposed before-exactly the sort of information I was concerned they would not want me to include in my writing. If one of the important purposes of a qualitative study is to explore human experience and understand the meanings that subjects give to their experiences, then this study will serve this purpose, even if it does not fulfill a desire for large-scale generalizability in the traditional sense.

\footnotetext{
${ }^{25}$ I taught one of the program courses for the district.
} 
There are two other post-mortem observations. First, the interview guide should have been pilot-tested. By doing so, the probable flow of conversation could have been examined in advance, helping to make me more confident about what I was asking and about the direction of the flow of the conversation. In interviews, as a novice researcher, I sometimes felt as if we were circling around core issues. Pilot interviewing would have allowed me to modify the content of each question, change the order of the questions, and/or add and delete questions, and enabled the interview participants to reach the core issues to be talked through.

Second, more classroom observations in advance of or between interviews could have supported, or not, the teachers' reputations as good teachers of ELLs. Since this reputation was a premise, more observations could have revealed any disparity between educators' ideas of good teachers of ELLs, i.e., in their nominations, and the researcher's observed behaviors of participating teachers, allowing for richer or different perspectives.

\section{Recommendations}

\section{Implications for Small Districts}

The need to deal with culturally and linguistically diverse students is no news in big cities such as Los Angeles, New York, Houston, or San Francisco. However, the problem, once thought to be only an urban school problem, now affects small, rural farming communities, too. The growing number of immigrants 
in these communities has given rise to a new challenge for their school districts as they are no longer homogeneous.

My research deals with one of these small-town school districts and has implications for such small districts across the country. Cascadia is the kind of community where there was little need to deal with a culturally and linguistically diverse population only a decade ago, schools included. Many teachers even seemed indifferent to and uninformed about the issues. This was evident in educators' low response rate to my solicitation for nominations and my invitations to nominated teachers. Thus the study noticed this low awareness level even before the actual data collection started. I consider it an essential sign that such small, traditionally White districts have to face up to the issue. The lack of awareness implies that districts must raise teachers' consciousness, convincing them that diversity is "here" in their very districts, that it is "reality." Since my study is one of the rare studies dealing with small districts, it can serve as a messenger to other small districts.

One of the ways to raise teachers' consciousness is to have all of them join trainings such as ESL or bilingual endorsement programs. It could be difficult to persuade all teachers to join such trainings, as Cascadia experienced with its first round of sending teachers to the ESL endorsement program run by a public university. However, through such programs, teachers would come to realize that working well with students from diverse backgrounds does not simply mean 
acquiring new skills to remediate challenges that predictably accompany such students, because they are different from known students. Teachers may learn that building good relationships with ELL students does not mean having to speak their first language, but to be interested in and understand who their students are and what they bring to the classroom. Teachers may conclude that their districts would do as well to spend money on ESL training as on teachers' learning a second language. Obviously the new language learning helps, making communication much easier, but teachers could end up speaking to students, without being interested in the students themselves. Small school districts ought to put intercultural training, such as ESL endorsement, in their systems of regular teacher development, even as a required element, especially given the disparity between the current teacher demographic and the changing student demographic.

My study also has an important implication for hiring teachers. Districts in small farming communities like Cascadia generally have personnel from the traditional mainstream population, unfamiliar with diverse cultures and languages, and tending to associate primarily with people like themselves. In districts like this, teachers who have different cultural experiences and an understanding of what it is like to be an "other" are vitally needed for quality education of culturally and linguistically diverse students. Such experiences and understanding will show in their classroom practice through such personal traits as caring, empathy and justice. One way to increase the number of teachers who have these experiences is to hire 
candidates from diverse cultural backgrounds. It may also be delete helpful to have candidates talk about their life and cultural experiences in the interviews or write a brief essay about them, and to be certain that interviewers have some appreciation of the characteristics that make good teachers of ELLs.

\section{Implications for Teacher Education}

One of the key findings from this study offers a valuable insight for teacher education. It has already been noted that teachers need to be culturally sensitive and competent to teach increasingly diverse students (referring to diversity not only in language but also in race, class, gender, ethnicity, disability and sexual orientation). However, this study tells us that it is not only "regular" cultural and linguistic experiences—such as traveling abroad or understanding other languages - that make good teachers of diverse students. I learned, even though the sample size was small, that understanding and compassion and a sense of justice are essential characteristics of effective teachers. I learned that this compassion can come from the experience of having been an "other." Based on this realization, I make recommendations for (a) admitting students into teacher education programs, and (b) teacher education program design.

It is desirable to use a screening system, such as pre-admission interviews, for admission of students into teacher education programs. Interviewing may then look at entrants" "different" or "diverse" experiences—not only living overseas, speaking languages other than English, or working in the Peace Corps, but 
experiencing "otherness" in more affecting ways such as being adopted, marrying a person from a different culture, or having a disability. If the candidate understands what it is like to be a "marginalized" other, it would be more valuable for development as a teacher of ELLs.

Ideally, all teacher education programs should be founded with the concept of multicultural education embedded into their curricula, as one of the main pillars. This would provide teacher education students with better opportunities to develop understanding and knowledge of ways to work well with diverse populations. This remains relevant, considering how many teachers are not even aware of the effect of diversity in the classroom.

In general terms, multicultural education is recognized as having become an important subject for teacher education over the years. However, in many programs, courses that teach diversity or multiculturalism are considered nonessential or have a marginal status (Bonner, 2006), and in many cases, students are only taking these courses because they are required. Unless the importance of learning these concepts is emphasized by building entire programs on the idea of multiculturalism, it is difficult to ensure that students will become serious about studying and understanding the importance of diversity in teaching and learning. They may just try to get by, as I have seen in my classes in a teacher education program at a public university. By genuinely integrating multicultural education into the curriculum, hopefully, students will come to realize that multiculturalism is not something that 
they study "about" "other" cultures and peoples, but involves learning about themselves; examining and transforming their perceptions about themselves; realizing that their viewpoints are just a few among many that exist in the classroom; and learning to embrace others' viewpoints. This would not only lead teachers to have better relationships with their culturally and linguistically diverse students, but also allow them to rethink school reform (Nieto, 2000). In such programs, there are a variety of ways we can promote students' awareness of diversity and connect it to teaching skills. For example, it is important to provide a conceptual basis. This must afford an opportunity for students to come to deeply understand the profound effect of culture and language in teaching and learning. They need to be able to translate this knowledge into effective instructional skills by learning practical strategies, and they must learn to engage in dialogue with their colleagues. Discussing class readings, assignments and projects would give students opportunities to reflect on their own assumptions, beliefs and values about diversity; on their own cultural identities, and on their assumptions, beliefs and values about themselves. These are vital opportunities for teachers to "rethink" their understanding of themselves. Considering who they really are is a first step toward becoming a "multicultural teacher" (Nieto, 2000)—especially if they think they know themselves well.

Given the current demographics of the teaching force, one thing that is extremely important to consider in designing teacher education programs is that 
they should provide their students with opportunities to experience what it is like to be "others." This would provide vital reinforcement for teacher education students to connect all coursework to the reality of ELL students' lived experience.

Teachers' intellectual learning could hit home-could become internalizedthrough this physical experience. I have a student who exemplifies the effect of this project. Below is an excerpt from her writing about the experience:

During reading for class I was irritated at the assumption that a White teacher who was competent and willing, will have trouble teaching ELL students .... Through the ... [class] reading and because of this experience at the Hindi temple, I have come to realization of my own egocentrism and monoethnicity and how that may impact my teaching. I was surprised at how much more I would learn from the class and [the "becoming an other" project]. Hopefully [they] will help me to achieve "equity pedagogy (Darling-Hammond, 2002). I truly am going to make a concerted effort to find out more about ... my ELL students .... I hope never again to equate intellect with precision of written and spoken English. I also try not to judge families who still do not speak English, nor will I assume that it is the students' fault if they do not excel in my class .... I will know how lucky I am when the ELL students can read and write in their native language ....

This student's experience exemplifies Nieto's (2000) concept about "becoming a multicultural person" (p. 338):

Becoming a multicultural teacher ... means first becoming a multicultural person. Without this transformation of ourselves, any attempts at developing a multicultural perspective will be shallow and superficial. But becoming a multicultural person in a society that values monoculturalism is not easy. It means reeducating ourselves in several ways .... We need to confront our own racism and biases. It is impossible to be a teacher with a multicultural perspective without going through this process .... Our own reeducation means not only learning new things but also unlearning some of the old. The process can be difficult and painful but it is a necessary part of becoming multicultural. 
It is crucial that teachers develop an understanding of diverse students' needs, emotions, hopes, and positions in school and society, so that teachers can relate to them at a deeper level. Such opportunities help teachers cultivate more compassion for and understanding of culturally and linguistically diverse students.

\section{Policy Implications}

Considering the increasingly diverse population in our society, training provided by programs such as the ESL or bilingual endorsement programs should be a requirement for all teacher education students as well as in-service teachers. However, this is not to recommend that all teachers should be endorsed to be more recruitable on the job market, which is regrettably often a reason for teachers to join such training. Teachers who come into ESL training for such reasons usually want to get a quick fix or some techniques for teaching ELL students. They often prefer to skip the foundational part of the training, which does not teach "useful and practical" ideas and solutions for their teaching practice. There are also teachers who have good intentions and want to help culturally and linguistically diverse students succeed in school, but are not sure how to do so. When even these teachers decide to study this subject, too often they expect to be presented with definite, specific, and effective teaching strategies that they can take back to their classrooms to use the next day. Many, in fact most, pre- and in- service teachers who came into my multicultural education courses expected to gain techniques as quickly as possible, with which they could teach such students "effectively." As 
one of my students, in a course about the impact of culture and language on students' learning, said: "I need skills to teach my ELLs, skills I can use now" (emphasis added). And as one of my in-service teachers put it, "Are there five or 10 steps to efficiently teach ELL kids?" However, researchers' experience makes clear that the aspiration to become a quality teacher of culturally and linguistically students cannot be realized by diminishing the challenge of such practice to a mechanical level.

To work against the "quick fix" syndrome, my recommendation emphasizes exactly the opposite: the foundation courses themselves, in which participants gain insights in the following:

- how students' native language and culture deeply influence their identity development and learning,

- the relationship between Language 1 and Language 2

- how teachers' understanding of these factors in their students' learning affects their teaching and thereby students' learning,

- how teachers' understanding about their own cultural identity significantly impacts their understanding of how they teach and how students learn, and

- how these influence the relationship between the teacher and ELL students, which can be a determining factor of students' success or failure. 
Unless teachers understand these philosophical foundations, even "useful and effective" ideas will not be effective. In using teaching techniques without a firm understanding of the basis from which these derive, teachers are using these techniques only because they are told the underlying strategies were effective, not because they know why they are helpful to diverse students. This superficial and limited understanding will not enable the teacher to use such strategies in a more nuanced and sensitive manner. Such lack of understanding may well result in practices that are not in tune with the ELL students' real needs as a learner. Both strategies and techniques must be solidly connected with an understanding of the foundations so that teachers know why they are using them, why they are so important, and therefore what kind of effect the strategies and techniques can be expected to have on ELL students' learning.

Annette, one of my study participants, spoke of the merit of having studied in a teacher education program in which "multicultural content was infused in every class." The students in the program were immersed in multicultural education concepts because every course was taught from that viewpoint. The intensity was such that at the end of the $1 \frac{1 / 2}{2}$ years of the program, they were even feeling tired of discussing the multicultural issues:

[Multicultural content] was just present in every class, and that was part of our discussion. I think after a while, we all sort of got sick of it because we-there was 20 of us that was in one cohort, so we were together everyday for a year and a half, and ... always had these very intense conversations. And it ... it um ... seemed towards the end that we've been 
through everything and it was like, "Oh no, here we go again ... we're gonna talk about, you know, racial ....

However, in the end, Annette appreciated the value of the program she attended.

She thinks of the benefits of the program whose focus was diversity, equity and social justice:

[We had] a lot of um ... a lot of philosophical work in graduate school. And um ... a lot of discussion and writing and reading about the function of public schools in our society, and the importance of maintaining democracy in a classroom. Um ... we talked a lot about um ... stereotypes um ... like in different types of instruction, for example, in um ... schools that have a high rate of poverty, there's a lot more phonics instruction and reading, and then in wealthier schools tend to use more whole language approaches. So ... we would spend a lot, a lot of time talking about those kinds of issues. [The program] helped um ... with cultural sensitivity, and I can remember reading something by ... an Eskimo student about their white teacher, and we would read a lot of things like that from other ... from student's perspectives that were not white ... and who were at different culture than the teacher's culture. So it helped a lot with awareness, and helped a lot with ... we talked a lot about the um ... dominancy in white culture, which I probably hadn't really thought of that much before the program ... um ... you know, a lot of power issues in the classroom.

Annette is very appreciative of having learned the philosophical bases in the

program because she thinks that the technical part of teaching, such as writing

lesson plans and grading papers, can be learned on the job:

I was really glad I went into a program that I learned how to teach that way ... I think that having a good philosophical understanding of what you do is more beneficial in the long run than being able to manage the mechanics of the job ... [because] you wont' always have an opportunity to discuss the philosophy with people.

I have taught a class about how culture and language influence students'

learning. This class, being one of the foundation courses in the ESL Endorsement 
program, is supposed to be taken at the beginning of the program. But it was not unusual that students took the class as the last one before completing the program, and they did so for a variety of reasons. One such student in my class said, "Now I know why I should have taken this class first, and I wish I had." I also heard, from the program's coordinator, that in one district they had started with an "effective strategy" class because the district could not persuade teachers anxious to know "those strategies" to start with the foundation courses. The result was that the teachers did not understand why "those strategies" were effective, even as they went back to their classrooms with them. Without a conceptual understanding of the basis of the strategies, what they were essentially saying to themselves was: "I don't know why these strategies are important, but I'll use them anyway because I was told to do so." However, utilizing skills and techniques they learn in later courses, after starting with a sound philosophical basis, will help teachers more effectively help bilingual/ bicultural students learn.

Such training also makes teachers confident of becoming good teachers of students who are culturally very different from themselves. Two of my study participants, Terry and Dian, who attended an ESL endorsement program, said it helped them greatly in relating and teaching their ELLs. Terry said:

It's really, it's helped me tremendously as a teacher overall, not just as an ELL teacher, there's so many kids that have difficulties that are not ELL students, and um ... it's made me much more aware of all of the different things to look for. And um ... the ... different tools that we have available to us to use, um ... the people that we have available to use to talk to ... if 
we need the questions answered ... It's becoming more of um ... community thing ... where people are, I think, more aware ... I think, at least in the Mexican population, I don't know .... It's just made me understand ... it's made me more open and have a lot more patience and search for those problems if there's a problem that a kid has .... It makes me really search my mind and if I can't find it, I have to find it some other way .... I know there's always an answer out there ... or a way to help a kid, and so ... there's no way that you can't say that you can't help an ELL student to be able to be a much better student, or a much smarter student.

With understanding of diverse students and knowledge of helpful strategies and techniques for teaching them, which engender confidence, teachers would create a cooperative community of learning, which all four of my participating teachers have in mind as one of their goals.

\section{Recommendations for Further Study}

Studies like mine only set an area of research in motion. The study findings suggest an array of possible further research:

- A study complemented with classroom observations would enrich the current inquiry. Teachers' observable behaviors, such as classroom organization and discourse patterns, could be observed in comparison to the manifest content of the instructional curriculum, in order to obtain a holistic picture of the teacher's awareness of cultural sensitivity and inclusion of diversity in the classroom. Triangulated with interviews with the teacher, observations of these items would allow the researcher to explore connections between the teacher's core values about cultures and languages and ways these occur in classroom practices. 
- It would be interesting to track one of the four teachers, who has experienced neither ESL training nor a multiculturally infused teacher education program, for another few years. She would be provided with ESL training and this longitudinal case study would look at whether or not she showed any sign of change even though she is already identified as a good teacher of ELLs. If she did, in what areas and how would she improve?

- A larger scale study that involves a larger number of teachers from multiple small districts experiencing demographic change would allow for more generalizable findings.

- Related to this, a comparative study of teachers from representative small districts is also recommended. Investigate similar results across such districts would make the results more generalizable to other small school districts.

- A study that follows teachers over multiple years would be valuable. Such a longitudinal study could look at regular classroom teachers' life incidents after the study starts and identify whether any of these incidents influence their classroom practice.

- A study of students who are enrolling in an ESL training program would be helpful. Identifying students' multicultural awareness level before, in the middle of, and after the program, for example, would be informative. 
Tracking changes in students' behaviors and attitudes over the course of the program would provide insightful information about designing such programs.

- Related to the above study, and also helpful for designing ESL training programs, would be a comparative study to test the hypothesis that foundational curriculum increases teacher effectiveness in teaching ELL students. One group of trainees will start with foundation courses and then progress to more practical courses. The other group of trainees will only take practical courses with no courses that specifically deal with foundation and philosophy of multicultural education. Observe the teachers as they practice over the next 3-5 years.

Summary of the Study

The main purpose of this study was to explore and learn from the lives of mainstream elementary classroom teachers who are said to be good teachers of culturally and linguistically diverse students. The study is one of the first to consider "good" teachers of such students in a small rural school district, of a type that previously had little need to deal with this student population. The intention was to gain a better understanding of what contributed to the formation of teachers' perspectives and philosophy regarding the education of such students. It was also a hope that the study would offer information to help improve teacher education 
programs preparing pre-service teachers to work with culturally and linguistically diverse students.

Four teachers from a small rural school district participated in the study, sharing stories of their lives and the self-assigned meaning of events in their lives. The study showed how they are connected to their "who they are" today. Its focus was to portray through the teachers' stories the incidents and experiences in their lives that may have contributed to constructing who they are as people and as teachers. The teachers had externally similar backgrounds in that they were all White, in their 40s and 50s, and all except one were born and raised in small rural communities. However, their life stories showed how four people from the same mainstream culture traveled very different pathways to become who they were.

The four participants' profiles and life histories, and critical incidents over the course of their lives, were described in detail. Despite their individual uniqueness, similarities emerged during data analysis. Examining these similarities created an understanding of who these teachers were and what processes made them good teachers of ELL students.

A fundamental finding, the most prominent commonality, was that all had lived the experience of being an "other." Although settings and contexts varied, each experienced the emotion of "being different" and "being marginalized." This attribute was judged to have contributed to shaping the teachers' ability to relate to 
and understand more deeply the experiences of culturally and linguistically diverse students, and thereby enable more profound compassion for such students.

The second prominent finding was that the teachers had a risk- or challenge-taking aspect to their personalities, which they used to overcome obstacles in their lives, and intend to keep using to embark on new possibilities.

A third finding, perhaps more of a realization, concerned the way that the teachers brought all of these experiences, through the personality traits the experiences helped create, into their classrooms.

Several recommendations were offered, based on the findings. Small rural school districts need to raise teachers' awareness about diversity and should make intercultural training, such as ESL endorsement, part of teacher development. Teacher education programs should seek participants who have had "otherness" cultural experiences, which tend to increase teachers' understanding of, attentiveness to and sense of equity about diversity and experiences of students from different backgrounds. Such programs should develop methods for this, such as pre-admission interviews. They should institute multicultural education as a central theoretical concept. And they should give vital emphasis to providing opportunities for students to experience what it is like to be an "other," so that all of the cognitive work can "hit home," physically.

As for policy implications, it was recommended that all in-service teachers should be ESL endorsed. Their training should build learning on a solid 
philosophical foundation, then connect this with useful teaching strategies, based on the conviction that effective teaching techniques for ELL students become effective only when the students know why the techniques work.

Suggestions for further research identified opportunities to continue adding to understanding the lives and identities of quality teachers of culturally and linguistically diverse students. There has been an abundance of research about noneffective teachers of ELL students, but research about good teachers of such students is still in a beginning phase.

\section{Closing Thoughts}

Dian told me a story of her principal: how his family did not value education and how one teacher helped him be successful in school. The story was her way of saying how much teachers can do in a student's life.

We can do ... we can do a lot though, because the ... our principal, um ... his family didn't value education, and uh ... he has this doctorate, and the rest of the family, you know, "Why are you doing that?" But he was ... he said the only reason he did was because a teacher ... got to him someway, to say you have ... you are very smart; you're getting kind of into trouble because you're so smart not enough challenge; let's challenge you; and a teacher did something. So ... not that I'm saying that you're better, for having a.... doctorate than somebody who's working, but to me, he kind of broke away from his social class, anyway, he's not, you know ... I mean, this sounds really awful to say, but you see his family, and you could see that they look pretty lower class, and when you look at him you can see that he is middle class, I'm not saying that he's anywhere near elite, but he is ... you can do things with education, and ... and if a teacher hadn't done that ... he says, "Well I don't know where I'd be; working, some ...." you know .... So I think we make a difference. 
I started chapter 4 with the story of a friend of mine, who thinks that she owes who she is today to her first American teacher, who kept her Korean student's poem for more than 30 years. That story, and the one just presented about an elementary school principal who also thinks he owes his life to one of his teachers, are real life examples that prove teachers can actually change their students' lives. The fact that I stumbled into these stories just by accident--not intentionally seeking them-makes clear that one can find many more stories like these. In this closing section, I will present how they might have done so by telling two other favorite stories.

Teachers can be significantly influential in a student's life, and no matter how great a program is, it would have little worth without personal relationships between the teacher and students. Without teachers such as those mentioned above, and the ones in this study, an effective program would not be effective. "There is a well-known adage that even the best curriculum materials will fail if the teacher's heart is not in it" (Feuerverger, 2005, p. 178). Without committed teachers who care for quality and meaningful education, even a well-designed program would be just an empty skeleton. It is the teachers and the students who have faith in and learn from each other, and construct trusting relationships that make a good curriculum work.

There is a tendency among educators to feel embarrassed if we use the word "love" in describing the motivation to educate our youth. This may be especially 
true in writing academic theses. Nonetheless, I have always considered it a tenet of education that to educate is to love the person to whom you are devoting yourself. As we know, education does not only take place in school. At home, parents teach their children that they sometimes have to bend their desire and conform to the society; they care for them so that they will not stumble on the road to their adulthood; they nurture them so that they grow up to be productive citizens. At school, teachers cultivate their students' potential in a classroom environment. No matter what the context is, I think that the basis of the act of the person who is nurturing the young is love. Love that has confidence in the young mind's potential; love that firmly believes in its promise. Teaching is an act of "love," which translates into a "core belief in students" and "a fundamental belief in the lives and minds of students" (Nieto, 2003, p. 37).

Kohl (1984) calls this love "faith." He maintains: "Faith in the learner leads some teachers to find strengths where others see nothing but weakness and failure. Such faith ... is a form of what I call the love for students as learners" (p. 64). He says that not all teachers and students will or can be expected to like one another. "Nevertheless, a teacher has an obligation to care about every student as a learner" (p. 66). The quote below from Kohl's story of his relationship with an angry 14-year-old student illustrates what he means:

I ... explained that books and writing were not small school things ... but central to life and understanding, that it was not a joke not to be able to read, that it was a form of poverty, and that he didn't have a right to not read. I 
doubt that he had ever experienced an adult express so much care for learning and books-not for some relationship to a reading test or grade .... His whole attitude toward reading began to change. I felt that my love of learning and my pride in teaching him gave him a very different perception of himself as a learner .... After a while, he could read. I loved to see him learning and, of course, to feel that I was some part of that process .... I took great pleasure in seeing him focus his previously undisciplined energy and learn to read. I loved him as a learner .... That affection led me to study him carefully and build on the strengths and personal interests I could tease out of him. It required that my personal feelings about him be subordinated to my feelings about him as a learner. (p. 65)

The love, the faith, and the recognition become real when they are

communicated, as when teachers and culturally and linguistically diverse students work together on projects such as that described in the next story, which comes from the journal of one of my ESL endorsement students:

I am making great headway with Maria .... I have had her write several of her assignments in Spanish. I can decipher just enough to get the general drift of what she is saying. I have asked another Hispanic student to help me with the vocabulary I don't know or have forgotten, so he is also coming along, since he and Maria are teaching me Spanish as I grade her papers. Hopefully I am conveying the value I place on Maria's intelligence and the respect I have for Roberto in helping me.

With this love, students come to realize that they are respected, valued and cared for. This is what culturally and linguistically diverse students need the most in the relationship with their teachers. With this relationship, school becomes more relevant to their lives and a place where they feel affirmed.

In closing this study, I would like to present a written excerpt by a student of mine, which encapsulates her transformational journey as a teacher and person: 
Today I teach 10 ELL students .... Some speak little English, such as Annie, who emigrated from Mexico. Juan has attended ... public schools his whole life yet he struggles to read and write in English .... It is the Annies and Juans that prompted me to pursue further training .... I was hoping for the quick fix to be this course .... Instead I am gaining an appreciation of how important it is to learn more about the cultures of my students. I realize I need to make more of connection with them. Hopefully, they'll realize I am interested in them as individuals and in their culture and traditions. This knowledge and understanding will have to be the bridge that words currently can't span .... I am in the process of acquiring Gadamer's "concept of horizon" $\left.{ }^{26}\right]$ so that I can see myself in the context of a bigger world, made up of other equally important and valid cultures and ethnicities.

The four teachers who devoted their time and their valuable stories to this study may have experienced a similar transformation, perhaps unconsciously and non-systematically, sometime, somewhere in their lives, which shaped their way of thinking into a more inclusive and open one. Dian's hope to be with "citizens of Earth" is an eloquent statement that captures the spirit of quality educators of culturally and linguistically diverse students.

${ }^{26}$ Gadamer's concept of horizon: "Gadamer writes that 'To acquire a horizon means that one learns to look beyond what is close at hand-not in order to look away from it, but to see better within a larger whole and in truer proportion"' (Noel, 2000, p. 160). 


\section{REFERENCES}

Agee, J. (2004). Negotiating a teaching identity: An African American teacher's struggle to teach in test-driven contexts. Teachers College Record, 106(4), 747-774.

Armendariz, A. L., \& Armendariz, E. J. (2002, Spring). An administrative perspective of a two-way bilingual immersion program. Bilingual Research Journal, 26(1), 1-11.

Ashton-Warner, S. (1963). Teacher. New York: Simon \& Schuster.

Auerbach, S. (2002). "Why do they give the good classes to some and not to others?" Latino parents narratives of struggle in a college access program. Teachers College Record, 104(7), 1369-1392.

August, D., \& Hakuta, K. (Eds.). (1997). Improving schooling for languageminority children: A research agenda. Washington, DC: National Academy Press.

Ayers, W. (Ed.). (1995). To become a teacher: Making a difference in children's lives. New York: Teachers College Press.

Ayers, W. (2001). To teach: The journey of a teacher. New York: Teachers College Press.

Baker, K. A., \& de Kanter, A. A. (1983). An answer from research on bilingual education. American Education, 19(6), 40-48.

Banks, A. J. (1998). The lives and values of researchers: Implications for educating citizens in multicultural society. Educational Researcher, 27(7), 4-17.

Banks, J. (1991). Curriculum for empowerment. In C. E. Sleeter (Ed.), Empowerment through multicultural education (pp. 125-141). Albany: State University of New York Press.

Banks, J. (2002). Series foreword. In L. Darling-Hammond, J. French, \& S. P. García-Lopez (Eds.), Learning to teach for social justice (pp. ix-xii). New York: Teachers College Press. 
Bennett, C. I. (2003). Comprehensive multicultural education: Theory and practice. Boston: Allyn and Bacon.

Bialystok, E. (Ed.). (1991). Language processing in bilingual children. New York: Cambridge University Press.

Bialystok, E., \& Hakuta, K. (1994). In other words: The science and psychology of second-language acquisition. New York: Basic Books.

Bonner, F. A., II. (2006). Wade in the water: lessons learned from Katrina by one African American academic. Teachers College Record (ID \#12318).

Retrieved March 9, 2006, from http://www.tcrecord.org

Bruner, J. (1977). Early social interaction and language development. In H. R. Schaffer (Ed.), Studies in mother-child interaction (pp. 271-289). London: Academic Press.

Bruner, J. (1996). The culture of education. Cambridge: Harvard University Press.

Collier, V. P. (1987/1988, Winter). The effect of age on acquisition of a second language for school. New Focus, The National Clearinghouse for Bilingual Education Occasional Papers in Bilingual Education, 2. Retrieved January 30, 2004, from http://www.ncela.gwu.edu/ncbepubs/classics/focus/ 02aage.htm

Coppock, M. (1995). Mentoring at-risk Hispanic students in self-esteem, academic growth, and citizenship awareness. Equity and Excellence in Education, 28(1), 36-43.

Coughlin, M. (2003). Life history influence on teaching United States history. Paper presented at the annual meeting of the American Educational Research Association. (ERIC Document Reproduction Service No. ED 478392).

Council of Chief School Officers. (1987). Assuring school success for students at risk: Policy statement of the Council of Chief School Officers. Washington DC: Author.

Crawford, J. (1999). Bilingual education: History, politics, theory and practice $\left(4^{\text {th }}\right.$ ed.). Los Angeles: Bilingual Education Services. 
Crawford, J. (2002). Making sense of census 2000. Retrieved May 21, 2004, from http://www.asu.edu/educ/epsl/LPRU/features/article5.htm

Crawford, J. (2003). Census 2000: A guide for the perplexed. Retrieved October, 21, 2003, from http://ourworld.compuserve.com/homepages/ JWCRAWFORD/census02.htm

Creswell, J. W. (2002). Educational research: Planning, conducting, and evaluating quantitative and qualitative research. Upper Saddle River, NJ: Merrill Prentice Hall.

Creswell, J. W. (2003). Research Design: Qualitative, quantitative, and mixed methods approaches. Thousand Oaks, CA: Sage.

Cummins, J. (1979). Linguistic interdependence and the educational development of bilingual children. Review of Educational Research, 49(2), 131-149.

Cummins, J. (2000). Beyond adversarial discourse: Searching for common ground in the education of bilingual students. In C. J. Ovando \& P. McLaren (Eds.), The politics of multiculturalism and bilingual education: Students and teachers caught in the cross fire (pp. 127-147). Boston: The McGraw-Hill Companies.

Cummins, J. (2001). Negotiating identities: Education for empowerment in a diverse society ( $2^{\text {nd }}$ ed.). Los Angeles: California Association for Bilingual Education.

Cummins, J. (2002). Primary language instruction and the education of language minority students. In C. F. Leyba (Ed.), Schooling and language minority students: A theoretical framework ( $2^{\text {nd }}$ ed.; pp. 3-46). Los Angeles: Legal Books Distributing.

Darling-Hammond, L. (2002a). Educating a professional for equitable practice. In L. Darling-Hammond, J. French, \& S. P. García-Lopez (Eds.), Learning to teach for social justice (pp. 201-212). New York: Teachers College Press.

Darling-Hammond, L. (2002b). What is the problem and what can we do about it? In L. Darling-Hammond, J. French, \& S. P. García-Lopez (Eds.). Learning to teach for social justice (pp. 149-152). New York: Teachers College Press. 
Darling-Hammond, L., \& Ancess, J. (1996). Democracy and access to education. In R. Soder (Ed.), Democracy, education, and the schools (pp. 151-181). San Francisco: Jossey-Bass.

Darling-Hammond, L., French, J., \& García-Lopez, S. P. (Eds.). (2002). Learning to teach for social justice. New York: Teachers College Press.

Delpit, L. (1995). Other people's children: Cultural conflict in the classroom. New York: The New Press.

Denzin, N. K. (1989). Interpretive biography. Newbury Park, CA: Sage.

Donmoyer, R. (1990). Generalizability and the single-case study. In E. W. Eisner \& A. Peshkin (Eds.), Qualitative inquiry in education: The continuing debate (pp. 171-200). New York: Teachers College Press.

Feuerverger, G. (2005) Multicultural perspective in teacher development. In J. Phillion, M. F. He, \& F. M. Connelly (Eds.), Narrative and experience in multicultural education (pp. 175-199). Thousand Oaks, CA: Sage.

Fickel, L. H. (1999, April 19-22). Democracy is messy: Exploring the beliefs and personal theories of a high school social studies teacher. Paper presented at the annual conference of the American Educational Research Association, Montreal. (ERIC Document Reproduction Service No. ED 433282)

Freeman, D. E., \& Freeman, Y. S. (1994). Between worlds: Access to second language acquisition. Portsmouth, $\mathrm{NH}$ : Heinemann.

Freeman, D. E., \& Freeman, Y. S. (2001). Between worlds: Access to second language acquisition ( $2^{\text {nd }}$ ed.). Portsmouth, $\mathrm{NH}$ : Heinemann.

Freeman, R. D. (1998). Bilingual education and social change. Philadelphia: Multilingual Matters Ltd.

Freire, P. (1999). Pedagogy of the oppressed. New York: Continuum.

Fueyo, V., \& Bechtol, S. (1999, Summer). Those who can, teach: Reflections on teaching diverse populations. Teacher Education Quarterly, 26(3), 25-35. 
Galindo, R. (1996, November). Reframing the past in the present: Chicana teacher role identity as a bridging identity. Education and Urban Society, 29(1), 85-102.

Gándara, P. (1995). Over the ivy walls: The educational mobility of low-income Chicanos. Albany: State University of New York Press.

Gaudelli, B. (1999). Teacher as self: Understanding pedagogy in global education. Paper presented at the Annual Meeting of the College and University Faculty Association National Council for the Social Studies, Orlando, FL. (ERIC Document Reproduction Service No. ED 437 393)

Gay, G. (2000). Culturally responsive teaching: Theory, research and practice. New York: Teachers College Press.

Gay, G. (2003). Introduction: Planting seeds to harvest fruits. In G. Gay (Ed.), Becoming multicultural educators: Personal journey toward professional agency (pp. 1-16). San Francisco: Jossey-Bass.

Gay, G., \& Kirkland, K. (2003). Developing cultural critical consciousness and self-reflection in preservice teacher education. Theory Into Practice, 42(3), 181-187.

Gee, J. P. (2000). New people in new worlds: Networks, the new capitalism and schools. In B. Cope \& M. Kalantzis (Eds.), Multiliteracies: Literacy learning and the design of social futures. (pp. 43-68). London: Routledge.

Gillani, B. B. (2001). Creating multiculturally responsive educational settings for the web. In L. Ramírez \& O. M. Gallardo (Eds.), Portraits of teachers in multicultural settings: A critical literacy approach (pp. 123-137). Needham Heights, MA: Allyn \& Bacon.

Glatthorn, A. A. (1998). Writing the winning dissertation: A step-by-step guide. Thousand Oak, CA: Corwin Press.

Goetz, J. P., \& LeCompte, M. D. (1981). Ethnographic research and the problem of data reduction. Anthropology and Education Quarterly, 12, 51-70. 
Gonzalez, N., Moll, L. C., Floyd-Tenery, M., Rivera, A., Rendon, P., Gonzales, R., \& Amanti, C. (1993). Teacher research on funds of knowledge: Learning from households. Retrieved December 11, 2006, from http://www.ncela. gwu.edu/pubs/ncrcdsll/epr6.htm

Good, T. L. (1996). Teaching effects and teacher evaluation. In J. Sikula, T. J. Buttery, \& E. Guyton (Eds.), Handbook of research on teacher education: A project of the Association of Teacher Educators (2nd ed.; pp. 617-665). New York: Macmillan.

Goodson, I., \& Sikes. P. (2001). Life history research in educational settings: Learning from lives. Philadelphia: Open University Press.

Grant, C. A., \& Secada, W. G. (1990). Preparing teachers for diversity. In W. R. Houston, M. Haberman, \& J. Sikula (Eds.), Handbook of research on teacher education: A project of the Association of Teacher Educators (pp. 403-422). New York: Macmillan.

Graybill, S. W. (1997, July/August). Questions of race and culture: How they relate to the classroom for African American students. The Clearing House 70, 311-318.

Gruwell, E. (1999). The freedom writers diary: How a teacher and 150 teens used writing to change themselves and the world around them. New York: Broadway Books.

Haberman, M. (1995, June). Selecting "star" teachers for children and youth in urban poverty. Phi Delta Kappan, 76(10), 777-781. Retrieved April, 20, 2005, from http://vikat.pdx.edu/search/tphi+delta+kappan/tphi+delta+ kappan $/ 1 \% 2 \mathrm{C} 1 \% 2 \mathrm{C} 2 \% 2 \mathrm{CB} / 1856 \& \mathrm{FF}=$ tphi+delta+kappan $\& 2 \% 2 \mathrm{C} \% 2 \mathrm{C} 2 \% 2$ $\mathrm{C} 1 \% 2 \mathrm{C} 0$

Hakuta, K. (1986). Mirror of language: The debate on bilingualism. New York: Basic Books.

Hakuta, K., \& McLaughlin, B. (1996). Bilingualism and second language learning: Seven tensions that define the research. In D. C. Berliner \& R. C. Calfee (Eds.), Handbook of educational psychology (pp. 603-621). New York: Simon \& Schuster Macmillan. 
Hollins, E. R. (1996). Culture in school learning: Revealing the deep meaning. Mahwah, NJ: Lawrence Erlbaum Associates.

Hoy, W., \& Miskel, C. (1996). Educational administration: Theory, research, and practice. New York: McGraw-Hill.

Igowa, C. (1995). The inner world of the immigrant children. Mahwah, NJ: Lawrence Erlbaum Associates.

Irvine, J. J. (2003). Educating teachers for diversity: Seeing with a cultural eye. New York: Teachers College Press.

Kazoullis, V. K. (2001). Foreword: What did you bring with you to school? In J. Cummins, Negotiating identities: Education for empowerment in a diverse society ( $2^{\text {nd }}$ ed.; pp. iii-iv). Los Angeles: California Association for Bilingual Education.

Kindler, A. L. (2002). Survey of the states' limited English proficient students and available educational programs and services 1999-2000 summary report. Washington, DC: U.S. Department of Education, Office of English Language Acquisition, Language Enhancement, and Academic Achievement for Limited English Proficient Students.

Knowles, J. G. (1992). Models for understanding pre-service and beginning teachers' biographies: Illustrations from case studies. In I. F. Goodson (Ed.), Studying teachers' lives (pp. 99-152). New York: Teachers College Press.

Kohl, H. (1984). Growing minds on becoming a teacher. New York: Harper \& Row.

Kohl, H. (1994). "I won't learn from you": And other thoughts on creative maladjustment. New York: The New Press.

Kohl, H. (1998). The discipline of hope: Learning from a lifetime of teaching. New York: Simon \& Schuster.

Kozol, J. (1991). Savage inequalities: Children in American schools. New York: Crown.

Kozol, J. (1995). Amazing grace: The lives of children and the conscience of a nation. New York: Crown. 
Kozol, J. (2000). Ordinary resurrections: Children in the years of hope. New York: Crown.

Kozol, J. (2007). Letters to a young teacher. New York: Three River Press.

Ladson-Billings, G. (1994). The dreamkeepers: Successful teachers of African American children. San Francisco: Jossey-Bass.

Ladson-Billings, G. (2001). Crossing over to Canaan: The journey of new teachers in diverse classrooms. San Francisco: Jossey-Bass.

Lambert, L., Walker, D., Zimmerman, D. P., Cooper, J., Lambert, M. D., Gardner, M. E., \& Szabo, M. (2002). The constructivist leader ( $2^{\text {nd }}$ ed.). New York: Teachers College.

Lincoln, Y. S. (1996, April 24-26). At the contentious edge: Postmodern criticisms of modernist science. Paper prepared as an address, Portland State University, Portland, Oregon.

Lopez, M. E. (1999). When discourses collide: An ethnography of migrant children at home and in school. New York: Peter Lang.

Lucas, T., Henze, R., \& Donato, R. (1990). Promoting success of Latino languageminority students: An exploratory study of six high schools. Harvard Educational Review, 60(3), 315-340.

Lucas, T. Henze, R., \& Donato, R. (1991). Promoting the success of Latino language-minority students: An exploratory study of six high schools. In M. Minami \& B. P. Kennedy (Eds.), Language issues in literacy and bilingual/multicultural education (Reprint Series No. 22; pp. 456-482). Cambridge MA: Harvard Educational Review.

Marshall, C., \& Rossman, G. B. (1999). Designing qualitative research. Thousand Oaks, CA: Sage.

McIntosh, P. (1988). Unpacking the knapsack of White privilege. Retrieved October 22, 2007, from http://faculty.headroyce.org/ kbradley/ ethics/knapsack.pdf

McMillan, J. H., \& Schumacher, S. (1997). Research in education: A conceptual introduction. New York: Addison-Wesley. 
Mehan, H., Lintz, A., Okamoto, D., \& Wills, J. S. (1995). Ethnographic studies of multicultural education in classrooms and schools. In J. A. Banks \& C. A. McGee Banks (Eds.), Handbook of research on multicultural education (pp. 129-144). New York: Macmillan.

Merton, R. K., Fiske, M., \& Kendall, P. (1990). The focused interview: A manual of problems and procedures. New York: The Free Press.

Meyer, L. M. (2000). Barriers to meaningful instruction for English learners. Theory Into Practice, 39(4), 228-236.

Michie, G. (2007). Seeing, hearing and talking race: Lessons for White Teachers from four teachers of color. Multicultural Perspectives, 9(1), 3-9.

Minami, M., \& Ovando, C. J. (1995).Language issues in multicultural contexts. In J. A. Banks \& C. A. McGee Banks (Eds.), Handbook of research on multicultural education (pp. 427-444). New York: Macmillan.

Minami, M., \& Ovando, C. J. (2004). Language issues in multicultural contexts. In J. Banks \& C. A. McGee Banks (Eds.), Handbook of research on multicultural education (pp. 567-588). San Francisco: John Wiley \& Sons.

Moran, D. E., \& Hakuta, K. (1995). Bilingual Education: Broadening research perspectives. In J. A. Banks \& C. A. McGee Banks (Eds.), Handbook of research on multicultural education (pp. 445-462). New York: Macmillan.

Muchmore, J. A. (2001). The story of "Anna": A life history study of the literacy beliefs and teaching practices of an urban high school English teacher. Teacher Education Quarterly, 28(3), 89-110.

Muchmore, J. A. (2002). Methods and ethics in a life history study of teacher thinking. The Qualitative Report, 7(4). Retrieved April 20, 2005, from http://www.nova.edu/ssss/QR/QR7-4/muchmore.html

National Institute for Literacy. (2003). English as a second language literacy. Washington, DC: Author.

Nieto, S. (1999). The light in their eyes: Creating multicultural learning communities. New York: Teachers College Press. 
Nieto, S. (2000). Affirming diversity: The sociopolitical context of multicultural education. New York: Addison Wesley Longman.

Nieto, S. (2002). Language, culture, and teaching: Critical perspectives for a new century. Mahwah, NJ: Lawrence Erlbaum Associates.

Nieto, S. (2003). What keeps teachers going? New York: Teachers College Press.

Nieto, S. (2004). Racism, discrimination, and expectations of students' achievement. In A. S. Canestrari \& B A. Marlowe (Eds.), Educational foundations: An anthology of critical readings (pp. 44-63). Thousand Oaks, CA: Sage.

Nieto, S., \& Gordon, S. (2002). Adult conversations about unasked questions: Teaching for educational justice. In S. M. Intrator (Ed.), Stories of the courage to teach: Honoring the teacher's heart (pp. 64-77). San Francisco: Jossey-Bass.

Noddings, N. (1995, May). Teaching themes of care. Phi Delta Kappan, 76(9), 675-679. Retrieved November 23, 2004, from http://vikat.pdx.edu/search/ tphi+delta+kappan/tphi+delta+kappan/1\%2C1\%2C2\%2CB/1856\&FF=tphi+ delta+kappan\& $2 \% 2 \mathrm{C} \% 2 \mathrm{C} 2 \% 2 \mathrm{C} 1 \% 2 \mathrm{C} 0$

Noddings, N. (2003). Is teaching a practice? Journal of Philosophy of Education, $37(2), 241-251$.

Noel, J. (2000). Developing multicultural educators. New York: Longman.

Noguera, P. (2003). City schools and the American dream: Reclaiming the promise of public education. New York: Teachers College Press.

Oakes, J., \& Lipton, M. (2003). Teaching to change the world ( $2^{\text {nd }}$ ed.). New York: McGraw-Hill.

Ochs, E., \& Schieffelin, B. B. (1984). Language acquisition and socialization: Three developmental stories. In R. Schweder \& R. LeVine (Eds.), Culture theory: Essays on mind, self and emotion (pp. 276-320). New York: Cambridge University Press. 
Office of U.S. Senator Jeff Bingaman. (n.d.). Hispanic dropout project: Data book. In Senator Jeff Bingaman Legislative issues: Education issues. Office of U.S. Senator Jeff Bingaman. Retrieved November 26, 2003, from http:// www.senate.gov/ bingaman/bingaman/hispanic_dropout_prevention.html

Olneck, M. R. (1995). Immigrants and education. In J. A. Banks \& C. A. McGee Banks (Eds.), Handbook of research on multicultural education (pp. 310327). San Francisco: Jossey-Bass.

Oregon Department of Education. (2002). Dropout rates in Oregon high schools 2000-2001: State summary report. Salem: Author.

Ovando, C. J., Collier, V. P., \& Combs, M. C. (2003). Bilingual and ESL classrooms: Teaching in multicultural contexts ( $3^{\text {rd }}$ ed.). New York: McGraw-Hill.

Paccione, A. V. (2000). Developing a commitment to multicultural education. Teachers College Record, 102(6), 980-1005.

Palmer, P. J. (1998). The courage to teach: Exploring the inner landscape of a teacher's life. San Francisco: Jossey-Bass.

Pang, V. O. (2001). Multicultural education: A caring-centered, reflective approach. New York: McGraw-Hill.

Phuntsog, N. (1995). Teacher educators' perceptions of the importance of multicultural education in the preparation of elementary teachers. Equity and Excellence in Education, 28(1), 10-1.4.

Plata, M., \& Robertson, H. (1998). Cultural sensitivity: A factor in the success for students of color. Journal of Instructional Psychology, 25(2), 115-121.

Poplin, M., \&Weeres, J. (1992). Voices from the inside: A report on schooling from inside the classroom. Claremont, CA: Claremont Graduate School, Institute for Education in Transformation.

Pransky, K., \& Bailey, F. (2003). To meet your students where they are, first you have to find them: Working with culturally and linguistically diverse at-risk students. The Reading Teacher, 56(4), 370-383. 
Ramírez, D., Yuen, S., Ramey, D., \& Billings, D. (1991). Final report:

Longitudinal study of structured English immersion strategy, early-exit and late-exit transitional bilingual education programs for language-minority children - Executive summary. San Mateo, CA: Aguirre International.

Ramírez, L., \& Gallardo, O. M. (2001). Beyond multicultural education: Transformative approaches. In L. Ramírez \& O. M. Gallardo (Eds.), Portraits of teachers in multicultural settings: A critical literacy approach (pp. 1-8). Needham Heights, MA: Allyn \& Bacon.

Rose, M. (1995). Possible life: The promise of public education in America. New York: Penguin Books Group.

Rosenthal, R., \& Jacobson, L. (1968). Pygmalion in the classroom: Teacher expectation and pupils' intellectual development. New York: Holt, Rinehart and Winston.

Rossman, G., \& Rallis, S. (1998). Learning in the field: An introduction to qualitative research. Thousand Oaks, CA: Sage.

Ruíz, R. (1988). Orientations in language planning. In S. L. McKay \& S. C. Wong (Eds.), Language diversity: Problem or resource? A social and educational perspective on language minorities in the United States (pp. 1-25). New York: Newbury House.

Ruíz, R. (1991). The empowerment of language-minority students. In C. E. Sleeter (Ed.), Empowerment through multicultural education (pp. 217-227). Albany: State University of New York Press.

Rumberger, R. W., \& Rodríguez, G. M. (2002). Chicano dropouts: An update of research and policy issues. In R. R. Valencia (Ed.), Chicano school failure and success: Past, present, and future ( ${ }^{\text {nd }}$ ed.; pp. 115-146). London: Routledge Falmer.

Secada, W. G., \& Lockwood A. T. (1999). Transforming education for Hispanic youth: Exemplary practice, programs, and schools. Washington, DC: The George Washington University, Graduate School of Education \& Human Development, Center for the Study of Language and Education.

Sheets, R. H. (2005). Diversity pedagogy: Examining the role of culture in the teaching-learning process. Boston: Pearson Education. 
Shor, I. (1992). Empowering education: Critical teaching for social change. Chicago: The University of Chicago Press.

Shribman, D. (2001). I remember my teacher: 365 reminiscences of the teachers who changed our lives. Kansas City, MO: McMeel.

Sleeter, C. E. (1991). Introduction: Multicultural education and empowerment. In C. E. Sleeter (Ed.), Empowerment through multicultural education (pp. 1-23). Albany: State University of New York Press.

Sleeter, C. E. (2001). Epistemological diversity in research on preservice teacher preparation for historically underserved children. In W. G. Secada (Ed.), Review of research in education (pp. 209-250). Washington, DC: American Educational Research Association.

Snow, M. A. (1994). Primary language instruction: A bridge to literacy. In C. F. Leyba (Ed.), Schooling and language minority students: A theoretical framework ( $2^{\text {nd }}$ ed., pp. 133-164). Albany: State University of New York Press.

Soto, L. (1997). Language, culture, and power: Bilingual families and the struggle for quality education. Albany: State University of New York Press.

Strauss, A., \& Corbin, J. (1998). Grounded theory methodology: An overview. In N. K. Denzin \& Y. S. Lincoln (Eds.), Strategies of qualitative inquiry (pp. 158183). Thousand Oaks, CA: Sage.

Tatum, B. D. (1997). "Why are all the black kids sitting together in the cafeteria?": And other conversations about race. New York: Basic Books.

Thomas, A. J., \& Schwarzbaum, S. (2006). Culture and identity: Life stories for counselors and therapists. Thousand Oaks, CA: Sage.

Tikunoff, W. J. (1985). Applying significant bilingual instructional features in the classroom. Rosslyn, VA: National Clearinghouse for Bilingual Education.

Valenzuela, A. (1999). Subtractive schooling: U.S.-Mexican youth and the politics of caring. Albany: State University of New York Press.

Villegas, A. M., \& Lucas, T. (2002). Preparing culturally responsive teachers: Rethinking the curriculum. Journal of Teacher Education, 53(1), 20-32. 
Vygotsky, L. S. (1978). Mind in society: the development of higher psychological processes. Cambridge, MA: Harvard University Press.

Wink, J., \& Putney, L. (2002). A vision of Vygotsky. Boston: Allyn \& Bacon.

Wink, J., \& Wink, D. (2004). Teaching passionately: What's love got to do with it? Boston: Allyn \& Bacon.

Wong Fillmore, L. (1991). When learning a second language means losing the first. Early Childhood Research Quarterly, 6(3), 323-346.

Zeichner, K. M. (2003). The adequacies and inadequacies of three current strategies to recruit, prepare, and retain the best teachers for all students. Teachers College Record, 105 (3), 490-519. 
APPENDIX A

INTERVIEW GUIDE 


\section{Interview Guide ${ }^{27}$}

1 Can you tell me about your family and childhood experiences?

- Place and date of birth

- Family background

- Parents' (grandparents'/guardians', if not parents') occupations during the informant's life, their education, general character and interests

- Information about any other family members who influenced the informant (i.e., brother and sister)

- Informant's childhood: description of home and general discussion of experiences

- Community and context: character and general status of the places where the informant grew up

2 Can you tell me about your school experience?

- General character of school experience

- Relationship with teachers

- Any particular teachers who influenced the informant in any way?

- Peer relations, reference group

- 'Good' and 'bad' experiences

- Courses taken, subjects favored

3 Can you tell me about your experience in teacher education/training programs?

- General experience

- Professors/instructors

- Courses, training and books

- Credentials achieved

4 Can you tell me about friendships, role models, mentors and mentees (protégés) that are meaningful to you?

- Persons who had a significant influence

5 Can you tell me about your job?

- General work history

- Types of school

- Types of position

- Change of jobs and why

${ }^{27}$ Most of the Interview Guide utilizes the ideas of Paccione (2000), Goodson and Sikes (2001), and Muchmore (2002). 
6 Have you had any critical events in your life that influenced your frame of reference?

- Kind of incidents

- General experience

- Informant's thoughts and feelings about the incidents (why were they significant?)

- Lessons learned

7 Have you had any immersion experiences in other cultures?

- Kind of culture

- General experience

- Prominent incidents

- Informant's thoughts and feelings about the incidents (why were they significant?)

- Lessons learned

8 Have you experienced any significant social or political [temporal] event (such as the Civil Right Movements) that influenced you?

- Kind of event

- General experience

- Informant's thoughts and feelings about the incidents (why were they significant?)

- Lessons learned

9 Would you describe yourself in terms of your race, ethnicity, gender, and spirituality?

- The most and least dominant ones in life

- Experience of discrimination because of any of these elements

10 Would you describe your characteristics as a person?

11 Would you describe your characteristics as a teacher?

12 How would you describe your moral disposition?

13 Can you tell me what guides your classroom practice/instruction?

- Theoretical orientation

- Reason for using this particular orientation (and not others)

- Classroom management style

- Reason for using this particular management style (and not others) 
14 What strategies do you use for this practice?

- Behaviorist activities?

- Constructivist activities?

- Inclusion/exclusion of diverse cultures in the curriculum?

- Incorporation of educational materials from diverse cultural groups?

- Connection of students' prior knowledge and life experience to content learning?

- Inclusion of students' social and cultural backgrounds and values in their learning?

- Use of students' home language

15 Can you tell me about your relationship with your students?

- Student(s) with whom the informant can most identify and why

- Student(s) about whom the informant feels most challenged and why

- The most challenging and troubling aspects of the teacher-student relationship

- The most enjoyable/rewarding moments in the teacher-student relationship

- Unforgettable students (good or bad)

- Student(s) whose lives the informant believes s/he has changed: when, how, and because of what action?

- Student(s) who had a critical influence on the informant: when, how, and because of what action by the student? 


\section{APPENDIX B}

INTRODUCTORY LETTER FOR NOMINATION AND NOMINATION FORM 


\section{Dear Educators,}

My name is Yumiko Otsuki, and I am a doctoral student in the Portland State University School of Education. I am beginning a study as part of my doctoral dissertation on the relationship between the life experiences and classroom practices of teachers whose students include English language learners, and who have a reputation for being effective teachers of such students.

I would like to invite you to nominate elementary school mainstream classroom teachers in your school district who you believe are effective in educating English language learners. As a nominee, you may remain anonymous. You can nominate others as well as self-nominate. Please nominate as many teachers as you can think of. As a result of providing names of such teachers, you will be helping with research intended to identify important aspects of the education of English language learners.

Please provide the following information for teachers you would like to nominate, using the attached form:

1. Names

2. Schools at which they teach

Please return the attached form with teachers' names in the enclosed self-addressed, stamped envelope by . Your cooperation will be greatly appreciated.

Sincerely,

Yumiko Otsuki 
Nomination of Teachers I Believe to Be Effective in Educating English Language Learners

Name:

School:

Name:

School:

Name:

School:

Name:

School:

Name:

School: 
APPENDIX C

CONSENT FORM 
Dear Teachers,

My name is Yumiko Otsuki, and I am a doctoral student in the Portland State University School of Education. I am beginning a study as part of my doctoral dissertation on the relationship between the life experiences and classroom practices of teachers whose students include English language learners, and who have a reputation for being effective teachers of such students.

I would like to invite you to participate, because you have been identified by your colleagues as a successful teacher of English language learners. Your participation will be an important contribution to helping us better understand how to improve the education of such students. If you decide to participate, you will be asked to have a series of conversational interviews with me. During the interviews, I will be asking about your classroom practices, and about your life experiences. The process should take from two to three interviews lasting about an hour each.

Any information that I obtain in connection to this study will be kept confidential and you and your school will remain anonymous. Participation is voluntary and you may withdraw from this study at any time without affecting your relationship with Portland State University.

If you have questions or concerns about your participation in this study, you may contact the Human subject Research Review Committee, Office of Research and Sponsored Projects, 111 Cramer Hall, Portland State University, (503) 725-4288. If you have any questions about the study itself, please contact me, Yumiko Otsuki, at 1855 Deana Dr., West Linn, OR 97068, (503) 657-7291.

Your signature indicates that you have read and understand the above information and agree to take part in this study. By signing, you are not waiving any legal claims, rights or remedies. You may withdraw your consent at any time without penalty. Please keep a copy of this form for your records. 